ALINE HAYASHI SUZUKI

\title{
OTIMIZAÇÃO NÃO LINEAR APLICADA À OPERAÇÃO DE SISTEMAS COM MÚLTIPLOS RESERVATÓRIOS PARA ABASTECIMENTO DE ÁGUA
}


ALINE HAYASHI SUZUKI

\section{OTIMIZAÇÃO NÃO LINEAR APLICADA À OPERAÇÃO DE SISTEMAS COM MÚLTIPLOS RESERVATÓRIOS PARA ABASTECIMENTO DE ÁGUA}

Dissertação apresentada à Escola Politécnica da Universidade de São Paulo para obtenção do título de Mestre em Ciências.

Área de Concentração: Engenharia Hidráulica

Orientador: Prof. Dr. Renato Carlos Zambon

São Paulo

2016 
Este exemplar foi revisado e corrigido em relação à versão original, sob responsabilidade única do autor e com a anuência de seu orientador.

São Paulo, de de

Assinatura do autor:

Assinatura do orientador:

Suzuki, Aline Hayashi

Otimização não linear aplicada à operação de sistemas com múltiplos reservatórios para abastecimento de água / A. H. Suzuki, R. C. Zambon -versão corr. -- São Paulo, 2016.

$145 \mathrm{p}$.

Dissertação (Mestrado) - Escola Politécnica da Universidade de São Paulo. Departamento de Engenharia de Hidráulica e Ambiental.

1.Abastecimento de água 2.Reservatórios (operação) 3.Recursos hídricos I.Universidade de São Paulo. Escola Politécnica. Departamento de Engenharia de Hidráulica e Ambiental II.t. III.Zambon, Renato Carlos 


\section{AGRADECIMENTOS}

Ao Professor Dr. Renato Carlos Zambon pela orientação e confiança.

Aos professores Dr. Kamel Zahed Filho e Dr. Alberto Luiz Francato pelas colaborações e dicas durante o desenvolvimento deste trabalho.

À Wandréa Dantas do Departamento de Engenharia Hidráulica e Ambiental.

À Tetra Tech Consultoria Ltda., representada pelo Eduardo Ayres Yassuda, que permitiu e apoiou o desenvolvimento desta dissertação concomitantemente à jornada de trabalho.

A todos que contribuíram direta ou indiretamente na execução deste trabalho. 


\section{RESUMO}

O presente estudo considera a aplicação do modelo SISAGUA de simulação matemática e de otimização para a operação de sistemas de reservatórios integrados em sistemas complexos para o abastecimento de água. O SISAGUA utiliza a programação não linear inteira mista (PNLIM) com os objetivos de evitar ou minimizar racionamentos, equilibrar a distribuição dos armazenamentos em sistemas com múltiplos reservatórios e minimizar os custos de operação.

A metodologia de otimização foi aplicada para o sistema produtor de água da Região Metropolitana de São Paulo (RMSP), que enfrenta a crise hídrica diante de um cenário de estiagem em 2013-2015, o pior na série histórica dos últimos 85 anos. Trata-se de uma região com 20,4 milhões de habitantes. O sistema é formado por oito sistemas produtores parcialmente integrados e operados pela Sabesp (Companhia de Saneamento do Estado de São Paulo). A RMSP é uma região com alta densidade demográfica, localizada na Bacia Hidrográfica do Alto Tietê e caracterizada pela baixa disponibilidade hídrica per capita.

Foi abordada a possibilidade de considerar a evaporação durante as simulações, e a aplicação de uma regra de racionamento contínua nos reservatórios, que transforma a formulação do problema em programação não linear (PNL). A evaporação se mostrou pouco representativa em relação a vazão de atendimento à demanda, com cerca de $1 \%$ da vazão. Se por um lado uma vazão desta magnitude pode contribuir em um cenário crítico, por outro essa ordem de grandeza pode ser comparada às incertezas de medições ou previsões de afluências. $O$ teste de sensibilidade das diferentes taxas de racionamento em função do volume armazenado permite analisar o tempo de resposta de cada sistema. A variação do tempo de recuperação, porém, não se mostrou muito significativo.

Palavras-chave: Recursos Hídricos, Operação de Reservatórios, Abastecimento de Água, Programação Não Linear 


\begin{abstract}
The current study considers the mathematical simulation and optimization model SISAGUA applied to operation of complex multireservoir systems for water supply. The SISAGUA model uses mixed integer nonlinear programming (MINLP) with objectives of avoid or minimize shortages, balance storage distribution in multireservoir systems and minimize operation costs.

The optimization methodology was applied in the water supply system from São Paulo Metropolitan Region, which faces a water crisis in a drought scenario in 2013-2015, the worst in the last 85 years historical series. It is a region with 20.4 million inhabitants, and the system consists of eight partially integrated supply systems operated by Sabesp (Sanitation Company of Sao Paulo State). The metropolitan region presents a high population density, located in the Upper Tiete hydrographic basin, characterized by low water availability per capita.

It was discussed the possibility of considering evaporation during simulations, and the application of a continuous hedging rule in the reservoirs which modifies the mathematical formulation to nonlinear programming (NLP). Evaporation proved barely representative in relation to demand flow, with about $1 \%$ of the flow. On one hand, a flow rate of this magnitude may be considered in a critical scenario, on the other hand, this order of magnitude can be compared to the uncertainties of measurement or inflow forecasts. The sensitivity test of different rationing rates depending on the stored volume can analyze the time of response of each system. The change in recovery time, however, was not very significant.
\end{abstract}

Keywords: Water Resources, Reservoir Operation, Water Supply, Nonlinear Analysis. 


\section{LISTA DE FIGURAS}

Figura 1 - Regras de operação para um reservatório de usos múltiplos. 39

Figura 2 - Curvas operacionais e regras de racionamento. Funções em escala. 40

Figura 3 - Página de desenho na interface do SISAGUA, com caixa de alteração de dados aberta. 41

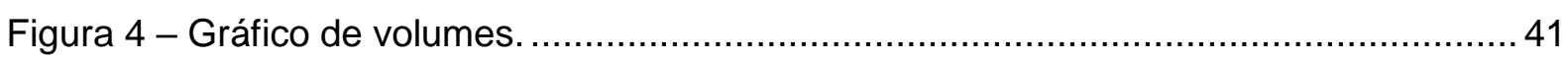

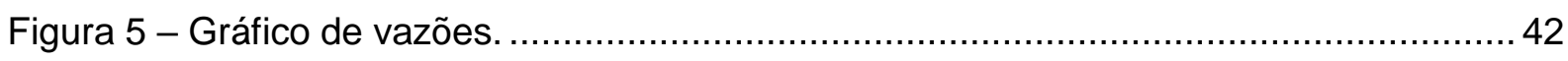

Figura 6 - Página de tabelas na interface do SISAGUA. ......................................... 42

Figura 7 - Página do modelo GAMS ..................................................................... 43

Figura 8 - Página com listagem de resultados do GAMS. ............................................. 43

Figura 9 - Página de relatório na interface do SISAGUA ............................................ 44

Figura 10 - Porcentagem da capacidade nominal referente a cada sistema. (Fonte: Secretaria de Saneamento e Recursos Hídricos, 2015).....

Figura 11 - Localização dos Sistemas de Abastecimento da RMSP e suas respectivas áreas de abrangência. (Fonte: SABESP) ........................................................................ 48

Figura 12 - Desenho esquemático do Sistema Cantareira. (Fonte: SABESP) ....................50

Figura 13 - Sistema Alto Tietê.......................................................................... 53

Figura 14 - Sistema Alto Tietê - Perfil unifilar. (Fonte: Adaptado de DAEE, 2012) ..............54

Figura 15 - Sistema Cantareira nos afluentes do Rio Piracicaba e Bacias dos Rios PCJ. (Fonte: RODRIGUES; BRENHA, 2014)

Figura 16 - Vazões médias mensais afluentes ao Sistema Equivalente. Valores médios mensais de referência dos anos de 1930 a 2013, e dos anos de 2013, 2014 e 1953. (Fonte: ANA, 2015)

Figura 17 - Evolução do avanço dos sistemas sobre a região atendida pelo Cantareira (Fonte: Sabep, 2015a). 61

Figura 18 - Adesão ao programa de taxação. (Fonte: Sabesp, 2015a) 63

Figura 19 - Programa de Combate às Perdas - 2004 a 2015.

Figura 20 - Evolução do volume Acumulado no sistema Equivalente. (Fonte: ANA, DAEE, 2015)

Figura 21 - Instalações do SPLP nos municípios da área de influência. (Fonte: RODRIGUES,

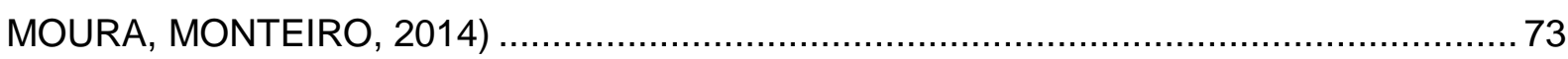

Figura 22 - Bacia do Rio Paraíba do Sul. (Fonte: ANA) …............................................ 75

Figura 23 - Representação completa da Bacia do Rio Paraíba do Sul - diagrama esquemático das usinas com regras de transformação de vazões. (Fonte: ONS, 2013). 
Figura 24 - Comparação do crescimento da demanda hídrica total por setor nos horizontes

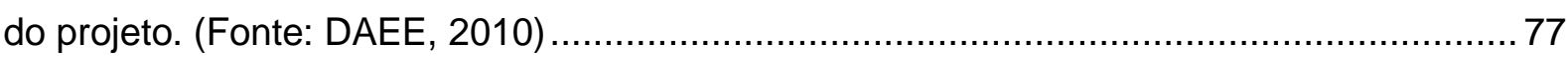

Figura 25 - Transposição da Represa Jaguari à Represa Atibainha. (Fonte: SOUZA, 2014) .78

Figura 26 - Traçado em perfil do projeto proposta da transposição. (Fonte: DAEE, 2010) .. 79 Figura 27 - Perfil (variante) do projeto proposta da transposição. (Fonte: DAEE, 2010)...... 79 Figura 28 - Traçado em perfil escolhido após avaliação de alternativas. (Fonte: Leite, 2014d) 80

Figura 29 - Vazões mensais afluentes aos sistemas produtores da RMSP. .83

Figura 30 - Curva de permanência dos sistemas de abastecimento da RMSP. 83

Figura 31 - Série de vazões afluentes à represa de Guarapiranga................................... 84

Figura 32 - Curva de permanência de Guarapiranga. .................................................... 85

Figura 33 - Gráfico de autocorrelação da série de Guarapiranga...................................... 85

Figura 34 - Médias mensais e desvio padrão de Guarapiranga. ...................................... 86

Figura 35 - Série de Guarapiranga após a aplicação da padronização. ............................ 86

Figura 36 - Gráfico de Autocorrelação da série de Guarapiranga após a padronização. ..... 87

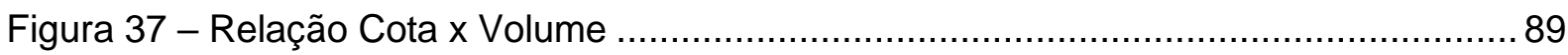

Figura 38 - Cota Área Volume - Jaguari / Jacareí ........................................................ 92

Figura 39 - Cota Área Volume - Cachoeira......................................................... 92

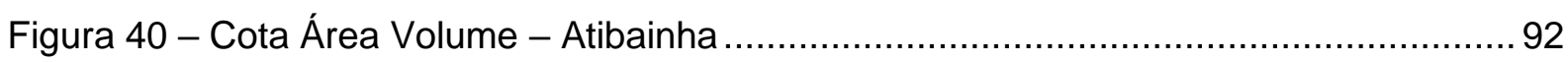

Figura 41 - Cota Área Volume - Paiva Castro........................................................ 93

Figura 42 - Relação Área x Volume - Sistema Cantareira ............................................. 93

Figura 43 - Relação Área x Volume - Paraitinga........................................................ 94

Figura 44 - Relação Área x Volume - Ponte Nova.................................................... 94

Figura 45 - Relação Área x Volume - Biritiba............................................................ 95

Figura 46 - Relação Área x Volume - Jundiaí. …...................................................... 95

Figura 47 - Relação Área x Volume - Taiaçupeba. ....................................................... 95

Figura 48 - Relação Área x Volume - Sistema Produtor Alto Tietê. ..................................96

Figura 49 - Relação Área x Volume - Guarapiranga.............................................. 97

Figura 50 - Relação Área x Volume - Guarapiranga............................................... 97

Figura 51 - Curvas operacionais e regras de racionamento - Funções em escada. ........... 98

Figura 52 - Curvas operacionais e regras de racionamento - Função contínua.................. 99

Figura 53 - Racionamento - Função Contínua - Cantareira - $Q_{0 \%}=0 \mathrm{~m}^{3} / \mathrm{s}$ - Volume reservado. 100

Figura 54 - Racionamento - Função Contínua - Cantareira - Q $\%=0 \mathrm{~m}^{3} / \mathrm{s}$ - Vazão atendida. 
Figura 55 - Racionamento - Função Contínua - Cantareira - $Q_{0 \%}=5 \mathrm{~m}^{3} / \mathrm{s}$ - Volume reservado 101

Figura 56 - Racionamento - Função Contínua - Cantareira - $Q_{0 \%}=5 \mathrm{~m}^{3} / \mathrm{s}-$ Vazão atendida. 101

Figura 57 - Racionamento - Função Contínua - Cantareira - $Q_{0 \%}=10 \mathrm{~m}^{3} / \mathrm{s}$ - Volume reservado.

Figura 58 - Racionamento - Função Contínua - Cantareira - $Q_{0 \%}=10 \mathrm{~m}^{3} / \mathrm{s}$ - Vazão atendida.

Figura 59 - Racionamento - Função Contínua - Cantareira - Q0 = $15 \mathrm{~m}^{3} / \mathrm{s}$ - Volume reservado. 103

Figura 60 - Racionamento - Função Contínua - Cantareira - Q0 = $15 \mathrm{~m}^{3} / \mathrm{s}$ - Vazão atendida. 103

Figura 61 - Racionamento - Função Contínua - Alto Tietê - $Q_{0 \%}=0 \mathrm{~m}^{3} / \mathrm{s}$ - Volume reservado. 104

Figura 62 - Racionamento - Função Contínua - Alto Tietê - $Q_{0 \%}=0 \mathrm{~m}^{3} / \mathrm{s}$ - Vazão atendida. 105

Figura 63 - Racionamento - Função Contínua - Alto Tietê - $Q_{0 \%}=2,5 \mathrm{~m}^{3} / \mathrm{s}$ - Volume reservado. 105

Figura 64 - Racionamento - Função Contínua - Alto Tietê - $Q_{0 \%}=2,5 \mathrm{~m}^{3} / \mathrm{s}$ - Vazão atendida. 106

Figura 65 - Racionamento - Função Contínua - Alto Tietê - $Q_{0 \%}=5 \mathrm{~m}^{3} / \mathrm{s}-$ Volume reservado. 106

Figura 66 - Racionamento - Função Contínua - Alto Tietê - Q 107

Figura 67 - Racionamento - Função Contínua - Alto Tietê - $Q_{0 \%}=7,5 \mathrm{~m}^{3} / \mathrm{s}$ - Volume reservado.

Figura 68 - Racionamento - Função Contínua - Alto Tietê - $Q_{0 \%}=7,5$ m³/s - Vazão atendida. 108

Figura 69 - Racionamento - Função Contínua - Guarapiranga - $Q_{0 \%}=0 \mathrm{~m}^{3} / \mathrm{s}$ - Volume reservado. 109

Figura 70 - Racionamento - Função Contínua - Guarapiranga - $Q_{0 \%}=0 \mathrm{~m}^{3} / \mathrm{s}$ - Vazão atendida.

Figura 71 - Racionamento - Função Contínua - Guarapiranga - $Q_{0 \%}=2,5 \mathrm{~m}^{3} / \mathrm{s}-$ Volume reservado.

Figura 72 - Racionamento - Função Contínua - Guarapiranga - $Q_{0 \%}=2,5 \mathrm{~m}^{3} / \mathrm{s}-$ Vazão atendida. 
Figura 73 - Racionamento - Função Contínua - Guarapiranga - $Q_{0 \%}=5 \mathrm{~m}^{3} / \mathrm{s}$ - Volume reservado

Figura 74 - Racionamento - Função Contínua - Guarapiranga - Q ${ }_{0 \%}=5 \mathrm{~m}^{3} / \mathrm{s}$ - Vazão atendida.

Figura 75 - Racionamento - Função Contínua - Guarapiranga - $Q_{0 \%}=7,5 \mathrm{~m}^{3} / \mathrm{s}-$ Volume reservado

Figura 76 - Racionamento - Função Contínua - Guarapiranga - $Q_{0 \%}=7,5 \mathrm{~m}^{3} / \mathrm{s}$ - Vazão atendida.

Figura 77 - Evaporação - Sistema Cantareira - Volume armazenado. 114

Figura 78 - Evaporação - Sistema Cantareira - Vazão atendida. 114

Figura 79 - Evaporação - Sistema Alto Tietê - Volume armazenado. 115

Figura 80 - Evaporação - Sistema Alto Tietê- Vazão atendida. 115

Figura 81 - Evaporação - Guarapiranga - Volume armazenado. 116

Figura 82 - Evaporação - Guarapiranga- Vazão atendida. 117

Figura 83 - Visualização gráfica do modelo. 119

Figura 84 - Modelo integrado - Resultados: Cantareira - Volume Armazenado. 119

Figura 85 - Modelo integrado - Resultados: Cantareira - Vazão atendida. 119

Figura 86 - Modelo integrado - Resultados: Alto Tietê - Volume Armazenado. 120

Figura 87 - Modelo integrado - Resultados: Alto Tietê - Vazão atendida. 120

Figura 88 - Modelo integrado - Resultados: Guarapiranga - Volume Armazenado. 121

Figura 89 - Modelo integrado - Resultados: Guarapiranga - Vazão atendida 121

Figura 90 - Sistema Cantareira: Vazão mínima de atendimento à demanda $\left(\mathrm{m}^{3} / \mathrm{s}\right) \times \mathrm{Q}_{100 \%}$ $\left(\mathrm{m}^{3} / \mathrm{s}\right)$.

Figura 91 - Sistema Cantareira: Volume Armazenado médio (\%) x $\mathrm{Q}_{100 \%}\left(\mathrm{~m}^{3} / \mathrm{s}\right)$. 124 Figura 92 - Sistema Cantareira: Volume armazenado médio (\%) x Vazão mínima de atendimento à demanda $\left(\mathrm{m}^{3} / \mathrm{s}\right)$. 125 Figura 93 - Sistema Alto Tietê: Vazão mínima de atendimento à demanda $\left(\mathrm{m}^{3} / \mathrm{s}\right) \times \mathrm{Q}_{100 \%}$ $\left(\mathrm{m}^{3} / \mathrm{s}\right)$ 126

Figura 94 - Sistema Alto Tietê: Volume Armazenado médio (\%) x $\mathrm{Q}_{100 \%}\left(\mathrm{~m}^{3} / \mathrm{s}\right)$ 127 Figura 95 - Sistema Alto Tietê: Volume armazenado médio (\%) x Vazão mínima de atendimento à demanda $\left(\mathrm{m}^{3} / \mathrm{s}\right)$.

Figura 96 - Sistema Guarapiranga: Vazão mínima de atendimento à demanda $\left(\mathrm{m}^{3 / \mathrm{s}}\right) \times \mathrm{Q}_{100 \%}$ $\left(\mathrm{m}^{3} / \mathrm{s}\right)$.

Figura 97 - Sistema Guarapiranga: Volume Armazenado médio (\%) x $\mathrm{Q}_{100 \%}\left(\mathrm{~m}^{3} / \mathrm{s}\right)$. 129

Figura 98 - Sistema Guarapiranga: Volume armazenado médio (\%) x Vazão mínima de atendimento à demanda $\left(\mathrm{m}^{3} / \mathrm{s}\right)$. 129 


\section{LISTA DE TABELAS}

Tabela 1 - Capacidade de Produção do Sistema Existente.

Tabela 2 - Sistemas de abastecimento, principais mananciais e sedes urbanas atendidas. 49

Tabela 3 - Características do Sistema Cantareira.

Tabela 4 - Ações de combate às perdas de 2014.

Tabela 5 - Comunicados conjuntos ANA DAEE referentes aos limites de operação do

Cantareira. 66

Tabela 6 - Matriz de correlação os componentes do Sistema Integrado da RMSP. 84

Tabela 8 - Volume máximo operacional permitido por mês nos reservatórios do Sistema Cantareira.

Tabela 9 - Volume máximo operacional permitido por mês no reservatório de Guarapiranga.

Tabela 10 - Capacidade de produção, volumes útil, mínimo operativo, máximo operativo e inicial utilizados como dado de entrada no modelo SISAGUA. 90

Tabela 11 - Valores de evaporação líquida $(\mathrm{mm})$

Tabela 12 - Resultados das simulações considerando a evaporação nos sistemas isolados de Cantareira, Alto Tietê e Guarapiranga.

Tabela 13 - Resumo dos resultados com diferentes regras de racionamento para o Sistema Cantareira 123

Tabela 14 - Resumo dos resultados com diferentes regras de racionamento para o Sistema Alto Tietê. 126

Tabela 15 - Resumo dos resultados com diferentes regras de racionamento para o Sistema Guarapiranga. 128 


\section{LISTA DE SIGLAS}

AG Algoritmos Genéticos

ANA Agência Nacional de Águas

ANEEL Agência Nacional de Energia Elétrica

Arsesp Agência Reguladora de Saneamento e Energia do Estado de São Paulo

CBH - AT Comitê de Bacia Hidrográfica do Alto Tietê

CCEE Câmara de Comercialização de Energia Elétrica

CESP Companhia Energética de São Paulo

CPI Comissão Parlamentar de Inquérito

DAEE Departamento de Águas e Energia Elétrica do Estado de São Paulo

EEAT Estação Elevatória de Água Tratada

ETA Estação de Tratamento de Água

GAMS General Algebraic Modeling System

IGAM Instituto Mineiro de Gestão as Águas

MME Ministério das Minas e Energia

MPE Ministério Público Estadual

OAB Ordem dos Advogados do Brasil

ONS Operador Nacional de Águas

PCJ Piracicaba, Capivari e Jundiaí

PD Programação Dinâmica

PL Programação Linear

PLIM Programação Linear Inteira Mista

PNL Programação Não Linear

PNLIM Programação Não Linear Inteira Mista

PPP Parceria Público Privada 


$\begin{array}{ll}\text { PRM } & \text { Prescriptive Reservoir Model } \\ \text { RMBS } & \text { Região Metropolitana da Baixada Santista } \\ \text { RMC } & \text { Região Metropolitana de Campinas } \\ \text { RMSP } & \text { Região Metropolitana de São Paulo } \\ \text { Sabesp } & \text { Companhia de Saneamento do estado de São Paulo } \\ \text { SAM } & \text { Sistema Adutor Metropolitano } \\ \text { SIM } & \text { Sistema Integrado Metropolitano } \\ \text { SPAT } & \text { Sistema Produtor Alto Tietê } \\ \text { SPLP } & \text { Sistema Produtor São Lourenço } \\ \text { SSD } & \text { Sistemas de Suporte à Decisão } \\ \text { STF } & \text { Supremo Tribunal Federal } \\ \text { UGRHIs } & \text { Unidades Hidrográficas de Gerenciamento de Recursos Hídricos do } \\ \text { Estado de São Paulo }\end{array}$

VA Valor Adicionado 


\section{SUMÁRIO}

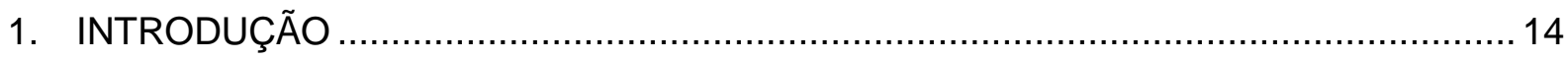

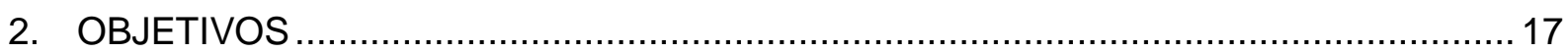

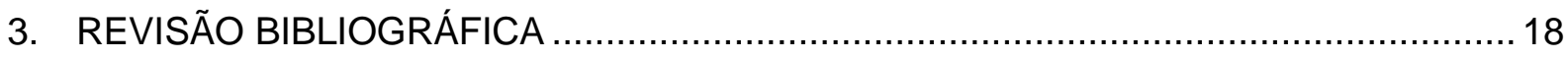

3.1 Técnicas de Otimização e Planejamento ……………………………………....... 18

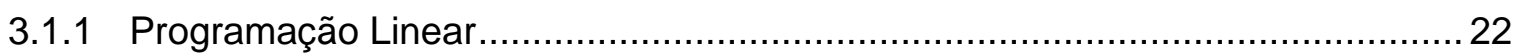

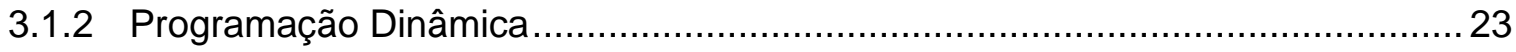

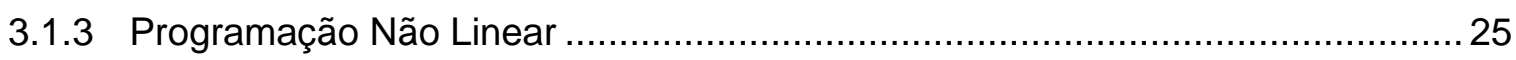

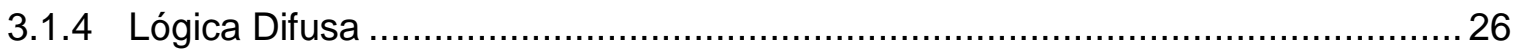

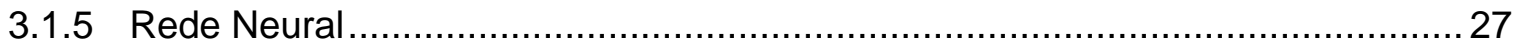

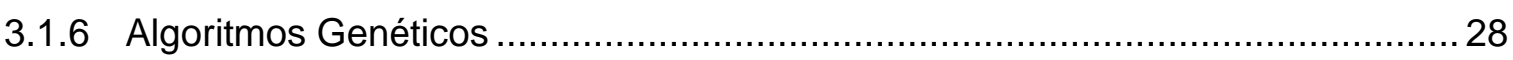

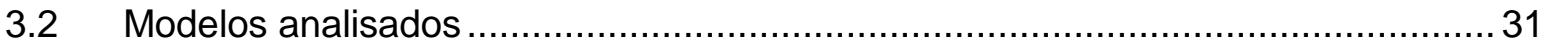

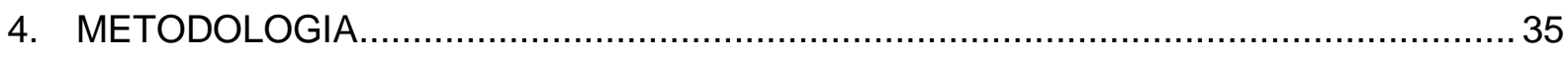

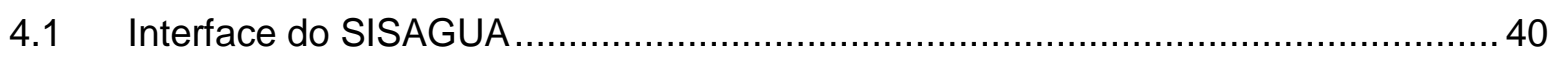

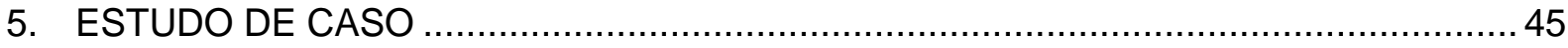

5.1 Região Metropolitana de São Paulo ............................................................... 46

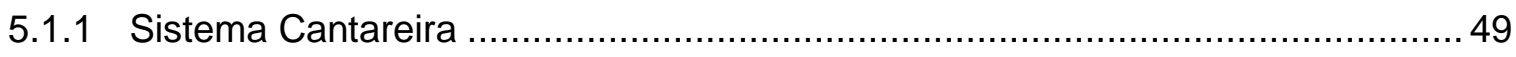

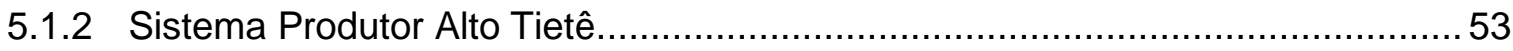

5.2 Características das Bacias dos Rios Piracicaba, Capivari e Jundiaí ........................55

5.3 Crise no sistema de abastecimento da RMSP ………......................................56

$5.4 \quad$ Medidas e acontecimentos relevantes …………................................................. 58

5.4.1 Transferência de água tratada de outros sistemas produtores .............................59

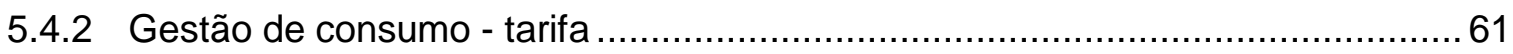

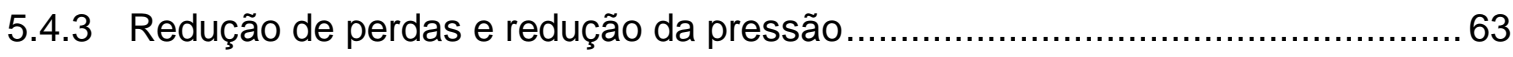

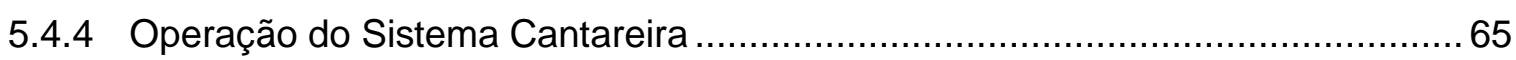

5.4.5 Obras para aumento da transferência entre sistemas ........................................ 69

5.4.6 Sistema Produtor São Lourenço .................................................................... 71

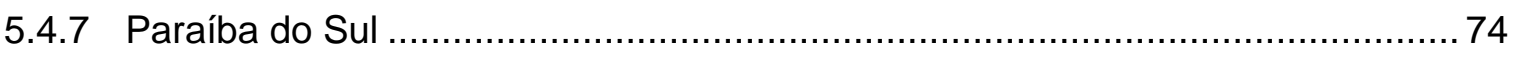




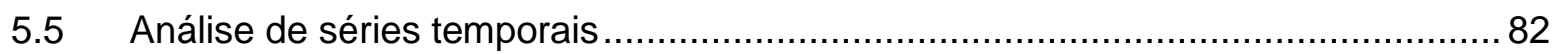

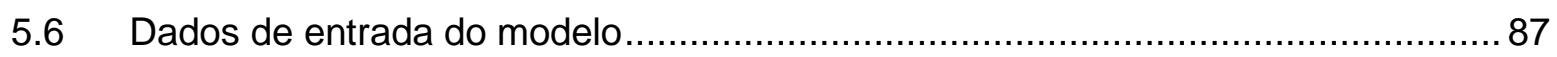

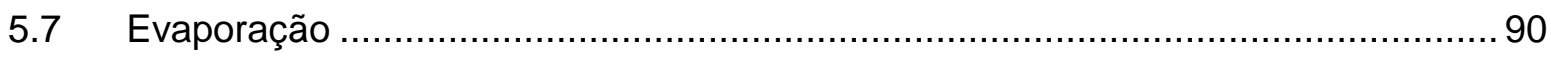

5.7.1 Sistema Cantareira - Área x Volume ...................................................... 91

5.7.2 Sistema Produtor Alto Tietê- Área x Volume ................................................ 94

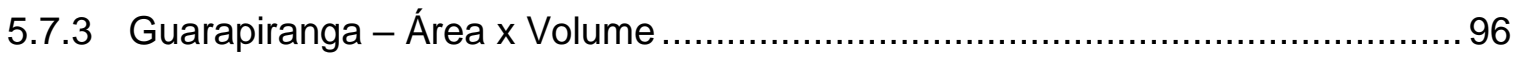

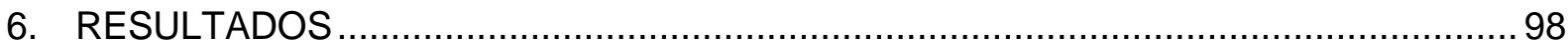

6.1 Regra de racionamento utilizando função contínua ........................................ 98

6.1.1 Sistema Cantareira - Racionamento Linear ................................................ 99

6.1.2 Sistema Produtor Alto Tietê - Racionamento Linear .................................... 104

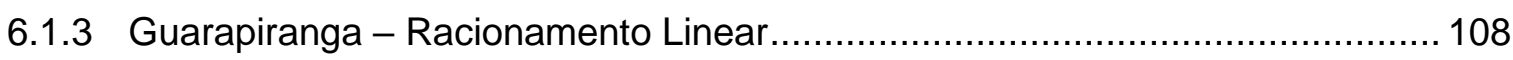

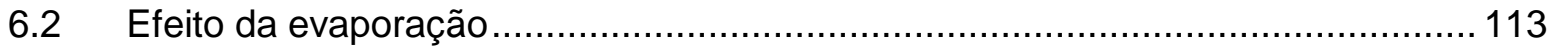

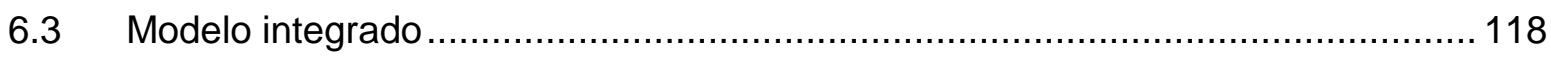

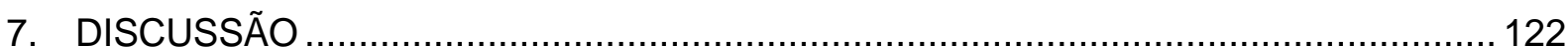

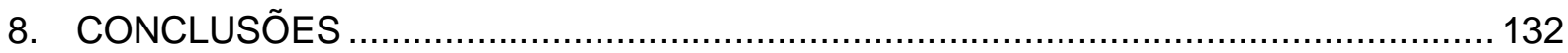

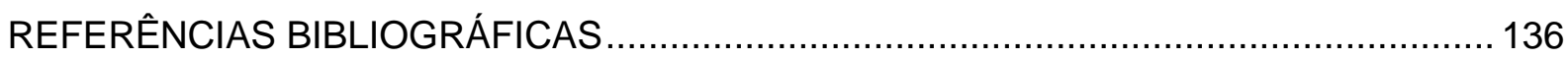




\section{INTRODUÇÃO}

A necessidade de planejar e gerir os recursos hídricos tem sido cada vez mais evidenciada diante do crescimento e desenvolvimento populacional e econômico em áreas com disponibilidade hídrica limitada. Ao lidar com sistemas complexos de recursos hídricos, ressalta-se o propósito múltiplo a que são submetidos de acordo com a demanda local: reservação para abastecimento público, dessedentação de animais, irrigação, industrial, concentrar desníveis para a produção de energia, controle de cheias, navegação e recreação.

O planejamento, projeto e operação dos diversos componentes nesses sistemas, particularmente os reservatórios de regularização, possuem grande importância para evitar ou minimizar as falhas de atendimento.

A operação de reservatórios deve respeitar diferentes prioridades de usos múltiplos, restrições relacionadas às capacidades das estruturas de armazenamento, captação, tratamento e adução, condições ambientais desejadas e impactos a jusante. Dessa maneira, a análise integrada do sistema se faz necessária para o atendimento a diferentes usuários, considerando a evolução da demanda e a incerteza hidrológica.

Dada a complexidade e o número elevado de variáveis e restrições a que um sistema hídrico é sujeito, os conflitos de interesses acabam sendo inerentes em um cenário de escassez hídrica.

Com relação aos conflitos relacionados aos recursos, Hardin (1968) introduziu em seu artigo a "Tragédia dos Comuns" argumentando que com o crescimento populacional, usuários comuns se veem em um processo inevitável que leva a destruição do recurso comum que eles dependem, uma vez que cada usuário ignora a necessidade dos demais, e as decisões individuais culminam em um uso excessivo. Considera-se, porém, uma visão pessimista sobre o prospecto humano e nela os usuários são retratados em uma situação que não podem mudar. As soluções estão relacionadas a imposições aos usuários por autoridades externas.

Ostrom (1999) afirma que por milhares de anos as pessoas se auto-organizaram para gerenciar esses recursos, e usuários criam instituições sustentáveis que visam o gerenciamento dos recursos a longo termo. Segundo Ostrom (1999), é de grande dificuldade se encontrar regras efetivas que combinem interações complexas e a 
dinâmica de um recurso e que sejam aceitas pelos usuários com legitimidade, justiça e efetividade. Há momentos em que as divergências sobre os recursos podem ser estrategicamente utilizadas para se propor políticas que beneficiam desproporcionalmente um dos lados.

Ao lidar com recursos comuns, a humanidade se depara com novos desafios ao gerir a biodiversidade e mudanças climáticas: há a necessidade de se buscar acordos de interesses múltiplos, lidar com a diversidade cultural; as aceleradas taxas de mudanças, como crescimento populacional, desenvolvimento da economia e da tecnologia; e mobilidade de capital e do trabalho; complicação de recursos interligados e o esgotamento do próprio recurso em questão.

Os estudos de operação e planejamento de sistemas de recursos hídricos requerem e abrangem áreas de hidráulica, hidrologia, meteorologia, economia e meio ambiente. Operar reservatórios tornou-se, portanto, um desafio para o poder público, a sociedade e os usuários, que buscam gerenciar o recurso hídrico a longo termo de forma a atender diferentes demandas atuais e futuras, de uma forma justa e sustentável.

O uso de ferramentas para a otimização da operação de reservatórios em um sistema de grande escala contendo vários reservatórios tem se mostrado aliado aos tomadores de decisões. A busca de uma operação ótima tem sido alvo de pesquisa de vários autores e os resultados dos estudos são referentes às diferentes metodologias com potenciais de aplicações distintos que variam em função do objetivo estabelecido, dos resultados esperados, e do sistema analisado. Não existe uma metodologia única a ser adotada, ao passo que os casos de aplicação se distinguem sob diferentes aspectos de complexidade e requerem diferentes tipos de soluções.

Uma das primeiras tentativas de se abordar o planejamento e operação de reservatórios foi em 1883, quando Rippl introduziu o método do diagrama de massas para o dimensionamento de volumes úteis de reservatórios simples. Os métodos foram evoluindo com o passar do tempo e com a necessidade de se gerir sistemas de reservatórios complexos que requerem operação conjunta.

A Região Metropolitana de São Paulo (RMSP), com cerca de 20 milhões de habitantes, sofre com a estiagem severa que vem acarretando a crise de abastecimento. O principal sistema produtor de água na RMSP, o Sistema Cantareira, 
passa pela pior seca, desde quando se tem registro, ou seja, os últimos 85 anos. O período de maior intensidade da seca ocorreu entre os anos de 2013 e 2015, e no início do ano de 2016 começa a apresentar sinais de recuperação.

Trata-se de uma região com elevada concentração populacional na área de cabeceira da Bacia do Alto Tietê, com baixa disponibilidade hídrica per capita. Exige, portanto, a importação com transposição de bacias vizinhas, o que ocorre já no sistema existente e nas alternativas de expansão, situação onde conflitos aparecem.

No cenário atual, para atender cerca de metade da demanda a RMSP importa água através do Sistema Cantareira, formado pelos reservatórios Jacareí-Jaguari, Cachoeira e Atibainha localizados nas Bacias PCJ dos Rios Piracicaba, Capivari e Jundiaí, além dos reservatórios de Paiva Castro e Águas Claras que se encontram na Bacia do Alto Tietê.

Há alguns anos foi desenvolvido o modelo matemático SISAGUA, que utiliza a otimização com programação não linear inteira mista (PNLIM) para o planejamento e operação de sistemas com múltiplos reservatórios, adutoras e pontos de demanda.

A utilização de modelagem matemática utilizando e propondo melhorias no modelo SISAGUA para dar suporte à tomada de decisão na operação de sistemas com múltiplos reservatórios é objeto deste estudo. Serão abordados sistemas com múltiplos reservatórios interligados através de adutoras aos pontos de demanda para abastecimento público, tendo a RMSP como estudo de caso. Sistemas desse tipo envolvem a minimização dos custos de captação, tratamento e distribuição, decisões sobre a distribuição espacial e temporal dos armazenamentos, possibilidade de racionamento dentro do horizonte de planejamento, segurança para abastecimento futuro, evolução da demanda, entre outros. 


\section{OBJETIVOS}

Este trabalho busca estudar a utilização do modelo matemático de otimização SISAGUA, que utiliza a otimização com programação não linear inteira mista, para o planejamento da operação de sistemas de distribuição de água com múltiplos reservatórios e a utilização de uma discretização temporal.

Entre os objetivos do modelo podem ser levados em consideração o atendimento das demandas, o armazenamento de água nos reservatórios, a minimização do custo de operação, sujeitos a restrições associadas às características físicas dos componentes do sistema e aos usos múltiplos dos reservatórios.

As análises serão realizadas a partir dos resultados obtidos com o SISAGUA aplicado para o estudo de caso na RMSP que passou por uma situação de escassez hídrica intensa e crise de abastecimento durante o período de 2013-2015.

São apresentadas aplicações do modelo SISAGUA no diagnóstico do sistema existente na RMSP, na avaliação das principais alternativas de expansão, do efeito da evaporação, na operação integrada dos principais sistemas produtores, comparada a aplicação da regra descontínua de racionamento conforme sua formulação original e a alternativa de uma regra contínua e gradual de racionamento que transforma o problema em programação não linear (PNL). 


\section{REVISÃO BIBLIOGRÁFICA}

\subsection{Técnicas de Otimização e Planejamento}

Os estudos de operação e planejamento de reservatórios tiveram como precursor Rippl em 1883 a partir do método do diagrama de massas com a finalidade de se determinar os volumes úteis para reservatórios simples (ZAHED FILHO, 1984). Nesta técnica são utilizados os dados históricos e parte-se da hipótese de que a série observada é a mais severa possível. Com o tempo, as técnicas foram sendo aprimoradas a partir da necessidade de se analisar sistemas complexos de reservatórios.

Os sistemas complexos de recursos hídricos podem ser planejados e projetados para diferentes finalidades, de acordo com a necessidade e demanda local. Os reservatórios são os elementos mais importantes de complexos sistemas de recursos hídricos e são utilizados para a redistribuição espacial e temporal de qualidade e quantidade de água, e geração de energia. Possuem em sua operação o objetivo de maximizar os benefícios esperados simultaneamente, sujeitos a restrições. Tais restrições incluem limites máximos ou mínimos relacionados ao armazenamento para a recreação, navegação, controle de cheias, abastecimento (público, industrial, dessedentação, irrigação) e geração de energia; e limites relacionados à vazão defluente visando a qualidade da água, preservação ambiental e controle de cheias (SIMONOVIC, 1992).

Além disso, a operação visa atender às diferentes demandas de acordo com as prioridades, e lidar com fatores como a legislação local, a disponibilidade hídrica, a capacidade de armazenamento, as características das estruturas de operação; condições sociais e econômicas, condições esperadas do ecossistema, e o fator de desenvolvimento, ligado à política.

Simonovic e Savic (1989) ressaltam que o gerenciamento e operação são tarefas complexas que envolvem aspectos científicos de um problema e elementos de julgamentos decorrentes de aspectos sociopolíticos. 
Neste contexto de complexidade, os conflitos de interesses podem dificultar a tomada de decisão. Segundo Labadie (2004), o conflito de interesses se dá quando o foco de um projeto é realizado com considerações inadequadas relacionadas à operação e à manutenção real, e com o aumento da demanda não considerado no projeto inicial.

Embora haja um grau de comensurabilidade entre os diversos objetivos em um sistema hídrico, o conflito se agrava durante períodos de secas severas. Além da baixa disponibilidade hídrica nestes casos, no geral, as performances são restringidas por acordos legais, contratos, regulações federais, pactos interestaduais, e pressões dos interessados, ao passo que diferentes valores têm uma percepção distinta sobre o problema ou a realidade.

De acordo com Oliveira e Loucks (1997), a necessidade de negociações e subsequentes acordos relacionados ao modo de operação dos sistemas de reservatórios são a principal razão pela qual os sistemas são gerenciados baseados em regras fixas e pré-definidas. Essas regras pré-definidas indicam com diferentes níveis de detalhamento as ações a serem realizadas pelos operadores como função de um número relativamente pequeno de variáveis, como por exemplo, a época do ano, estado do sistema, e condições hidrológicas futuras esperadas.

Dessa maneira, a análise integrada se faz necessária para que os múltiplos objetivos esperados sejam atendidos com o desempenho esperado durante as fases de planejamento, projeto e operação. Tal análise se torna mais complexa ao levar em consideração juntamente com os múltiplos interesses, os impactos ambientais, a incerteza hidrológica e uma possível mudança climática, ligada a impactos socioeconômicos.

Os Sistemas de Suporte à Decisão (SSD), por sua vez, têm se mostrado ferramentas importantes de forma crescente nas operações e planejamento e recursos hídricos ao emular o comportamento do recurso sob condições variadas (vazões, armazenamento e demanda) e diferentes alternativas de planejamento (REITSMA et. al., 1996). Os SSDs são tipicamente utilizados para fornecer elementos e informações resultantes de uma análise integrada e fundamentada de diferentes objetivos, com a finalidade de servir como instrumento para entendimento do sistema e auxiliar os tomadores de decisão. 
São definidos como sistemas computacionais que visam auxiliar na tomada de decisão de problemas não estruturados ou parcialmente estruturados (PORTO et al. 1997). Os problemas não estruturados ou parcialmente estruturados ocorrem quando há a falta de informação ou conhecimento, variáveis não quantificáveis ou muito complexas, e interações desconhecidas.

Com o avanço da tecnologia, redução de custos, habilidade computacional e o desenvolvimento de softwares e sistemas operacionais com uma interface amigável, os SSDs têm demonstrado um grande avanço nos campos da pesquisa e prática, desde quando começaram a ser aplicados aos recursos hídricos, na década de 70 (ITO et. al., 2001; LABADIE, SULLIVAN, 1986).

Os modelos de simulação são a representação de um sistema para se prever o comportamento quando submetido a um conjunto de condições. A simulação de alternativas são realizadas com a finalidade de se analisar a performance de um sistema sob condições variantes, como por exemplo políticas de operações (WURBS, 1993). Se o número de alternativas a serem analisadas for muito grande, porém, a procura iterativa do ótimo global pode ser muito custoso, neste caso.

Os modelos de otimização são algoritmos matemáticos que buscam identificar os pontos máximos ou mínimos da chamada função objetivo, que representa por meio de uma expressão matemática, os objetivos estabelecidos na operação.

De acordo com Wurbs (1995) os seguintes objetivos tem refletido nas funções de vários modelos de otimização disponíveis na literatura:

1. Benefícios econômicos e custos:

- Maximizar abastecimento de água e / ou receitas de energia hidrelétrica;

- Minimizar o custo de atender a compromissos de energia elétrica;

- Minimizar as perdas econômicas devido a escassez de água;

- Minimizar os custos de bombeamento da água num sistema de distribuição;

- Minimizar os danos associados a uma inundação;

- Maximizar os benefícios líquidos das operações de uso múltiplo.

2. Disponibilidade de água e confiabilidade:

- Maximizar a vazão firme, atender as vazões de confiabilidade especificadas, para demandas específicas;

- Minimizar frequências de escassez; 
- Maximizar a vazão atendimento à demanda;

- Maximizar o armazenamento do reservatório no final do horizonte otimização;

- Minimizar vertimentos ou perdas por evaporação;

- Minimizar as flutuações de armazenamentos médios mensais;

- Maximizar a disponibilidade de períodos para navegação.

3. Geração de energia por hidrelétricas:

- Maximizar a energia firme;

- Maximizar a energia média anual;

- Minimizar a escassez de energia ou índices de falta de energia;

- Maximizar a energia potencial da água armazenada no sistema.

Os modelos de otimização podem ser classificados como estocásticos ou determinísticos; de acordo com o horizonte de planejamento (curto prazo ou longo prazo); em função do período de operação (anual, mensal, diário, horário); quanto aos usos e propósitos; quanto à dimensão do sistema; e quanto ao número e tipos de funções objetivos.

Simulações determinísticas que utilizam longas séries hidrológicas representativas para obter uma operação ótima são também classificadas como otimização estocástica implícita. A hidrologia pode ser obtida de uma série sintética de vazões ou de uma série histórica observada. As técnicas de regressão são geralmente utilizadas para inferir políticas de operação de reservatórios (RANI, MOREIRA, 2010). A otimização estocástica explícita, por sua vez, requer uma representação das vazões probabilísticas. Existem estudos que comparam os dois métodos. Embora a abordagem determinística possa ser formulada de forma a representar melhor o problema, ela pode apresentar certas limitações, quando se trata de situações extremas, como, por exemplo, uma seca severa ou uma cheia.

Para a otimização da operação não há um algoritmo geral. A escolha da metodologia depende das características do sistema de reservatórios considerado, a disponibilidade de dados e dos objetivos e restrições especificadas (YEH, 1985). Na sequência, é feita uma breve apresentação e exemplos de aplicação dos métodos mais utilizados. 


\subsubsection{Programação Linear}

A Programação Linear (PL) é comumente utilizada em gestão de recursos hídricos e aborda a solução de um tipo de problema e a relação entre todas as variáveis são lineares, tanto nas restrições como na função objetivo. A PL lida com a alocação de recursos limitados com relação ao número de atividades competindo (SIMONOVIC, 1992). Problemas não lineares podem ser linearizados e resolvidos por processos de iteração ou aproximação (YEH, 1985).

Quando aplicada em sistemas em que as equações não são lineares, ocorre uma violação da estrutura real do sistema. Em algumas aplicações a PL é adotada de forma conjunta com a programação dinâmica, especialmente nas operações em curto prazo (ZAHED FILHO, 1984).

Se a PL é aplicada a um modelo de operação do reservatório, o objetivo de planejamento típico pode ser minimizar a capacidade (ou o custo) do reservatório que satisfaça todas as restrições ou para maximizar o benefício anual líquido total que é representado como uma função de armazenamento e solta em cada período de operação presumida. É necessário que as funções custo sejam convexas e funções de benefícios côncavas para a aplicação bem-sucedida da PL (YEH, 1985).

Tem sido aplicada em vários sistemas de reservatórios ao determinar políticas de operações ótimas, dimensionar a capacidade de armazenamento de reservatórios, avaliação do rendimento, controle de cheias, planejamento do uso conjunto. As vantagens de se utilizar esta técnica estão na flexibilidade de aplicação em problemas de grande escala e convergência global para uma solução ótima e pacotes de softwares disponíveis para a aplicação (RANI, MOREIRA, 2010).

As primeiras aplicações determinísticas em operações de reservatórios datam de 1962, realizada por Dorfman (1962) apud Simonovic (1992) quando PL era utilizada para um único reservatório sem a finalidade de se reservar água por mais de um ano. Ele aplicou três versões do modelo, cada um com um nível de complexidade crescente. Embora existam limitações da PL num ambiente determinístico, existem importantes aplicações combinadas com técnicas adicionais que ampliam a aplicabilidade desta técnica (SIMONOVIC, 1992). A também PL tem sido extensivamente aplicada em simulações estocásticas combinadas com outras metodologias. 
Como exemplo, Randall et. al. (1990) apud. Wurbs (1993) desenvolveu um estudo de PL para estudar a operação durante a seca em um sistema metropolitano de água de Indiana consistindo em múltiplos reservatórios, água subterrânea e estações de tratamento. De Azevedo et. al. (2000), com o uso do modelo MODSIM (PL), fez uma integração de quantidade e qualidade da água na bacia do Rio Piracicaba, no estado de São Paulo. Shane e Gilbert (1982) apud Wurbs (1993) descreveram um modelo chamado HYDROSIM, utilizado para simular 42 reservatórios do Sistema de Tenesse Authority Valley, que utiliza a PL baseado em um período de 52 semanas.

Crawley e Dandy (1993) aplicaram a PL determinística no Sul da Austrália, do sistema de abastecimento de água formado por múltiplos reservatórios na cidade de Adelaide. A PL aplicada ao controle ótimo e à programação estocástica foi abordada de uma forma geral por Slyke e Wets (1969) e aplicada a múltiplos reservatórios por Dahe e Srivastava (2002).

\subsubsection{Programação Dinâmica}

A Programação Dinâmica (PD), primeiramente introduzida em 1957 por Bellman é um método que aborda uma otimização de processo multiestágio e tem sido amplamente utilizado em operação de reservatórios. É utilizada para fazer uma sequência interrelacionada, ou seja, explora as decisões com o intuito de determinar soluções ótimas aos problemas sequenciais: possui a capacidade de abordar recursos não lineares e estocásticos, que caracterizam os sistemas de recursos hídricos, e a vantagem de efetivamente decompor problemas complexos com um grande número de variáveis em um serie de subproblemas que são resolvidos recursivamente a cada passo de tempo (YEH, 1985). Essas combinações de soluções maximizam ou minimizam uma certa função. Ao contrário da $\mathrm{PL}$, esta técnica não é restrita a nenhuma estrutura de problema, capaz de lidar com função objetivo e restrições não lineares (SIMONOVIC, 1992). Sua aplicação torna-se, portanto, mais genérica, porém sua metodologia não é padronizada, como na PL, o que faz com que o conhecimento da estrutura geral de problemas possam ser abordados por PD seja maior, ao passo que para cada problema específico, precisam ser desenvolvidas equações adaptadas às condições específicas de cada sistema. 
De acordo com Zahed Filho (1984), o problema pode ser dividido em estágios, no qual o sistema pode estar em diferentes situações (estados) A política de decisão adotada em cada estágio transforma o estado atual do sistema no estado associado a um próximo estágio. Uma vez conferido o estado atual do sistema, a política ótima para os estágios restantes é independente daquela adotada em estágios anteriores. 0 método se inicia a partir da definição da política ótima do último estágio, para cada um dos possíveis estados.

Para a maioria dos problemas do reservatório, se a PD é aplicada para determinar as descargas do reservatório, a variável de estado é o armazenamento, a variável de decisão é a liberação de água, e o estágio é representado pelo período de tempo (SIMONOVIC, 1992). Pode ser aplicada para otimizações determinísticas ou estocásticas e considera apenas um número finito de estágios. O número de estados pode ou não ser finito.

A primeira aplicação de PD em recursos hídricos foi realizada por Hall e Buras (1961) apud Sharif e Wardlaw (2000). A aplicabilidade desta técnica, porém, para sistemas de múltiplos reservatórios fica limitada pela grande demanda de recursos computacionais. Georgakakos, Yao e Yu (1997) aplicaram a modelagem para a otimização de controle hidrelétrico no gerenciamento de reservatórios no sistema Lanier-Allatoona-Carters, localizado na região sudeste dos EUA. A operação de reservatórios com a programação de irrigação por PD foi abordada por Teixeira e Mariño (2002); A PD estocástica foi abordada por Stedinger, Faber e Lamontagne (2013.).

Talukdar, Deb e Srivastava (2012) abordaram a PD estocástica multi-objetivo para examinar a operação do projeto Sardar Sarovar no Rio Narmada, localizado na parte central Índia. Os objetivos foram: maximizar a meta de liberação anual; maximizar a produção hidrelétrica; e maximizar a confiança da produção do sistema Chung e Helweg (1985) combinaram DP com HEC-3 para lidar com os problemas operacionais dos projetos do Estado da Califórnia: Lago Oroville e Reservatório San Luis. 


\subsubsection{Programação Não Linear}

A não linearidade existe em vários reservatórios devido a relações complexas entre diferentes variáveis físicas e hidrológicas e por causa de objetivos específicos que estão sendo atendidos pelos sistemas. Esses problemas podem ser simplificados e resolvidos por PL, também a PD consegue lidar com a não linearidade, porém existe uma classe de problemas que são resolvidos pela PNL.

A PNL possui uma matemática envolvida mais complexa, o processo de otimização ocupa mais memória e leva maior tempo de processamento (YEH, 1985). Por outro lado, a PNL aborda uma formulação matemática mais generalista (SIMONOVIC, 1992) e fornece uma base para análise de outros métodos. A PNL pode efetivamente lidar com uma função objetivo não separável, e restrições não lineares que muitas técnicas de programação não podem.

Inclui a programação quadrática, programação geométrica, e programação separável como casos especiais que podem ser usados de forma iterativa como um programa principal ou como um subprograma em problemas no sistema de grande escala. Técnicas de pesquisa também têm sido utilizadas em conjunto com a simulação, a fim de avaliar as funções dos sistemas alternativos de desempenho (MAASS et al., 1962 apud YEH, 1985). Para um sistema de reservatórios, o número de restrições é grande porque eles lidam com subsistemas semelhantes repetidos no tempo ou local.

A PNL ganhou mais espaço e conquistou sua importância prática em sistemas de recursos hídricos com o desenvolvimento da tecnologia de computador e algoritmos eficazes para grande escala.

Gagnon et. al. (1974) utilizaram a PNL para abordar a otimização do sistema hidrelétrico da bacia de Columbia. Taghavi, Howitt e Mariño (1994) aplicaram a PNL em recursos hídricos para resolver o controle ótimo do gerenciamento da geração e descarte na agricultura. As restrições possuem cunho físico, econômico e social.

Georgakakos e Marks (1987) apud Mizyed, Loftis e Fontane (1992) estenderam o problema linear quadrático Gaussiano em um sistema de dinâmica não linear e aplicaram essa extensão na operação da Represa Alta de Assuã, localizada no Rio Nilo, Egito. 


\subsubsection{Lógica Difusa}

A Lógica Difusa ("Fuzzy") é uma abordagem desenvolvida para lidar com a falta de precisão e incerteza nas variáveis do modelo, até mesmo nos objetivos. Pode ser utilizada para problemas de difícil compreensão devido à subjetividade e/ou falta de informação. Ao invés de usar equações matemáticas complexas, a lógica difusa utiliza descrições linguísticas para definir a relação entre a informação de entrada e saída da decisão.

O conceito foi introduzido por Zadeh, em 1965 e é um método matemático usado para caracterizar e quantificar a incerteza e imprecisão nos dados e relações funcionais. Conjuntos difusos são úteis quando o número de dados não é suficiente para caracterizar a incerteza por meio de medidas padrão estatística envolvendo a estimativa de frequências. Conjuntos fuzzy é um método matemático usado para caracterizar e quantificar a incerteza e imprecisão nos dados e relações funcionais. É uma técnica útil quando o número de dados não é suficiente para caracterizar a incerteza por meio de medidas padrão estatística envolvendo a estimativa de frequências. O conceito central da teoria dos conjuntos fuzzy é a função de pertinência que representa numericamente o grau em que um elemento pertence a um conjunto. Se um elemento pertence a um conjunto fuzzy em algum grau, o valor da sua função de pertinência pode ser qualquer número entre 0 e 1. Quando a função de pertinência de um elemento pode ter os valores 0 ou 1 , apenas, a teoria dos conjuntos se reduz à teoria clássica dos conjuntos.

O objetivo e restrições são caracterizados por suas funções de pertinência. A decisão em ambiente difuso pode ser visto como a interseção das restrições difusas e da função objetivo (RANI, MOREIRA, 2010).

Russel e Campbell (1996) aplicaram a programação difusa em operação de reservatórios com finalidade de gerar energia elétrica, com vazões afluentes e preço de energia elétrica como variáveis. A regressão difusa também pode fornecer uma maneira de lidar com o problema de escassez de inadequação de dados e erros, que continua a ser uma grande restrição na aplicação de técnicas de regressão estatística. Mousavi, Karamouz e Menhadj (2004) aplicaram o conceito na programação dinâmica estocástica, levando em consideração as incertezas das variáveis de natureza 
hidrológica aleatória e a imprecisão da discretização da variável, aplicado no sistema de reservatórios do Rio Zayandeh-Rud em Isfahan, na região central do Irã.

\subsubsection{Rede Neural}

A rede neural é um método computacional inspirado por estudos ligados ao cérebro e a sistema nervoso de organismos biológicos. Tipicamente, uma rede neural é composta por um conjunto de unidades de processamento (neurônios, funções de ativação) de camadas e interconexões ponderadas. Redes neurais operam com o princípio de aprender a partir de um conjunto de treinamento. Existe uma variedade de modelos de redes neurais e procedimentos de aprendizagem. (KARUNANITHI et. al.,1994).

A sua utilização pode ser vantajosa quando, por alguma razão se precisa de um grande número de soluções do modelo a ser obtido num curto período de tempo (Loucks e van Beek 2005). Nestas aplicações de rede neural é usado como um aproximador universal: mapeamento de rede neural de entrada-saída é relacionado a um mapeamento não linear desconhecido de interesse através de treinamento da rede. Para executar o treinamento, é preciso ter um conjunto de pares de entradasaída, que é representante do mapeamento desconhecido que é aproximada (RANI, MOREIRA, 2010).

De acordo com Karunanithi et. al.,(1994) duas classes conhecidas de redes neurais que podem ser usados para a previsão aplicações são: redes feedforward e redes recorrentes. Em uma rede feedforward as ponderações das conexões somente alimentam ativações direcionadas para frente, ou seja, da camada de entrada para a camada de saída. Por outro lado, em uma rede recorrente conexões ponderadas são utilizadas para alimentar ativações anteriores de volta para a rede. A aprendizagem em redes neurais envolve o ajustamento dos pesos de interconexões. $O$ algoritmo mais comumente utilizado para uma rede feedforward é o backpropagation, de Rumelhart em 1986, que é um método de gradiente descendente em que os pesos das conexões são atualizadas com derivada parcial de erro em relação a pesos. No entanto, o algoritmo backpropagation padrão pode treinar apenas em uma rede de tamanho pré-determinado. 
Como exemplo de aplicação, French et al. (1992) apud Chandramouli e Raman (2001) desenvolveu uma rede neural de três camadas para prever a intensidade da chuva em tempo e espaço. Após treinar os padrões de entrada, a rede neural foi utilizada para prever a precipitação utilizando os atuais campos como dados de entrada. French mostrou que a rede neural é capaz de aprender uma relação complexa descrevendo a evolução da chuva em tempo e espaço.

Karunanithi et. al.,1994 foca em rede feedforward e avaliou a aplicabilidade da rede neural com uma unidade de saída linear para a previsão de fluxo do Rio Huron, em Michigan. Neelakantan e Pundarikanthan (2000) utilizaram a rede neural para aproximar o modelo de simulação do abastecimento de água da cidade de Chennai. Chandramouli e Raman (2001) aplicam no estudo de caso em um sistema de múltiplos propósitos chamado Parambikulam Aliyar, localizado no distrito de Palakkad, Índia. Ele estuda a habilidade que uma rede neural possui para derivar políticas operacionais gerais para um caso de múltiplos reservatórios (três reservatórios). Um algoritmo discreto de PD foi desenvolvido com três variáveis.

\subsubsection{Algoritmos Genéticos}

A abordagem da computação evolucionária (CE) foi experimentada para superar as complexidades, como, múltiplos objetivos, a incerteza, não linearidade, descontinuidade e discretização que limitam as aplicações dos métodos de otimização analíticos na otimização de sistemas de reservatórios.

Os Algoritmos Genéticos (AG) são sistemas adaptativos dos Algoritmos Evolucionários baseados conceitualmente nos princípios da evolução natural e da adaptação (ROTHMAN, MAYS, 2014). Os estudos de Algoritmos Genéticos (AG) se originaram em 1975 com Holland (OLIVEIRA, LOUCKS, 1997) que baseou a sua pesquisa no princípio da evolução de Darwin. Inspirado pelo mecanismo de seleção natural e evolução, Holland criou uma forma inteligente de busca randômica que explora a solução espacial com a finalidade de encontrar regiões promissoras e busca mais intensamente soluções nessas áreas. Desde então os AG tem sido aplicados em vários casos relacionados aos recursos hídricos, tais como: modelos de água subterrânea, problemas de otimização de rede de tubulações, calibração de modelos de chuva-vazão, modelos de routing de reservatórios, entre outros. 
Destacam-se pelo fato de que as melhores soluções são mais prováveis de serem encontradas nas regiões que contém maior proporção de boas soluções. Essas regiões podem ser encontradas randomicamente, e quando essa região é encontrada, mais buscas são realizadas nessa região, mas ao mesmo tempo os AG mantém a busca por outras regiões promissoras. Os AG são a tentativa de balancear essa busca de soluções em novas áreas com a busca da busca mais detalhada em regiões identificadas promissoras. Os usuários configuram vários parâmetros do algoritmo que determinam esse equilíbrio.

Os AG lidam com conjuntos de possíveis soluções múltiplas discretas, ao invés de uma única solução e uma resposta diferencial da superfície sobre essa solução. Não garantem, porém, que cada nova solução será melhor que as outras as quais são derivadas, eles apenas garantem que a probabilidade deles serem melhor, é maior.

Goldberg (1989) apud Wardlaw, Sharif (1999) identifica as seguintes diferenças entre GAs e os demais métodos tradicionais de otimização:

$\checkmark$ Trabalham com a codificação de um conjunto de parâmetros, e não com os parâmetros isolados;

$\checkmark$ Buscam uma população de pontos e não um único ponto;

$\checkmark$ Utilizam a informação da função objetivo diretamente e não exigem seus derivativos ou outras informações auxiliares;

$\checkmark$ Utilizam regras de transição probabilísticas e não regras determinísticas.

De acordo com Oliveira e Loucks (1997) os GA são independentes de um problema particular ou de um sistema a ser analisado. As medidas requeridas podem ser não lineares, não diferenciáveis e até mesmo descontínuas. $O$ algoritmo exige apenas que qualquer proposta de solução possa ser avaliada com base em alguma medida de desempenho, e que o seu desempenho possa ser quantificado e comparado com os resultados de outras soluções. Ao aplicá-lo para a operação de múltiplos reservatórios, a função que gera valores de desempenho do sistema é um programa com estruturas lógicas complexas. Outras qualidades positivas de GA são a sua independência de domínio e robustez que é, sua capacidade de lidar com uma diversidade de problemas utilizando essencialmente o mesmo código computacional, e a facilidade de modificação, que permite a incorporação de conhecimentos específicos para melhorar a eficiência do algoritmo. A natureza paralela de algoritmos 
genéticos (muitas soluções independentes devem ser muitas vezes obtidos) torna apropriado para processamento paralelo. Isto pode ser especialmente atraente se avaliar o desempenho de uma única solução levar um tempo de processamento considerado, ao passo que a utilização de $A G$ requerem um grande número de tais avaliações.

Entre as desvantagens de algoritmos genéticos, pode-se citar sua incapacidade de identificar claramente a melhor solução única, ou seja a solução que vai dar o máximo de desempenho do sistema

Goldberg e Kuo (1987) utilizou os AG para uma otimização da operação de bombas ao longo de uma tubulação em série. Oliveira e Loucks (1997) utilizaram os GA para avaliar regras operacionais para sistemas de múltiplos reservatórios, demonstrando que os AG podem ser utilizados para identificar políticas de operações efetivas.

Cai, McKinney e Lasdon (2001) abordam a solução de modelos não lineares de gerenciamento de recursos hídricos a partir da combinação de AG e PL. Essa abordagem foi aplicada em modelos não lineares de operação de reservatório com a geração não linear de energia elétrica e reservatório com equações topológicas não lineares; e uma análise a longo-termo de uma bacia com um grande número de relações não lineares. Sharif e Wardlaw (2000) aplicaram os AG num sistema de reservatórios na Indonésia; Moridi e Karamouz (2007) utilizaram os AG no sistema de reservatórios Karkheh, localizado na parte sudoeste do Irã.

Ribeiro (2005) utilicou o AG para aplicar em tempo real, a operação de reservatórios, minimizando os custos de consumo de energia elétrica pelos boosters e estações elevatórias do sistema SAM Leste, pertencente ao Sistema Adutor Metropolitano (SAM) da RMSP. Gambale (2000) avaliou os AG na calibração de modelos de otimização de redes de distribuição de água. 


\subsection{Modelos analisados}

Modelos de simulação de reservatórios são programados para diferentes aplicações e tem-se como exemplo (RANI, MOREIRA, 2010):

- Modelos HEC desenvolvidos pelos Hydrologic Engineering Center;

- Interactive River System Simulation (IRIS) com suporte da Ford Foundation, United Nations Environment Program, International Institute for Applied System Analysis, Austria e Cornell University. Interactive River-Aquifer System (IRAS) extensão da versão IRIS;

- Water Rigths Analysis Package (Wrap Modeling System) desenvolvido pela Texas A\&M University em meados da década de 80;

- SWD SUPER Modeling System: desenvolvido pela Southern Division da USACE (United States Army Corps of Engineers).

Como exemplo de modelos de otimização tem-se (RANI, MOREIRA, 2010):

- MODSIM: desenvolvido pela Colorado State University e Buereau of Reclamation's Pacific North West Region;

- RiverWare: desenvolvido pelo Center for Advanced Decision Support for Water and Environmental Systems da Colorado University;

- CalSim: desenvolvido pela California State Department of Water Resources e a US Bureau of Reclamation;

- ARSP: Acres Reservoir Simulation Program desenvolvido pela Acres Internations Corporation;

- OASIS: Operation Analysis and Simulation of Integrated Systems desenvolvido pela HydroLogics.

Foram analisados três softwares relacionados à operação de reservatórios: Os modelos HEC, Acquanet e SISAGUA. Na sequência, será apresentada uma breve descrição de cada, bem como alguns exemplos de aplicação;

Uma variedade de modelos e ferramentas de apoio à decisão foram desenvolvidos no pelo Hydrologic Engineering Center da U.S Army Corps of Engineers, em Davis, Califórnia. Os pacotes de simulação de sistemas de reservatórios (HEC-3, HEC-5, e 
HEC-ResSim) são capazes de processar sistemas incluindo gestão de cheias, abastecimento de água e operação de hidrelétricas.

O HEC-5 foi programado inicialmente para operação de controle de cheias para um único evento em maio de 1973. O programa foi expandido com a finalidade de incluir a finalidade de armazenamento (1978). HEC-5 (USACE, 1998) é um dos modelos de simulação de operação de sistemas de reservatórios mais utilizados, que podem realizar investigações de realocações de armazenamento e outras modificações operacionais nos reservatórios existentes, bem como estudos de viabilidade para propostas de novos projetos. HEC-5 é uma versão atualizada do HEC-3, ambos os softwares que tem capacidades semelhantes, exceto que HEC-3 não permite que os recursos abrangentes de controle de inundações de HEC-5.

O software HEC-ResSim, (USACE, 2013) é sucessor de HEC-5, foi criado com a finalidade de auxiliar engenheiros e gestores de planejamento a realizar estudos de recursos hídricos ao prever o comportamento de reservatórios e ajudar os operadores de reservatórios a planejar operações diárias em tempo real e em situações de emergência. Trata-se de um sistema de simulação de reservatórios, criado para modelar um ou mais reservatórios cujas operações são definidas pelos objetivos operacionais e restrições. É composto por uma interface gráfica baseada em janelas, com capacidades de gestão de dados, gráficos e relatórios.

O HEC-ResSim é um componente do projeto de desenvolvimento de softwares chamado HEC Next Generation (NexGen). Sua primeira versão (1.0) foi lançada em 2002. Novas atualizações foram lançadas em 2003 (versão 2.0); 2007 (versão 3.0) e a versão atual (3.1) é a de 2013.

Zahed Filho (1984) fez a aplicação no HEC-5 para o estudo do projeto de reversão de parte das águas da bacia do Rio Juquiá para São Paulo. A transferência de água para São Paulo será realizada por uma inversão de fluxo natural do Rio São Lourenço, de forma que a água alcançasse sua cabeceira e a seguir atingisse a bacia do Alto Tietê, no reservatório de Guarapiranga. A meta de operação era aduzir uma vazão média mensal de $65 \mathrm{~m} 3 / \mathrm{s}$ para São Paulo. O projeto original foi proposto pelo Departamento de Águas e Energia Elétrica do Estado de São Paulo (DAEE) para abastecimento da RMSP simultaneamente à geração de energia de ponta e ao controle das cheias. 
Stefanovic e Kreyborg (2004) aplicaram o HEC-ResSim para o Red River em North Dakota, Minnesota. Piman et al. (2012), envolve os Rios Sekong, Sesan e Srepok na Ásia, situados na bacia Mekong. O Rio Mekong tem sua nascente no plateau tibetano em Qinghai, província chinesa e foz no mar da China Meridional. Com uma extensão de aproximadamente $4.350 \mathrm{~km}$, passa pelos países da China, Myanmar (Burma), Laos, Tailândia, Camboja e Vietnam. Foram simulados 20 anos para se obter a magnitude de mudanças potenciais ao futuro desenvolvimento de 42 barragens nesses três rios.

O Hydrologic Engineering Center desenvolveu também o HEC-ResPRM (Prescriptive Reservoir Model), que é um pacote de software de otimização do fluxo em rede para sugerir o melhor resultado que se pode esperar para o sistema baseado em qualquer priorização particular dos objetivos do sistema e dado de entrada de uma série histórica. Sua versão 1.0 é de agosto de 2009. HEC-ResPRM (modelos de otimização) é rodado com um intervalo de tempo mensal e simulações determinísticas e pode ser utilizado sozinho ou em conjunto com o modelo de simulação HEC-ResSim (modelo de simulação) para analisar e melhorar as operações de reservatório.

Um exemplo apresentado por Faber e Harou (2007) é a otimização multiobjetivo para sistemas de múltiplos reservatórios e fluxo em rede, como o Sistema do Rio Columbia, do Rio Missouri, Mississipi, e o sistema estadual de recursos hídricos da Califórnia. Foi realizada uma integração do PRM ("Prescriptive Reservoir Model”) ao HEC-Res.

O SISAGUA é um modelo de otimização com programação não linear inteira mista (PNLIM) para sistemas com múltiplos reservatórios ou outras fontes interligados em rede com pontos de demanda (BARROS et al., 2008), considerando regras operativas, expansão do sistema, regras de racionamento, etc. O SISAGUA utiliza como prioridades preemptivas evitar ou minimizar falhas no suprimento, manter uma distribuição equilibrada de armazenamentos em múltiplos reservatórios e minimizar os custos de operação em sistemas complexos de produção e adução de água.

Um exemplo foi a aplicação do modelo para a Região Metropolitana de São Paulo (BARROS et al., 2005) com os dados de entrada de vazão para a década de 1950 (período de secas severas). Uma nova aplicação do modelo foi realizada por Barros et al. em (2008) para a RMSP com diferentes exemplos de estudos de casos que mostraram diferentes aspectos da aplicação do modelo: (1) Um reservatório 
equivalente para um nó de demanda (de $67 \mathrm{~m} / \mathrm{s}$ ) para uma afluência de 10 anos (1950-1960) e uma previsão perfeita de afluências; (2) aborda diferentes previsões para uma operação em tempo real, ao adotar que a previsão só está disponível nos próximos dois meses e usa-se $70 \%$ da vazão de longo tempo para os outros meses; (3) aborda a expansão da capacidade com a construção de novas conexões para ligar trechos que não tem ligação; (4) o modelo foi aplicado para todo o sistema. Adicionalmente, o modelo fora aplicado em um sistema de distribuição de água em Taiwan (BARROS et al., 2008).

O SISAGUA também foi aplicado tendo como estudo de caso a transposição do Rio São Francisco (ZAMBON et al., 2008), em um sistema com 19 reservatórios e 35 pontos de demanda. Nessa aplicação a evaporação passou a ser considerada em sua formulação. A vazão histórica utilizada foi referente aos anos de 1931 a 1990 e os resultados apresentados mostram a relação entre a possibilidade de suprimento e a demanda para cada ponto, com e sem o projeto da transposição.

O AcquaNet de Porto et al. (2005) é um modelo integrado para a análise de sistemas complexos em recursos hídricos desenvolvido pelo LabSID (Laboratório de Sistemas de Suporte a Decisões em Engenharia Ambiental e de Recursos Hídricos), criado pelo Departamento de Engenharia Hidráulica e Sanitária da Escola Politécnica da Universidade de São Paulo. O AcquaNet é constituído por um módulo de base responsável pela integração dos demais: alocação de água; qualidade da água; irrigação; produção de energia; análise econômica para alocação e curvas de aversão a risco.

Foi aplicado para a Represa Jaguari-Jacareí no Sistema Cantareira de São Paulo (ALBANO, 2004), com a finalidade de gerenciar a tomada de água em termos quantitativos e qualitativos. Outro exemplo de aplicação foi o Sistema Produtor do Alto Tietê (SPAT) com a finalidade de otimizar a alocação de água, considerando o amortecimento de canais (SCHARDONG et al, 2006) 


\section{METODOLOGIA}

O objetivo do projeto visa comparar a metodologia abordada no modelo escolhido para a otimização da operação de reservatórios ao considerar uma hierarquia de prioridades. Uma breve descrição dos modelos adotados será realizada na sequência. O SISAGUA (BARROS et al. 2005) é um modelo que considera o fluxo em rede e os componentes do sistema são representados como nós representando reservatórios de regularização ou pontos de confluências, desvio, entrada ou demanda, e como arcos representando canais, adutoras, estações de tratamento, elevatórias e trechos naturais de rio.

Com a finalidade de lidar com os objetivos múltiplos, a otimização é realizada em três passos, utilizando o conceito de prioridades preemptivas.

$\checkmark$ Primeiramente o modelo minimiza a escassez quadrática para cada ponto de demanda e intervalo de tempo.

$\checkmark$ O segundo objetivo envolve a determinação de uma operação do sistema de reservatórios que minimize a diferença entre o armazenamento e a meta de cada reservatório.

$\checkmark \quad$ No terceiro objetivo o modelo minimiza os custos totais de operação.

As funções objetivo estão apresentadas na sequência.

Função Objetivo 1: O modelo minimiza o custo total de racionamento (Equações $1 \mathrm{e}$ 2).

$$
\min \sum_{i=1}^{T} d_{i} \sum_{k=1}^{n d}\left(1-X N_{(k, i)}\right)^{2} D_{(k, i)} C_{u s d(k, i)}
$$

Com:

$$
X N_{(k, i)}=\frac{P_{(k, i)}}{D_{(k, i)}}
$$

Onde:

$D_{(k, i)} \rightarrow$ Demanda planejada no nó $k$, intervalo i $\left(m^{3} / s\right)$;

$\mathrm{P}_{(\mathrm{k}, \mathrm{i})} \rightarrow$ Demanda atendida no nó $\mathrm{k}$, intervalo de tempo i $\left(\mathrm{m}^{3} / \mathrm{s}\right)$; 
Cusd(k,i) $\rightarrow$ Custo ou peso de não atendimento a demanda no intervalo de tempo i;

$\mathrm{XN}(\mathrm{n}, \mathrm{i}) \rightarrow$ Relação entre demanda atendida e demanda planejada no nó $\mathrm{k}$, intervalo de tempo i (adimensional);

nd $\rightarrow$ Número de nós de demanda;

$\mathrm{i} \rightarrow$ Índice de intervalos de tempo;

$\mathrm{k} \rightarrow$ índice de nós de demanda;

$d_{i} \rightarrow$ duração dos intervalos de tempo (s);

$T \rightarrow$ Número de intervalos de tempo.

Função Objetivo 2: Fixa os valores de atendimento a demanda obtidos na primeira etapa e minimiza o desvio dos volumes em relação aos máximo (Equação 3):

$$
\min \sum_{i=1}^{T} d_{i} \sum_{k=1}^{n d} \frac{\left(S_{\text {target }(m, i)}-S_{(m, i)}\right)^{2} C_{u s v(m, i)}}{S_{\text {target }(m, i)}}
$$

Onde

$\mathrm{S}_{\text {target }(m, \mathrm{i})} \rightarrow$ Volume meta no nó produtor $\mathrm{m}$, intervalo de tempo i $\left(\mathrm{m}^{3}\right)$;

$\mathrm{S}_{(\mathrm{m}, \mathrm{i})} \rightarrow$ Volume no nó produtor $\mathrm{m}$, intervalo de tempo i $\left(\mathrm{m}^{3}\right)$;

$\mathrm{Cusv}_{(m, i)} \rightarrow$ Custo ou peso de desvio em relação ao volume máximo no intervalo de tempo i;

$\mathrm{nr} \rightarrow$ Número de nós produtores;

$\mathrm{m} \rightarrow$ Índice de nós produtores.

Função Objetivo 3: Minimiza o custo de operação da rede enquanto o atendimento aos nós de demanda e a política de operação nos nós produtores já estão fixos. A função objetivo é dada pela Equação 4 a seguir:

$$
\min \sum_{i=1}^{T} d_{i} \sum_{a=1}^{n a} Q A_{(a, i)} C_{u s a(a, i)}
$$

Onde:

$\mathrm{QA}_{(a, \mathrm{i})} \rightarrow$ Fluxo no trecho a, intervalo de tempo i $\left(\mathrm{m}^{3} / \mathrm{s}\right)$;

$\mathrm{Cusa}_{(a, i)} \rightarrow$ Custos de adução nos trechos no intervalo de tempo i $\left(\mathrm{R} \$ / \mathrm{m}^{3}\right)$; 
na $\rightarrow$ Número de trechos;

$\mathrm{a} \rightarrow$ índice de trechos.

A otimização está sujeita a um conjunto de restrições que incluem:

$\checkmark$ Limites superiores e inferiores (Equação 5):

$$
\begin{gathered}
Q_{\min (a, i)} \leq Q A_{(a, i)} \leq Q_{\max (a, i)} \\
0 \leq X N_{(n, i)} \leq 1 \\
X N_{(n j, i)}=0 \\
Q E_{(n r, i)} \geq Q_{\mathrm{efm}(n r, i)}
\end{gathered}
$$

Onde:

$\mathrm{QE}_{(\mathrm{nr}, \mathrm{i})} \rightarrow$ Vazão efluente do reservatório $\mathrm{nr}$ no período de tempo i $\left(\mathrm{m}^{3} / \mathrm{s}\right)$;

Qefm(nr,i) $\rightarrow$ Vazão restritiva efluente do reservatório $n r$ no período de tempo i ( $\left.\mathrm{m}^{3} / \mathrm{s}\right)$.

$\checkmark$ Equação da continuidade para cada nó (Equação 6):

$$
X N_{(n, i)} D_{(n, i)}+\sum_{t(n o i=n)} Q A_{(a, i)}-\sum_{t(n o f=n)} Q A_{(a, i)}=0
$$

Onde,

$D_{(n, i)} \rightarrow$ Vazão de demanda no nó $n$ e intervalo de tempo i $\left(m^{3} / s\right)$.

$\checkmark$ Equação da continuidade para cada reservatório (Equação 7):

$$
S_{(n r, i)=} S_{(n r, i-1)}+d_{i}\left(I_{(n r, i)}-Q E_{(n r, i)}+X N_{(n r, i)} D_{(n r, i)}\right)
$$

Sendo que,

$I_{(n r, i)} \rightarrow$ Vazão afluente no reservatório $\mathrm{nr}$ em um intervalo de tempo i $\left(\mathrm{m}^{3} / \mathrm{s}\right)$;

$\mathrm{d}_{\mathrm{i}}=$ duração de tempo do período (s); 
$\checkmark$ Regras operativas dos reservatórios: nelas são adotadas as políticas de racionamento (Equações 8 e 9).

$$
\begin{gathered}
\sum_{s} B_{(s, n r, i)}=1 \\
X N_{(n r, i)} \leq \sum_{s} B_{(s, n r, i)} \alpha_{(n r, s)} \\
B_{(s 1, n r, i)} S_{\text {min }(n r, i)}+B_{(s 2, n r, i)} S_{\text {minoper }(n r, i)}+B_{(s 3, n r, i)} S_{f i r m(n r, i)} \leq S_{(n r, i)} \\
S_{(n r, i)} \leq B_{(s 0, n r, i)} S_{\min (n r, i)}+B_{(s 1, n r, i)} S_{\text {minoper }(n r, i)}+B_{(s 2, n r, i)} S_{f i r m(n r, i)} \\
+B_{(s 3, n r, i)} S_{\text {target }(n r, i)}
\end{gathered}
$$

Onde:

$\mathrm{S} \rightarrow$ Segmentos de racionamento (s0 , s1, s2 e s3);

nj $\rightarrow$ Conjunto de nós de junção;

$\mathrm{Q}_{\max (a, i)} \rightarrow$ Capacidade máxima de vazão no trecho a $\left(\mathrm{m}^{3 / \mathrm{s}}\right)$;

$Q_{\min (a, i)} \rightarrow$ Capacidade mínima de vazão no trecho a $\left(\mathrm{m}^{3} / \mathrm{s}\right)$;

$\mathrm{S}_{\min (\mathrm{nr}, \mathrm{i})} \rightarrow$ Volume mínimo no reservatório $\mathrm{nr}$, intervalo de tempo i $\left(\mathrm{m}^{3}\right)$;

$\mathrm{S}_{\mathrm{firm}(\mathrm{nr}, \mathrm{i})} \rightarrow$ Volume firme no reservatório $\mathrm{nr}$, intervalo de tempo i $\left(\mathrm{m}^{3}\right)$;

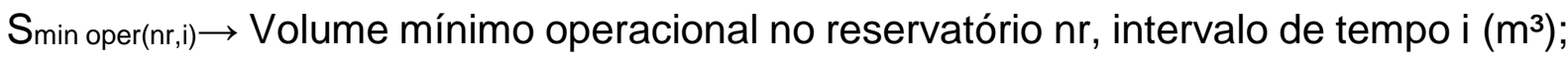

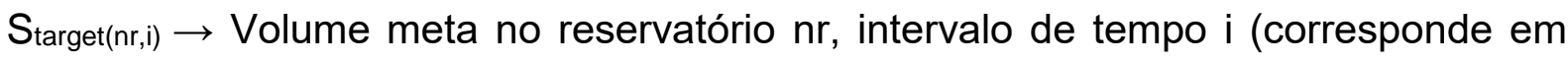
geral ao volume máximo operacional) $\left(m^{3}\right)$;

$\mathrm{B}_{(\mathrm{s}, \mathrm{nr}, \mathrm{i})} \rightarrow$ Variável binária (0 ou 1), indica a faixa de racionamento no reservatório $\mathrm{nr}$, intervalo de tempo i;

$\mathrm{I}_{(\mathrm{nr}, \mathrm{i})} \rightarrow$ Vazão afluente no reservatório $\mathrm{nr}$, intervalo de tempo i $\left(\mathrm{m}^{3} / \mathrm{s}\right)$;

$\mathrm{QE}(\mathrm{nr}, \mathrm{i}) \rightarrow$ Vazão efluente no reservatório $\mathrm{nr}$, intervalo de tempo i $\left(\mathrm{m}^{3} / \mathrm{s}\right)$;

Qefm(nr,i) $\rightarrow$ Vazão efluente mínima no reservatório $\mathrm{nr}$, intervalo de tempo i $\left(\mathrm{m}^{3} / \mathrm{s}\right)$;

$\alpha(n r, s) \rightarrow$ Fatores de racionamento $(\alpha 0=0<\alpha 1(n r, s)<\alpha 2(n r, s)<\alpha 3=1)$.

As variáveis de decisão são:

$Q A_{(a, i)} \rightarrow$ Fluxo em todos os trechos $\left(\mathrm{m}^{3} / \mathrm{s}\right)$; 
$\mathrm{XN}(\mathrm{n}, \mathrm{i}) \rightarrow$ Demanda atendida em todos os nós de demanda $\mathrm{P}(\mathrm{k}, \mathrm{i})\left(\mathrm{m}^{3} / \mathrm{s}\right)$;

$\mathrm{B}_{(\mathrm{s}, \mathrm{nr}, \mathrm{i})} \rightarrow$ Variável binária (0 ou 1 ), indica a faixa de racionamento no reservatório $\mathrm{nr}$, intervalo de tempo i;

Trata-se de uma formulação de programação não linear inteira mista (MINLP), resolvido por algoritmos disponíveis através do General Algebraic Modelin System (GAMS, 2013). O SISAGUA é um software que utiliza o GAMS e sua interface gráfica foi desenvolvida através do DELPHI. É um projeto em constante evolução e pode apresentar melhorias com regras de otimização contínuas.

A Figura 1 apresenta curvas-guia típicas, associadas a um sistema de reservatórios, operando com múltiplas finalidades. A curva superior define o volume meta, a curva intermediária corresponde ao volume firme sem racionamento e a curva inferior o volume mínimo operacional. Entre os volumes firme e o mínimo operacional é realizado o racionamento através do coeficiente $\alpha_{2}$ de redução de vazão de demanda a ser atendida. Abaixo do volume mínimo operacional o nível de racionamento é definido a partir do coeficiente $\alpha_{1}$. (BARROS et al. 2008)

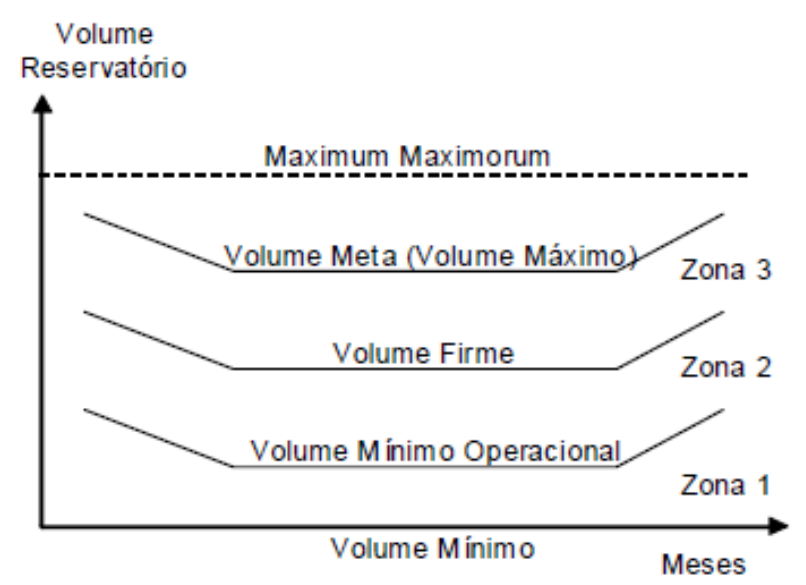

Figura 1 - Regras de operação para um reservatório de usos múltiplos.

Durante os períodos de escassez, abaixo da curva firme, as retiradas de vazão são reduzidas com a finalidade de se assegurar certa quantidade de água para o futuro.

De forma geral, as curvas de racionamento são expressas de forma progressiva, conforme apresentado na Figura 2. Quanto mais baixos os níveis dos reservatórios, maiores os níveis de racionamento, traduzido pelos coeficientes de redução de vazão 
(a's). Ao aplicar as regras de racionamento em conjunto com as curvas guias, obtémse um balanço entre o corte no abastecimento e volumes de reservação. (BARROS et al. 2008).

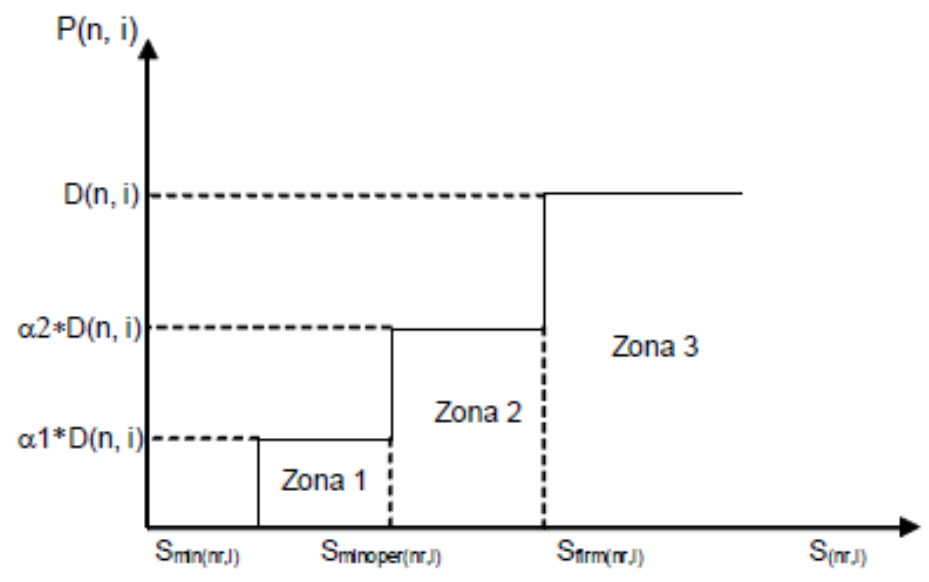

Figura 2 - Curvas operacionais e regras de racionamento. Funções em escala.

Uma breve apresentação da interface do SISAGUA será apresentada no item 4.1 a seguir.

\subsection{Interface do SISAGUA}

A página desenho (Figura 3) permite editar o desenho de rede e os dados de cada nó ou trecho. Os valores de armazenamento, vazões, custo podem ser fixos, definidos por um único valor que será constante em todos os intervalos de tempo; cíclicos, definidos para tantos quantos forem os intervalos de tempo definidos por ciclo, 12 no caso de modelo anual/mensal; e variáveis, que devem ser definidos para todos os intervalos de tempo considerados no modelo. 


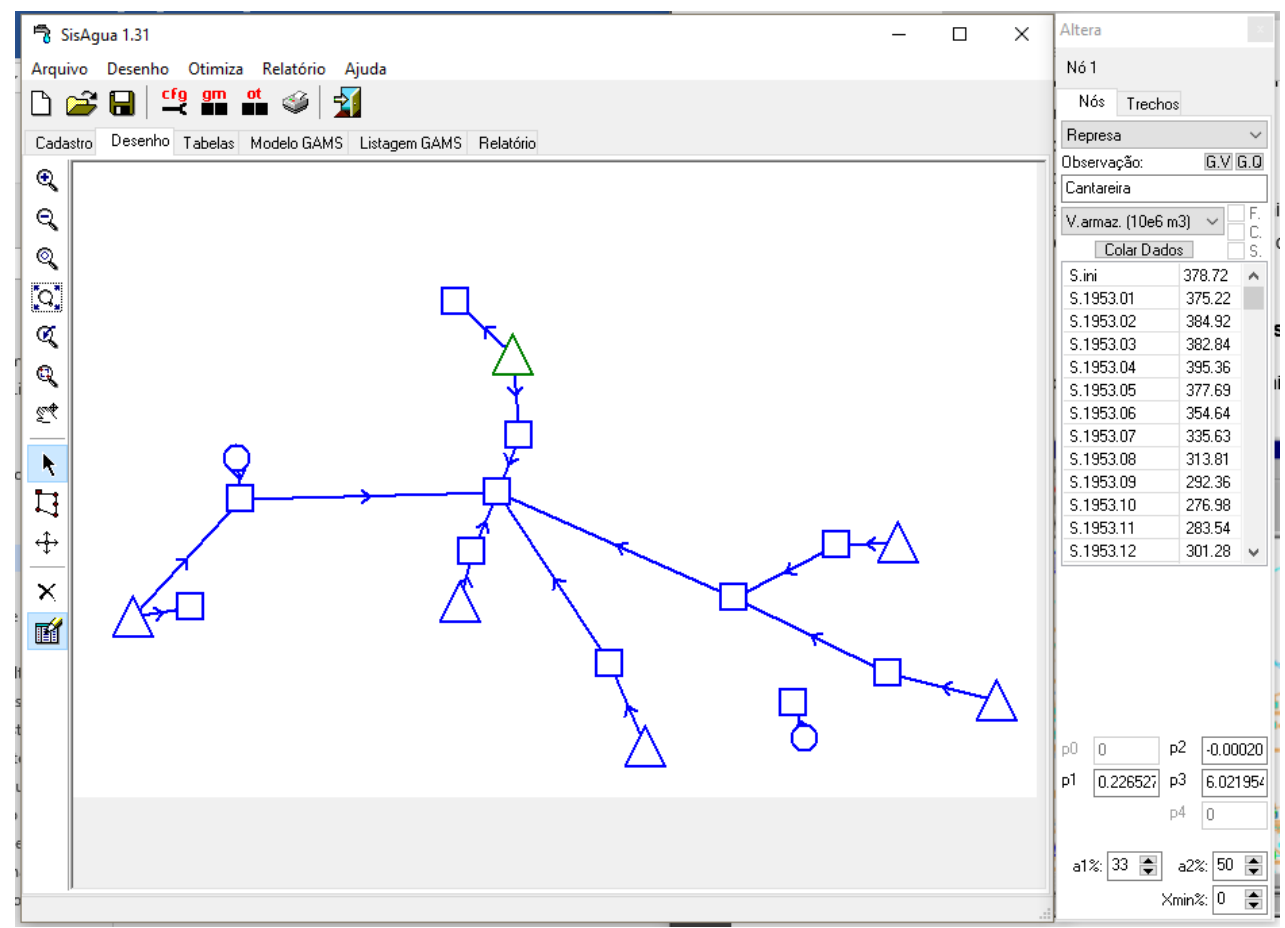

Figura 3 - Página de desenho na interface do SISAGUA, com caixa de alteração de dados aberta.

Volumes nas represas e vazões nos trechos, nós fonte e nós de demanda podem ser apresentados na forma de gráficos através dos botões G.V. e G.Q., como mostra a Figura 4 e a Figura 5 .

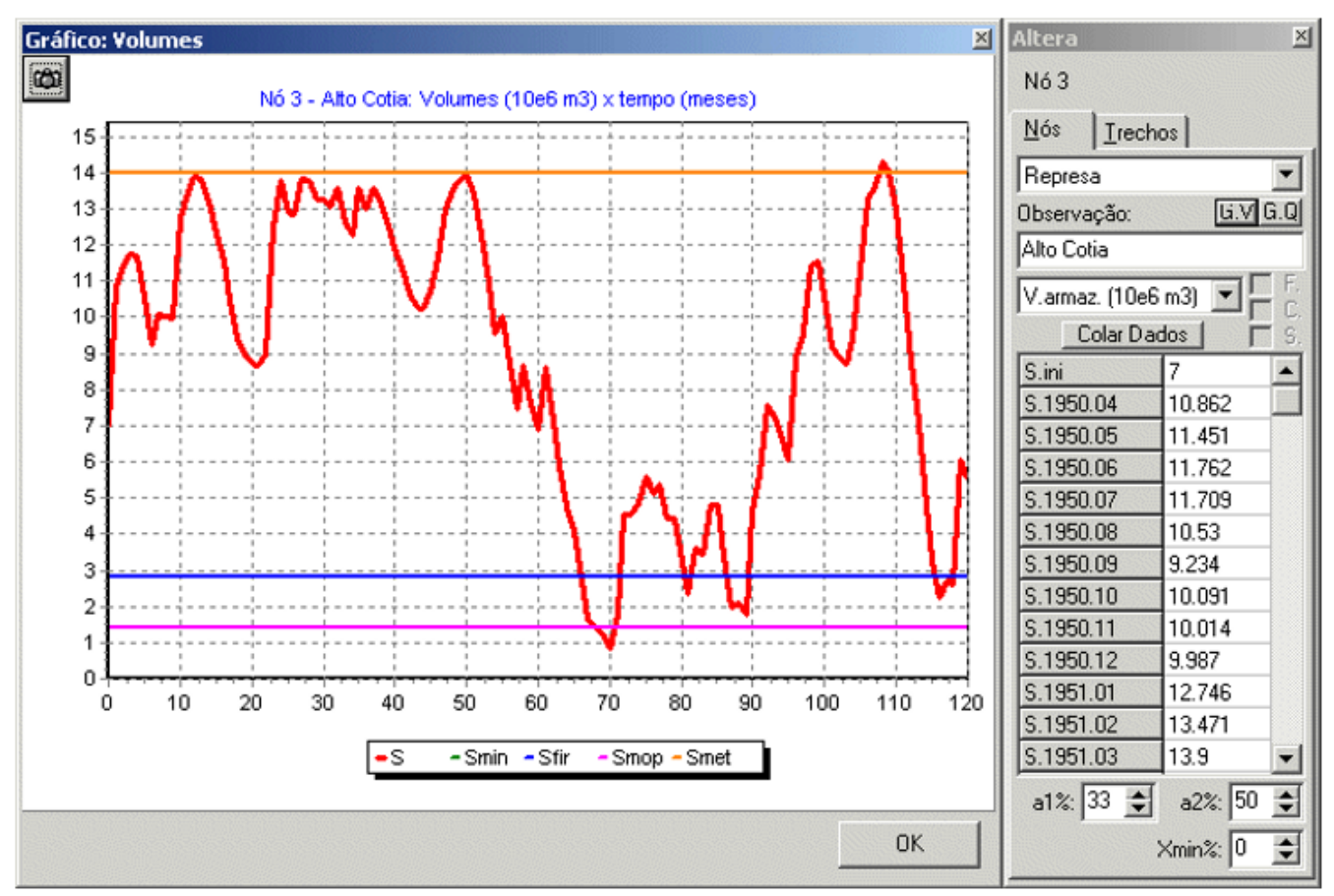

Figura 4- Gráfico de volumes. 


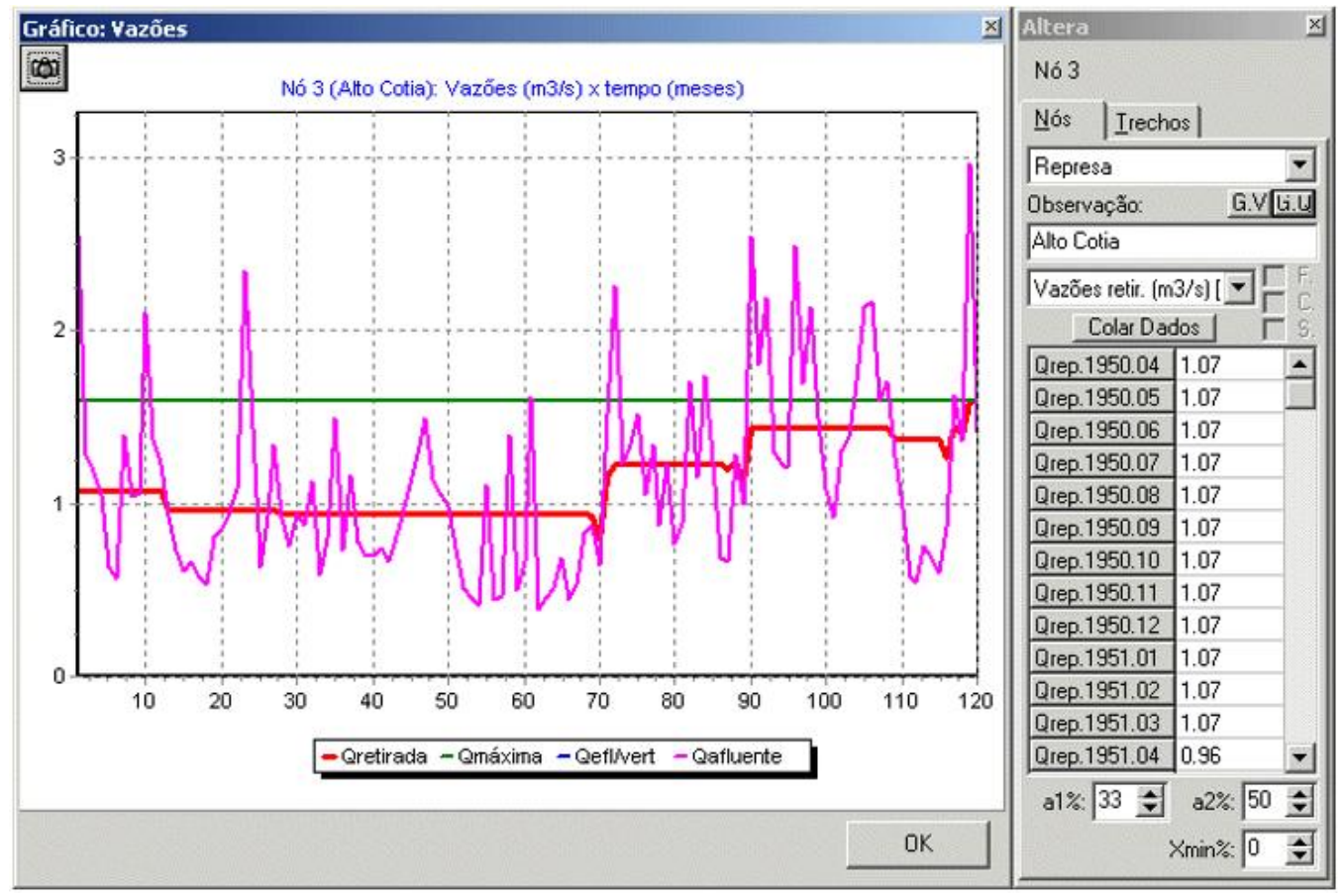

Figura 5- Gráfico de vazões.

A página de tabelas (Figura 6) mostra em forma de tabela os dados dos trechos e nós para cada intervalo de tempo. Os dados nesta página são apresentados apenas para visualização, a edição deve ser feita através da opção já apresentada na página de desenho.

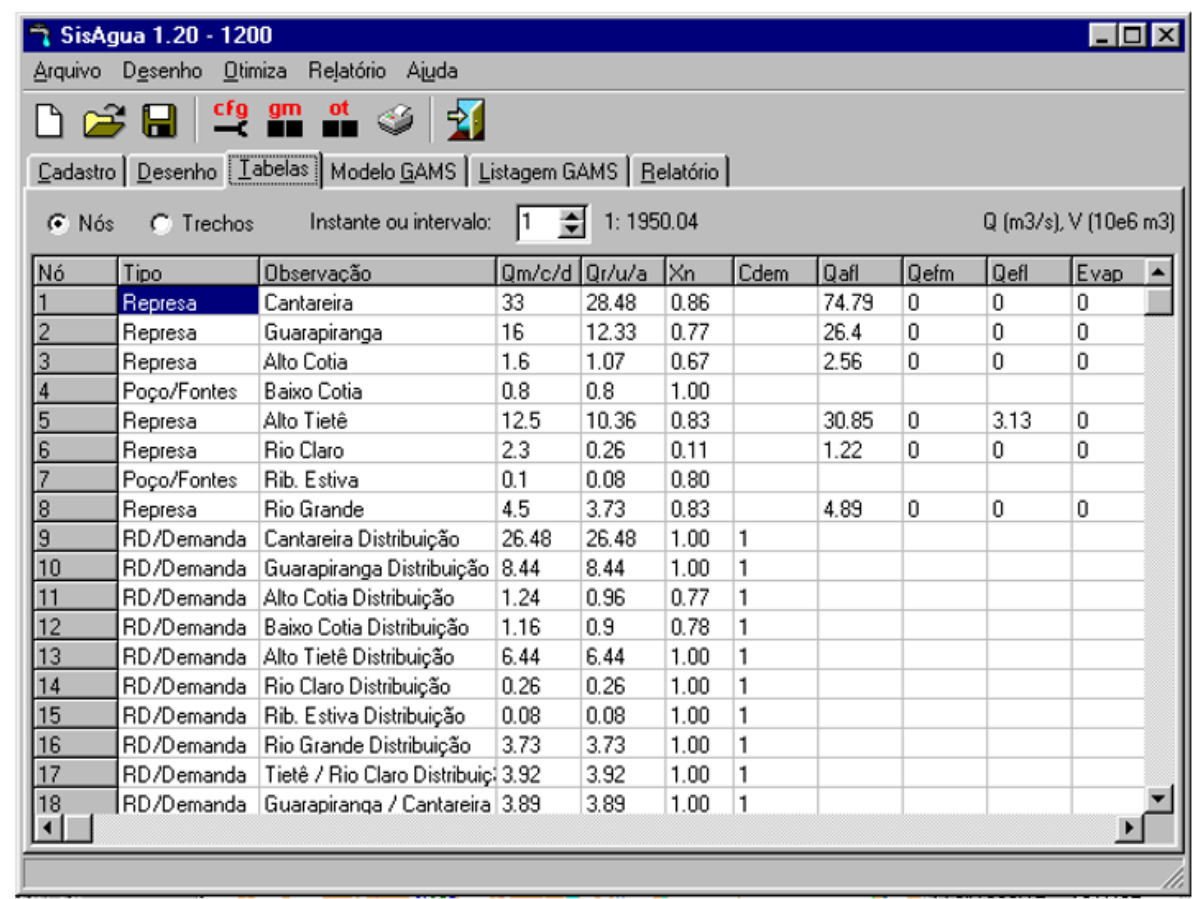

Figura 6 - Página de tabelas na interface do SISAGUA. 
As páginas modelo GAMS (Figura 7), listagem GAMS (Figura 8) e relatório (Figura 9): mostram, respectivamente e após a execução das opções correspondentes, o modelo completo do sistema na linguagem do GAMS, a listagem resultante da sua execução, e um relatório gerado pelo SISAGUA.

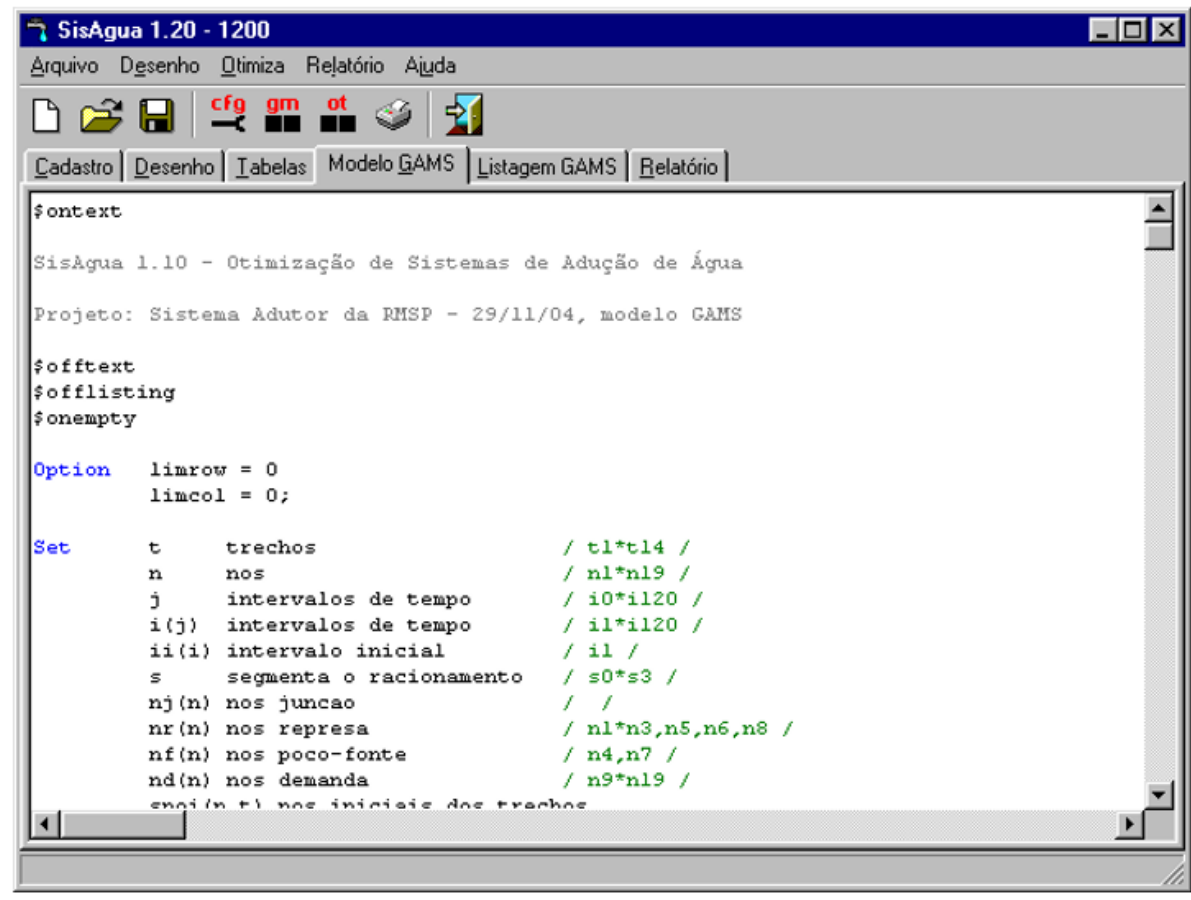

Figura 7 - Página do modelo GAMS.

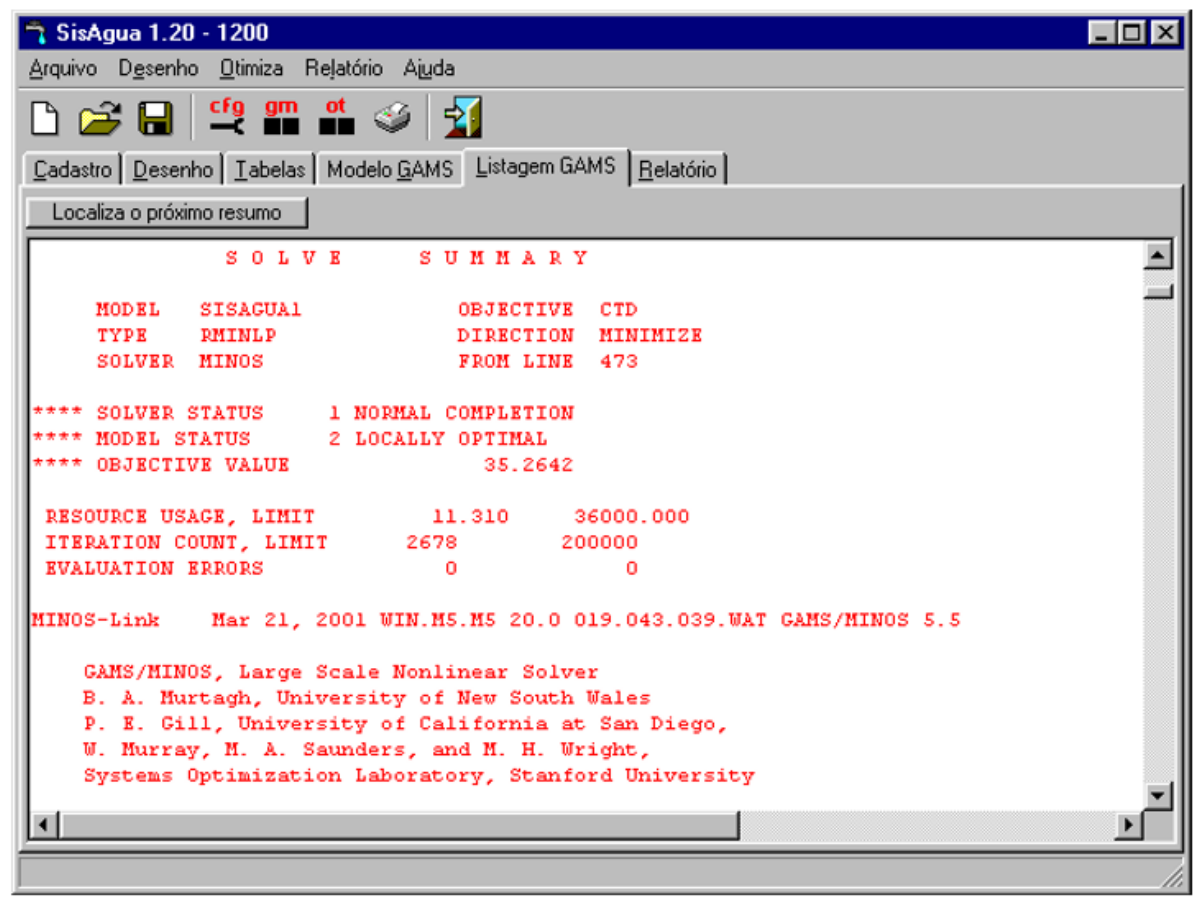

Figura 8 - Página com listagem de resultados do GAMS. 


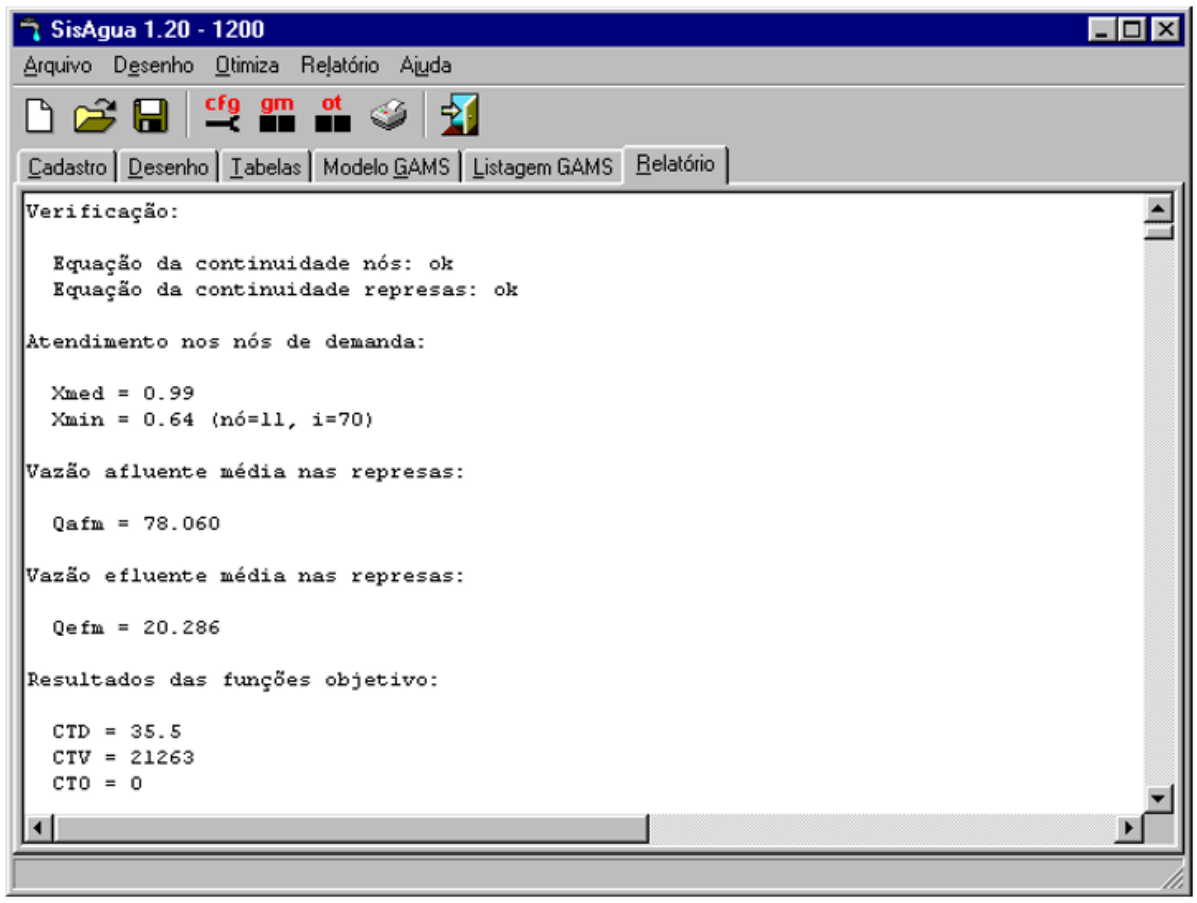

Figura 9 - Página de relatório na interface do SISAGUA. 


\section{ESTUDO DE CASO}

Os baixos índices de precipitação ocorreram na região sudeste de 2013 a 2015, o que afeta diretamente o abastecimento público, a geração de energia, sendo que a matriz energética brasileira depende muito de usinas hidrelétricas, além de afetar atividades relacionadas às navegações por hidrovias, à indústria e ao agronegócio.

Neste trabalho o abastecimento público é evidenciado como objeto de estudo. Grande parte das captações do abastecimento público, no Brasil, provém de mananciais superficiais ou mistos (superficiais e poços), (ANA, 2010). Durante a crise hídrica, a estiagem afetou as vazões afluentes e, portanto, diminuiu a disponibilidade em corpos hídricos superficiais e a recarga dos aquíferos subterrâneos, alterando a dinâmica dos escoamentos básicos. O estado de São Paulo contabilizou diversos casos de municípios com restrições no abastecimento público, como foi o caso de Itu, Salto, Barretos, Guarulhos, Mauá, Cruzeiro, Mirassol, Americana, Araras, Casa Branca e São Sebastião da Grama.

A região metropolitana de São Paulo, por sua vez, sentiu os impactos relacionados às baixas afluências. Trata-se de uma região expressiva em termos de população, área, atividades industriais e econômicas e, portanto, requer e demanda recursos em uma ordem de grandeza significativa. Dada a complexidade da região e a baixa disponibilidade hídrica e características do sistema existente, o abastecimento ficou vulnerável à estiagem.

Varias medidas estruturais e operacionais foram tomadas pelo Governo do Estado de São Paulo e pela Sabesp visando minimizar os impactos de não atendimento à demanda e do rebaixamento dos níveis dos reservatórios. Neste âmbito, surgiram questionamentos sobre o planejamento, a fragilidade do sistema de abastecimento, $\mathrm{e}$ sobre os investimentos destinados a este ramo de saneamento.

Diante de adversidades, esta região foi selecionada como estudo de caso. O sistema de abastecimento e o contexto da crise hídrica estão descritos nos itens a seguir. 


\subsection{Região Metropolitana de São Paulo}

O Brasil é um grande país com ecossistemas diferentes, no qual a hidrologia varia consideravelmente (ZAMBON, BARROS, YEH, 2008). A região sudeste é muito importante para o desenvolvimento econômico do País ao concentrar importantes complexos industriais, comerciais e financeiros.

A Região Metropolitana de São Paulo (RMSP), por sua vez, concentra hoje, cerca de 20,4 milhões de habitantes (SEADE, 2015), que representam aproximadamente $48 \%$ da população total do Estado de São Paulo. Abrangendo 39 municípios, e uma área de $8.051 \mathrm{~km}^{2}$ correspondente a $3,2 \%$ do território do Estado (SABESP, 2014) a região apresenta disparidades internas expressivas de distribuição de crescimento demográfico, expansão urbana, desenvolvimento econômico e indicadores sociais.

O Sistema Integrado Metropolitano (SIM) de abastecimento da RMSP operado pela Sabesp, que é responsável por atender 30 municípios. Os outros municípios da RMSP e núcleos de alguns desses 30 municípios são abastecidos por sistemas isolados, sendo a maioria operada pela própria Sabesp (SABESP, 2014).

A Bacia do Alto Tietê, com área de drenagem de $5.888 \mathrm{~km}^{2}$, abriga quase toda a população da RMSP. Os mananciais responsáveis pelo abastecimento de água na Bacia do Alto Tietê e que compõem o SIM, são (SABESP, 2014): Cantareira, Alto Tietê, Rio Claro, Rio Grande, Guarapiranga, Alto Cotia; Baixo Cotia, Ribeirão da Estiva e Capivari.

O sistema, denominado Capivari foi implementado em 2013. Este sistema trata na ETA Embu-Guaçu, parte da vazão que seria afluente ao Sistema Guarapiranga com a finalidade de atender a demanda que era prejudicada pela baixa pressão. A ETA Embu-Guaçu é responsável pelo tratamento da água captada no Rio Embu-Guaçu e possui a capacidade nominal de $0,132 \mathrm{~m}^{3} / \mathrm{s}$ de vazão com a finalidade de beneficiar 120 mil habitantes. A obra foi inaugurada em 24 de março de 2013. O sistema Capivari possui relevância no atendimento a região, porém não está contido nos principais documentos de descrição do SIM.

A Tabela 1 apresenta a disponibilidade hídrica e a capacidade nominal de produção de cada um dos componentes do SIM (SECRETARIA DE SANEAMENTO E RECURSOS HÍDRICOS, 2015). 
Tabela 1 - Capacidade de Produção do Sistema Existente.

Sistema Produtor

Cantareira

Guarapiranga

Alto Tietê

Rio Grande

Rio Claro

Alto Cotia

Baixo Cotia

Ribeirão da Estiva

Total

Fonte: Secretaria de Saneamento e Recursos Hídricos, 2015.

A Figura 10 contém a proporção entre a capacidade de produção de cada sistema com relação à produção total da RMSP em 2015.

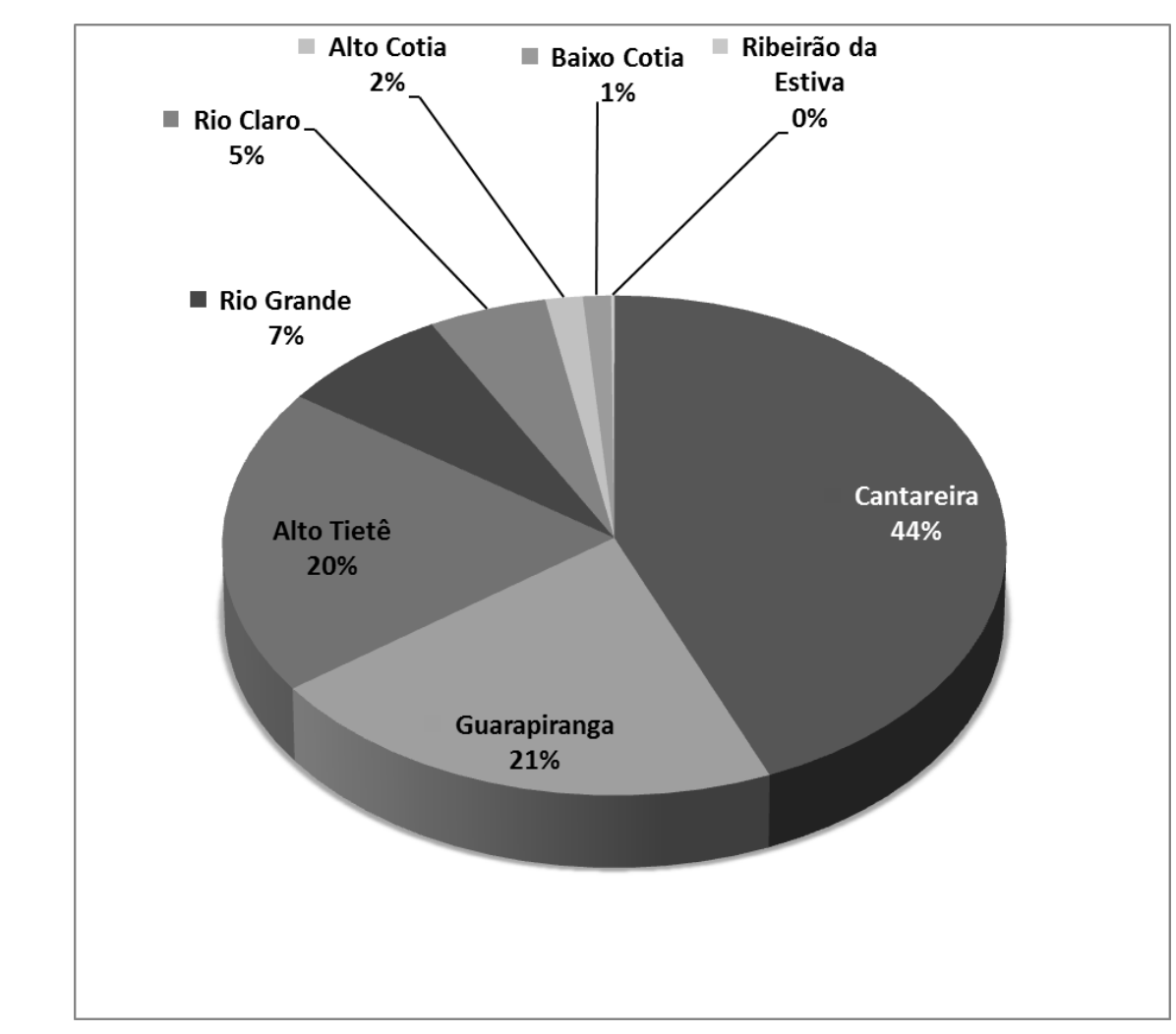

Figura 10 - Porcentagem da capacidade nominal referente a cada sistema. (Fonte: Secretaria

de Saneamento e Recursos Hídricos, 2015)

33,0

16,0

15,0

5,5

3,8

1,2

0,9

0,1

$\mathbf{7 3 , 5}$ com relaçà à produça total da RMSP em 2015. 
O SIM é constituído por (SABESP, 2014):

$\checkmark 9$ estações de tratamento de água (ETAs): Guaraú, ABV, Taiaçupeba, Rio Grande, Casa Grande, Alto Cotia, Baixo Cotia, Ribeirão Estiva e Embu Guaçu;

$\checkmark 1.200 \mathrm{~km}$ de adutoras;

$\checkmark 135$ reservatórios;

$\checkmark 60$ estações elevatórias de água;

$\checkmark 25.000 \mathrm{~km}$ de redes de distribuição.

Os sistemas produtores são interligados por meio de adutoras, o que permite uma gestão integrada do sistema.

A área de abrangência de cada sistema produtor está limitada fundamentalmente pelas características topográficas da RMSP (SABESP, 2014). As áreas geográficas de abrangência são divididas em setores de abastecimento. A RMSP é composta por 171 setores de abastecimento e vários setores podem ter a sua fonte de adução realizada por mais de um sistema produtor.

A Figura 11 contém a localização dos sistemas produtores existentes com suas respectivas áreas de abrangência na Bacia do Alto Tietê.

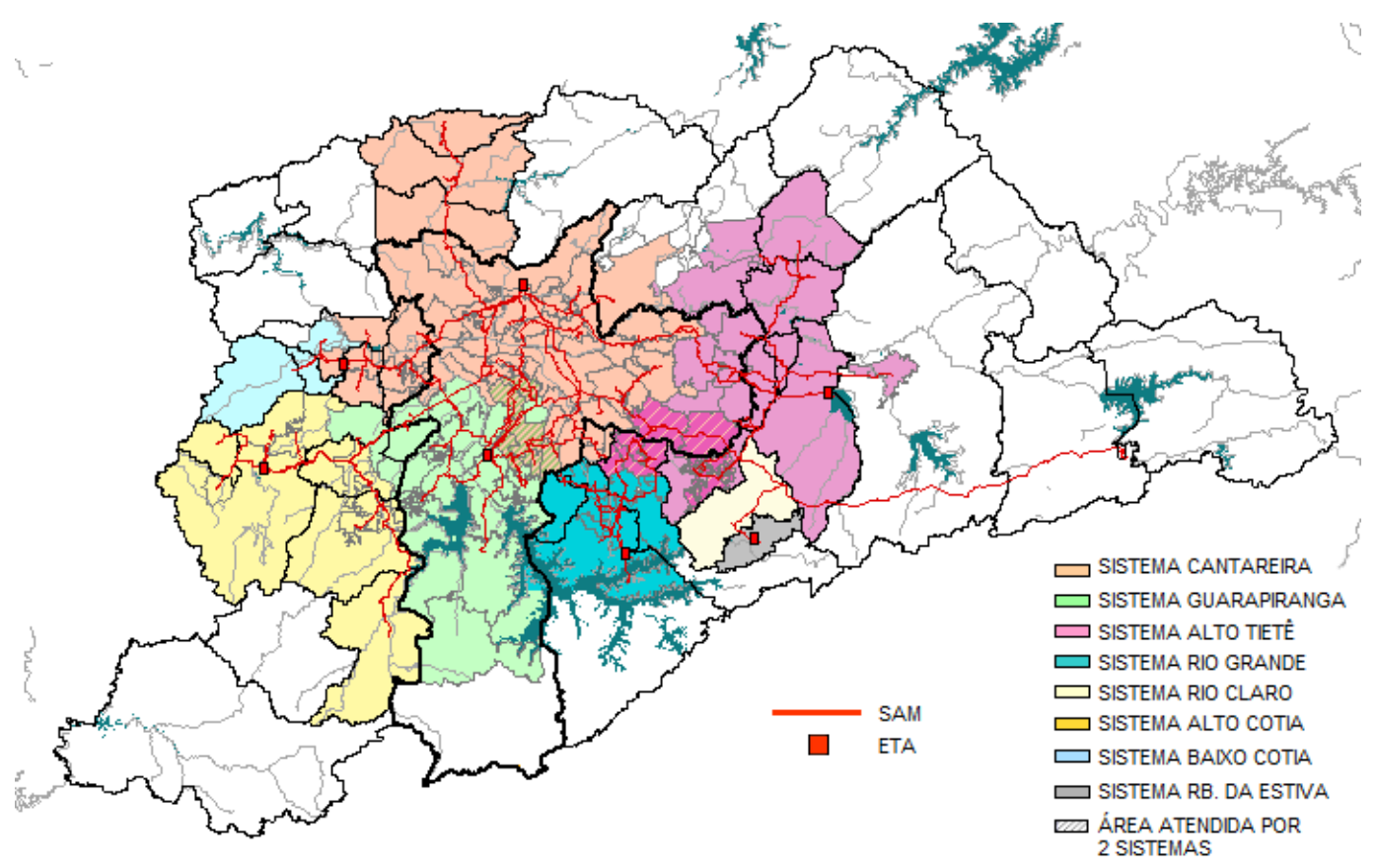

Figura 11 - Localização dos Sistemas de Abastecimento da RMSP e suas respectivas áreas de abrangência. (Fonte: SABESP) 
Os principais mananciais atrelados a cada um dos sistemas produtores e as sedes urbanas atendidas estão contidos na Tabela 2.

Tabela 2 - Sistemas de abastecimento, principais mananciais e sedes urbanas atendidas.

\begin{tabular}{|c|c|c|}
\hline Sistema & Principais Mananciais & Sedes Urbanas Atendidas \\
\hline Cantareira & $\begin{array}{l}\text { Represas Jaguari, Jacareí, } \\
\text { Atibainha, Cachoeira e Paiva Castro }\end{array}$ & $\begin{array}{l}\text { Barueri; Caieiras; Cajamar; Carapicuiba; } \\
\text { Fracisco Morato; Franco da Rocha; } \\
\text { Guarulhos; Osasco; São Caetano do Sul; } \\
\text { São Paulo. }\end{array}$ \\
\hline Guarapiranga & $\begin{array}{l}\text { Represas Guarapiranga e Billings } \\
\text { (Taquacetuba) e Rio Capivari }\end{array}$ & $\begin{array}{l}\text { Cotia; Embu; Itapecerica da Serra; São } \\
\text { Paulo; Taboão da Serra. }\end{array}$ \\
\hline Alto Tietê & $\begin{array}{l}\text { Represas Paraitinga, Ponte Nova, } \\
\text { Jundiaí, Biritiba-Mirim e Taiaçupeba }\end{array}$ & $\begin{array}{l}\text { Arujá; Ferraz de Vasconcelos; } \\
\text { Itaquaquecetuba; Guarulhos; Mauá; Mogi } \\
\text { das Cruzes; Poá; Suzano; São Paulo. }\end{array}$ \\
\hline Rio Claro & $\begin{array}{l}\text { Rio Claro - Represa Ribeirão do } \\
\text { Campo }\end{array}$ & $\begin{array}{l}\text { Mauá; Ribeirão Pires; Santo André; São } \\
\text { Paulo }\end{array}$ \\
\hline Rio Grande & $\begin{array}{l}\text { Represa Billings - Braço do Rio } \\
\text { Grande }\end{array}$ & $\begin{array}{l}\text { Diadema; Santo André; São Bernardo do } \\
\text { Campo }\end{array}$ \\
\hline Alto Cotia & $\begin{array}{l}\text { Represas Pedro Beicht e Cachoeira } \\
\text { da Graça }\end{array}$ & $\begin{array}{l}\text { Cotia; Embu; Embu-Guaçu; Itapecerica da } \\
\text { Serra; Vargem Grande Paulista. }\end{array}$ \\
\hline Baixo Cotia & Rio Cotia - Isolinas & Barueri; Itapevi; Jandira. \\
\hline Ribeirão da Estiva & Ribeirão da Estiva & Rio Grande da Serra \\
\hline Sistemas Isolados & Mananciais Superficiais / Mistos & $\begin{array}{l}\text { Biritiba-Mirim; Juquitiba; Mairiporã; } \\
\text { Pirapora do Bom Jesus; Salesópolis; } \\
\text { Santana de Parnaíba; São Lourenço da } \\
\text { Serra }\end{array}$ \\
\hline
\end{tabular}

Fonte: ANA, 2010.

\subsubsection{Sistema Cantareira}

O Sistema Cantareira é responsável por captar e desviar água dos cursos água da Bacia do Rio Piracicaba, pertencente às Bacias dos Rios PCJ, para o Rio Juqueri, na Bacia do Alto Tietê, de onde, no Reservatório de Paiva Castro, as águas são bombeadas para o Reservatório de Águas Claras, tendo como finalidade o abastecimento da RMSP. Essa transposição é formalizada a partir da outorga renovada de direito de uso da água (ANA, DAEE, 2013).

Este sistema é composto pelos reservatórios Jaguari-Jacareí, Cachoeira e Atibainha, (denominado sistema equivalente) localizados nos afluentes do Rio Piracicaba e os reservatórios de Paiva Castro e Águas Claras, localizado na Bacia do Alto Tietê.

A Figura 12 apresenta de forma esquemática o funcionamento do Sistema Cantareira e o posicionamento dos reservatórios. 


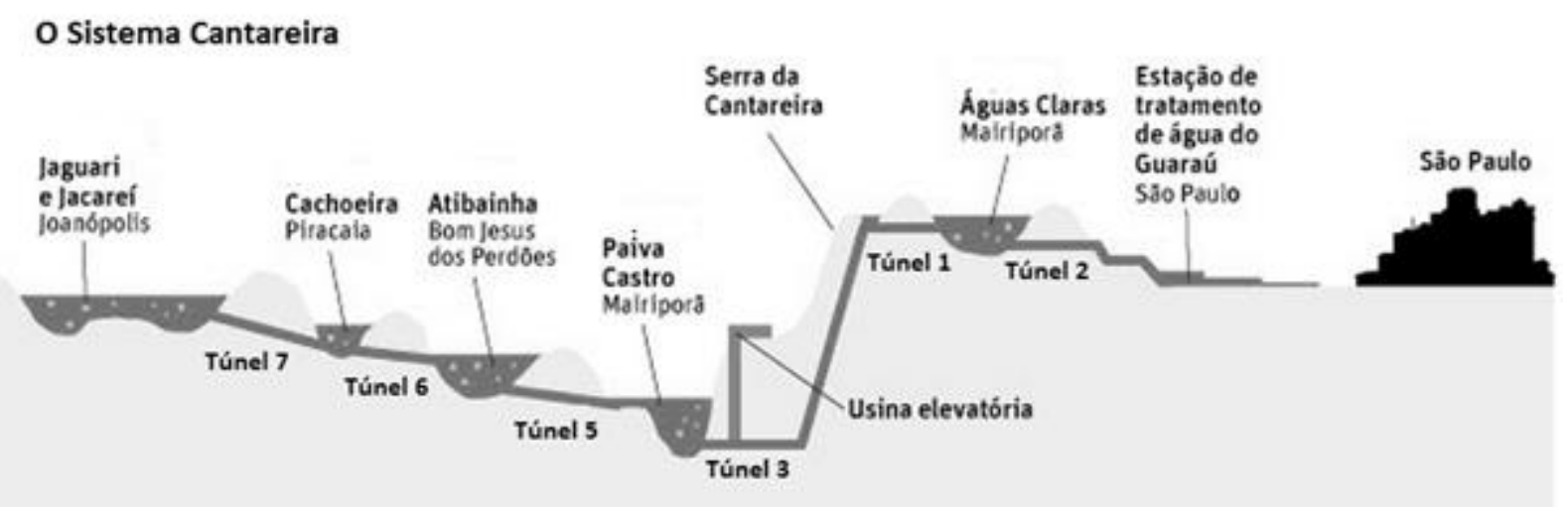

Figura 12 - Desenho esquemático do Sistema Cantareira. (Fonte: SABESP)

A área total das bacias que servem como manancial do Sistema Cantareira é de aproximadamente 227.950 ha. e abrange 12 municípios em Minas Gerais (Camanducaia, Extrema, Itapeva e Sapucaí Mirim) e São Paulo (Bragança Paulista, Caieiras, Franco da Rocha, Joanópolis, Nazaré Paulista, Mairiporã, Piracaia e Vargem).

O sistema equivalente possui uma capacidade total de armazenamento de $1.487,24 \mathrm{hm}^{3}$, dos quais $980,74 \mathrm{hm}^{3}$ estão na faixa normal de operação por gravidade (ANA, DAEE; 2013) e é responsável pelo fornecimento de água para cerca de 9 milhões de habitantes na RMSP (GTAG - CANTAREIRA, 2014b).

Os reservatórios Jaguari e Jacareí funcionam como um único conjunto devido à interligação propiciada por um canal aberto de $700 \mathrm{~m}$ de comprimento. Os reservatórios Jaguari-Jacareí e Cachoeira são conectados pelo túnel 7. O túnel 6 conecta os reservatórios de Cachoeira e Atibainha e o túnel 5 liga Atibainha ao Rio Juqueri-Mirim (Paiva-Castro). (ANA, DAEE; 2013).

As informações técnicas relevantes referentes ao Sistema Cantareira estão disponíveis na Tabela 3: 
Tabela 3 - Características do Sistema Cantareira.

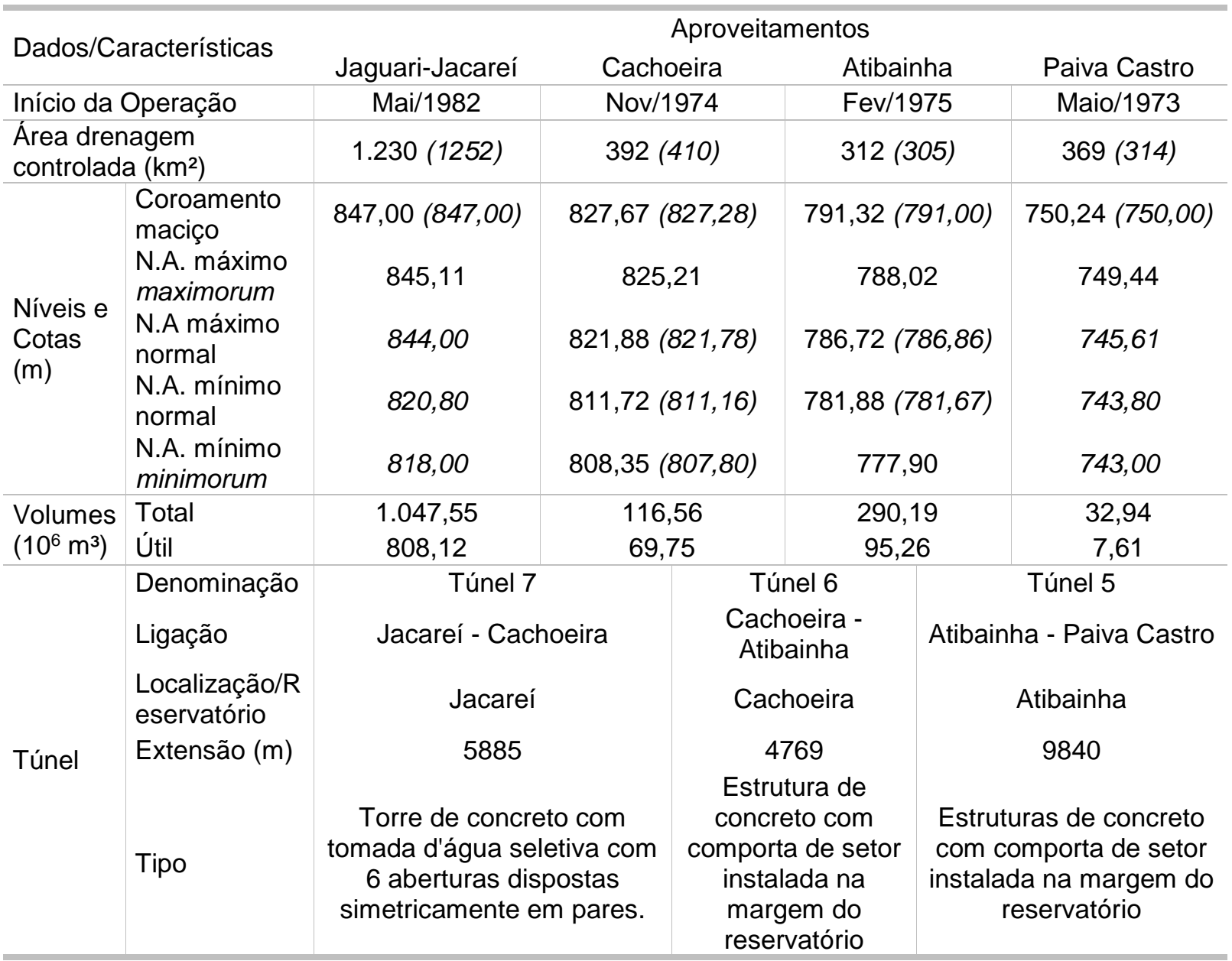

Em fonte normal: Dados dos relatórios da Sabesp de outubro de 2009

Em Itálico: Dados anteriormente utilizados pela Sabesp, não revisados e, por isso, mantidos.

Em Itálico e entre parênteses: Dados anteriormente utilizados pela Sabesp, revisados e substituídos.

Volumes úteis dos reservatórios: Entre os N.A. mínimo normal e máximo normal.

Fonte: ANA, DAEE, 2013

O túnel 3 liga o Reservatório Paiva Castro à Estação Elevatória Santa Inês (localizada em Caieiras), que possui a capacidade de $33 \mathrm{~m} 3 / \mathrm{s}$ e opera com três bombas e uma reserva. Os túneis 1 e 4 conectam a Estação Elevatória Santa Inês ao reservatório Águas Claras (1.194 m). O túnel 2 conecta Águas Claras à ETA Guaraú. (4.878 m). A ETA Guaraú por sua vez, possui a capacidade de $33 \mathrm{~m} 3 / \mathrm{s}$ e é composta por camas de mistura rápida, câmaras de floculação e decantadores. (ANA, DAEE, 2013)

O direito de uso de recursos hídricos é realizado por meio de uma outorga, tendo em vista a necessidade de gerenciamento frente ao interesse comum com as Bacias dos Rios Piracicaba, Capivari e Jundiaí, representadas pelo Comitê PCJ. Em 05 de agosto de 1974 a portaria do MME $n^{\circ} 750$ autorizou a Sabesp derivar 33 m³ dos 
reservatórios do Sistema Equivalente, com um prazo de 30 anos de vigência (DAEE, 2014b).

O pedido de renovação passou a ser de responsabilidade da ANA, que realizou interlocuções com o IGAM (Instituto Mineiro de Gestão as Águas) e o DAEE de São Paulo. A partir disso, foi emitida a nota técnica conjunta ANA/DAEE com subsídios para a análise do pedido de outorga do Sistema Cantareira e propôs condições de operações dos reservatórios mediante a realização de estudos hidrológicos e operacionais. (ANA, DAEE, 2013).

Com a Resolução № 429 (4 de agosto de 2004) a ANA definiu critérios e procedimentos técnicos de análise de pedidos de outorga e delegou competência para a emissão de outorgas de direito de recursos hídricos da União, para os estados de São Paulo e Minas Gerais. Desta forma, a renovação da outorga passou a ser competência do DAEE (ANA, DAEE, 2013).

A renovação da outorga (DAEE, 2004) de direito de uso do Sistema Cantareira para a Sabesp foi renovado em 06 de agosto de 2004, com o prazo de 10 anos. Após a emissão da Portaria DAEE no 1213/2004 os valores revertidos para a RMSP foram estipulados em ordem de prioridade, sendo a prioridade mínima da vazão de $24,80 \mathrm{~m}^{3} / \mathrm{s}$ e de prioridade secundária de $6,20 \mathrm{~m}^{3} / \mathrm{s}$ (total de $31 \mathrm{~m}^{3} / \mathrm{s}$ ). Para as Bacias dos Rios PCJ a vazão estipulada de total de descarregamento foi de $5 \mathrm{~m}^{3} / \mathrm{s}$, sendo $3 \mathrm{~m}^{3} / \mathrm{s}$ a vazão prioritária e $2 \mathrm{~m}^{3} / \mathrm{s}$ a secundária (GTAG - CANTAREIRA, 2014d).

A vazão de prioridade primária é aquela liberada constantemente, independentemente do nível dos reservatórios e do regime pluviométrico do momento. Já a vazão de prioridade secundária pode ser definida como complementar à vazão primária, garantindo o atendimento em situações nas quais o reservatório permite essa margem na operação.

Diante da situação de escassez hídrica, conforme apresentado no item 5.3, na sequência, ficou prorrogado até 31 de outubro de 2015 (DAEE, 2014b) o prazo de vigência da Portaria DAEE 1213/04 a qual em agosto de 2004, renovou pelo prazo de 10 anos, a outorga de direto de uso do Sistema Cantareira para a Sabesp.

Em reunião no dia 29 de outubro de 2015 entre as partes interessadas na renovação da outorga do Sistema Cantareira, convocada pela ANA (ANA, 2015), ficou acertado que a proposta de nova outorga será concluída até maio de 2017. 


\subsubsection{Sistema Produtor Alto Tietê}

O Sistema Produtor Alto Tietê (SPAT) é o conjunto de cinco reservatórios localizados entre Suzano e Salesópolis concebidos com a finalidade de atender a aproveitamento múltiplo da qual se destaca uma participação expressiva na produção de água potável para o abastecimento público $\left(15 \mathrm{~m}^{3} / \mathrm{s}\right)$ e o controle de enchentes e a regularização das vazões mínimas para o curso do Rio Tietê na região da cabeceira. Foi proposto nos estudos no Plano HIBRACE e foi prevista a construção de sete represas: Taiaçupeba, Jundiaí, Ponte Nova, Biritiba, Paraitinga, Itapanhaú e Itatinga, estas duas últimas situadas na serra do mar (vertente marítima).

Atualmente encontram-se implantadas e em operação (DAEE, 2012):

$\checkmark$ Ponte Nova (1972) em Salesópolis;

$\checkmark$ Jundiaí (1989) em Mogi das Cruzes;

$\checkmark$ Taiaçupeba (1979) situada na divisa dos municípios de Mogi das Cruzes e Suzano;

$\checkmark$ Biritiba (05/2005) situada no município de Biritiba-Mirim;

$\checkmark$ Paraitinga (01/2005) situada no município de Salesópolis.

De forma ilustrativa é possível visualizar o posicionamento dos cinco reservatórios em relação ao Rio Tietê, conforme apresentado na Figura 13.

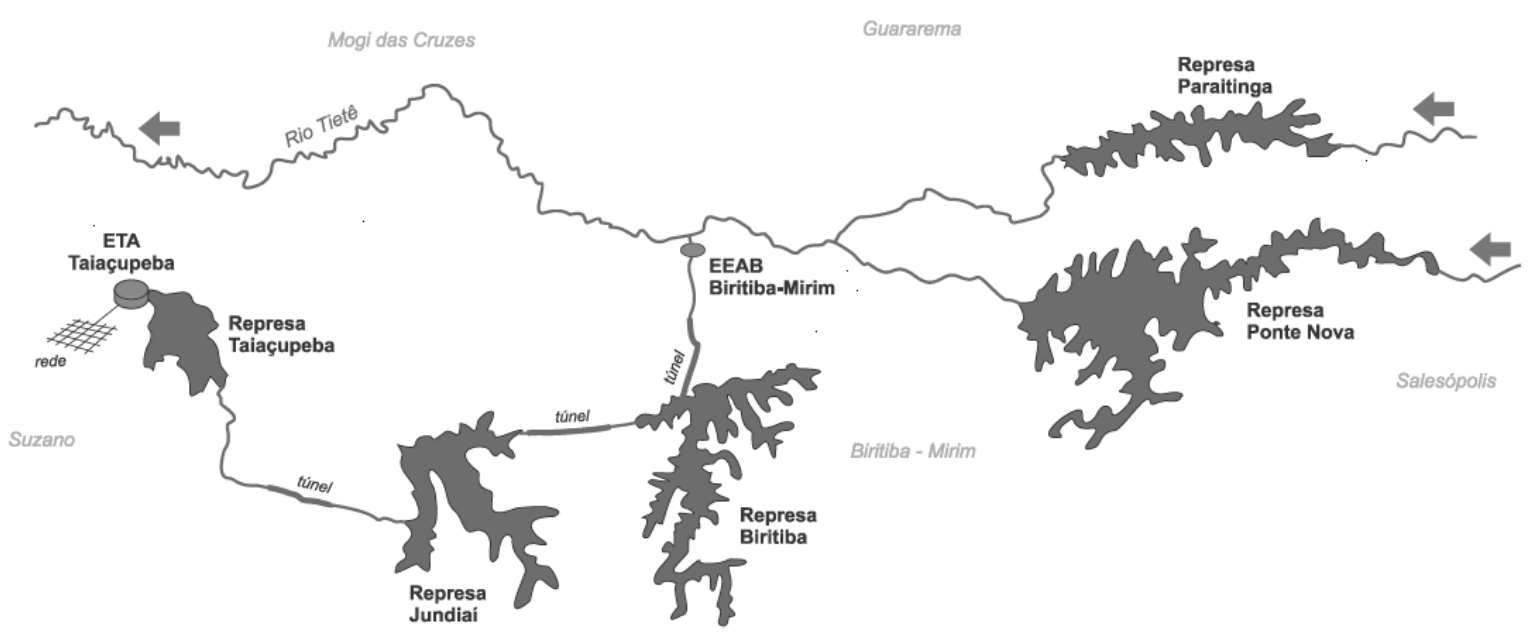

Figura 13-Sistema Alto Tietê. 
A regra operacional do SPAT, apresentada em Nota Técnica (DAEE, 2012), foi elaborada em parceria entre a Sabesp e o DAEE e tem como premissas os seguintes itens:

$\checkmark$ Garantir a vazão de $15 \mathrm{~m}^{3} / \mathrm{s}$, destinadas a abastecimento público de água potável realizado na operação da Sabesp;

$\checkmark$ Garantir a perenização dos rios imeditamente a jusante das barragens, Rio Paraitinga, Rio Tietê, Rio Biritiba-Mirim, Rio Jundiaí e Taiaçupeba, com descargas mínimas definidas como, mantendo-se um residual mínimo à jusante igual ou maior que o valor do $Q_{7,10}$;

$\checkmark$ Atendimento aos demais usuários atendendo o determinado em outorga pelo órgão regulador, e orientação da Secretaria do Meio Ambiente.

O perfil unifilar (Figura 14) do SPAT representa de forma esquemática como é realizada a transferência nos reservatórios da água levada até a ETA Taiaçupeba:

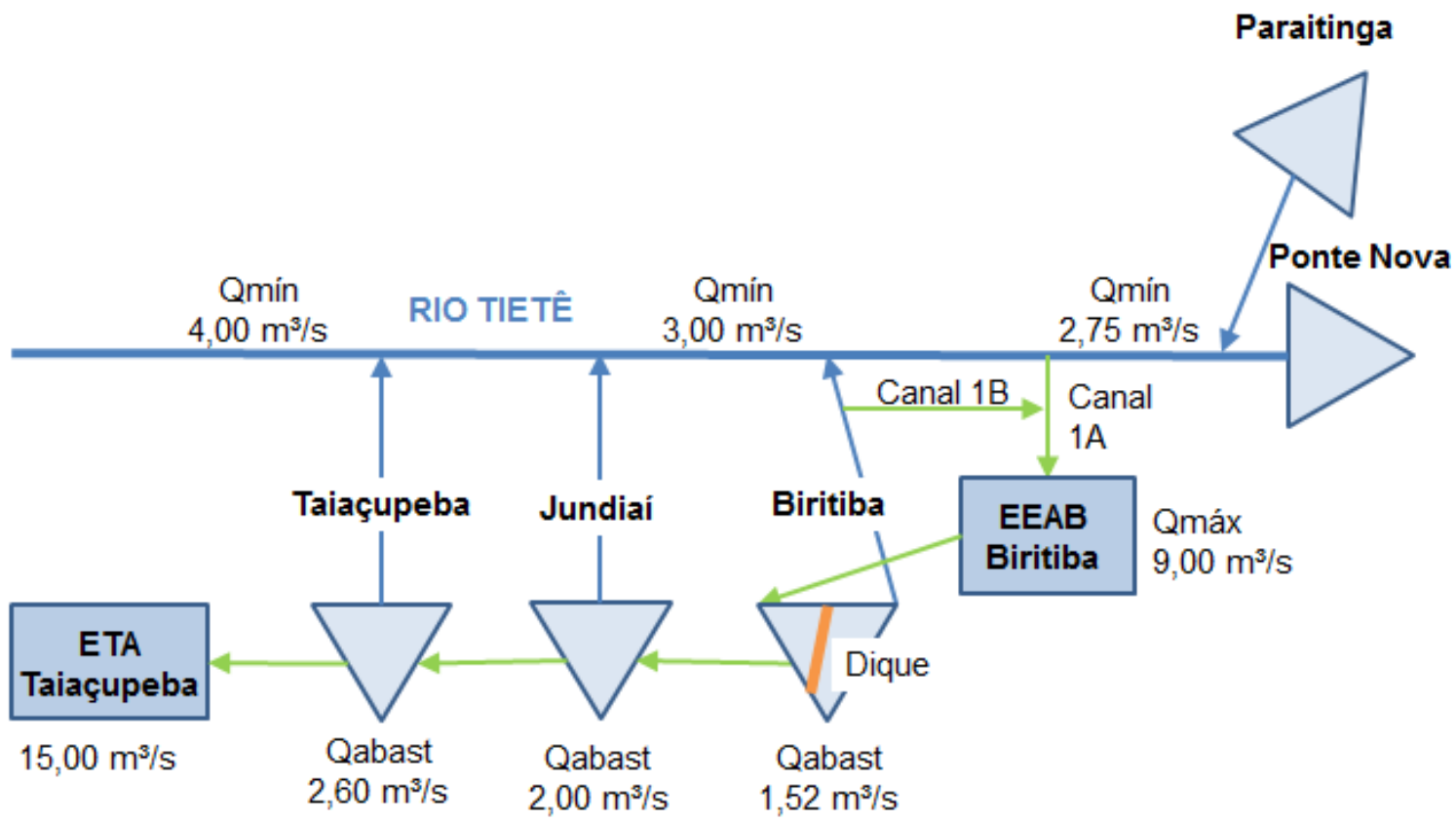

Figura 14 - Sistema Alto Tietê - Perfil unifilar. (Fonte: Adaptado de DAEE, 2012)

A partir do dia 14 de dezembro de 2014 o volume adicional de $39,4 \mathrm{hm}^{3}$ passou a ser considerado no Sistema Alto Tietê, especificamente no reservatório de Ponte Nova. A capacidade de armazenamento aumentou 7,5\%, dessa forma, para 10,7\%. A 
captação de tal volume adicional foi autorizada pelo DAEE e não necessita de bombeamento no reservatório de Ponte Nova (RESK, 2014).

\subsection{Características das Bacias dos Rios Piracicaba, Capivari e Jundiaí}

As Bacias dos Rios Piracicaba, Capivari e Jundiaí são denominadas como PCJ. Concentram hoje sessenta e cinco (65) municípios no Estado de São Paulo e cinco (5) cidades no Estado de Minas Gerais e cerca de 5,5 milhões de habitantes (SAMPAIO, 2014).

Contém a cidade de Campinas, com um parque industrial em constante desenvolvimento, além de atividades relacionadas à agroindústria, com impactos significativos na qualidade da água das bacias, devido ao lançamento de efluentes. $O$ atendimento das demandas de águas das Bacias PCJ está concentrado a jusante do Sistema Cantareira.

A partir da implantação do Sistema Cantareira, houve uma requisição das Bacias dos Rios PCJ para a manutenção de uma vazão mínima a jusante das barragens do Sistema Cantareira, devido à baixa qualidade da água no período de estiagem, que influencia no preço do tratamento da água para o abastecimento público. (ANA/DAEE, 2004). A vazão de descarregamento estipulada foi de $5 \mathrm{~m}^{3} / \mathrm{s}$, sendo $3 \mathrm{~m}^{3} / \mathrm{s}$ a vazão prioritária e 2 m³/s a secundária, conforme a Portaria DAEE no 1213/2004.

Embora a reversão do Sistema Cantareira afete diretamente somente a Bacia do Rio Piracicaba, nota-se que as Bacias dos Rios Piracicaba, Capivari e Jundiaí sofrem os efeitos de tal retirada.

A qualidade da água é afetada pela falta de tratamento de esgotos nos municípios da Região e a regularização pretendida estava associada na concepção do Sistema Cantareira à construção de várias barragens nos Rios Camanducaia e Jaguari, que até hoje não foram implantadas.

A Figura 15 apresenta a localização do Sistema Cantareira em relação às Bacias dos Rios PCJ, nos afluentes do Rio Piracicaba, na cabeceira da bacia. 


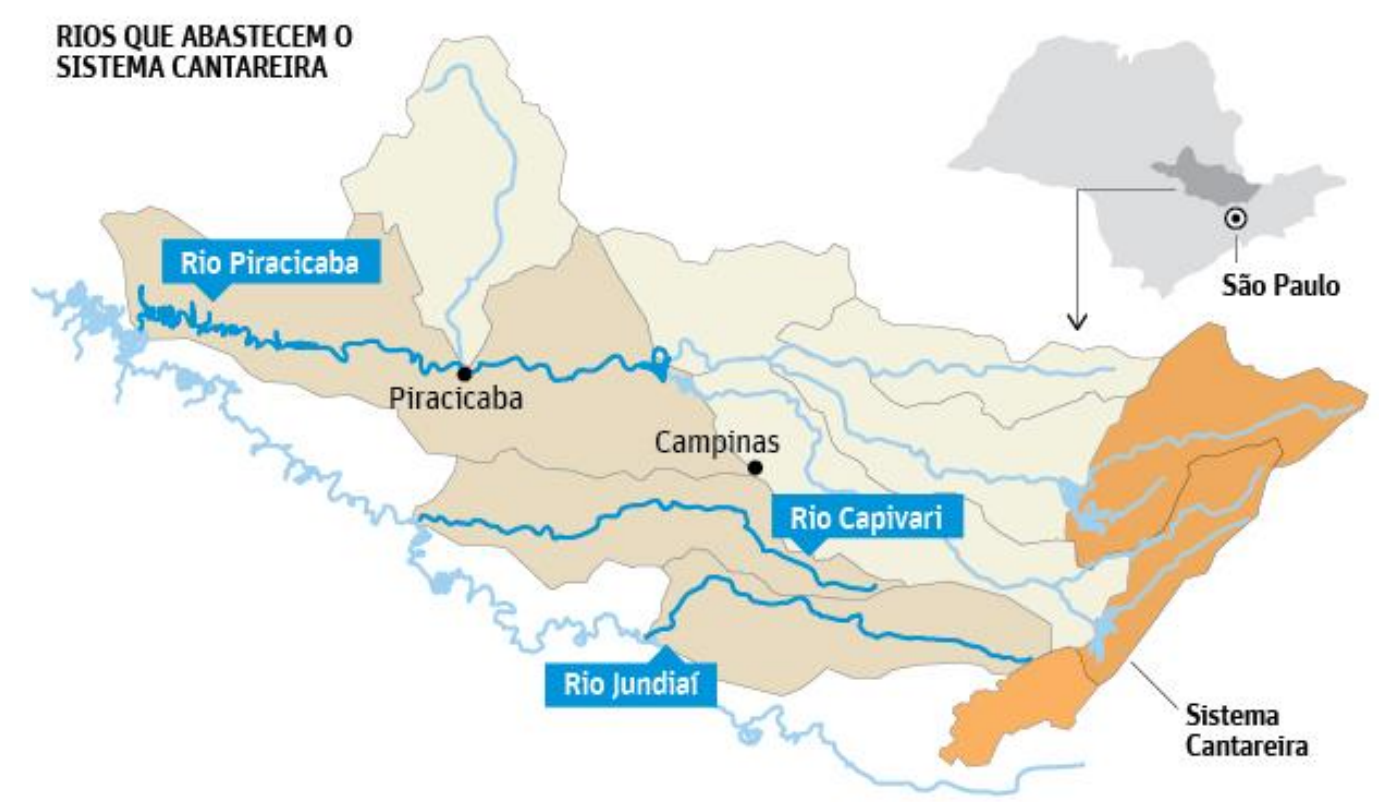

Figura 15 - Sistema Cantareira nos afluentes do Rio Piracicaba e Bacias dos Rios PCJ. (Fonte: RODRIGUES; BRENHA, 2014)

É importante salientar que há a necessidade de gerenciar as três bacias de forma integrada, dado que a captação e descarte não ocorrem necessariamente na mesma bacia. Por exemplo, a cidade de Campinas, que capta água para abastecimento na bacia do Rio Piracicaba e lança efluentes na Bacia do Rio Capivari. Jundiaí por sua vez, capta no Rio Atibaia, afluente do Piracicaba e lança esgotos no Rio Jundiaí.

\subsection{Crise no sistema de abastecimento da RMSP}

O acúmulo de águas para a região de São Paulo é realizado principalmente nos meses chuvosos, de outubro a março, visando garantir o abastecimento nos períodos de estiagem. Entre outubro de 2013 até janeiro de 2015, porém, foram observadas vazões afluentes excepcionalmente baixas. Segundo a Sabesp, trata-se da pior seca, desde que se tem registro, ou seja, dos últimos 84 anos; o que desencadeou uma crise de abastecimento na Região Metropolitana de São Paulo.

$\mathrm{Na}$ Figura 16 podem-se analisar as vazões médias mensais afluentes ao sistema equivalente de referência, de 1930 a 2013 e as vazões médias observadas durante os anos de 2013 a 2015. 


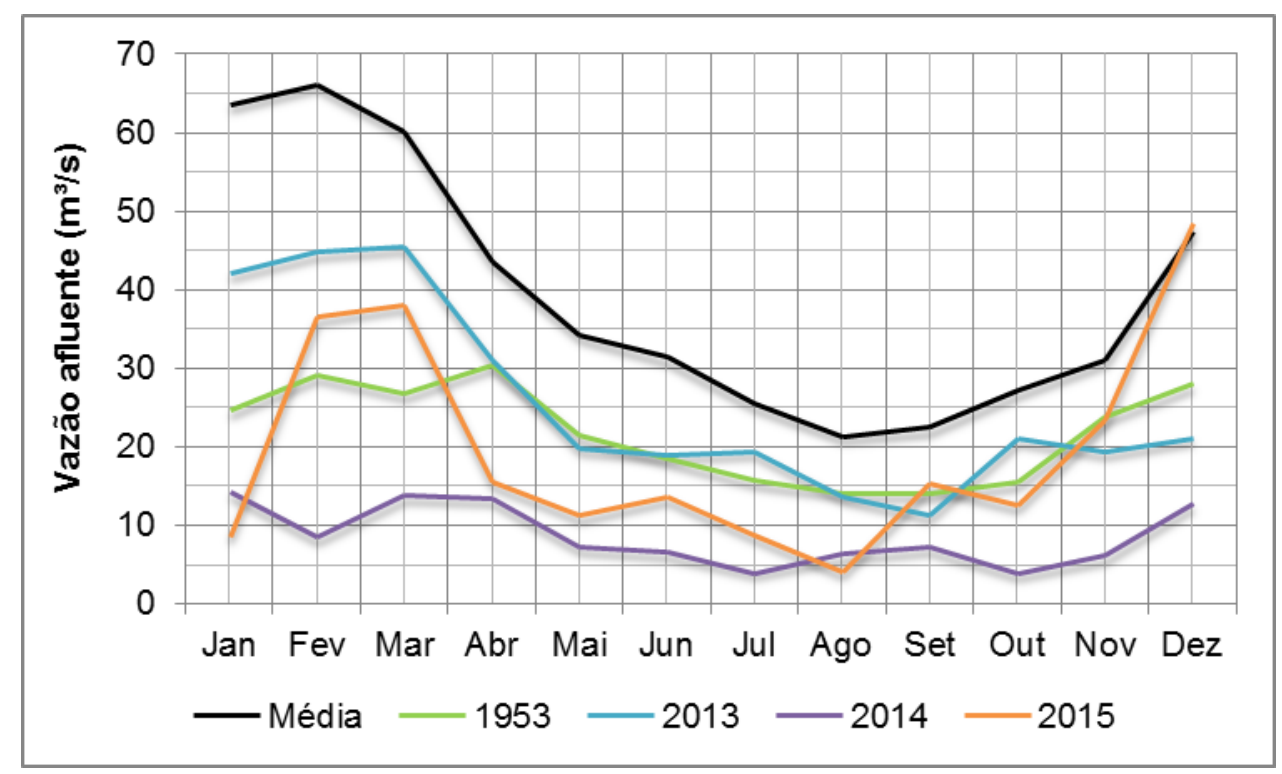

Figura 16 - Vazões médias mensais afluentes ao Sistema Equivalente. Valores médios mensais de referência dos anos de 1930 a 2013, e dos anos de 2013, 2014 e 1953. (Fonte: ANA, 2015)

Nota-se que as vazões afluentes ao sistema equivalente não são suficientes para manter os níveis nos reservatórios, dadas as demandas para a RMSP, e as Bacias dos Rios PCJ. O pior cenário de afluências observado até então, foi do ano de 1953 e as vazões afluentes observadas no ano de 2014 foram consideravelmente mais baixas.

De acordo com o CEMADEN (SABESP, 2015a), ocorreu a formação de zona de alta pressão atmosférica a 6.000 metros de altitude, que bloqueou a chegada das frentes da Amazônia, da Zona de Convergência do Atlântico Sul e das frentes frias do Polo Sul, alterando a dinâmica da região Sudeste do Brasil, caracterizada pela ausência das chuvas de primavera e verão de 2013/2014. Neste período do ano hidrológico (outubro/13 a fevereiro/14) ocorreram $444 \mathrm{~mm}$ de chuvas na região do Cantareira, frente à média de 995 mm (-55\%).

Em decorrência dessa escassez, uma série de iniciativas de curto, médio e longo prazo foram tomadas com a finalidade de se garantir o abastecimento durante a crise atual e nos próximos anos, ao considerar a incerteza hidrológica e a possibilidade de não haver a recuperação dos níveis dos sistemas de reservatórios. As medidas realizadas durante a crise e os acontecimentos relevantes estão apresentados no item 5.4 . 


\subsection{Medidas e acontecimentos relevantes}

Frente ao cenário hidrológico de escassez, as instituições do governo do Estado de São Paulo e a Sabesp tomaram providências com a finalidade de se atender a demanda consuntiva. As principais medidas adotadas a curto e médio prazo estão apresentadas nos itens a seguir.

As medidas adotadas em curto prazo consideradas foram: transferência de água tratada de outros sistemas produtores (item 5.4.1); gestão de consumo a partir de tarifas (item 5.4.2); redução de perdas e redução da pressão na rede (item 5.4.3); operação do sistema Cantareira incluindo a utilização de reservas técnicas e atuação de órgãos reguladores na operação (item 5.4.4) e obras para aumento da transferência entre sistemas (item 5.4.5).

Além da crise atual do sistema devido às baixas afluências hidrológicas, é importante ressaltar que a Região Metropolitana está inserida em um contexto geográfico de escassez hídrica. Dessa forma, soluções em médio e longo prazo possuem extrema importância, visto que existe uma necessidade de expansão do sistema produtor de adução para acompanhar as projeções de crescimento demográfico da região.

As obras consideradas de médio prazo são: Sistema Produtor São Lourenço (item 5.4.6); transferência de água do Jaguari (Paraíba do Sul) para o Sistema Cantareira (item 5.4.7); estações de reuso potável indireto (ETE Barueri / ETA Baixo Cotia e Guarapiranga) e o reforço para o Rio Grande (transferência do Rio Pequeno para o Rio Grande).

A intervenção de bombeamento de $4 \mathrm{~m}^{3} / \mathrm{s}$ do Rio Pequeno para o Rio Grande é composta de uma estrutura de captação localizada no braço do Rio Pequeno formada por três flutuantes e a estação elevatória com desnível de 10 metros irá bombear a água para o braço do Rio Grande.

Com relação ao reuso, a legislação brasileira não faz referência a nenhuma regulamentação específica para a água de reuso, portanto a qualidade buscada pelo sistema de tratamento causa o encarecimento do sistema. O tratamento será baseado em membranas permeáveis e a osmose reversa, ou por foto-oxidação, processo baseado em bombas de alta pressão. (FERRAZ, ITALIANI, 2014) 


\subsubsection{Transferência de água tratada de outros sistemas produtores}

Com a finalidade de se atender a demanda da população atendida pelo Sistema Cantareira, houve a intensificação da integração e transferência de água entre os sistemas produtores a partir de obras que permitem as inversões de fluxos.

Dentre as obras emergenciais executadas em 2014, destacam-se (SABESP, 2015a):

$\checkmark$ Ampliação da Estação de Tratamento de Água (ETA) Rodolfo José da Costa e Silva: aumento da capacidade de tratamento em $2 \mathrm{~m} 3 / \mathrm{s}$ com a utilização de membranas de ultra filtração;

$\checkmark$ Ampliação da Estação de Tratamento de Água (ETA) Rio Grande: ampliação de capacidade de tratamento em $0,5 \mathrm{~m}^{3} / \mathrm{s}$, implantação de sistema de membranas de ultra filtração;

$\checkmark$ Implantação da adutora Bela Vista/Conceição, em Osasco, 1.300 metros extensão e diâmetro de 700 mm;

$\checkmark$ Intervenções elétricas no Booster Ermelino Matarazzo, do Sistema Alto Tietê, possibilitando transferência de $300 \mathrm{l} / \mathrm{s}$ para o Sistema Cantareira;

$\checkmark$ Readequação hidráulica no Booster Cidade Líder, permitindo transferência de $0,5 \mathrm{~m}^{3} / \mathrm{s}$ para o Sistema Cantareira;

$\checkmark$ Adequações elétricas nas Estações Elevatórias da ETA Taiaçupeba, aumentando a capacidade de produção de 13 para $15 \mathrm{~m} 3 / \mathrm{s}$;

$\checkmark$ Adequação dos painéis elétricos da EEAB Biritiba, ampliando recalque do Rio Tietê em 2 m³/s para o dique da represa Biritiba-Mirim;

$\checkmark$ Adequação hidráulica na EEAT Vila Guarani, transferindo cerca de $0,2 \mathrm{~m}^{3} / \mathrm{s}$ para o Cantareira;

$\checkmark$ Intervenções na EEAT Theodoro Ramos e adequações operacionais na adutora V. Olímpia, para avanço do Sistema Guarapiranga em cerca de $0,5 \mathrm{~m}^{3} / \mathrm{s}$;

$\checkmark$ Operacionalização da Adutora Jabaquara-Sacomã, do Sistema Guarapiranga, ampliando transferência em cerca de $0,2 \mathrm{~m} / \mathrm{s}$;

$\checkmark$ Nova regra operacional na EEAT ABV/Jabaquara e no Booster Cadiriri, possibilitando transferência de cerca de $0,7 \mathrm{~m}^{3} / \mathrm{s}$ para o Sistema Cantareira; 
$\checkmark$ Alteração da regra operacional da EEAT França Pinto, possibilitando transferência de cerca de $0,25 \mathrm{~m}^{3} / \mathrm{s}$ para o Sistema Cantareira;

$\checkmark$ Instalação da Adutora Haras/Vila Vitória, do Sistema Rio Grande, permitindo a transferência de $0,5 \mathrm{~m} 3 / \mathrm{s}$ para o município de Santo André;

$\checkmark$ Conclusão das obras da Adutora Jardim das Nações/Parque Real em Diadema, permitindo a transferência do Sistema Rio Grande para Guarapiranga e Cantareira.

$\checkmark$ EEAB Guaratuba - adequações para aumento de vazão na ordem de 0,5 m³/s.

Na Figura 17 estão contidas figuras ilustrativas que mostram o avanço dos sistemas sobre a região atendida pelo Sistema Cantareira, em dezembro de 2014, setembro de 2014 e março de 2015. 


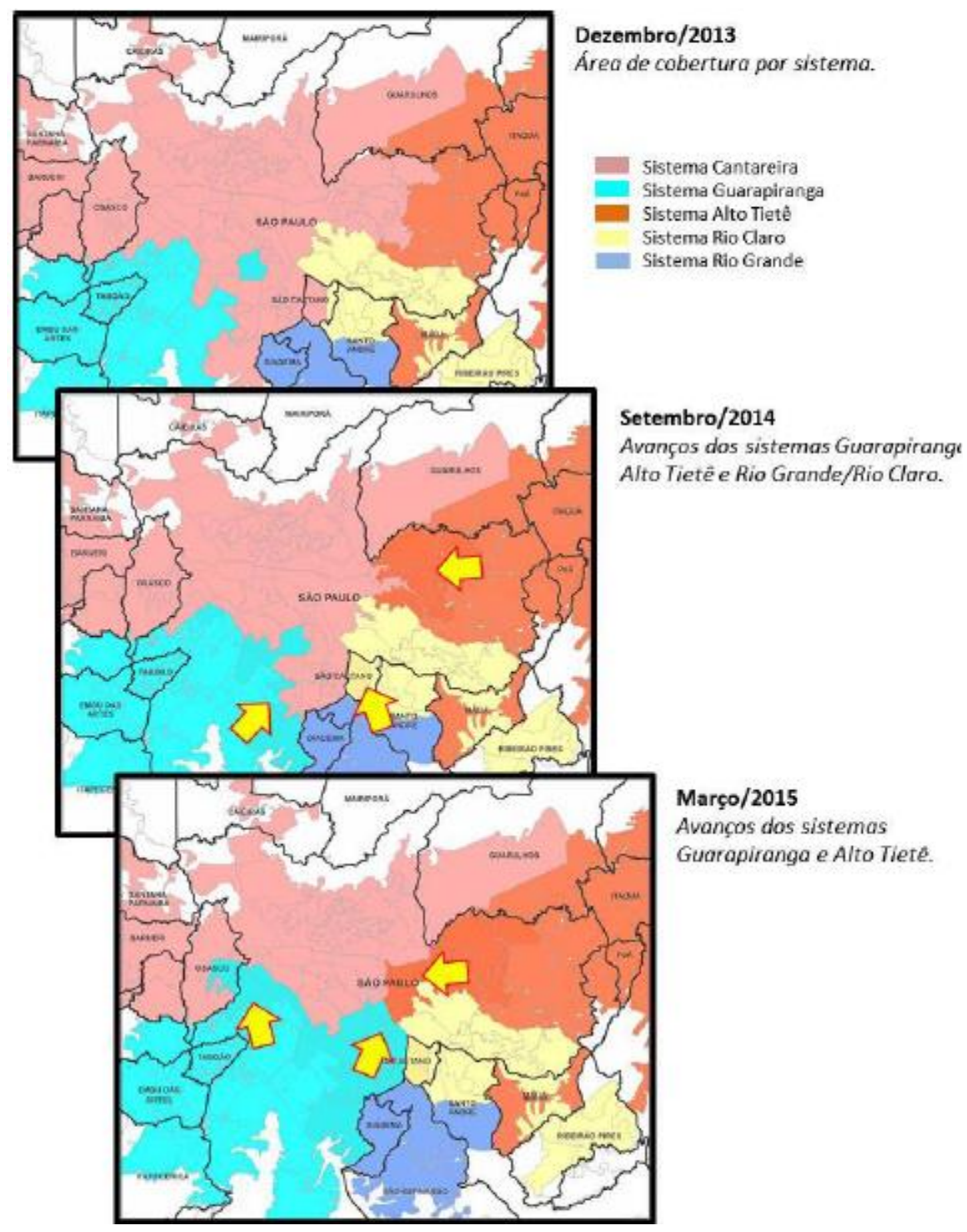

Figura 17- Evolução do avanço dos sistemas sobre a região atendida pelo Cantareira (Fonte: Sabep, 2015a).

\subsubsection{Gestão de consumo - tarifa}

O Programa de Incentivo à Redução de Consumo se iniciou em $1^{\circ}$ de fevereiro de 2014 com a finalidade de se incentivar a população a mudar os costumes. A implantação do programa foi aprovada pela Agência Reguladora de Saneamento e Energia do Estado de São Paulo (Arsesp) através da deliberação no 468/2014 (SABESP, 2015a). 
A Sabesp concedeu aos seus clientes um desconto de 30\% na conta de quem reduziu o consumo de água em ao menos 20\% (a partir de março de 2014), inicialmente restrito aos consumidores da região da Grande São Paulo atendida pelo Cantareira (LEITE, 2014C).

A partir de abril, o Programa de Incentivo à Redução do Consumo de Água foi ampliado para todas as cidades atendidas pela Sabesp na RMSP (LEITE, 2014a).

Foi considerada a hipótese de se cobrar a multa de 30\% aos clientes da Sabesp que aumentassem o consumo de água na Grande São Paulo em 20\% ou mais em relação à média de doze (12) meses (LEITE, 2014a).

A proposta feita pelo governador Geraldo Alckmin (22 de abril) recebeu o aval da Arsesp e da Procuradoria do Estado, porém entidades de defesa do consumidor, como o IDEC, OAB (Ordem dos Advogados do Brasil) e a Proteste, alegaram que tal cobrança é inconstitucional ao afirmar que a taxação utilizava como base jurídica um decreto federal segundo o qual tarifas de contingência deveriam incidir sobre quem ultrapassasse os limites de consumo definidos no racionamento. O governo, contudo, sempre negou que houvesse qualquer tipo de restrição de consumo (LEITE, CHAPOLA, 2014).

A partir de maio, o programa foi ampliado para os municípios operados pela Sabesp na Bacias dos Rios PCJ (SABESP, 2015a).

No dia 9 de julho, o governador Alckmin descartou sobretaxa de 30\% e afirmou que $91 \%$ da população aderiu ao uso racional da água (LEITE, CHAPOLA, 2014).

A partir de novembro de 2014 o bônus começou a valer em três faixas de desconto, de $10 \%$ a $15 \%$, com a redução de $10 \%$ a pagar; de $15 \%$ a $20 \%$, com desconto de $20 \%$; e com a economia de $20 \%$ a $30 \%$, o bônus é de $30 \%$ (RODRIGUES, 2014b).

A partir do dia 8 de janeiro foi regulamentada a multa para quem consumir agua acima da média. A Sabesp recebeu no dia 7 a autorização da Arsesp para cobrar sobretaxas de 40 a $100 \%$ de clientes que gastarem mais água neste ano do que antes da crise hídrica. Quem consumir até $20 \%$ mais água do que a média anterior à crise (fevereiro de 2013 e janeiro de 2014) será sobretaxado de 40\%. Quem aumentar o consumo além desse limite receberá uma tarifa adicional de 100\%. A proposta apresentada pela Sabesp à agência previa sobretaxas de 20 a 50\%, respectivamente, mas sobre o valor total da conta (CHAPOLA, LEITE, 2015). 
Em 13 de janeiro tal medida foi barrada pela juíza da $8^{\text {a }}$ Vara de Fazenda Pública a pedido da Proteste (Associação Brasileira de Defesa do Consumidor) com a alegação de que a sobretaxa deve ser precedida de uma declaração oficial de racionamento, como diz a Lei de Saneamento de 2007. Alckmin admitiu no dia 14 de janeiro que São Paulo enfrenta um racionamento de água há meses, o presidente TJ-SP derrubou a liminar. Os clientes começaram a receber a conta com a tarifa de contingência a partir do dia 9 de fevereiro de 2015.

Em março de 2015, a economia de água obtida foi de $6,2 \mathrm{~m}^{3} / \mathrm{s}$, sendo que $82 \%$ dos clientes da RMSP reduziram o consumo de água em relação à média estabelecida pelo programa. Na Figura 18 estão apresentadas as adesões mensais de março de 2014 a 2015 (SABESP, 2015a).

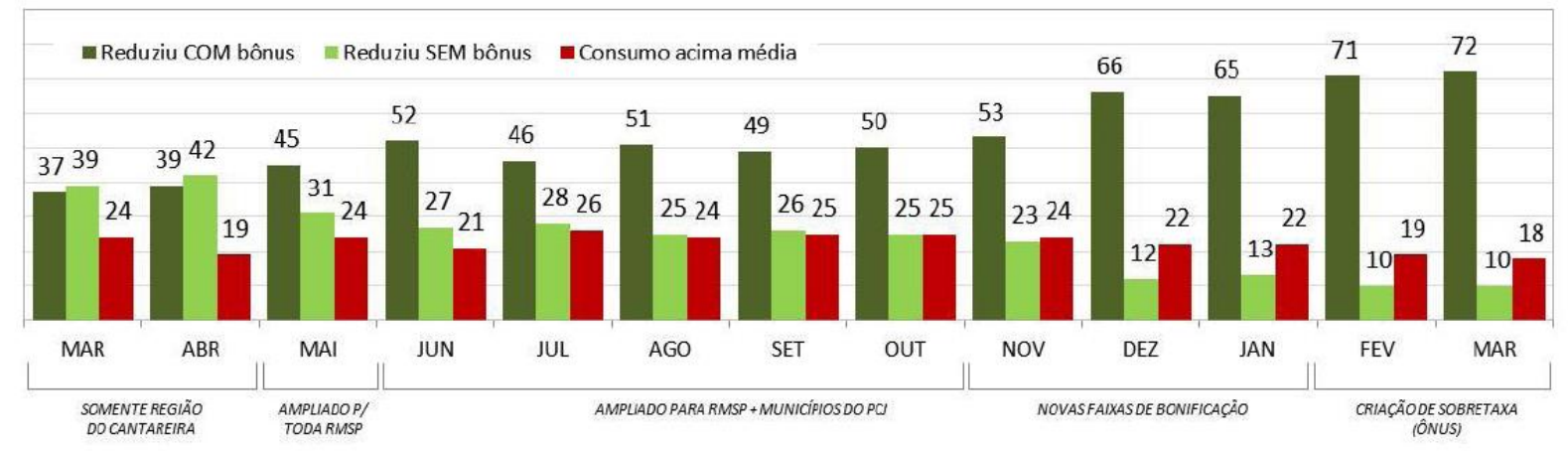

Figura 18 - Adesão ao programa de taxação. (Fonte: Sabesp, 2015a)

\subsubsection{Redução de perdas e redução da pressão}

O programa de combate às perdas realizado pela Sabesp possui um caráter permanente. $O$ índice de perdas relativo à micromedição na RMSP passou de 40,5\% em 2004 para 27,9\% em março de 2015 (SABESP, 2015a), conforme Figura 19. As principais medidas apresentadas pela Sabesp foram:

$\checkmark$ Instalação e otimização de Válvulas Redutoras de Pressão (VRPs);

$\checkmark$ Implantação e revisão de setorização e distritos de medições e controle;

$\checkmark$ Otimização de boosteres;

$\checkmark$ Pesquisa de vazamentos não visíveis por métodos acústicos;

$\checkmark$ Apontamento de vazamentos pelos TACE (Técnico de Atendimento ao Cliente Externo); 
$\checkmark$ Mutirão de caça-vazamentos;

$\checkmark$ Reabilitação e troca de redes de água;

$\checkmark$ Intensificação da troca de ramais de água;

$\checkmark$ Treinamento, qualificação e certificação de mão de obra;

$\checkmark$ Redução dos prazos de atendimento para conserto dos vazamentos.

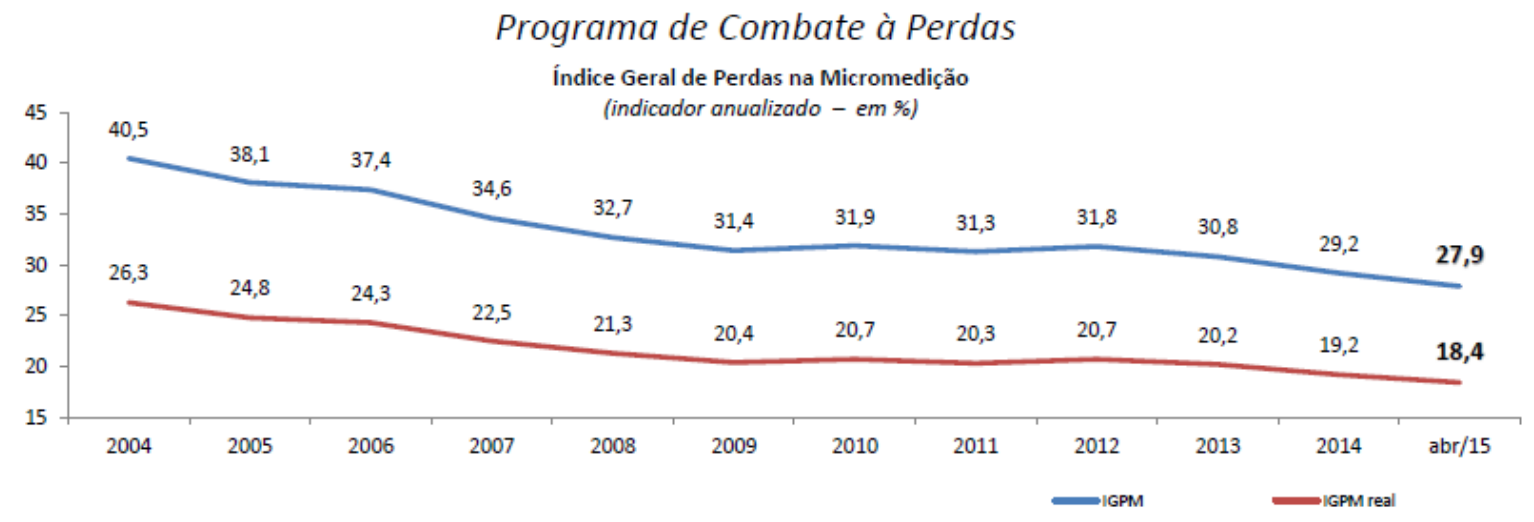

Figura 19 - Programa de Combate às Perdas - 2004 a 2015.

$\mathrm{Na}$ Tabela 4 estão apresentadas as ações de combates às perdas em 2014 e as suas devidas quantificações (SABESP, 2015b).

Tabela 4-Ações de combate às perdas de 2014.

\begin{tabular}{lcr}
\hline Ações de Combate às Perdas & Unidade & Total 2014 \\
\hline Substituições de ramais & unit & 168.535 \\
Reparo de ramais & unit & 73.390 \\
Reparo de rede & unit & 26.694 \\
Substituição de hidrômetros & unit & 296.769 \\
Pesquisa de vazamentos não visíveis & $\mathrm{km}$ & 15.490 \\
Substituição de redes & $\mathrm{km}$ & 62 \\
Instalação das válvulas redutoras de pressão (VRP) & unit & 140 \\
Serviços em cavalete & unit & 219.034 \\
Troca de cavalete & unit & 13.433 \\
\hline
\end{tabular}

Outra medida realizada pela Sabesp foi redução de pressão da água na rede de distribuição de modo a diminuir as perdas físicas, em horários pré-estabelecidos $\mathrm{Em}$ março de 2015 foram registrados 1500 válvulas redutoras de pressão, o que representa cerca de $46 \%$ da rede de distribuição. Nas demais áreas, não cobertas por essas válvulas, a manobra é realizada manualmente (SABESP, 2015). Até esta data as reduções de pressões representam a medida mais eficiente durante a crise hídrica 
sendo responsável apenas no Sistema Cantareira, de $7,3 \mathrm{~m}^{3} / \mathrm{s}$, equivalente a $41 \%$ de toda a economia obtida neste Sistema.

A partir de 2015 houve a intensificação do período de redução de pressão nas tubulações, juntamente com a distribuição de caixas d'água para imóveis com renda familiar de até três salários mínimos e moradores de região com alta vulnerabilidade relacionada à falta d'água.

Concomitantemente foi iniciada a entrega aos clientes da RMSP de kits economizadores para reduzir aproximadamente $20 \%$ da vazão de torneiras.

\subsubsection{Operação do Sistema Cantareira}

A operação do Sistema Cantareira tem sido feito de forma conjunta entre a Sabesp, e os órgãos reguladores DAEE e ANA. O Grupo Técnico de Assessoramento para a Gestão do Sistema Cantareira (GTAG - Cantareira) foi criado a partir de resolução conjunta entre o DAEE (Departamento de águas e Energia elétrica de São Paulo) e a ANA (Agência Nacional de Águas) n 120 de 10 de fevereiro de 2014 (DAEE, 2014a). A finalidade do grupo é proporcionar uma administração diferenciada do armazenamento do Sistema. Também fazem parte, representantes da Sabesp, do Comitê das Bacias Hidrográficas dos Rios Piracicaba, Capivari e Jundiaí (Comitê PCJ) e do Comitê de Bacia Hidrográfica do Alto Tietê (CBH - AT).

Diante dos baixos níveis dos reservatórios, a resolução conjunta ANA-DAEE o335 (5 de março de 2014) dispõe sobre as condições especiais de operação dos reservatórios Jaguari-Jacareí, Cachoeira e Atibainha estabelecendo regras complementares à operação do Sistema Cantareira. A resolução conjunta ㄲo 336 dispõe sobre a suspensão temporária de concessão de outorgas de captações de águas superficiais na área paulista das Bacias Hidrográficas dos Rios Jaguari e Atibaia, formadores do rio Piracicaba.

Em 27 de maio o DAEE e a ANA publicaram a resolução conjunta $n^{\circ} 699$ ampliou a suspensão temporariamente as outorgas de uso da água para as Bacias dos rios Piracicaba, Capivari e Jundiaí.

No dia 11 de julho, por meio do Diário Oficial do Estado de São Paulo, ficou prorrogado até 31 de outubro de 2015 (DAEE, 2014b) o prazo de vigência da Portaria DAEE 
1213/04 a qual em agosto de 2004, renovou pelo prazo de 10 anos, a outorga de direto de uso do Sistema Cantareira para a Sabesp.

A ANA decidiu deixar o GTAG-Cantareira em 19 de setembro de 2014 ao alegar que não conseguiu chegar a um acordo sobre a proposta de novos limites de retirada de água do Sistema Cantareira para a RMSP com os demais integrantes (GOY, 2014b). Mesmo com o encerramento do GTAG, ANA/DAEE permanecem impondo novas restrições de vazão, obrigando à Sabesp a buscar novas ações para minimizar o impacto da restrição sobre a população.

Os comunicados conjuntos ANA e DAEE referentes aos limites de operação para o Sistema Cantareira, tanto para o Ato Tietê quanto para as Bacias dos Rios PCJ têm as principais informações apresentadas na Tabela 5.

Tabela 5- Comunicados conjuntos ANA DAEE referentes aos limites de operação do Cantareira.

\begin{tabular}{|c|c|c|c|c|}
\hline Comunicado & Data & Vigência & $\begin{array}{l}\text { Alto Tietê } \\
\left(\mathrm{m}^{3} / \mathbf{s}\right)\end{array}$ & PCJ $\left(m^{3} / \mathbf{s}\right)$ \\
\hline ANA DAEE $n^{\circ} 230$ & 06/03/2014 & $\mathrm{mar} / 14$ & 27,9 & 4,0 \\
\hline ANA DAEE n²31 & $31 / 03 / 2014$ & $a b r / 14$ & 24,8 & 3,0 \\
\hline ANA DAEE $n^{\circ} 232$ & $30 / 04 / 2014$ & $1^{a}$ quinzena mai/2015 & 22,4 & 3,0 \\
\hline ANA DAEE $n^{\circ} 233$ & $16 / 05 / 2014$ & $2^{\mathrm{a}}$ quinzena mai/2015 & 22,4 & 3,0 \\
\hline ANA DAEE n²34 & $30 / 05 / 2014$ & 1a quinzena jun/2015 & 21,5 & 3,0 \\
\hline ANA DAEE n² 235 & $16 / 06 / 2014$ & $2^{\mathrm{a}}$ quinzena jun/2015 & 21,5 & 3,0 \\
\hline ANA DAEE n² 236 & $21 / 06 / 2014$ & $\begin{array}{l}\text { Vazão adicional p/ } \\
\text { jusante de PCJ }\end{array}$ & - & 4,0 \\
\hline ANA DAEE n 237 & 01/07/2014 & $\mathrm{jul} / 14$ & 19,7 & $\begin{array}{c}\text { 3,0 }(4,0 \text { em caráter } \\
\text { excepcional) }\end{array}$ \\
\hline ANA DAEE n 238 & $18 / 09 / 2014$ & A partir de 19/set/2014 & - & 5,0 \\
\hline ANA DAEE n²39 & $17 / 11 / 2014$ & nov $/ 14$ & - & 4,0 \\
\hline ANA DAEE n² 240 & 02/12/2014 & $\operatorname{dez} / 14$ & - & 3,0 \\
\hline ANA DAEE n² 241 & 20/01/2015 & jan/15 & - & 2,5 \\
\hline ANA DAEE n² 242 & 06/02/2015 & $\mathrm{fev} / 15$ & 13,5 & 2,0 \\
\hline ANA DAEE n² 243 & 05/03/2015 & $1^{\text {a }}$ quinzena mar/2015 & 13,5 & 2,0 \\
\hline ANA DAEE n² 244 & 02/04/2015 & $a b r / 15$ & 9,5 a 13,0 & 0,5 a 1,5 \\
\hline ANA DAEE n² 245 & 30/04/2015 & $1^{1 \mathrm{a}}$ quinzena mai/2015 & 9,5 a 13,0 & 0,5 a 1,5 \\
\hline ANA DAEE n² 246 & $13 / 05 / 2015$ & $2^{\mathrm{a}}$ quinzena mai/2015 & 9,5 a 13,5 & 0,5 a 2,5 \\
\hline ANA DAEE n 247 & $25 / 05 / 2015$ & $\begin{array}{c}\text { jun/2015 a ago/2015 } \\
\text { set/2015 a nov/2015 } \\
\text { ago/15 }\end{array}$ & $\begin{array}{l}13,5 \\
10,0 \\
14,5\end{array}$ & 3,5 \\
\hline ANA DAEE n 248 & $31 / 07 / 2015$ & $\begin{array}{c}\text { set/2015 e out/2015 } \\
\text { nov/15 }\end{array}$ & $\begin{array}{l}13,5 \\
10,0\end{array}$ & 3,5 \\
\hline ANA DAEE n² 249 & $13 / 10 / 2015$ & nov/15 & 13,5 & 3,5 \\
\hline ANA DAEE n² 250 & 23/11/2015 & dez/2015 e jan/2016 & 13,5 & 3,5 \\
\hline
\end{tabular}

Fonte: ANA 
Além dos limites de operação, a utilização do volume morto teve uma importância muito grande para o sistema de abastecimento suprido pelo Sistema Cantareira.

Em meados de março de 2014, a Sabesp concebeu empreendimento para aproveitamento de $182,5 \mathrm{hm}^{3}$ das represas Jaguari/Jacareí (município de Joanópolis) e represa Atibainha (município de Nazaré Paulista), denominado Reserva Técnica I (SABESP, 2015a).

A partir de 15 de maio de 2014, a Sabesp passou a contabilizar os volumes da reserva técnica do aproveitamento Jaguari-Jacareí. Conforme comunicado ANA DAEE n 233 (de 16 de maio de 2014) ficou autorizada a transferir vazões, através do túnel 7 , provenientes do bombeamento de volumes do reservatório Jaguari-Jacareí situados em cotas inferiores à correspondente ao N.A. mínimo operacional de 820,80 m, descrito na Portaria DAEE no 1213/04 de 6 de agosto de 2004, até a cota 815,00 m. A Sabesp, da mesma forma, ficou também autorizada a transferir vazões para o canal do Rio Juqueri, através do túnel 5 , provenientes do bombeamento de volumes do reservatório Atibainha situados em cotas inferiores à correspondente ao N.A. mínimo operacional de 781,88 m, descrito na Portaria DAEE no 1213/04 de 6 de agosto de 2004 , até a cota $777,00 \mathrm{~m}$;

Na represa Atibainha, a água foi elevada pelos conjuntos moto-bombas até uma caixa de dissipação e escoada por gravidade através de um canal de $890 \mathrm{~m}$ de comprimento desaguando em ponto no canal de captação do Túnel 5. No local foi construída barragem de 100 metros de comprimento onde a água represada mantém a vazão transferida pelo Túnel 5 para a represa Paiva Castro, já na Bacia do Alto Tietê (SABESP,2015a).

A partir do dia 15 de agosto de 2014, a Sabesp, por meio desses conjuntos de motobombas, passou a contabilizar a reserva técnica do reservatório de Atibainha (LEITE, 2014b).

A Figura 20 apresenta a queda do volume armazenado nos mesmos Sistemas, durante $o$ ano de 2014. 


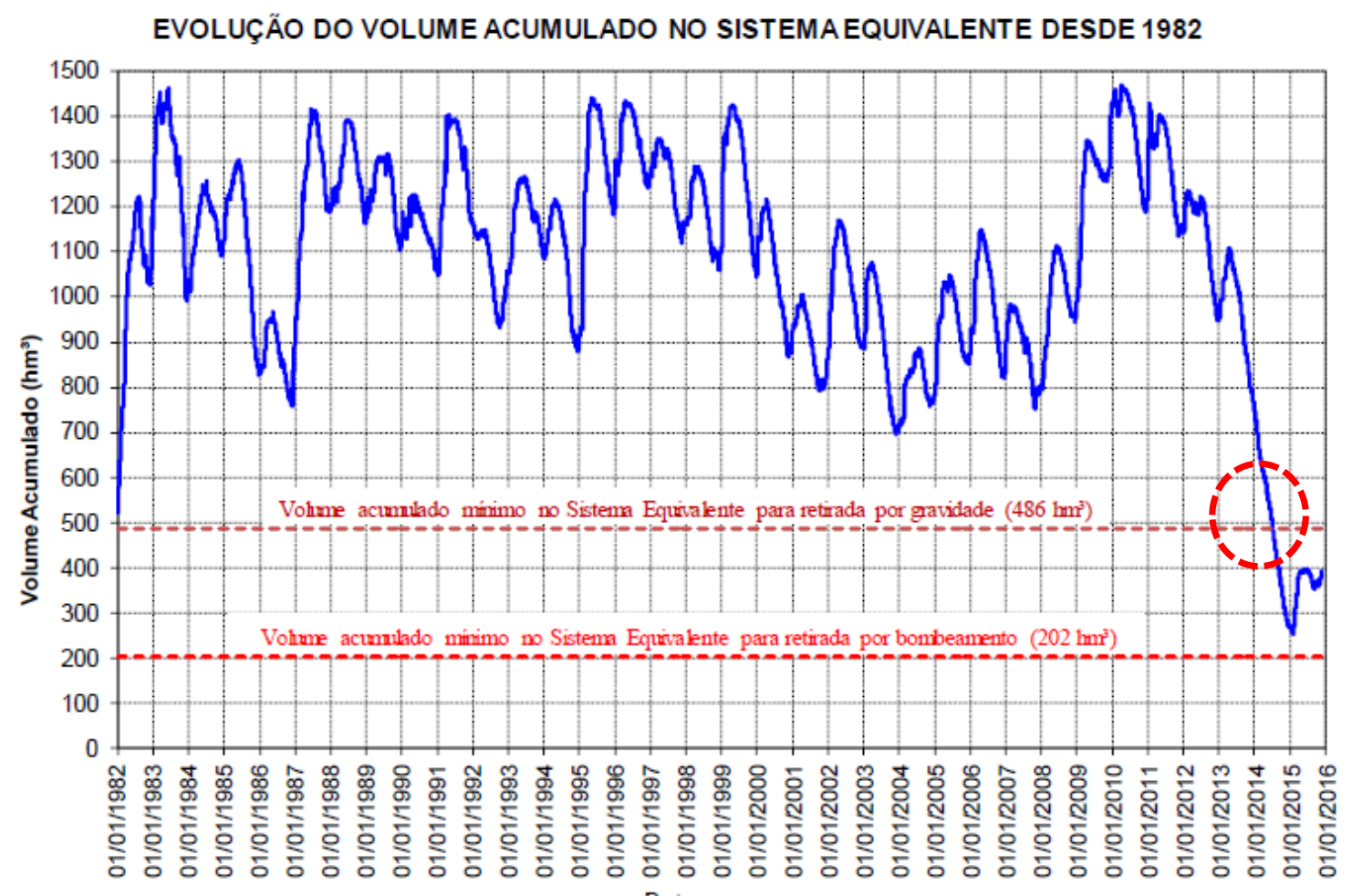

Figura 20 - Evolução do volume Acumulado no sistema Equivalente. (Fonte: ANA, DAEE, 2015)

A Sabesp pediu ao DAEE a autorização para usar mais $100 \mathrm{hm}^{3}$ de água da reserva técnica ( $2^{a}$ cota) e o pedido foi encaminhado aos demais integrantes do GTAG (GOY, 2014a). No segundo semestre foram executadas novas obras para a retirada de uma segunda cota de reserva técnica - denominada Reserva Técnica II, com construção de nova ensecadeira na Represa do Jacareí, com extensão de 400 metros e novos conjuntos moto-bombas (SABESP, 2015a).

O direito de captação da segunda cota da reserva técnica, denominado volume morto, foi concedido pela ANA (Agência Nacional de Águas) em 17 de outubro de 2014, segundo Collet (2014) e passou a ser contabilizado a partir do dia 24 de outubro de 2014. O volume útil de reservação passou de $3 \%$ para 13,6\% (VIEIRA, 2014). A autorização para o uso foi concedida pelos órgãos reguladores por meio da Resolução Conjunta ANA/DAEE n 1672, em 17 de novembro de 2014 (ANA, DAEE, 2014) que definiu novas cotas limite para o bombeamento de água, pela Sabesp, nos reservatórios Jaguari-Jacareí, Cachoeira e Atibainha. Diferente da autorização para o uso da primeira parcela do volume morto, a nova Resolução autorizou a utilização de volumes adicionais por parcelas, que serão definidos por meio de Comunicados Conjuntos ANA-DAEE. Os limites estabelecidos foram: 
$\checkmark$ Jaguari: $817,50 \mathrm{~m}$;

$\checkmark$ Jacareí: 807,00 m;

$\checkmark$ Cachoeira: 811,72 m;

$\checkmark$ Atibainha: $775,00 \mathrm{~m}$.

\subsubsection{Obras para aumento da transferência entre sistemas}

$\mathrm{Na}$ sequência estão apresentadas as obras emergenciais definidas para serem realizadas em curto prazo apresentadas pela Sabesp: Crise Hídrica, Estratégia e soluções da Sabesp para a Região Metropolitana de São Paulo (Sabesp, 2015a).

$\checkmark$ Bombeamento de até $4 \mathrm{~m}^{3} / \mathrm{s}$ do Rio Grande para a represa Taiaçupeba (Sistema Alto Tietê): serviços de infraestrutura para instalação de conjuntos moto bombas posicionados em um ponto da represa fixados em flutuadores, com linha de recalque para uma elevatória de água bruta em terra, composta por conjuntos moto bombas, com vazão de até $4 \mathrm{~m}^{3} / \mathrm{s}$. execução de adutoras, composta por 2 tubulações paralelas de diâmetro 1200 mm em PEAD, lançadas diretamente sobre a superfície, em trechos com água e pântano. A obra foi inaugurada em 30 de setembro de 2015 e custou $\mathrm{R} \$ 130$ milhões. (ITALLIANI, 2015)

$\checkmark$ Ampliação da Estação de Tratamento de Água (ETA) ABV do Sistema Guarapiranga: aumento da capacidade de tratamento de $14 \mathrm{~m}^{3} / \mathrm{s}$ para $16 \mathrm{~m}^{3} / \mathrm{s}$ com a utilização de membranas de ultrafiltração. A partir de 01 de dezembro de 2014 o Sistema passou a ter a capacidade de produção de $15 \mathrm{~m} / \mathrm{s}$ e do dia 20 de julho de 2015, $16 \mathrm{~m}^{3} / \mathrm{s}$;

$\checkmark$ Bombeamento de até $1 \mathrm{~m}^{3} / \mathrm{s}$ do Rio Guaió para a represa Taiaçupeba: Empreendimento composto de estrutura de captação localizada no Rio Guaió, estação elevatória, adutora e estrutura de descarga localizada em tributário da represa Taiaçupeba. São $9 \mathrm{~km}$ de adutoras de $800 \mathrm{~mm}$ de diâmetro e uma estação de bombeamento. A obra custou $R \$ 28,9$ milhões e foi inaugurada em 29 de junho de 2015 (LEITE, 2015b).

$\checkmark$ Ampliação da Estação de Tratamento de Água (ETA) Rio Grande: ampliação de capacidade de tratamento em $0,5 \mathrm{~m}^{3} / \mathrm{s}$, implantação de sistema de 
membranas de ultra filtração, tendo a capacidade aumentada para $5,5 \mathrm{~m}^{3} / \mathrm{s}$. Inauguração em dezembro de 2014.

$\checkmark$ Ampliação da capacidade de bombeamento do braço Taquacetuba para a represa Guarapiranga: Intervenções nos equipamentos elétricos da Estação Elevatório de Água Bruta do braço Taquacetuba, possibilitando ampliar a transferência em mais $0,5 \mathrm{~m}^{3} / \mathrm{s}$ do braço Taquacetuba para a represa Guarapiranga. O correspondente pedido de ampliação da outorga para $5 \mathrm{~m}^{3} / \mathrm{s}$ será submetido ao DAEE e aos órgãos ambientais.

$\checkmark$ Transferência de 1,0 m³/s do Alto Juquiá para o Ribeirão Santa Rita (Bacia Guarapiranga): Captação e estação elevatória no Rio Juquiá, e implantação de adutora até o Ribeirão Santa Rita, com extensão em torno de 5,3 km e diâmetro de $1000 \mathrm{~mm}$. A Sabesp tornou público que requereu à Cetesb a Licença Prévia para Obras de Reversão do Alto Juquiá para Ribeirão Santa Rita, na Bacia do Reservatório Guarapiranga, localizada nos Municípios de Embu-Guaçu e Juquitiba-SP, mediante a apresentação do Estudo de Impacto Ambiental e Relatório de Impacto Ambiental no Diário Oficial do Estado de São Paulo de 23 de dezembro de 2015 (ESTADO DE SÃO PAULO, 2015).

$\checkmark$ Transferência de $0,5 \mathrm{~m}^{3} / \mathrm{s}$ do Rio Guaratuba Sistema Rio Claro / Ponte Nova: A Sabesp ampliou a adutora e a estação elevatória localizadas no córrego, na altura de Biritiba Mirim (SP). A água captada é bombeada para o Rio Claro, que deságua na represa de Ponte Nova. A obra foi inaugurada pelo governador Alckmin em 27 de janeiro de 2015 (SANTANA, CAPANI, LOURENÇO, 2015).

$\checkmark$ Transferência de $2,5 \mathrm{~m}^{3} / \mathrm{s}$ do Rio Itapanhaú para a represa Biritiba (Sistema Alto Tietê): Captação e estação elevatória no Rio Sertãozinho, afluente do Rio Itapanhaú e implantação de adutora até o Rio Biritiba Açu, tributário da Represa Biritiba-Mirim, na Bacia do Alto Tietê, com extensão em torno de 7,3 km e diâmetro de $1.200 \mathrm{~mm}$. No ofício MA 055/2015 de 23 de julho de 2015 (SABESP, 2015c) foi comunicado que essa ação proposta estava na fase de elaboração do EIA-RIMA.

$\checkmark$ Transferência de $2 \mathrm{~m}^{3} / \mathrm{s}$ do Rio São Lourenço para o Ribeirão das Lavras (Bacia Guarapiranga): Captação e estação elevatória no Rio São Lourenço, e implantação de adutora até o Ribeirão Lavras, com extensão em torno de $9 \mathrm{~km}$ e diâmetro de $1.200 \mathrm{~mm}$. No ofício MA 055/2015 de 23 de julho de 2015 
(SABESP, 2015c) foi comunicado que esta alternativa encontrava-se em fase de projeto;

$\checkmark$ Transferência de $1,2 \mathrm{~m}^{3} / \mathrm{s}$ do Rio Itatinga para a represa Jundiaí (Sistema Alto Tietê): Captação e estação elevatória no Rio Itatinga, e implantação de adutora até tributário da represa Jundiaí, na Bacia do Alto Tietê, com extensão em torno de 5,7 km e diâmetro de $900 \mathrm{~mm}$. No ofício MA 055/2015 de 23 de julho de 2015 (SABESP, 2015c) foi comunicado que esta alternativa encontrava-se em fase de projeto;

Na apresentação da Sabesp e do Governo do Estado de São Paulo sobre Ações para Enfretamento da Crise Hídrica, foram apresentadas algumas obras adicionais para ao aumento da transferência entre Sistemas foram mencionadas (SABESP, 2015b).

$\checkmark$ Nova regra operacional na EEAT ABV/Jabaquara e no Booster Cadiriri, possibilitando transferência de $0,7 \mathrm{~m}^{3} / \mathrm{s}$ para o Cantareira;

$\checkmark$ Alteração da regra operacional da EEAT França Pìnto, possibilitando transferência de cerca de $0,25 \mathrm{~m}^{3} / \mathrm{s}$ para o Sistema Cantareira, para a região da Avenida Paulista, Ipiranga e São Caetano do Sul;

$\checkmark$ Readequação hidráulica no Booster Cidade Líder, permitindo transferência de cerca de $0,5 \mathrm{~m}^{3} / \mathrm{s}$ para o sistema Cantareira;

$\checkmark$ Adequação hidráulica na EEAT Vila Guarani, transferindo cerca de $0,2 \mathrm{~m} 3 / \mathrm{s}$ para o Sistema Cantareira;

$\checkmark$ Intervenções na EEAT Theodoro Ramos e adequações operacionais na adutora V. Olímpia, para avanço do Sistema Guarapiranga em cerca de $0,5 \mathrm{~m}^{3} / \mathrm{s}$;

$\checkmark$ Operacionalização da Adutora Jabaquara-Sacomã, do Sistema Guarapiranga, ampliando transferência em cerca de $0,2 \mathrm{~m} / \mathrm{s}$;

$\checkmark$ Conclusão das obras da Adutora Jardim das Nações / Parque Real em Diadema, permitindo a transferência do Sistema Rio Grande para Guarapiranga e Cantareira.

\subsubsection{Sistema Produtor São Lourenço}

Uma medida estrutural adotada pelo Governo de São Paulo é o Sistema Produtor São Lourenço (SPSL) a partir de um contrato de PPP (Parceria Público-Privada) que foi 
assinada em agosto de $2013 \mathrm{com}$ as construtoras Camargo Correa e a Andrade Gutierrez. O SPSL objetiva aumentar a oferta de água tratada para reforço e regularização do abastecimento público de água na zona oeste da RMSP, mediante interligação ao Sistema Integrado Metropolitano (SIM) de Abastecimento de Água da RMSP. Na zona oeste da RMSP a produção dos sistemas Alto e Baixo Cotia é insuficiente e requer transferências dos Sistemas Cantareira e Guarapiranga, os quais deixam de atender satisfatoriamente setores das suas próprias áreas de influência (SABESP, 2011).

Este projeto constitui uma evolução do antigo projeto Juquitiba proposto pela Sabesp em 1996/1997 e previa a captação a fio d'água no Rio Juquiá (município de Juquitiba) da vazão de $4,7 \mathrm{~m}^{3} / \mathrm{s}$ autorizada legalmente, e sua reversão mediante estação elevatória, adutora e túnel para a Bacia Guarapiranga, A vazão revertida seria descarregada nas cabeceiras do Ribeirão Santa Rita, seguindo pelo leito desse rio até o reservatório Guarapiranga, onde haveria uma captação para a alimentação da ETA Alvorada (SABESP, 2011).

A obra visa ampliar a capacidade de produção de água tratada para a RMSP com uma vazão média diária de $4,7 \mathrm{~m} 3 / \mathrm{s}$ e vazão nominal de $6,0 \mathrm{~m} 3 / \mathrm{s}$. O novo sistema vai captar água na represa Cachoeira do França (Ibiúna), que é formada pelo Rio Juquiá e percorrer a distância de $83 \mathrm{~km}$ e superar o desnível de 300 metros na Serra de Paranapiacaba (REOLOM, 2013).

O SPSL será responsável pelo suprimento de água de 13 setores de abastecimento em 7 municípios da zona oeste da RMSP, que hoje são abastecidos pelos Sistemas Produtores Alto Cotia, Baixo Cotia, Guarapiranga e Cantareira. Esses 13 setores têm uma população estimada de 1,43 milhão de habitantes em 2015 e 1,7 milhão de habitantes em 2025 (SABESP, 2011). O SPSL beneficiará também diversos outros municípios que serão melhor abastecidos pelos atuais sistemas produtores. Terá, portanto, intervenções nos seguintes 11 municípios: Ibiúna, Juquitiba, São Lourenço da Serra, Embu Guaçu, Cotia, Vargem Grande Paulista, Itapevi, Jandira, Barueri, Carapicuíba, Santana de Parnaíba.

O SPSL compõe-se de um conjunto de instalações lineares com 48,22 km de adutora de água bruta (com $2100 \mathrm{~mm}$ de diâmetro), $30,75 \mathrm{~km}$ de adutora de água tratada (em 2100, 1800, 1500 e 1200 mm de diâmetro), 14,3 km de 4 sub-adutoras (em 800 e 400 
$\mathrm{mm}$ ), cerca de 40,36 km de linha de transmissão em $138 \mathrm{kV}$, e mais instalações localizadas - tomada de água, estações elevatórias, chaminés de equilíbrio, Estação de Tratamento de Água (ETA) e reservatórios - situadas no território de 10 municípios da RMSP e mais Ibiúna (SABESP).

O traçado pretendido em planta do SPSL está apresentado na Figura 21.

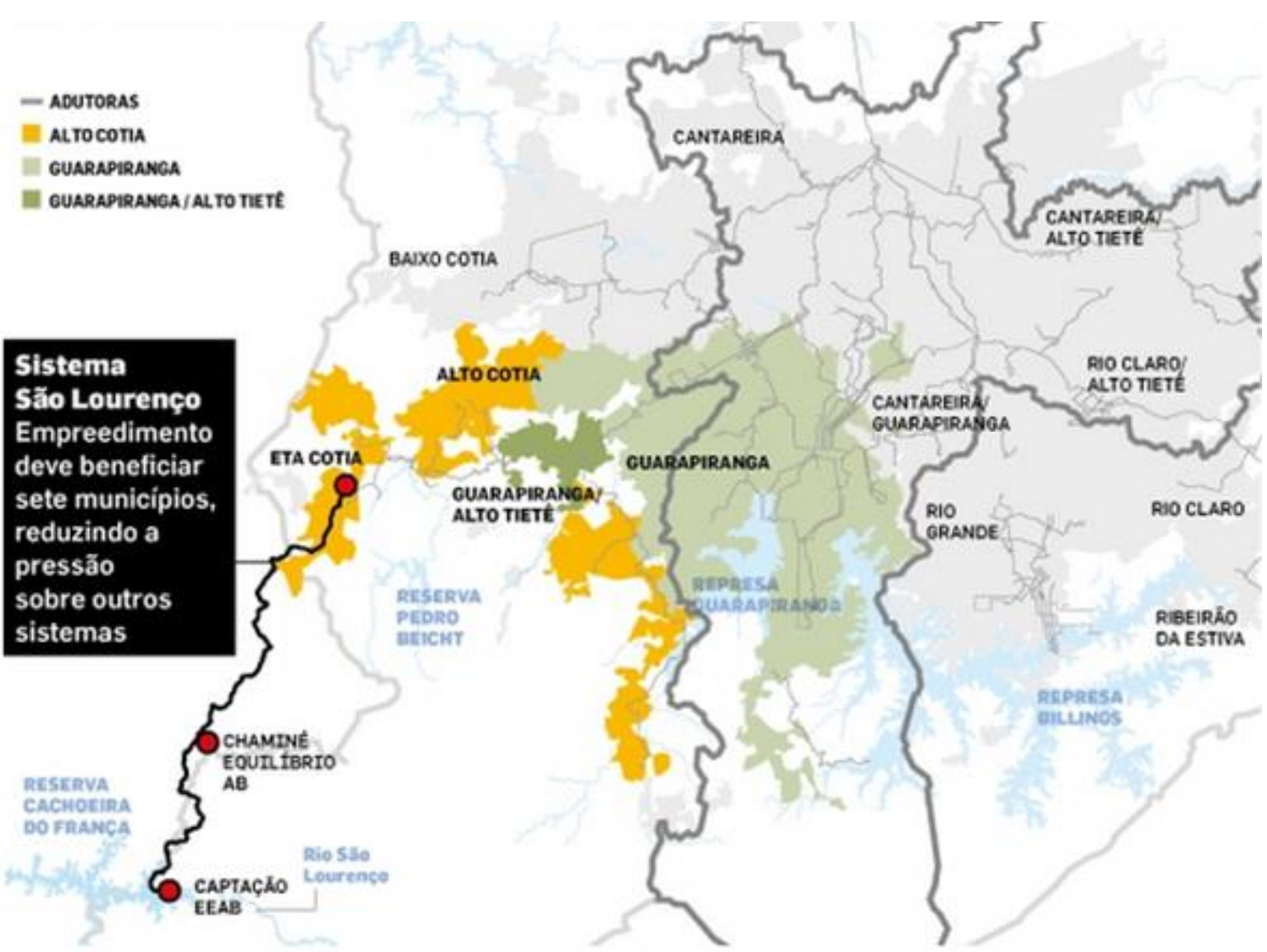

Figura 21 - Instalações do SPLP nos municípios da área de influência. (Fonte: RODRIGUES, MOURA, MONTEIRO, 2014)

Caberá ao parceiro privado todos os investimentos necessários, inicialmente estimados de R \$ 1,6 bilhão1. Serão instalados uma Estação de Tratamento de água, estações de bombeamento e reservatórios para armazenar $110.000 \mathrm{~m}^{3}$ de água. A conclusão está prevista para 2018 (CAMARGO CORREA, 2014).

Em 4 de dezembro de 2014 o governador Geraldo Alckmin assinou com a presidente Dilma Roussef um contrato que garante o financiamento de $R \$ 2,6$ bilhões às obras

\footnotetext{
1 SABESP: Disponível em < http://site.sabesp.com.br/site/interna/Default.aspx?secaold=485> Acesso em 09 de novembro de 2014.
} 
do SPSL. O empreendimento será financiado pela Caixa Econômica com recursos do FGTS destinado às construtoras do consórcio (RODRIGUES, MOURA, MONTEIRO, 2014).

No próximo item é descrita a a medida estrutural de transpor as águas da Bacia do Paraíba do Sul para o Sistema Cantareira, uma das ações do Plano Diretor de Aproveitamento de Recursos Hídricos para a Macrometrópole Paulista (DAEE, 2009), e os conflitos de interesse na região e atrelados a essa medida.

\subsubsection{Paraíba do Sul}

O Rio Paraíba do Sul, localizado na Bacia Hidrográfica do Atlântico Sudeste, é formado na cidade de Paraibuna (SP) a partir da junção dos rios Paraitinga e Paraibuna.

A Bacia Hidrográfica do Rio Paraíba do Sul se estende por territórios pertencentes a três Estados da Região Sudeste, numa área de drenagem total de 57.000 km²: São Paulo (13.605 km²), Rio de Janeiro $\left(22.600 \mathrm{~km}^{2}\right)$ e Minas Gerais $\left(20.500 \mathrm{~km}^{2}\right)$. A sua abrangência compreende 184 municípios²:

$\checkmark 39$ municípios do Estado de São Paulo (Vale do Paraíba Paulista);

$\checkmark 88$ municípios do Estado de Minas Gerais (Zona da Mata Mineira);

$\checkmark 57$ municípios do Estado do Rio de Janeiro.

A extensão das bacias hidrográficas está apresentada da Figura 22.

Comitê das Bacias Hidrográficas do Rio Paraíba do Sul. Disponível em $<$ http://www.comiteps.sp.gov.br/quem-somos> Acesso em 12 de novembro de 2014. 


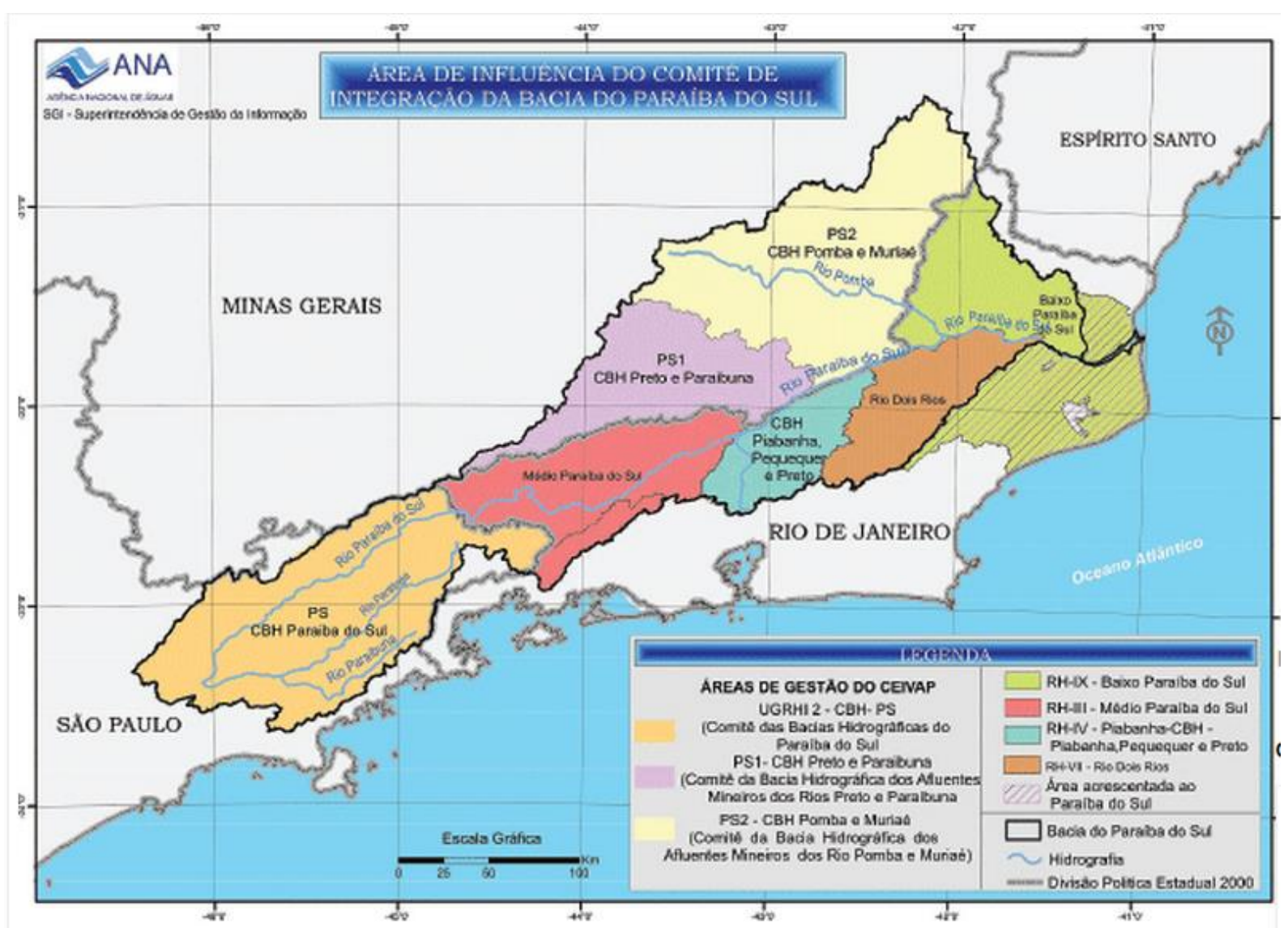

Figura 22 - Bacia do Rio Paraíba do Sul. (Fonte: ANA)

De acordo com o comitê de Bacias Hidrográficas do Rio Paraíba do Sul, a população urbana total da bacia, segundo estimativa do IBGE/2005, é de aproximadamente 5,3 milhões de habitantes.

A bacia do Rio Paraíba do Sul também abastece, por meio de transposição de suas águas, a Região Metropolitana do Rio de Janeiro, que possui cerca de 11 milhões de habitantes. Essa transposição é uma operação realizada na Usina Elevatória de Santa Cecília, na altura do município de Barra do Piraí (RJ), transfere ao Sistema LagesGuandu cerca de 160 m³/s de água (praticamente 66\% da vazão do Rio Paraíba do Sul), permitindo a geração de energia e o Rio Guandu ter o volume necessário para o abastecimento de $85 \%$ da capital e de $78 \%$ dos municípios da Baixada Fluminense.

As principais barragens ao longo do Rio Paraíba do Sul relacionadas à geração de energia elétrica são: Paraibuna/Paraitinga e Jaguari, que pertencem à CESP, e Santa Branca, da Light (no Estado de São Paulo), Funil, operada por FURNAS, Santa Cecília e llha dos Pombos, também sob concessão da Light (no Estado do Rio de Janeiro). 
No diagrama esquemático apresentado na Figura 23 há a representação da Bacia do Rio Paraíba do Sul

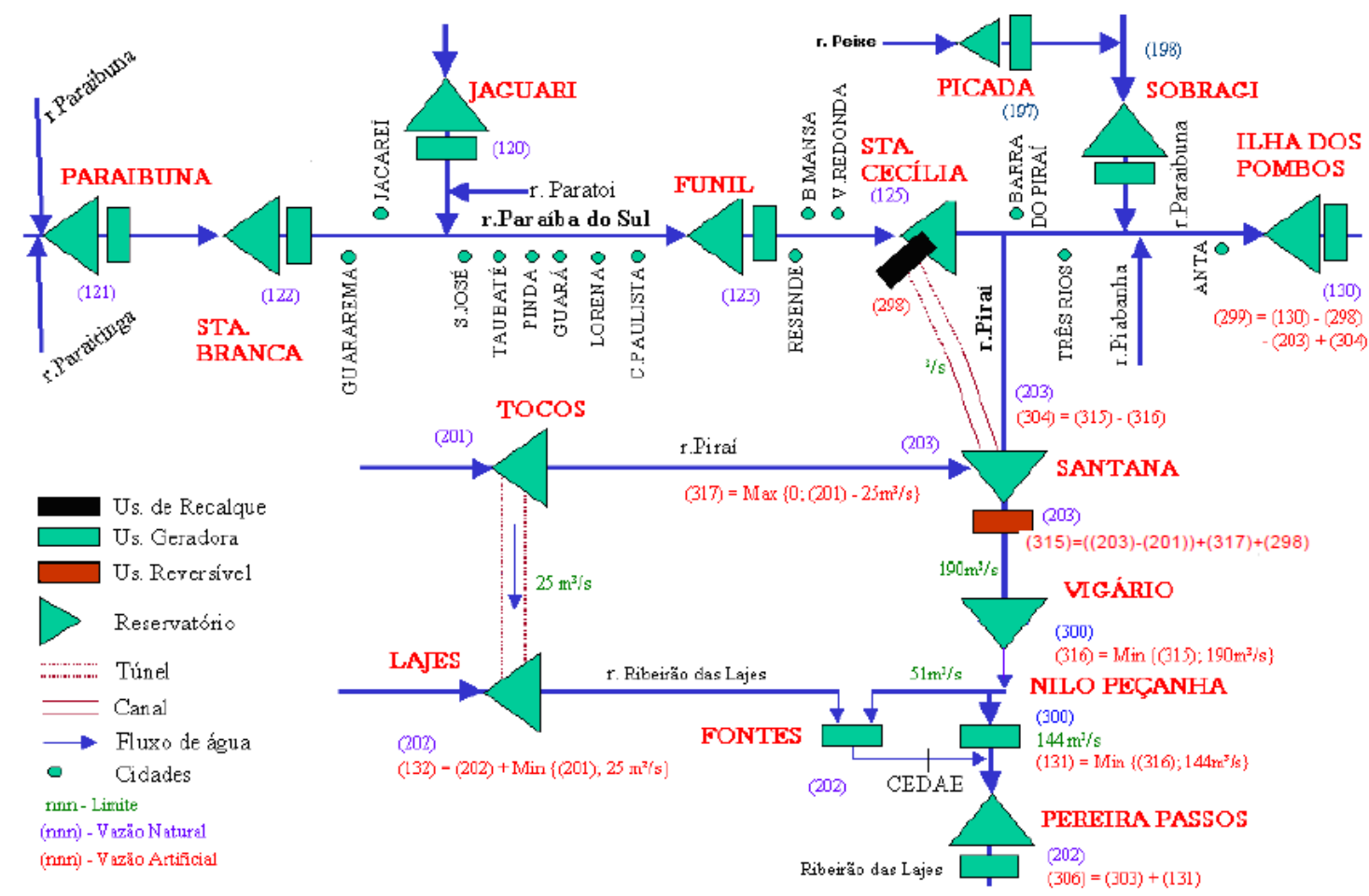

Figura 23 - Representação completa da Bacia do Rio Paraíba do Sul - diagrama esquemático das usinas com regras de transformação de vazões. (Fonte: ONS, 2013)

A medida estrutural de transposição estava prevista para 2020 e foi adiantada, frente à crise hídrica. Prevê a interligação do Sistema Cantareira com o Paraíba com o intuito de se aumentar a reservação (ALCKMIN, 2014).

A região geográfica denominada Macrometrópole é composta pelas regiões de São Paulo (RMSP), Campinas (RMC) e Baixada Santista (RMBS), mais as regiões limítrofes ou adjacentes, como as regiões de Registro, São José dos Campos e Sorocaba. Estão incluídas, total ou parcialmente, as UGRHIs (Unidades Hidrográficas de Gerenciamento de Recursos Hídricos do Estado de São Paulo): Paraíba do Sul; Litoral Norte; Piracicaba, Capivari e Jundiaí; Alto Tietê; Baixada Santista; Mogi Guaçu; Tietê e Sorocaba; Ribeira de Iguape e Litoral Sul. Trata-se de uma área que engloba cerca de 270 municípios, abriga cerca de 35 milhões de habitantes (estimativa para 2014) (DAEE, 2009). 
Ao gerir o aproveitamento múltiplo dos recursos hídricos dessa área de forma conjunta, tem-se o propósito de avaliar a situação atual e futura das disponibilidades e demandas de múltiplos usos e os possíveis conflitos e alternativas (DAEE, 2009).

O Plano Diretor de Aproveitamento de Recursos Hídricos para a macrometrópole Paulista visa garantir o abastecimento da região até 2035, explorando as alternativas disponíveis de abastecimento para fazer frente à expansão econômica e populacional da região (TOMAZELA, 2014). A Figura 24 contem as projeções de demandas de água total da macrometrópole.

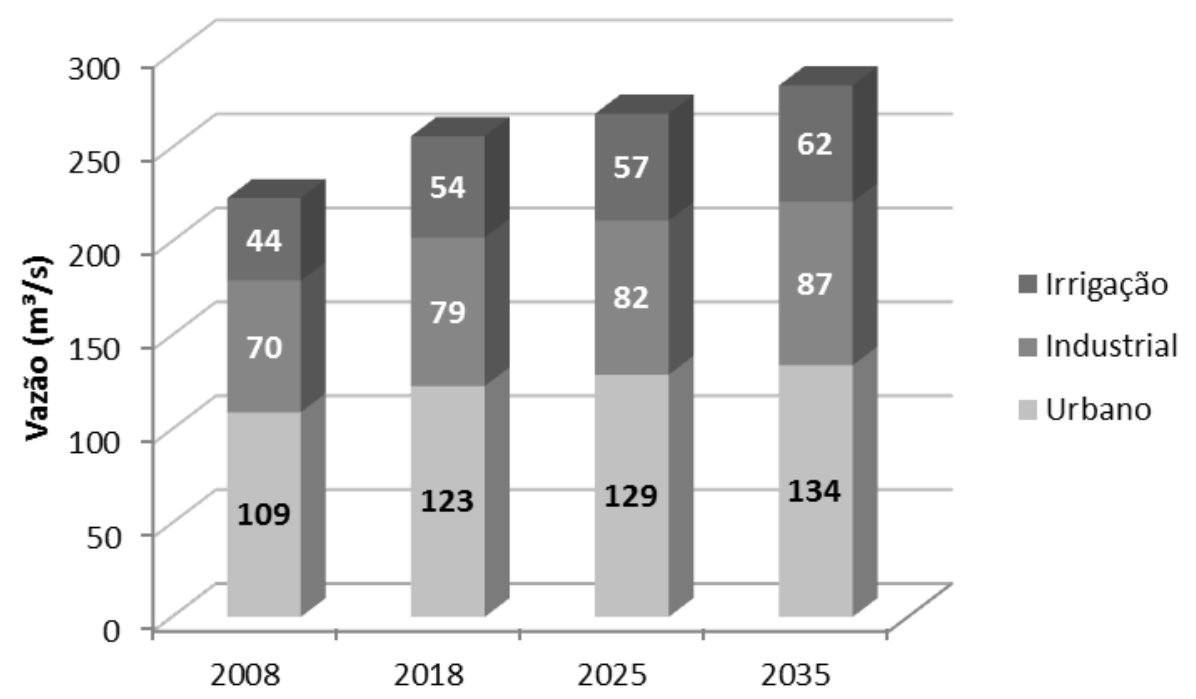

Figura 24 - Comparação do crescimento da demanda hídrica total por setor nos horizontes do projeto. (Fonte: DAEE, 2010)

A transposição do Paraíba do Sul, do reservatório de Jaguari para o reservatório de Atibainha, com a vazão pretendida de $5 \mathrm{~m}^{3} / \mathrm{s}$ teve seu projeto anunciado oficialmente em março de 2014 (CONSTANCIO, 2014). O projeto é pretendido pelo Governo do Estado de São Paulo e a Sabesp apresentou o plano ao Comitê da Bacia do Paraíba do Sul. A obra estava prevista de terminar no início de 2016 (RODRIGUES, 2014a). Uma representação em planta da obra pretendida está apresentada na sequência (Figura 25). 


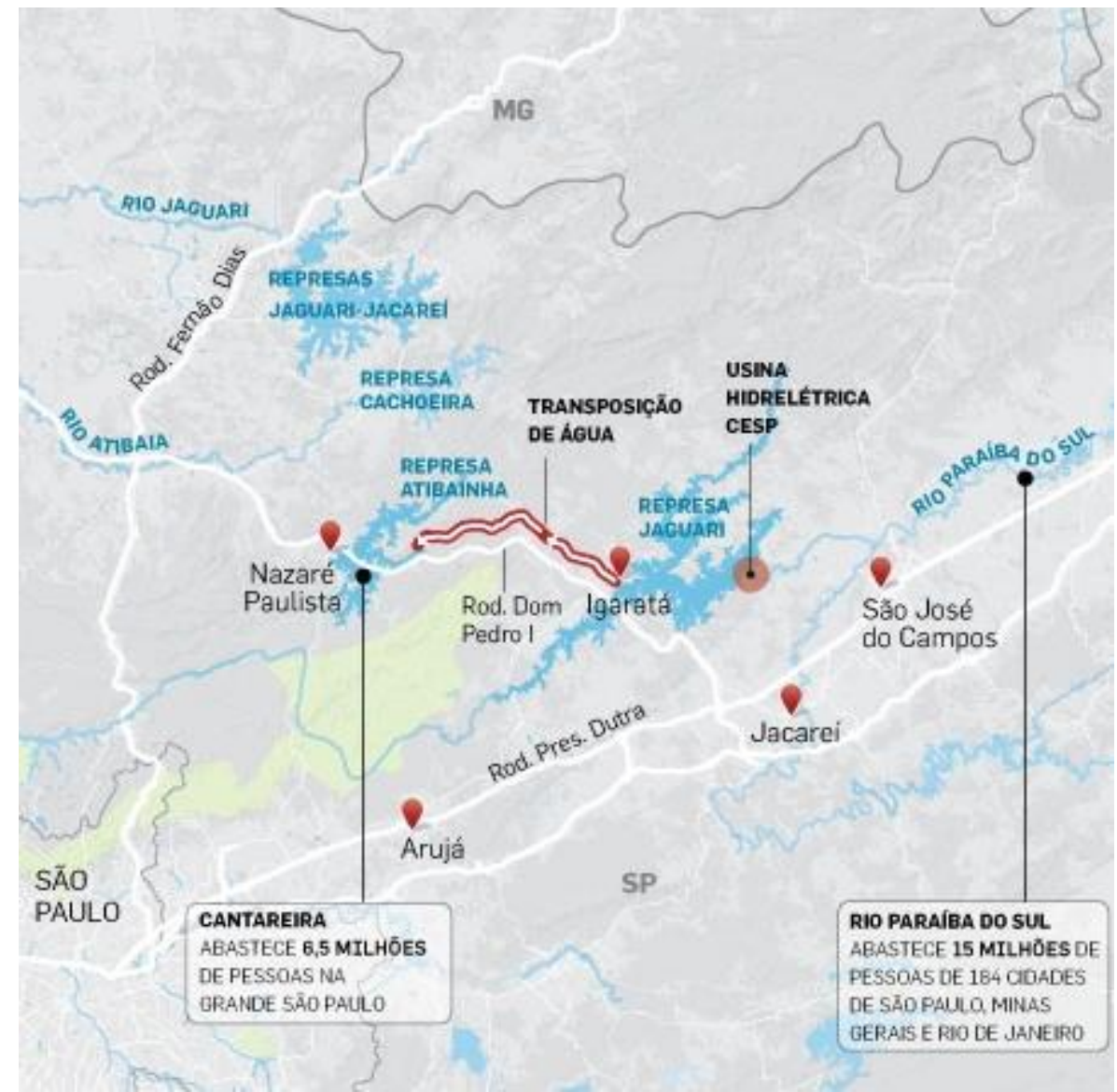

Figura 25 - Transposição da Represa Jaguari à Represa Atibainha. (Fonte: SOUZA, 2014)

Essa alternativa não prevê o aumento da capacidade nominal do Sistema Cantareira, portanto não haverá o aumento da capacidade de captação, tratamento ou transferência. Objetiva, portanto a recuperação dos níveis dos reservatórios.

Uma das alternativas treze alternativas estudadas pela Sabesp contempla a tomada d'água associada a uma estação elevatória na margem esquerda do Reservatório do Rio Jaguari (afluente do Rio Paraíba do Sul) a montante da ponte da Rodovia Dom Pedro, adutora de comprimento de 11,3 km e diâmetro de 2,10 m que se desenvolve ao longo da mesma rodovia até alcançar as imediações do divisor de águas da Bacia do Rio Atibainha, e finaliza num reservatório de passagem situado ainda na vertente da Bacia do Rio Jaguari. Este reservatório de passagem conecta-se com o reservatório de Atibainha (Sistema Canteira) através de túnel de $5,5 \mathrm{~km}$ de comprimento e diâmetro de 3,0 m, que opera por gravidade (DAEE, 2010). Na Figura 26 está contida uma ilustração esquemática do perfil do traçado longitudinal proposto. 


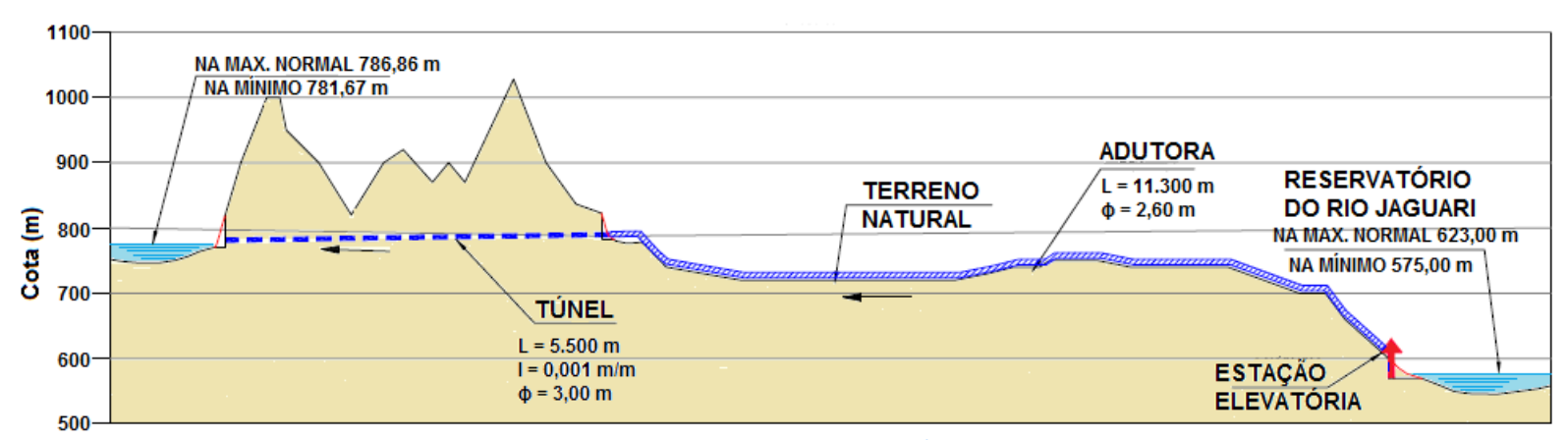

Figura 26 - Traçado em perfil do projeto proposta da transposição. (Fonte: DAEE, 2010)

Uma variante deste traçado compreende: tomada d'água associada a uma estação elevatória na margem esquerda do Reservatório do Rio Jaguari (afluente do Rio Paraíba do Sul), adutora de comprimento de $4,6 \mathrm{~km}$ finalizando num primeiro reservatório de passagem situado na vertente da Bacia do Rio Jaguari. Este reservatório está conectado com o reservatório de Atibainha mediante estação elevatória seguida de túnel operando por gravidade com extensão de 7,2km (DAEE, 2010). Na Figura 27 está apresentada uma ilustração esquemática do perfil longitudinal do traçado variante.

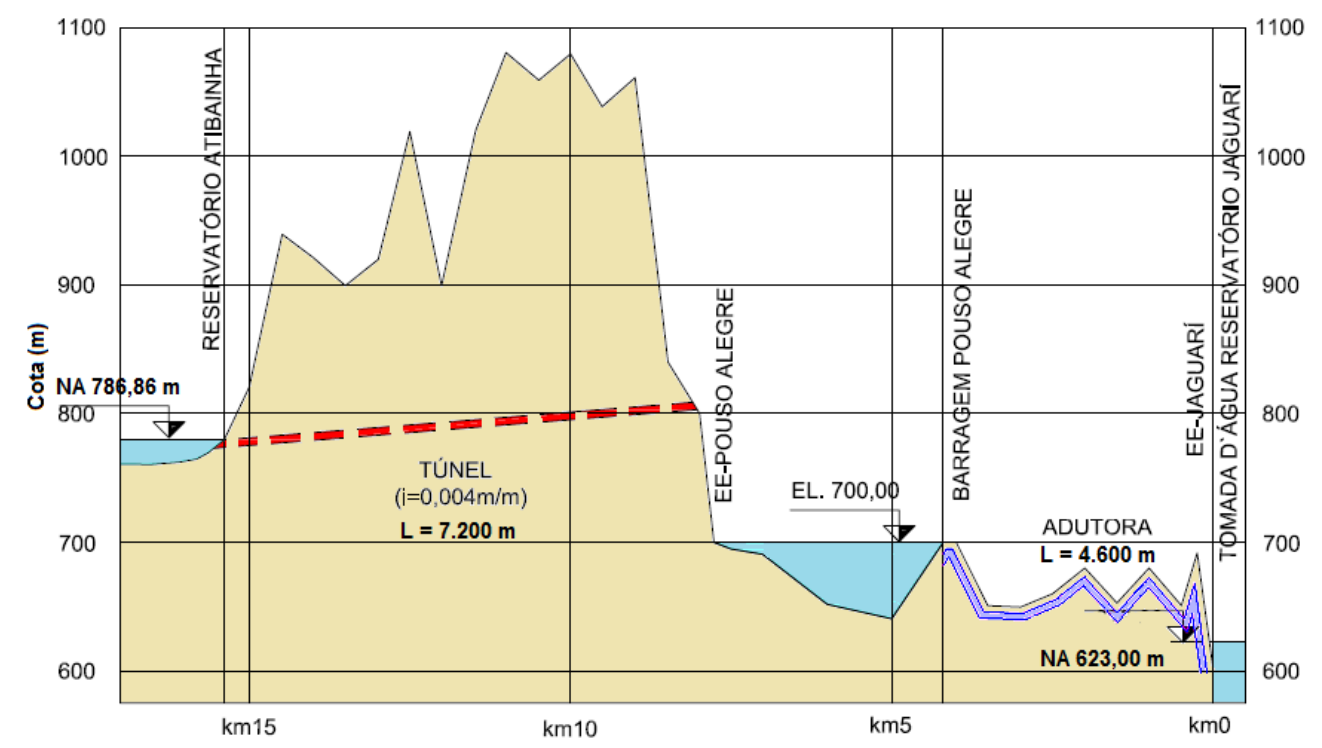

Figura 27 - Perfil (variante) do projeto proposta da transposição. (Fonte: DAEE, 2010)

Em ambos os traçados, o esquema é complementado pela implantação dos reservatórios em afluentes da margem esquerda do Rio Paraíba do Sul referidos, com o propósito de compensar as vazões a serem transferidas para a bacia vizinha. (DAEE, 2010). 
De acordo com Leite (2014d), foi decidido que o traçado mais viável terá 13,3 km de adutora em vala e outros $6,2 \mathrm{~km}$ de túnel, atravessando a estrada privatizada. O prazo de execução é de 14 anos. A transferência de água pode ser feita nos dois sentidos quando os níveis das represas estiverem cima de $75 \%$ e abaixo de $35 \%$ da capacidade. O novo traçado pode ser visualizado na Figura 28.

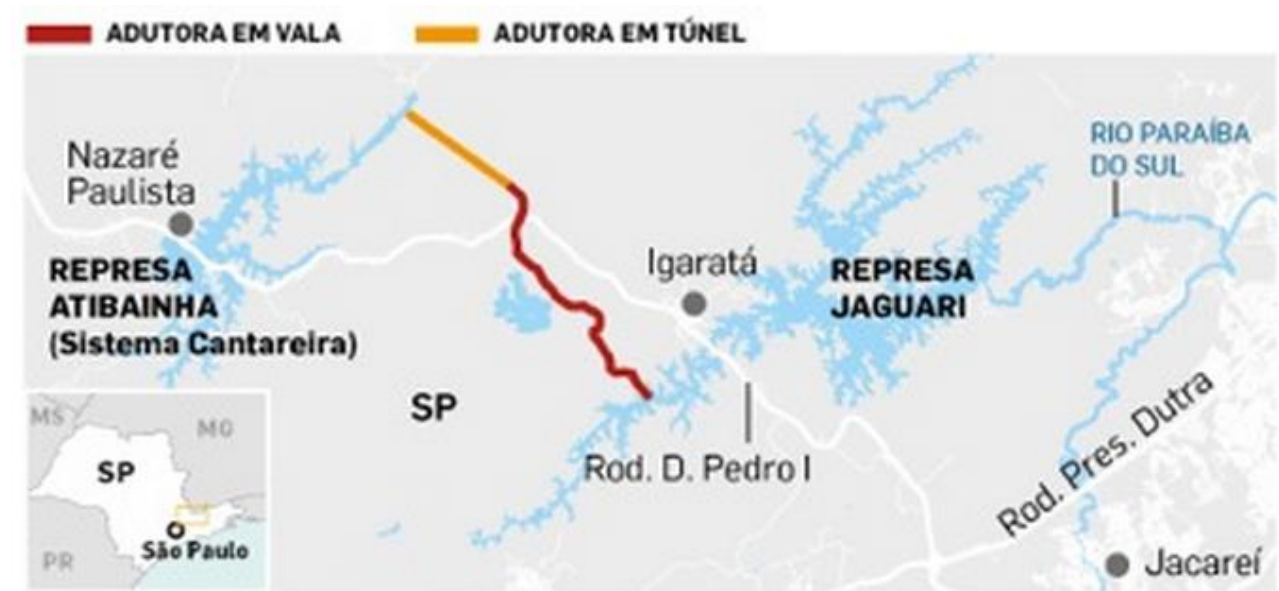

Figura 28 - Traçado em perfil escolhido após avaliação de alternativas. (Fonte: Leite, 2014d)

Tal projeto desencadeou uma crise entre o Rio Janeiro e São Paulo (conflito federativo), visto que o Rio Paraíba do Sul garante o abastecimento da Região Metropolitana do Rio de Janeiro, de Minas Gerais e do interior de São Paulo. Foi movida uma ação pública civil em maio pelo Ministério Público Federal do Rio (MPFRJ) contra a transposição (CONSTANCIO, 2014). Os procuradores da República solicitaram em junho, que a ANA não autorizasse a transposição do rio pelo menos até que o IBAMA realizasse estudos de viabilidade ambiental necessários para avaliar o projeto. (SALOMÃO, 2014).

Em novembro medida se encontrava em fase de estudo e, portanto, dependia da autorização da ANA. Técnicos discutiram alternativas para a operação de reservatórios do sistema Paraíba do Sul para verificar a viabilidade de interligação entre o reservatório Rio Jaguari ao reservatório Atibainha. O presidente da ANA, Vicente Andreu, em 5 de novembro de 2014 participou de uma reunião da CPI (Comissão Parlamentar de Inquérito) da Sabesp, da câmara Municipal de São Paulo e afirmou que considera possível conciliar interesses em torno da proposta da obra ao considerar que a obra é tecnicamente viável. O governador fluminense afirma que acatará a determinação dos órgãos de regulação federal: ANA, ANEEL e Ministério do Meio Ambiente (SALOMÃO, 2014). 
A partir de um estudo realizado (FERRAZ, ITALIANI, 2014) pelo LABSID (Laboratório de Sistema de Suporte a Decisões), da USP, a Sabesp pretende criar uma reserva técnica de $162 \mathrm{hm}^{3}$, no reservatório de Paraibuna, como forma de compensar a obra de transposição, como uma garantia. Ressalta-se que ao mesmo tempo em que o projeto de transposição possibilita a reversão de água de Jaguari para Atibainha, a transposição libera a captação inversa.

Em 27 de novembro, com a intermediação do Supremo Tribunal Federal, os governos de São Paulo, Minas Gerais e Rio de Janeiro assinaram um acordo sobre a transposição que permite o processo de contratação das obras. Para tal, São Paulo deverá fazer acertos com os governos de RJ e MG (SOUZA, 2014). A obra está estimada em $\mathrm{R} \$ 830$ milhões.

Em 16 de janeiro (LEITE, 2015a), o presidente da ANA, Vicente de Andreu, e representantes dos governos de São Paulo, Rio de Janeiro e Minas Gerais, aprovaram um relatório no qual ficou definido que a transferência de água só poderá ser iniciada após a recuperação da Bacia do Rio Paraíba do Sul, ou seja, ao menos $25 \%$ da capacidade de armazenamento.

Perante a Lei n 9984/2000 da Criação da natureza jurídica e competências da ANA, no artigo $4^{\circ}$ fica estabelecido que a ANA tem um papel fundamental nestes casos, cabendo supervisionar, controlar, disciplinar em caráter normativo o controle e avaliação dos instrumentos da Política Nacional de Recursos Hídricos.

O governo do Estado de São Paulo alega que perante a Lei n 9433/1997 que contém a Política Nacional de Recursos Hídricos, no artigo $1^{\circ}$, em situações de escassez, o uso prioritário dos recursos hídricos é o consumo humano e a dessedentação de animais. Dessa forma, justifica a diminuição da vazão para resolver o problema de abastecimento em torno de Jaguari, ao afirmar que a liberação da vazão possui finalidades de produção de energia, visto que a energia elétrica pode ser gerada de outras formas, como as usinas termelétricas.

Segundo Kelman (2014), da COPPE - UFRJ, esse assunto diz respeito a todas as cidades localizadas ao longo do Vale do Paraíba do Sul. Essa medida coloca em risco o abastecimento de água da Região Metropolitana do Rio de Janeiro e que a produção de energia de fato fica em segundo plano. 
Kelman alega que no Rio Paraíba do Sul, em Santa Cecília (em Piraí), parte da água $\left(45 \mathrm{~m}^{3} / \mathrm{s}\right.$ ) é desviada para a Região Metropolitana do Rio de Janeiro para formar o Rio Guandu. A maior vazão do Sistema Lages-Guandu é destinada à produção de energia, porém alega-se que a redução da vazão compromete a qualidade da água de abastecimento, tendo em vista que a água é necessária para diluir os efluentes lançados ao longo do curso do rio, de forma a não inviabilizar o tratamento adequado dela pela CEDAE (Companhia Estadual de Águas e Esgotos).

\subsection{Análise de séries temporais}

Para o presente estudo, foram analisadas as séries temporais de vazões afluentes aos reservatórios do sistema produtor da RMSP. As séries de vazão foram obtidas a partir da Atualização de Séries Históricas de Vazões (ONS, 2013) e da Sabesp

A análise de dados experimentais observados em diferentes pontos no tempo conduz à modelagem estatística e de interferência ao assumir que as observações adjacentes são independentes e igualmente distribuídas (SHUMWAY, 2006).

Define-se série temporal qualquer conjunto de observações ordenadas no tempo. Ao analisar uma série temporal é possível investigar o mecanismo gerador da série; fazer previsão de valores futuros; descrever o comportamento (verificação de tendências, ciclos, variações sazonais); estudar a periodicidade com a análise espectral. (MORETTIN, TOLOI, 2004).

As séries temporais mensais de vazões afluentes aos Sistemas de Abastecimento da RMSP: Alto Cotia, Cantareira, Guarapiranga e Alto Tietê estão representadas na Figura 29 na sequência, com a finalidade de se analisar o comportamento. Para os sistemas Rio Grande e Rio Claro foram utilizados os ciclos de afluências anuais enquanto os sistemas de Baixo Cotia e Ribeirão Estiva foram consideradas como fontes constantes de vazão. 


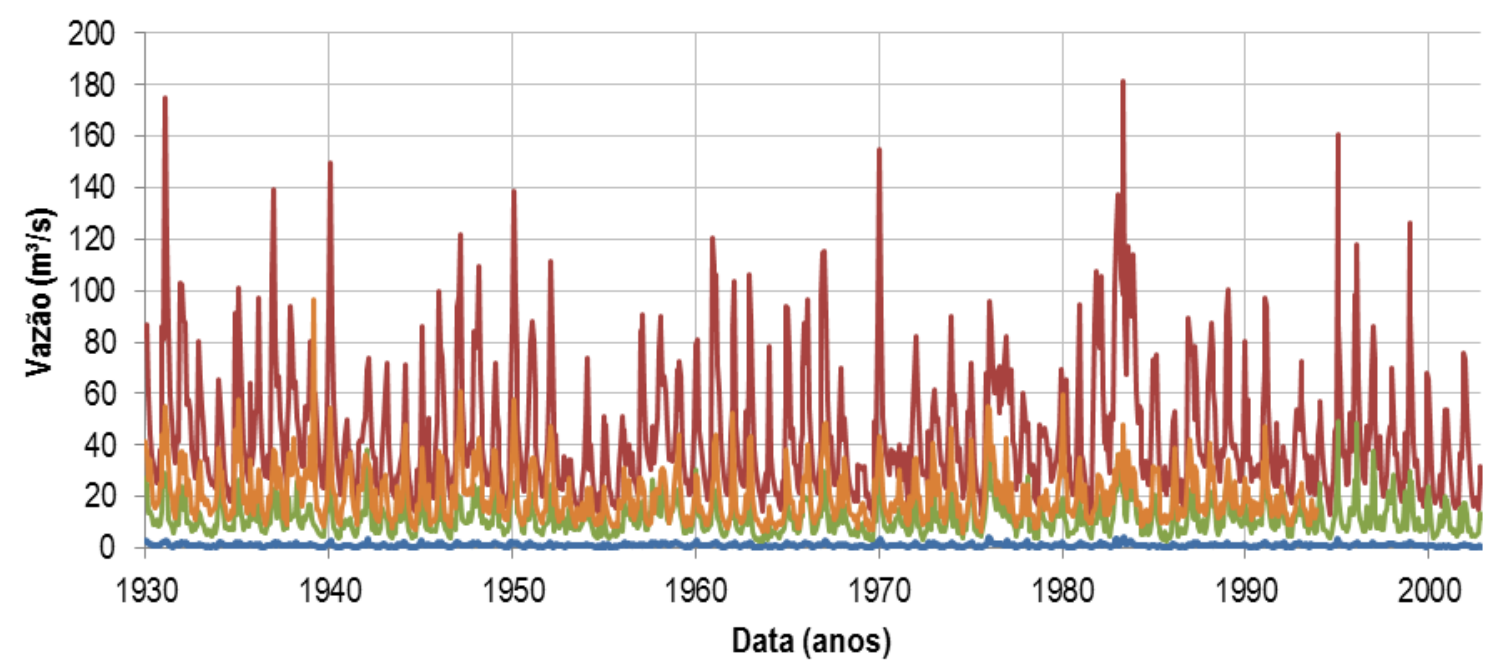

- Alto Cotia - Cantareira Guarapiranga - Alto Tietê

Figura 29 - Vazões mensais afluentes aos sistemas produtores da RMSP.

A curva de permanência expressa a relação entre a variável aleatória de estudo e a frequência com que ela é igualada ou superada. Neste caso, a curva de permanência apresenta a probabilidade baseada em dados de vazões médias mensais. A Figura 30 apresenta as vazões naturais mensais afluentes totais dos Sistemas de Abastecimento da RMSP.

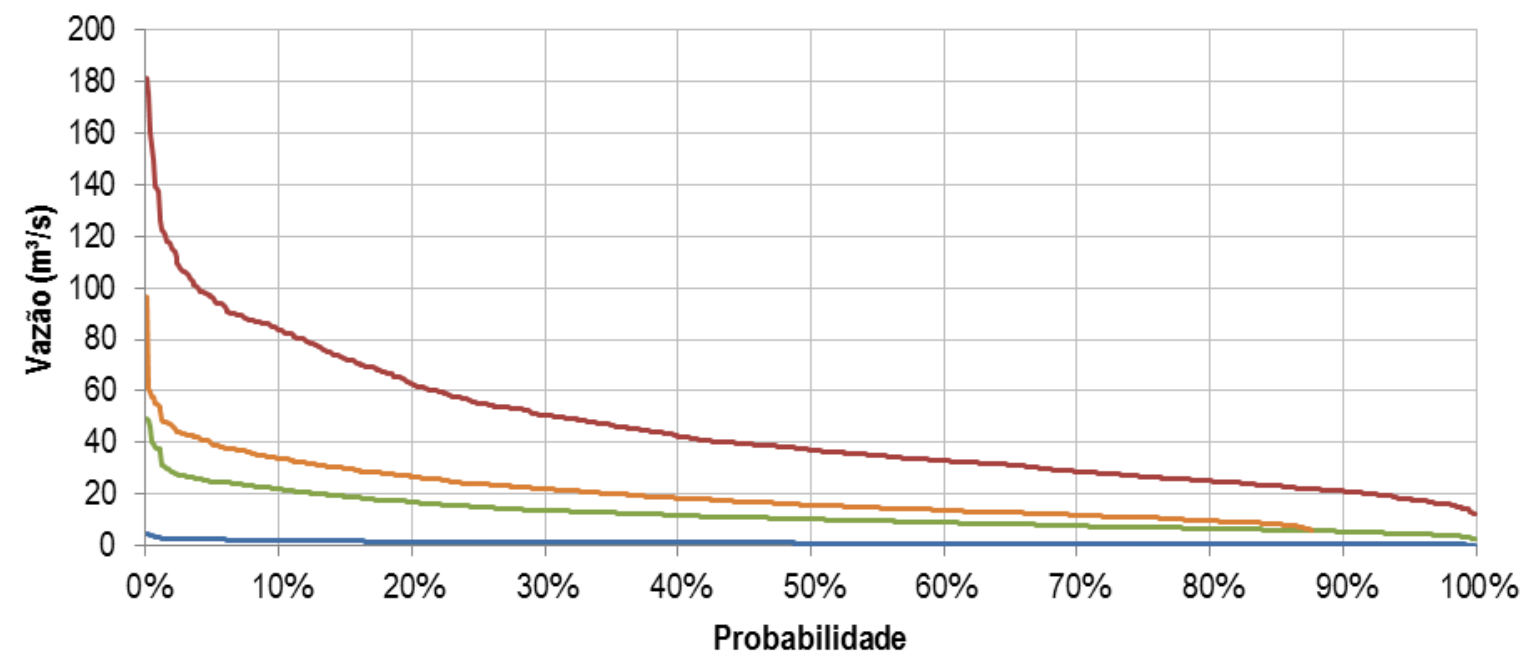

- Alto Cotia —Cantareira - Guarapiranga - Alto Tietê

Figura 30 - Curva de permanência dos sistemas de abastecimento da RMSP. 
A partir dos dados observados, foi possível de se analisar a relação a cada duas séries a partir do índice de correlação. A matriz contida na Tabela 6 contém as correlações mensais entre os Sistemas que compõem o sistema de adução da RMSP.

Tabela 6 - Matriz de correlação os componentes do Sistema Integrado da RMSP.

\begin{tabular}{lcccc}
\hline & Cantareira & Guarapiranga & Alto Tietê & Alto Cotia \\
\hline Cantareira & 1,00 & - & - & - \\
Guarapiranga & 0,78 & 1,00 & - & - \\
Alto Tietê & 0,79 & 0,78 & 1,00 & - \\
Alto Cotia & 0,77 & 0,92 & 0,76 & 1,00 \\
\hline
\end{tabular}

Nota-se que o comportamento das vazões é muito similar, dado que a correlação entre os locais é considerada alta.

Uma série temporal é estacionária quando ela se desenvolve aleatoriamente no tempo em torno de uma média constante, refletindo de alguma forma no equilibro estável. Presume-se que a correlação entre pontos adjacentes no tempo são definidos a partir de uma dependência do valor atual dos valores passados.

Na sequência está apresentada a análise realizada para a série histórica de vazões afluentes ao Guarapiranga. Na Figura 31 está apresentada a série temporal de vazão e na Figura 32 está contida a curva de permanência referente à mesma série.

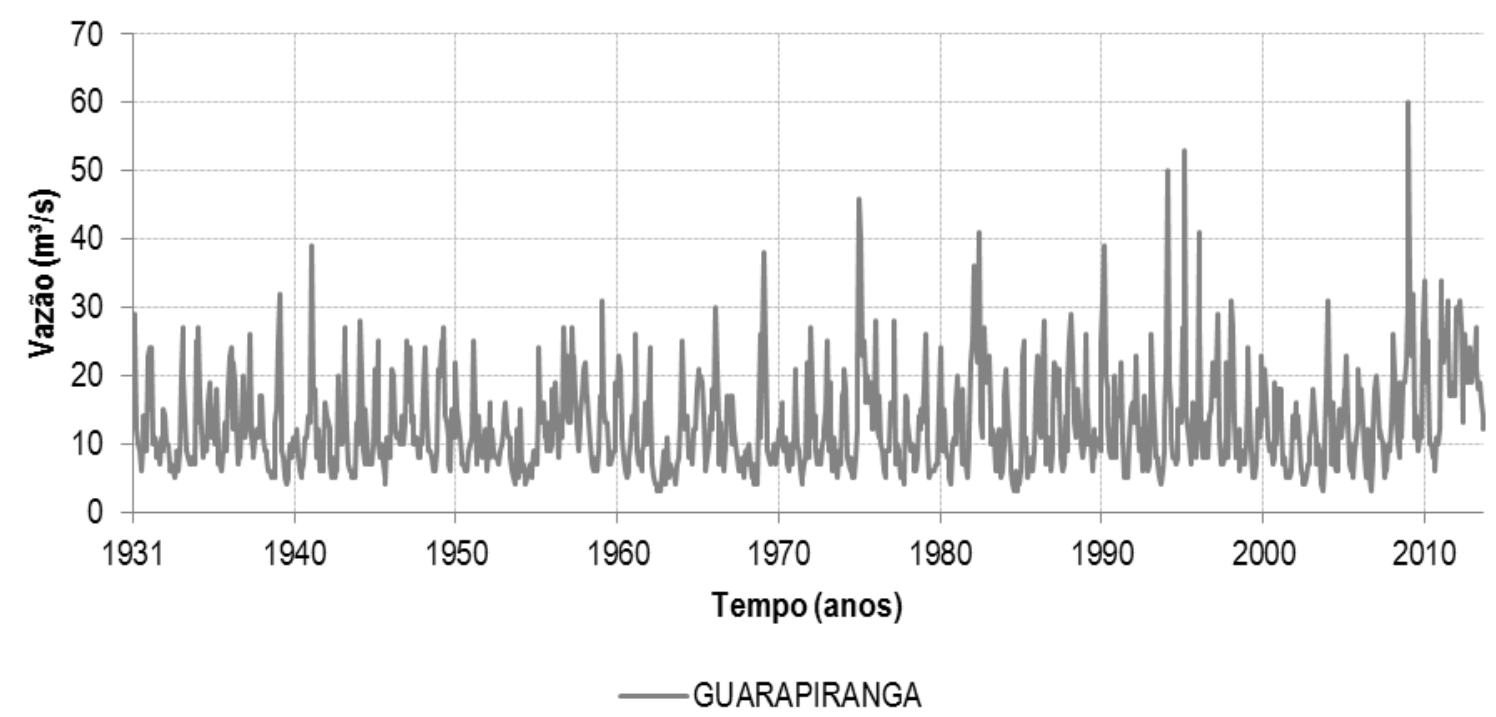

Figura 31 - Série de vazões afluentes à represa de Guarapiranga. 


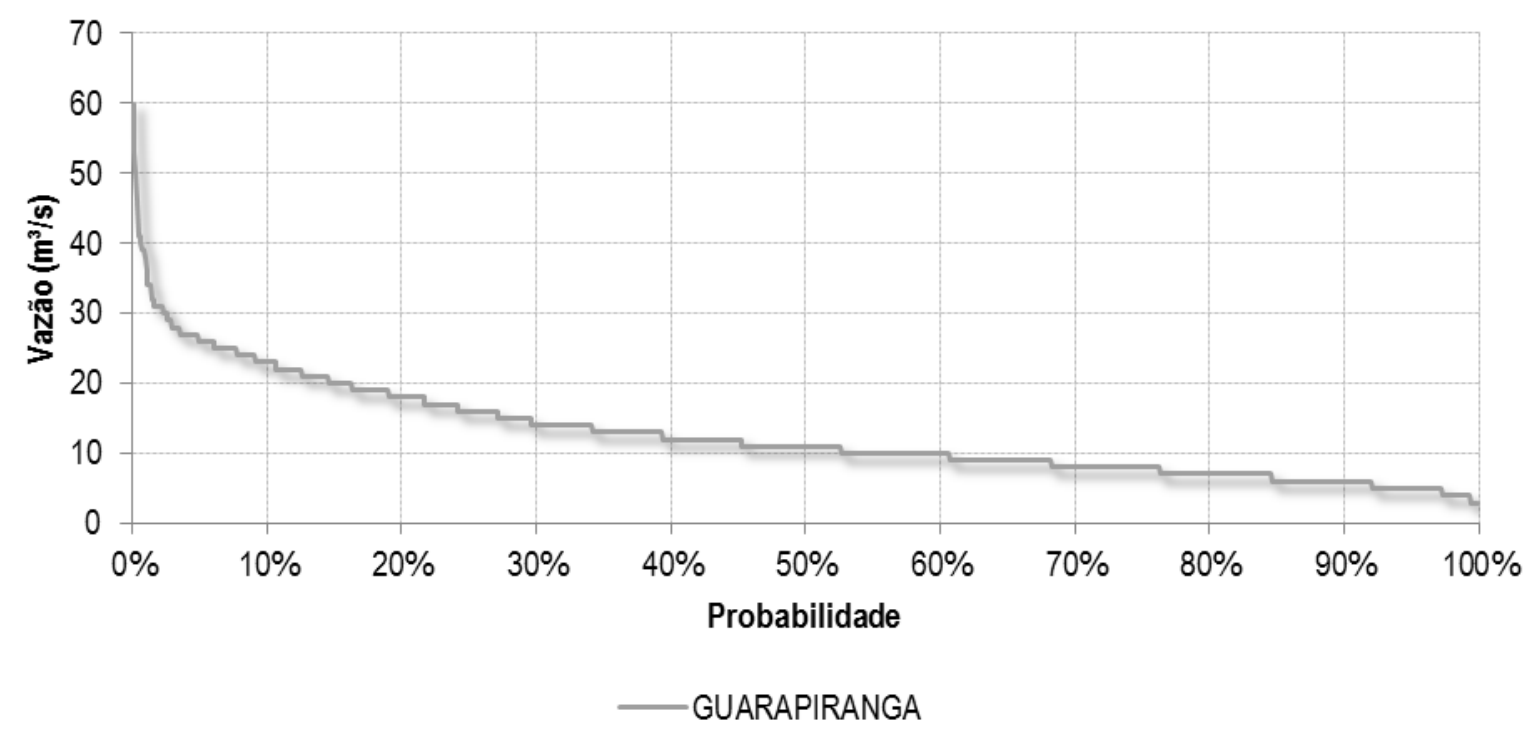

Figura 32 - Curva de permanência de Guarapiranga.

A partir dos dados de vazão, foi calculada a autocorrelação da série mensal com a defasagem k no tempo. A Figura 33 contém o gráfico de autocorrelação da série e nele nota-se um comportamento senoidal com a periodicidade de 12 meses. A partir disso pode-se aferir tal comportamento se dá devido à sazonalidade.

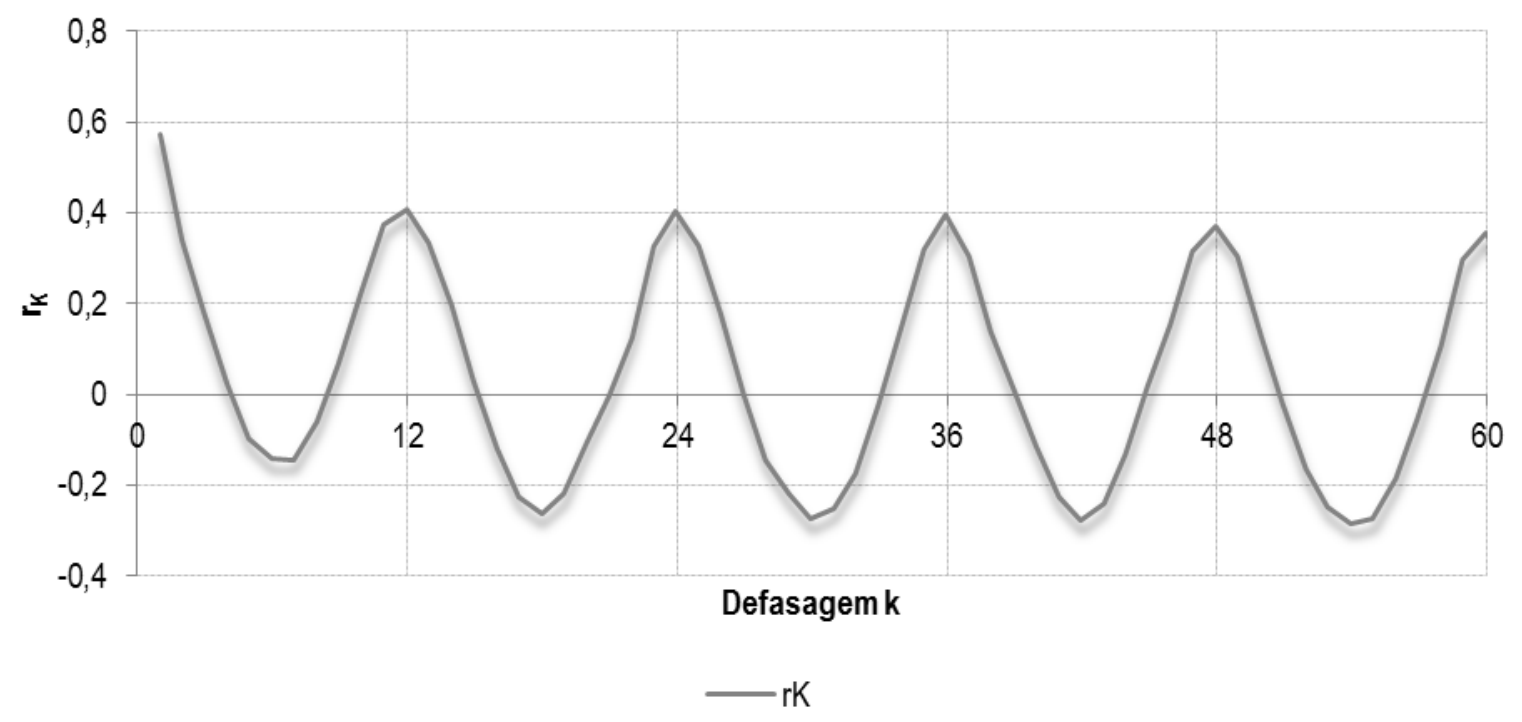

Figura 33 - Gráfico de autocorrelação da série de Guarapiranga.

A padronização dos dados foi realizada com a finalidade de se remover a sazonalidade:

$$
z_{i, j}=\frac{x_{i, j}-\bar{x}_{i}}{s_{i}}
$$


Onde $\mathrm{Z}_{\mathrm{i}, \mathrm{j}}=$ Variável padronizada; $\mathrm{i}=$ mês; $\mathrm{j}=$ ano; $\mathrm{S}$ = Desvio padrão.

A média e os desvios padrões mensais estão apresentados na Figura 34.

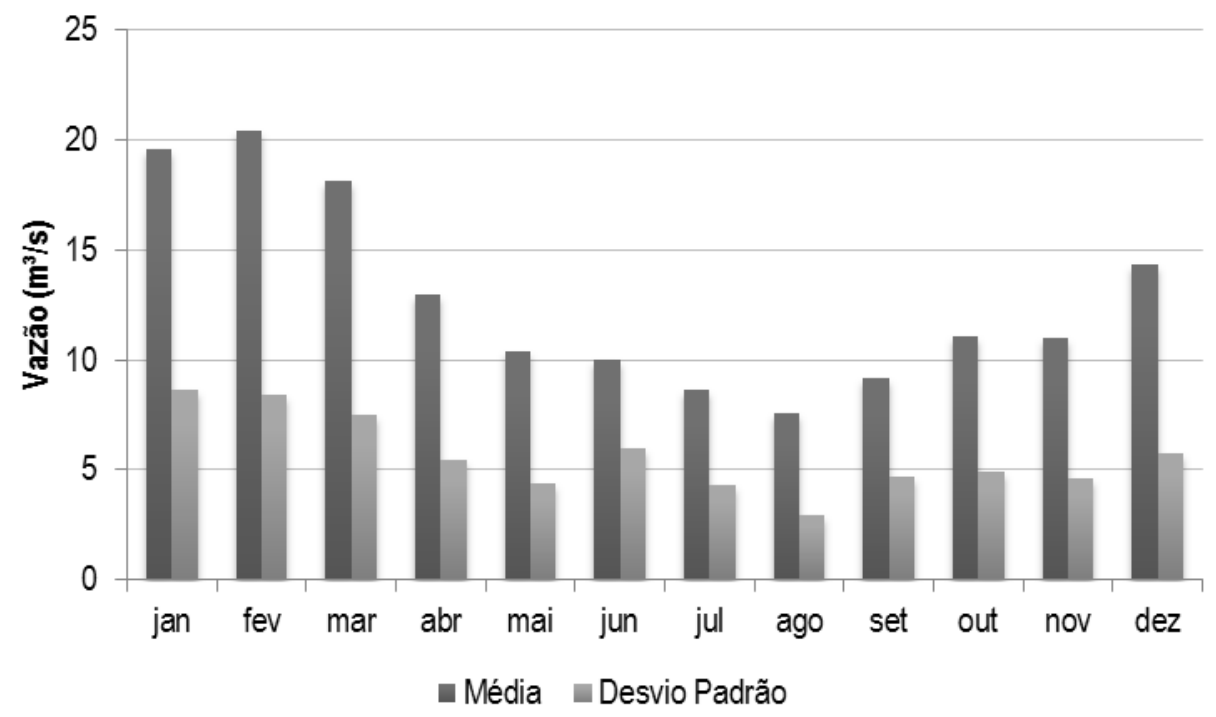

Figura 34 - Médias mensais e desvio padrão de Guarapiranga.

A série padronizada (Figura 35) e a seu respectivo gráfico de autocorrelação (Figura 36) estão apresentados na sequencia.

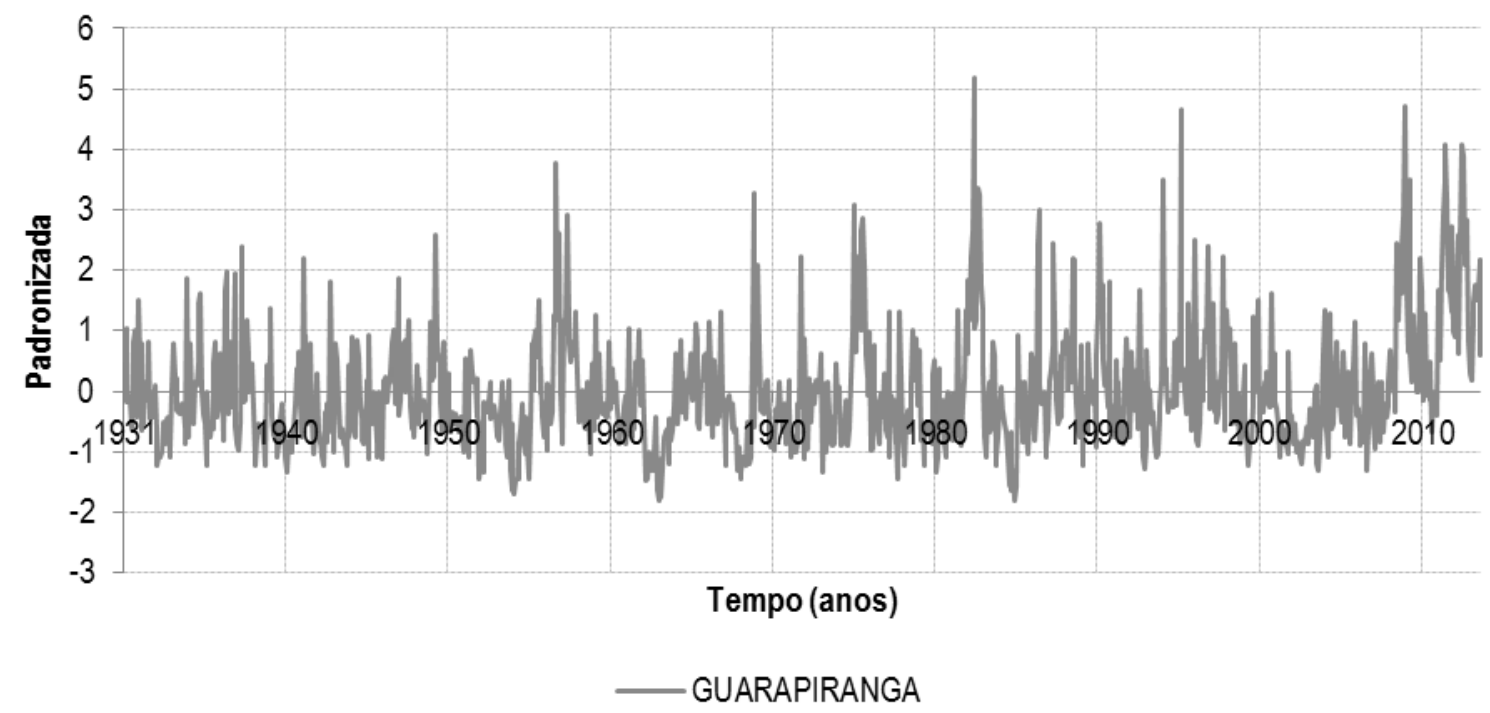

Figura 35 - Série de Guarapiranga após a aplicação da padronização. 


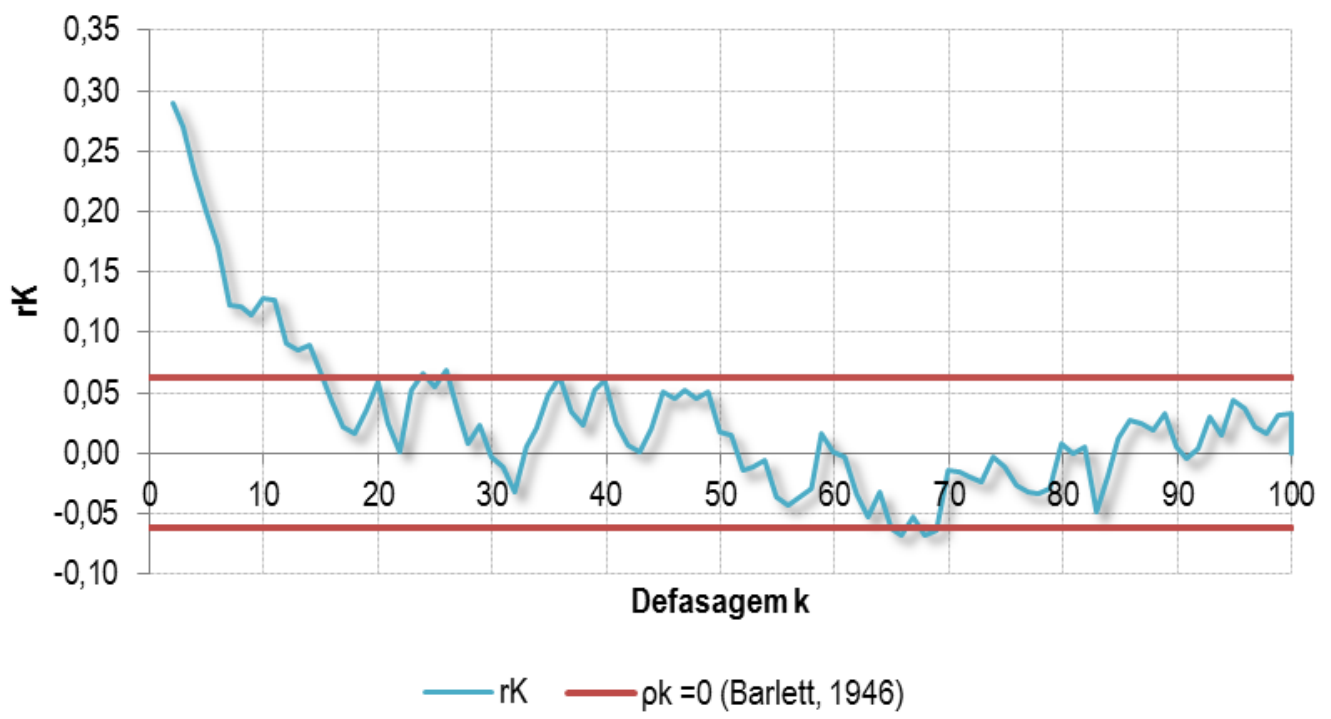

Figura 36 - Gráfico de Autocorrelação da série de Guarapiranga após a padronização.

Uma abordagem desenvolve uma classe sistemática de modelos auto-regressivos de média móvel ARIMA (autoregressive integrated moving average) (BOX; JENKINS, 1970 apud SHUMWAY, 2006), que são capazes de descrever séries estacionárias e não estacionárias, sem comportamento explosivo.

\subsection{Dados de entrada do modelo}

O modelo foi processado considerando 120 intervalos de tempo mensais repetindo as vazões do histórico de 1953 e 1954 e com horizonte de planejamento de 10 anos e os valores iniciais de volume nos reservatórios foram de 1 de setembro de 2015, divulgados pela Sabesp ${ }^{3}$. Os valores de volumes armazenados por data são dados pela porcentagem do volume útil. Este período foi utilizado por estar disponíel no momento da pesquisa, porém é importante salientar que o período de 2014-2015 foi mais crítico.

O volume útil dos reservatórios do Sistema Cantareira considerado foi de $1.264,80 \mathrm{hm}^{3}$ que é composto pelos reservatórios de Jaguari/Jacareí $\left(986,91 \mathrm{hm}^{3}\right)$, Cachoeira $\left(69,65 \mathrm{hm}^{3}\right)$, Atibainha $\left(200,63 \mathrm{hm}^{3}\right)$ e Paiva Castro $\left(7,61 \mathrm{hm}^{3}\right)$. Os valores

\footnotetext{
${ }^{3}$ Sabesp: Situação dos Mananciais. Disponível em <http://www2.sabesp.com.br/mananciais/DivulgacaoSiteSabesp.aspx> Acesso em 01 de setembro de 2015.
} 
foram obtidos do Boletim Diário ANA/DAEE de monitoramento do Sistema Cantareira (do dia 01 de setembro de 2015) referente ao volume total disponível por bombeamento. O volume disponível pelo bombeamento foi considerado neste caso, ao passo que o nível inicial considerado no modelo encontra-se abaixo do nível que permite a captação por gravidade. O nível mínimo operacional é correspondente ai volume de $227,65 \mathrm{hm}^{3}$ e o volume máximo operacional varia mensalmente, ao considerar os volumes de espera (Tabela 7).

Tabela 7- Volume máximo operacional permitido por mês nos reservatórios do Sistema Cantareira.

\begin{tabular}{ccc}
\hline Mês & $\begin{array}{c}\text { Volume } \\
\left(\mathrm{hm}^{3}\right)\end{array}$ & $\begin{array}{c}\text { Volume } \\
\text { Útil }(\%)\end{array}$ \\
\hline JAN & 1335,45 & $88 \%$ \\
FEV & 1335,45 & $88 \%$ \\
MAR & 1413,45 & $94 \%$ \\
ABR & 1492,45 & $100 \%$ \\
MAI & 1492,45 & $100 \%$ \\
JUN & 1492,45 & $100 \%$ \\
JUL & 1492,45 & $100 \%$ \\
AGO & 1492,45 & $100 \%$ \\
SET & 1492,45 & $100 \%$ \\
OUT & 1492,45 & $100 \%$ \\
NOV & 1492,45 & $100 \%$ \\
DEZ & 1335,45 & $88 \%$ \\
\hline
\end{tabular}

No reservatório de Guarapiranga os níveis máximos estabelecidos foram baseados nos limites de segurança para controle de cheia, apresentados na Filosofia de Operação da EMAE (Empresa Metropolitana de Águas e Energia S.A.) apresentados no Terceiro Plano Diretor de Macrodrenagem da Bacia do Alto Tietê - PDMAT 3 (DAEE, 2012). Nas regras operacionais, os dados fornecidos são as cotas por mês e a porcentagem de volume permitido no reservatório. A relação entre os níveis e os volumes e porcentagens do volume totais foram obtidos a partir da curva Cota $x$ Volume disponibilizada pelo ONS $^{4}$ (Figura 37 ). As informações de limites de segurança para nível, porcentagem do volume e volume estão contidos na Tabela 8 apresentada na sequência.

4 ONS: Inventário de dados técnicos de aproveitamentos hidroelétricos. Disponível em $<$ http://www.ons.org.br/operacao/hidrologia.aspx> Acesso em 16 de setembro de 2015. 


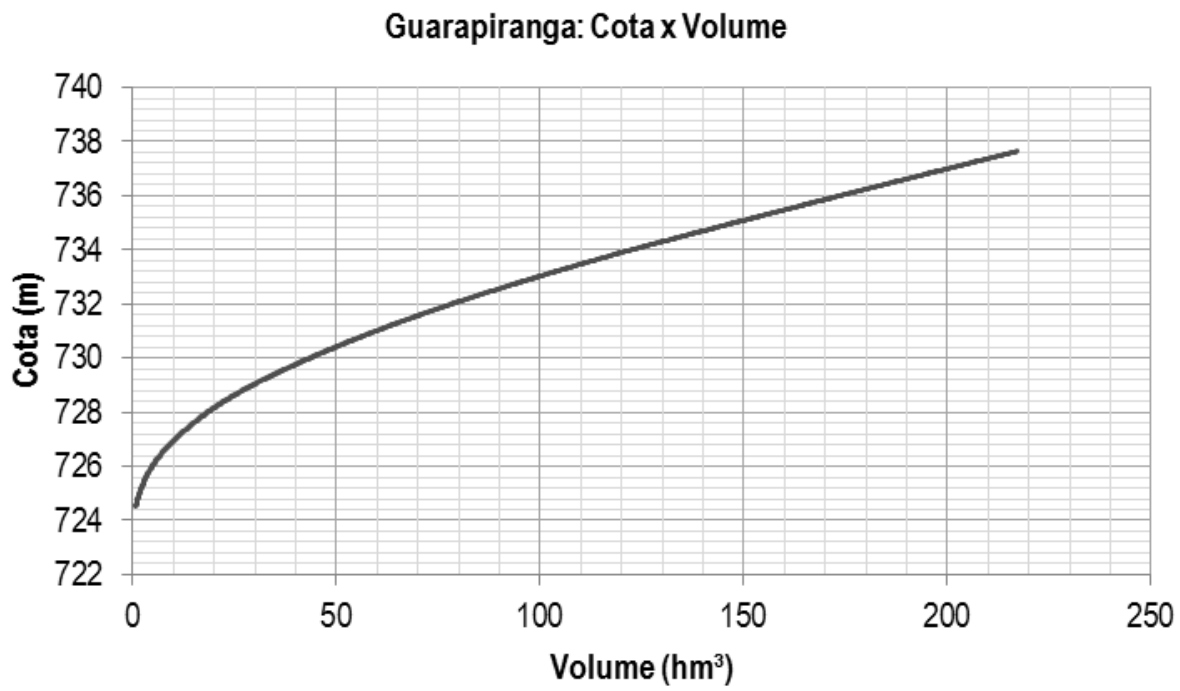

Figura 37-Relação Cota x Volume

Tabela 8 - Volume máximo operacional permitido por mês no reservatório de Guarapiranga.

\begin{tabular}{cccc}
\hline Mês & Cota $(\mathrm{m})$ & Volume $(\%)$ & Volume $\left(\mathrm{hm}^{3}\right)$ \\
\hline JAN & 734,95 a 735,27 & 76,98 a 81,34 & 146.42 \\
FEV & 735,59 & 85,72 & 162.93 \\
MAR & 735,59 a 736,10 & 85,72 a 92,76 & 162.93 \\
ABR & 736,10 & 92,76 & 176.25 \\
MAI & 736,10 & 92,76 & 176.25 \\
JUN & 736,10 & 92,76 & 176.25 \\
JUL & 736,29 & 95,40 & 181.24 \\
AGO & 736,29 & 95,40 & 181.24 \\
SET & 736,29 & 95,40 & 181.24 \\
OUT & 736,29 & 95,40 & 181.24 \\
NOV & 736,23 & 94,56 & 179.66 \\
DEZ & 735,83 & 89,02 & 169.18 \\
\hline
\end{tabular}

Para os reservatórios de Alto Tietê, Rio Grande, Alto Cotia e Rio Claro as informações de volume útil foram obtidas do Boletim dos Mananciais, que apresenta as condições de armazenamento dos mananciais que abastecem a RMSP. O boletim utilizado foi 0 de 1 de setembro de 2015. Os reservatórios do Sistema Produtor Alto Tietê são: Ponte Nova $\left(329,37 \mathrm{hm}^{3}\right)$, Paraitinga $\left(36,73 \mathrm{hm}^{3}\right)$, Biritiba $\left(48,42 \mathrm{hm}^{3}\right)$, Jundiaí $\left(74,09 \mathrm{hm}^{3}\right) \mathrm{e}$ Taiaçupeba $\left(85,20 \mathrm{hm}^{3}\right)$ que totalizam um volume útil de $573,81 \mathrm{hm}^{3}$.

De forma resumida, na Tabela 9, estão apresentados os dados de volume inseridos no modelo SISAGUA. 
Tabela 9 - Capacidade de produção, volumes útil, mínimo operativo, máximo operativo e inicial utilizados como dado de entrada no modelo SISAGUA.

\begin{tabular}{lccccc}
\hline Reservatórios & $\begin{array}{c}\text { Vazão- } \\
\text { Capacidade } \\
\text { Nominal }\left(\mathrm{m}^{3} / \mathrm{s}\right)\end{array}$ & $\begin{array}{c}\text { Volume útil } \\
\left(\mathrm{hm}^{3}\right)\end{array}$ & $\begin{array}{c}\text { Volume } \\
\text { Mínimo }\left(\mathrm{hm}^{3}\right)\end{array}$ & $\begin{array}{c}\text { Volume } \\
\text { Máximo }\left(\mathrm{hm}^{3}\right)\end{array}$ & $\begin{array}{c}\text { Volume Inicial - } \\
01 / 09 / 2015 \\
\left(\mathrm{hm}^{3}\right)\end{array}$ \\
\hline Cantareira & 33,0 & 1264,80 & 227,65 & 1492.45 & 378,72 \\
Alto Tietê & 15,0 & 573,81 & 68,98 & 642.79 & 147,59 \\
Guarapiranga & 16,0 & 181,24 & 0,00 & 181.24 & 115,90 \\
Rio Grande & 5,5 & 112,80 & 0,00 & 112.80 & 90,98 \\
Alto Cotia & 1,2 & 16,51 & 0,00 & 16.51 & 8,80 \\
Rio Claro & 3,8 & 13,67 & 0,00 & 13.67 & 8,04 \\
\hline
\end{tabular}

\subsection{Evaporação}

No modelo foi considerada a evaporação nos maiores sistemas de reservatórios (Cantareira, Guarapiranga e Alto Tietê), com a finalidade de se determinar a sua significância em reservatórios da Região Metropolitana de São Paulo. Foram utilizadas as informações do ONS de evaporações líquidas nas usinas hidrelétricas (ONS, 2004).

A evaporação líquida é obtida a partir da diferença entre a evaporação real do reservatório e a evapotranspiração real da bacia hidrográfica no local do reservatório antes da sua implantação. Os resultados de evaporação líquida foram estimados a partir do programa SisEvapo para os aproveitamentos, tomando como referência normais climatológicas geradas a partir de estações meteorológicas.

Dos reservatórios estudados da RMSP somente o Reservatório Guarapiranga e o Reservatório Ponte Nova do Sistema Alto Tietê possuem valores de evaporação, portanto, os valores utilizados no presente estudo foram estimados pela proximidade. 
Tabela 10 - Valores de evaporação líquida $(\mathrm{mm})$.

\begin{tabular}{cccc}
\hline Reservatórios & Cantareira & Alto Tietê & Guarapiranga \\
\hline mês $\backslash$ estação ONS & Jaguari & Ponte Nova & Guarapiranga \\
JAN & 9 & 4 & 12 \\
FEV & 17 & 11 & 14 \\
MAR & 29 & 34 & 34 \\
ABR & 43 & 47 & 38 \\
MAl & 52 & 49 & 40 \\
JUN & 52 & 45 & 35 \\
JUL & 40 & 27 & 25 \\
AGO & 28 & 17 & 26 \\
SET & 29 & 13 & 21 \\
OUT & 17 & 2 & 7 \\
NOV & 3 & -9 & 5 \\
DEZ & 12 & -1 & 22 \\
\hline
\end{tabular}

Para que o cálculo do volume evaporado fosse computado de acordo com o nível e a área do reservatório, foi preciso estabelecer a relação entre a área e volume a partir de um polinômio de terceiro grau.

\subsubsection{Sistema Cantareira - Área x Volume}

A partir dos dados de cota e volume, foram calculadas as áreas correspondentes a cada nível. Neste estudo adotou-se a simplificação de que todos os reservatórios do mesmo sistema operam com a mesma porcentagem de reservação, portanto foram representados em um único ponto. Para tal, a relação de área e volume foi calculada a partir de todos os reservatórios componentes. Nas Figura 38 a Figura 41 estão apresentadas as relações de área, volume e cota para os reservatórios de Jaguari e Jacareí, Cachoeira, Atibainha e Paiva Castro. 


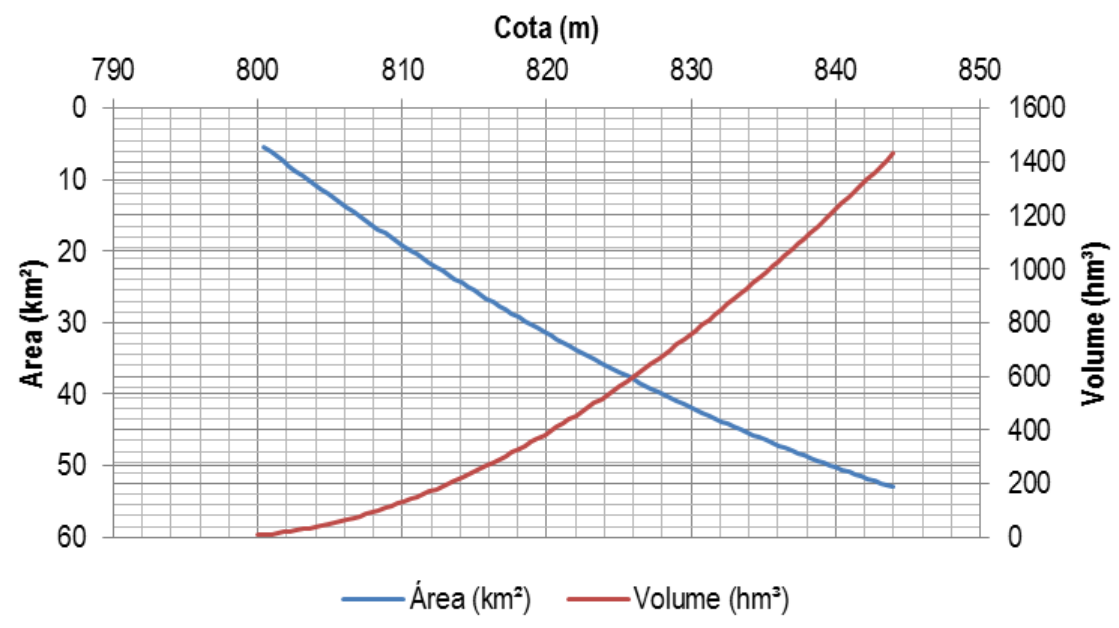

Figura 38 - Cota Área Volume - Jaguari / Jacareí

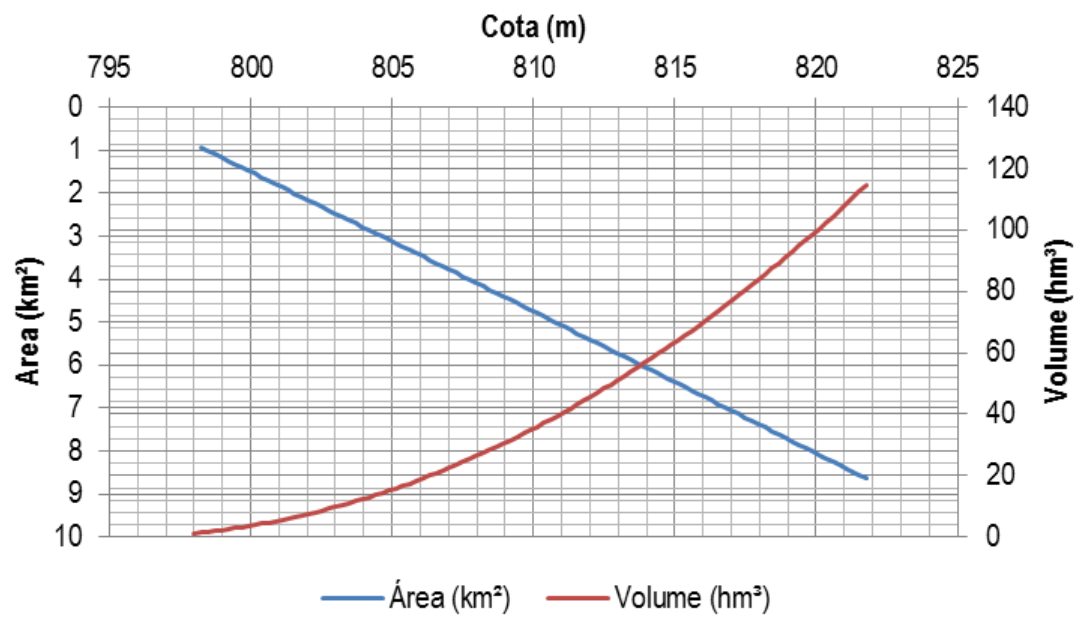

Figura 39 - Cota Área Volume - Cachoeira

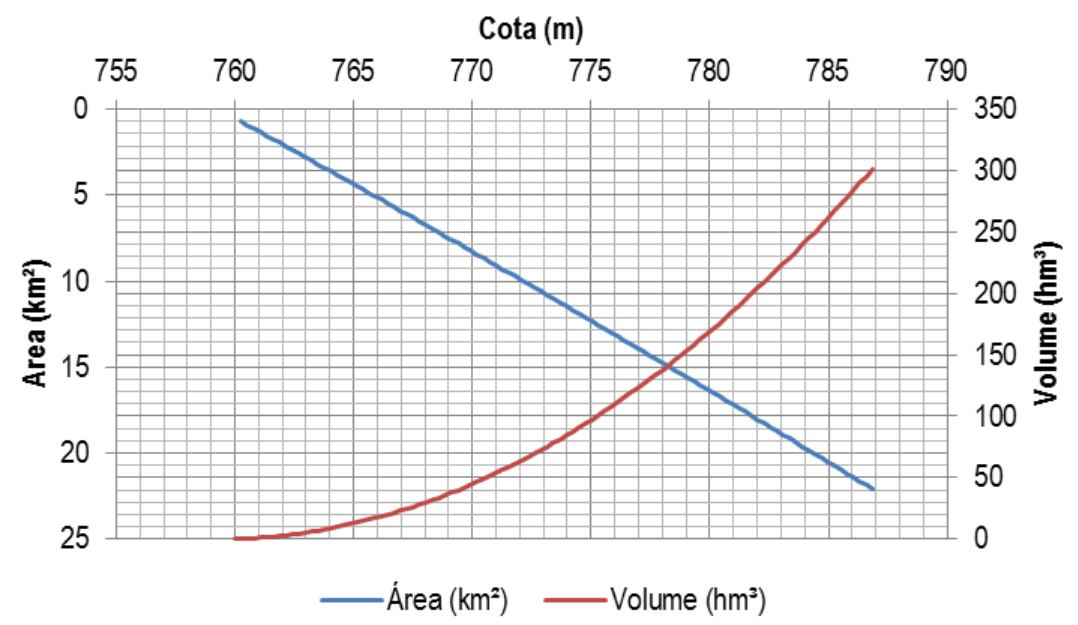

Figura 40 - Cota Área Volume - Atibainha 


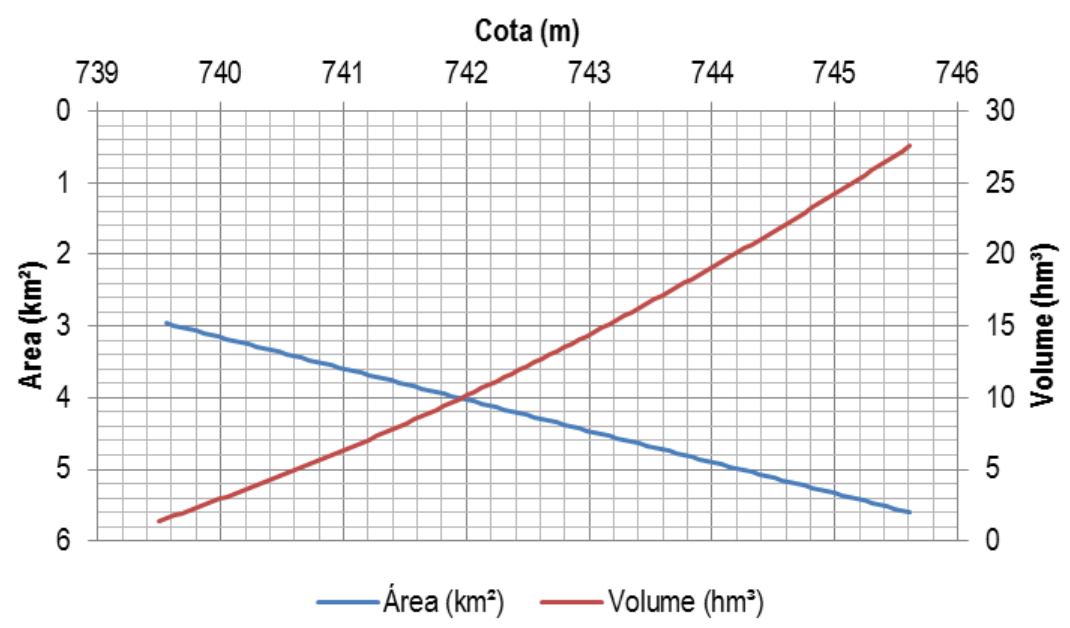

Figura 41 - Cota Área Volume - Paiva Castro

A partir dos valores de volume e área para cada cota, foi possível de se estabelecer a área correspondente a cada volume e tal relação foi aproximada por um polinômio de terceiro grau, conforme apresentado na Figura 42.

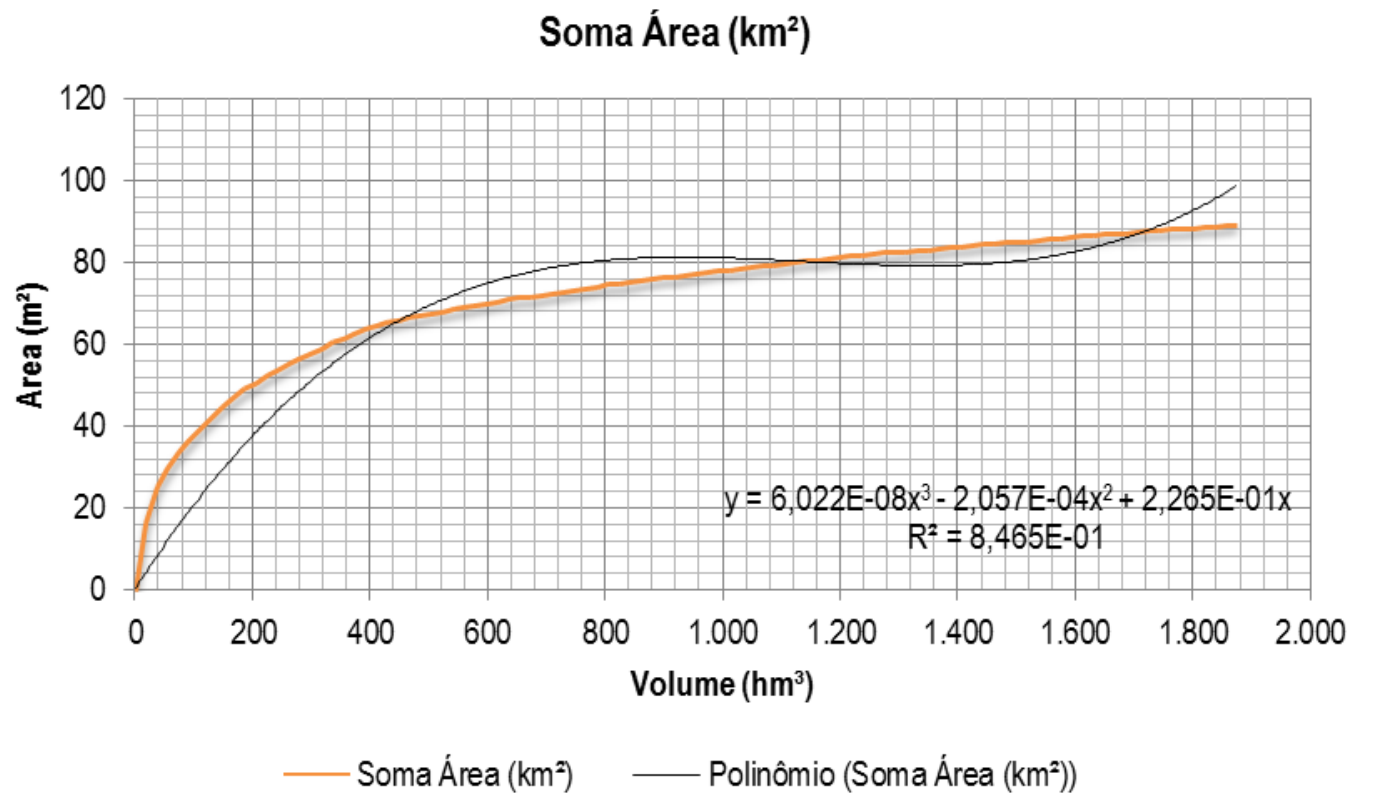

Figura 42 - Relação Área x Volume - Sistema Cantareira 


\subsubsection{Sistema Produtor Alto Tietê- Área x Volume}

A mesma abordagem foi realizada com os reservatórios do sistema produtor do Alto Tietê, composto pelos reservatórios de Paraitinga, Ponte Nova, Biritiba, Jundiaí e Taiaçupeba, representados pela Figura 43 até a Figura 47.

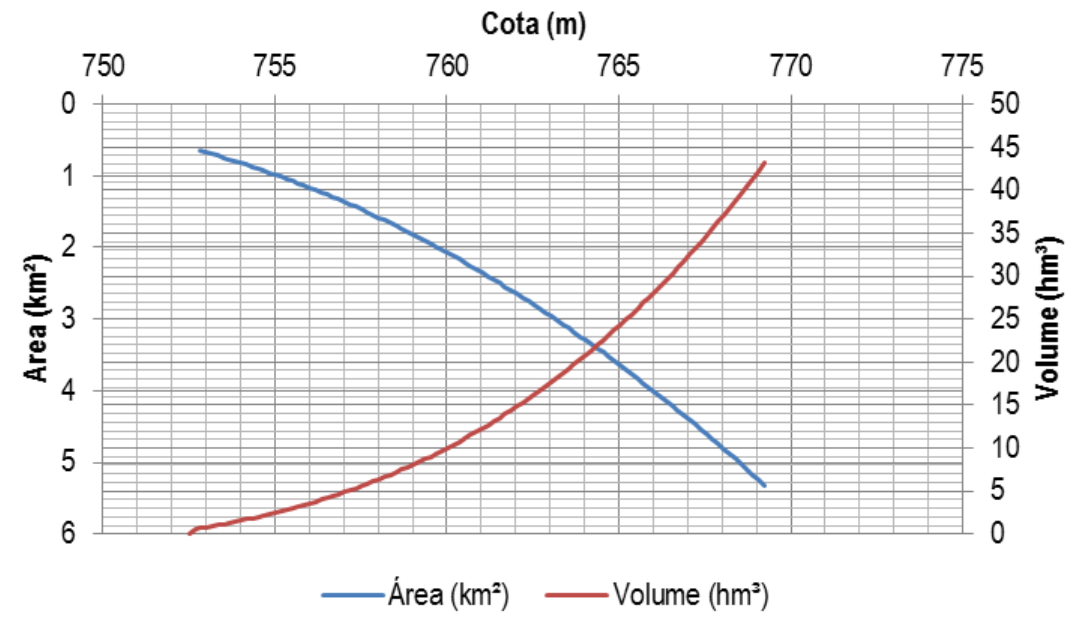

Figura 43-Relação Área x Volume - Paraitinga.

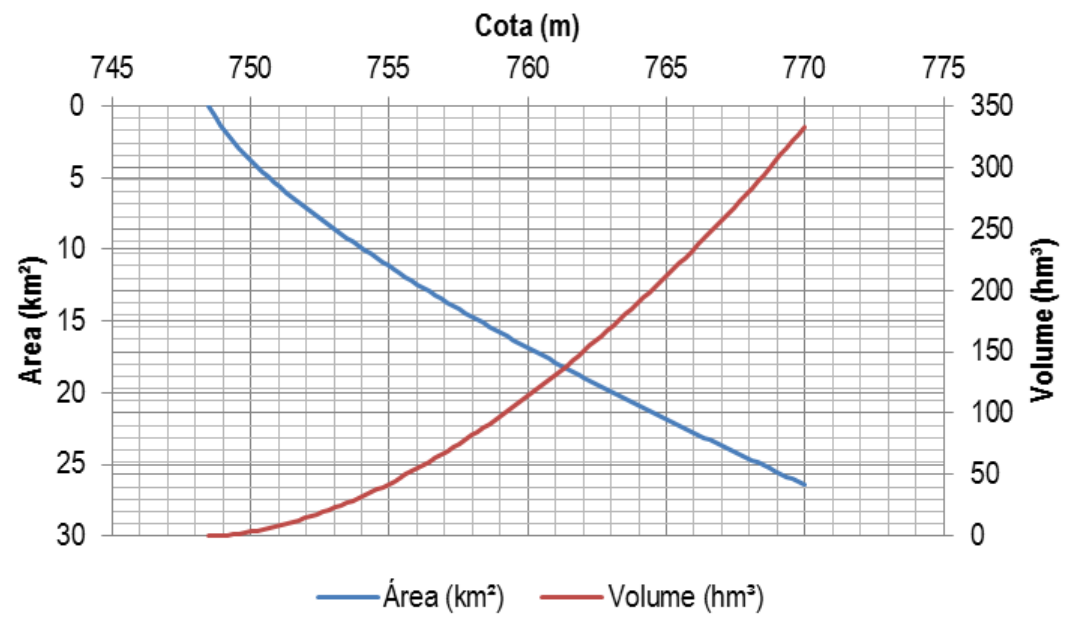

Figura 44 - Relação Área x Volume - Ponte Nova. 


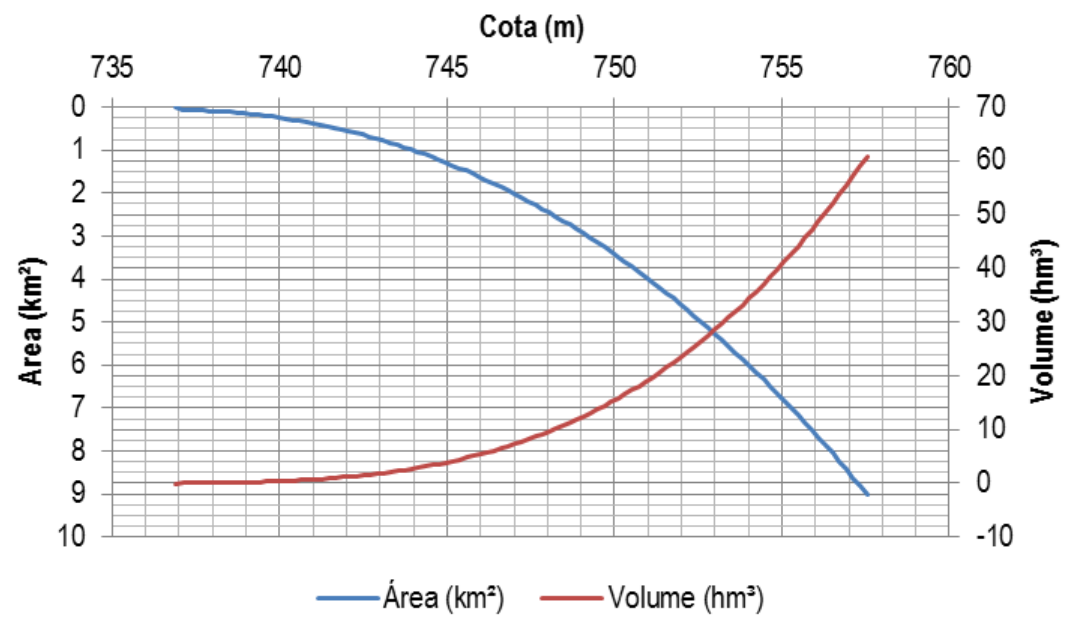

Figura 45-Relação Área x Volume - Biritiba.

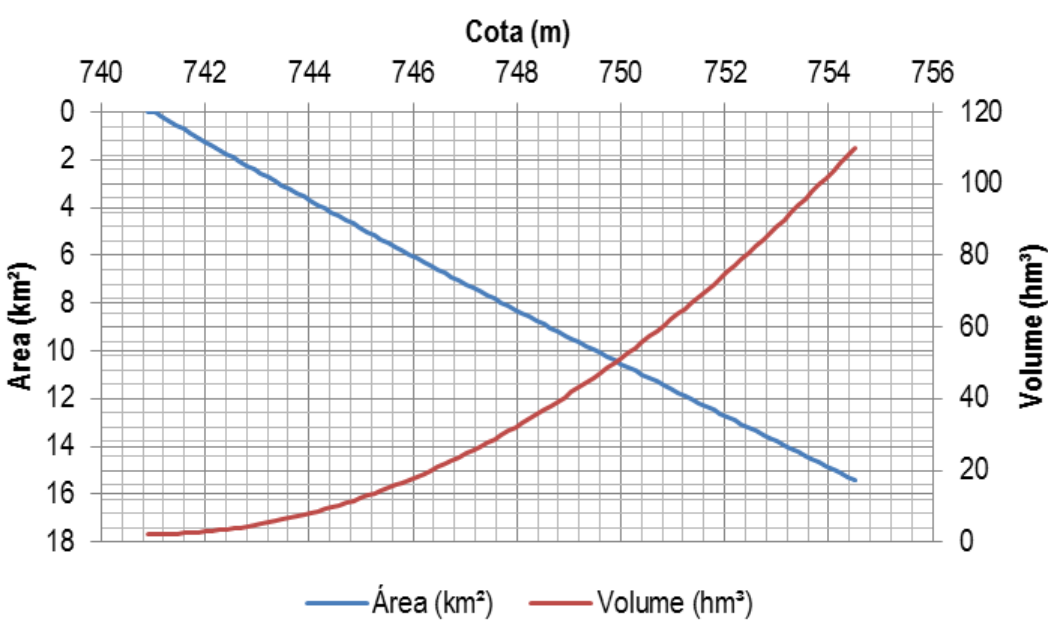

Figura 46 - Relação Área x Volume - Jundiaí.

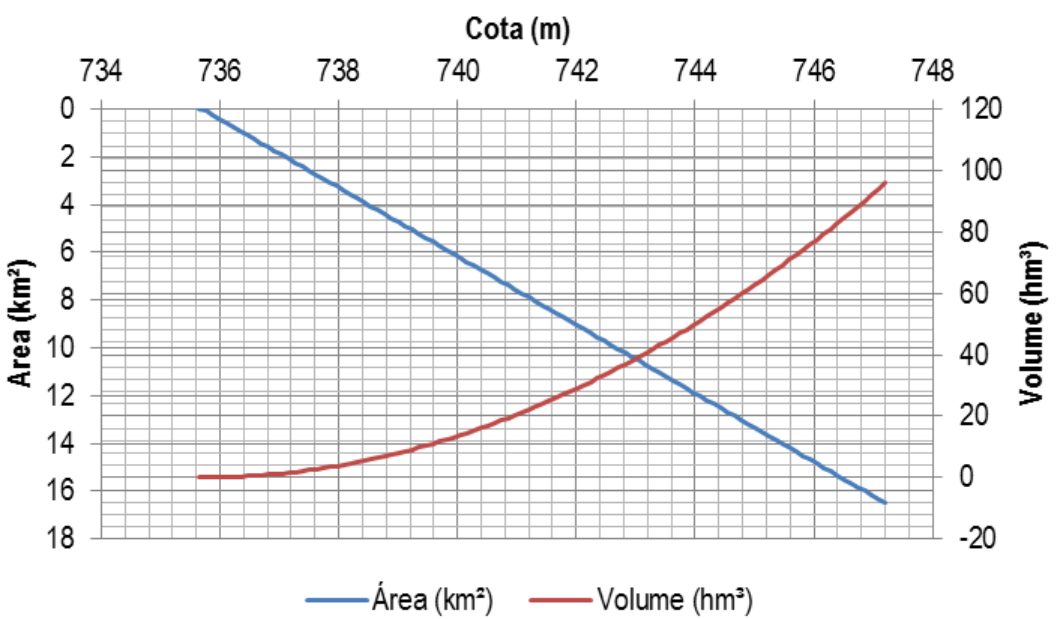

Figura 47-Relação Área x Volume - Taiaçupeba. 
Na Figura 48 está apresentada a relação entre a área e o volume e o polinômio de terceiro grau calculado a partir desta relação.

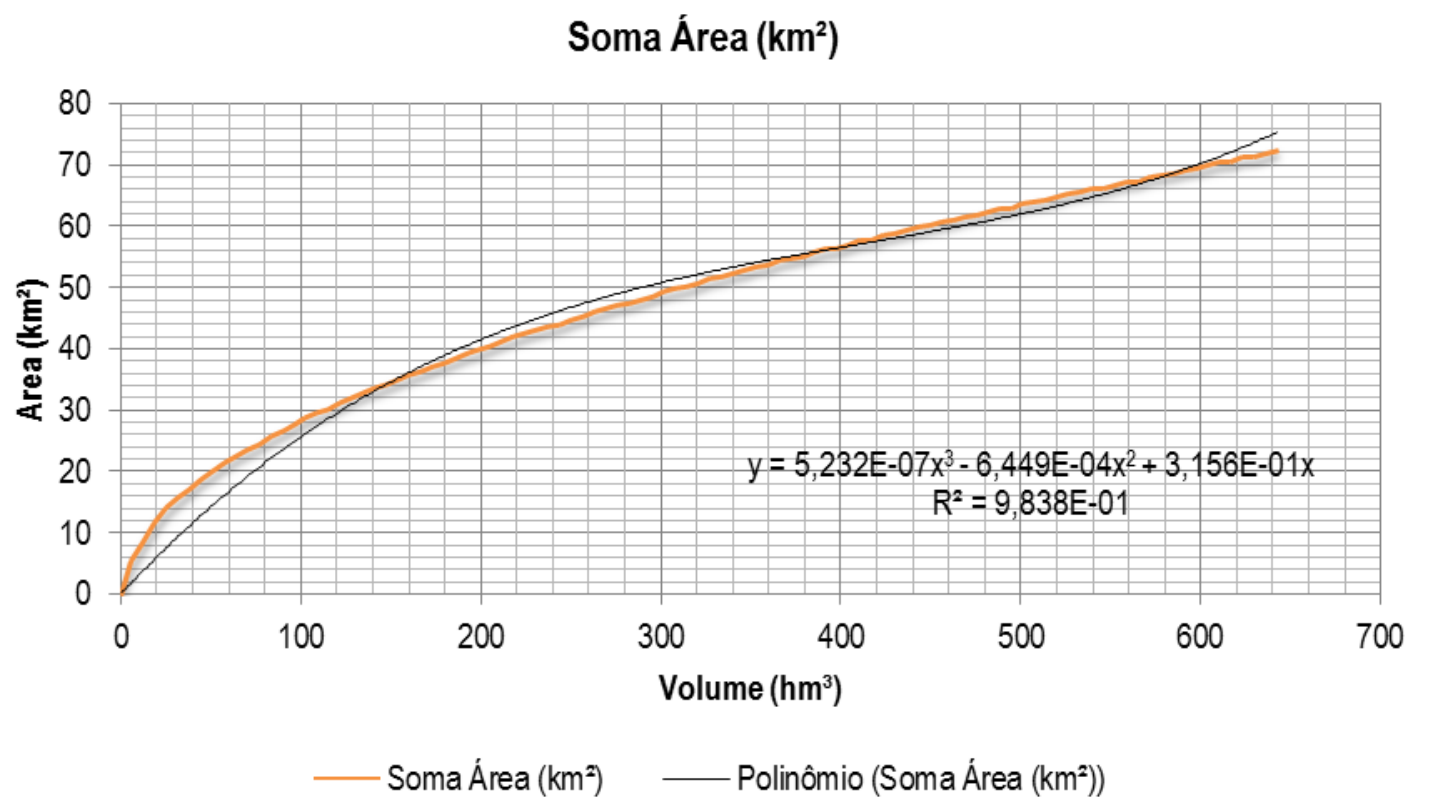

Figura 48 - Relação Área x Volume - Sistema Produtor Alto Tietê.

\subsubsection{Guarapiranga - Área x Volume}

Para o reservatório Guarapiranga os dados de cota e volume foram obtidos do Inventário de dados técnicos de aproveitamentos hidrelétricos do ONS. Na Figura 49 está apresentado o gráfico contendo informações de Volume e Área em função da Cota do reservatório e na Figura 50 a relação entre área e volume, e o polinômio de terceiro grau. 


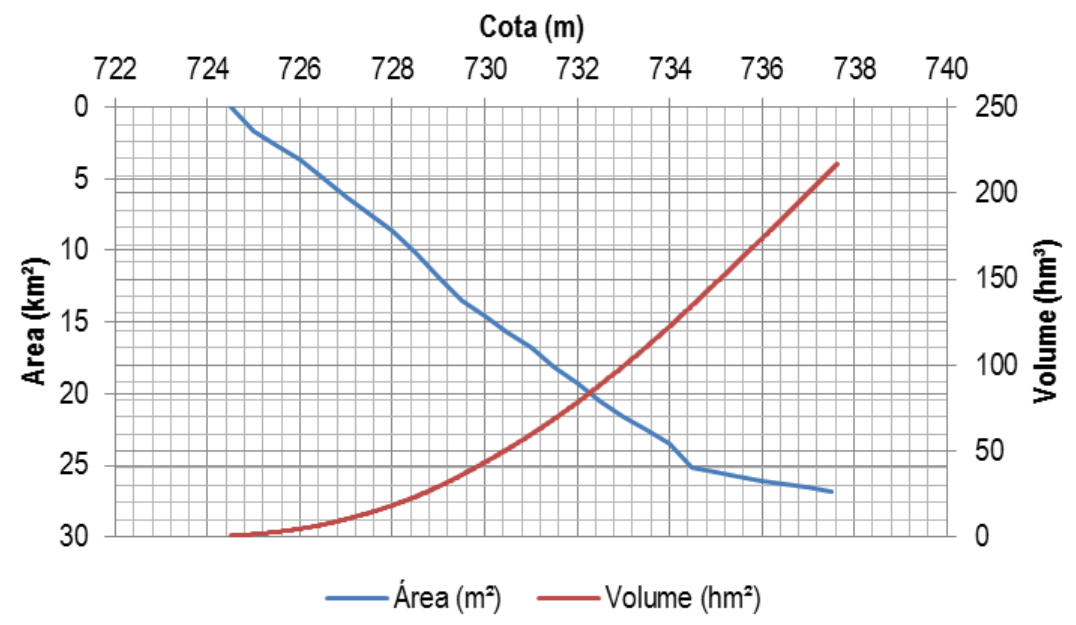

Figura 49 - Relação Área x Volume - Guarapiranga.

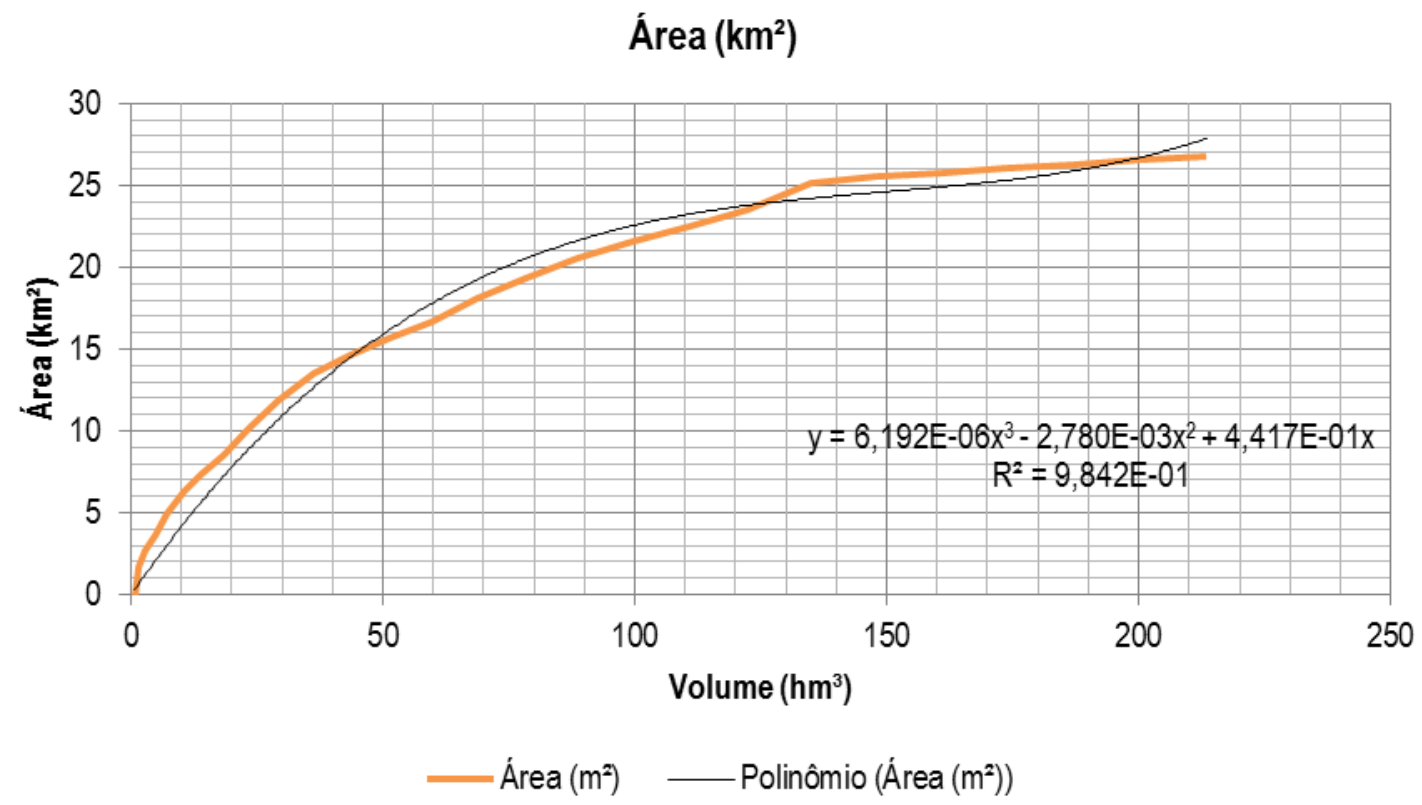

Figura 50 - Relação Área x Volume - Guarapiranga. 


\section{RESULTADOS}

\subsection{Regra de racionamento utilizando função contínua}

Um dos objetivos do estudo foi a aplicação da regra de racionamento contínua do sistema de abastecimento da Região Metropolitana de São Paulo, com função linear de redução no lugar de patamares fixos. Em estudos anteriores de estudos de casos aplicados no modelo SISAGUA, o racionamento se dava em forma progressiva, porém por patamares (Figura 51).
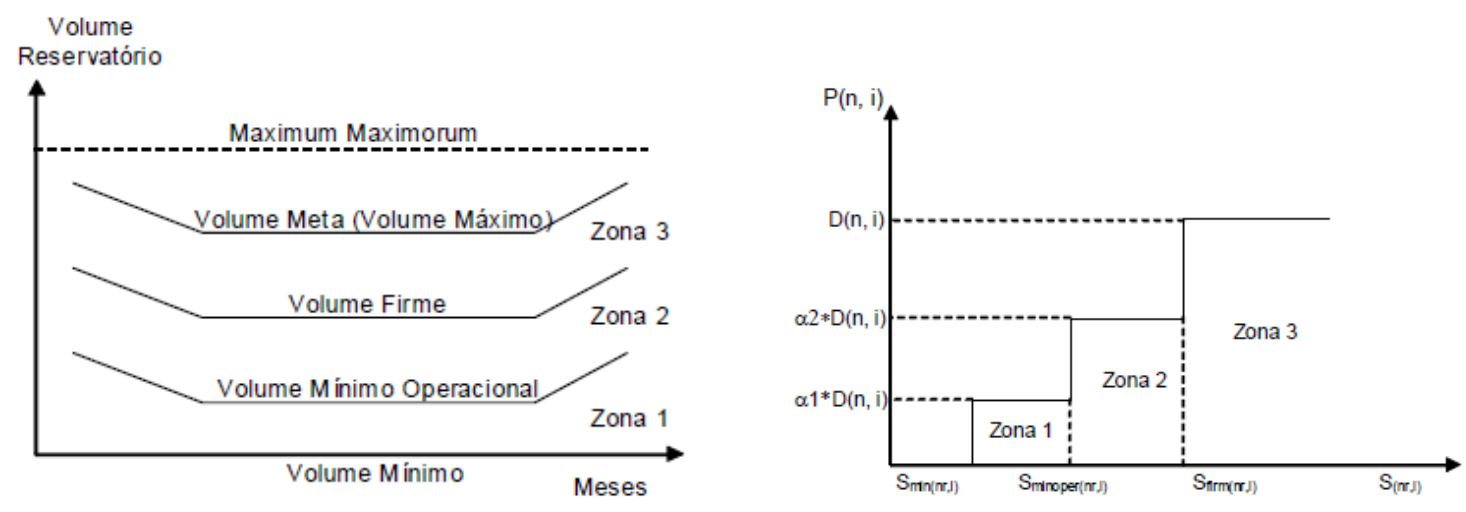

Figura 51 - Curvas operacionais e regras de racionamento - Funções em escada.

$\mathrm{Na}$ abordagem do racionamento utilizando a função contínua, a variação do racionamento se dá de forma linear de acordo com a variação do nível do reservatório, sendo que quanto mais baixos os níveis dos reservatórios, maiores os níveis de racionamento.

Os valores de vazão mínima $\left(Q_{0 \%}\right)$ e máxima $\left(Q_{100 \%}\right)$ determinam a curva de operação (vazão retirada x nível d'água), referentes aos níveis mínimo e máximo do volume do reservatório, respectivamente. O valor máximo $\left(Q_{100 \%}\right)$, porém, neste caso, tem a função de determinar a inclinação da curva, sendo que durante a operação, o teto adotado é o limite de capacidade de produção ou atendimento à demanda, conforme pode ser visualizado na Figura 52. 


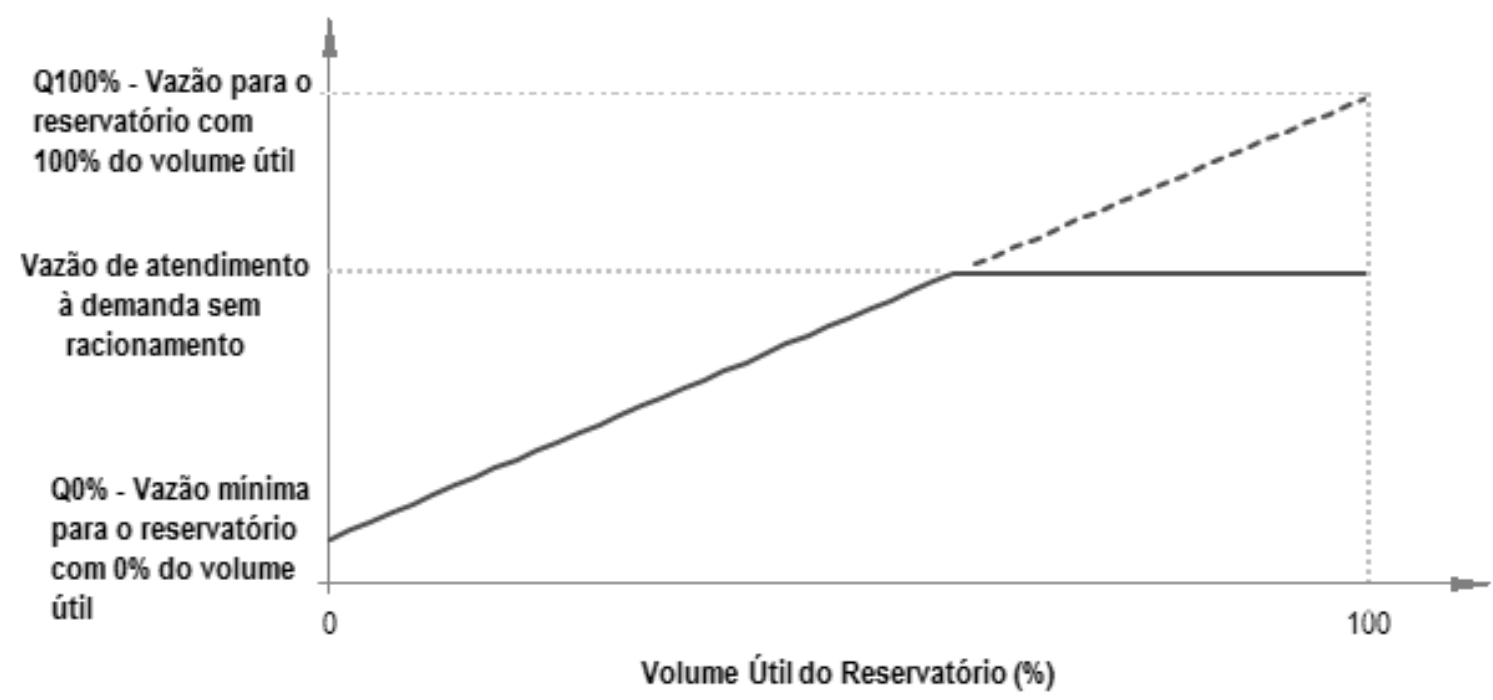

Figura 52 - Curvas operacionais e regras de racionamento - Função contínua.

Primeiramente, o racionamento contínuo foi aplicado nos principais reservatórios de forma isolada com a demanda fixada na capacidade nominal produtiva. Os resultados para os reservatórios da Cantareira, Guarapiranga e Alto Tietê estão apresentados nos itens 6.1.1 a 6.1.3. Na sequência, o racionamento foi aplicado a todos os sistemas de forma integrada, com a mesma proporcionalidade de racionamento aplicada a cada sistema, de acordo com a capacidade produtiva.

\subsubsection{Sistema Cantareira - Racionamento Linear}

O racionamento linear adotado visa 0 atendimento à demanda de $33 \mathrm{~m} / \mathrm{s}$ para a Região Metropolitana de São Paulo e de $3 \mathrm{~m}^{3} / \mathrm{s}$ para as Bacias dos Rios PCJ. O volume inicial do reservatório foi de $378,72 \mathrm{hm}^{3}$, sendo que o volume mínimo de operação é de $227,65 \mathrm{hm}^{3}$. Com a finalidade de se testar a sensibilidade do sistema em função da variação dos índices de racionamento foram testadas diferentes vazões mínimas e máximas para quando o reservatório contendo 0\% e 100\% de seu volume armazenado. Na Figura 53 e na Figura 54 estão apresentados os resultados de volume armazenado e de vazão retirada para atendimento da demanda, para um racionamento severo, que libera $0 \mathrm{~m}^{3} / \mathrm{s}$ quando o reservatório encontra-se com $0 \%$ do volume disponível. A vazão máxima para quando o reservatório contém $100 \%$ de seu volume armazenado foi variada em valores até que o comportamento seja semelhante à operação sem racionamento. 


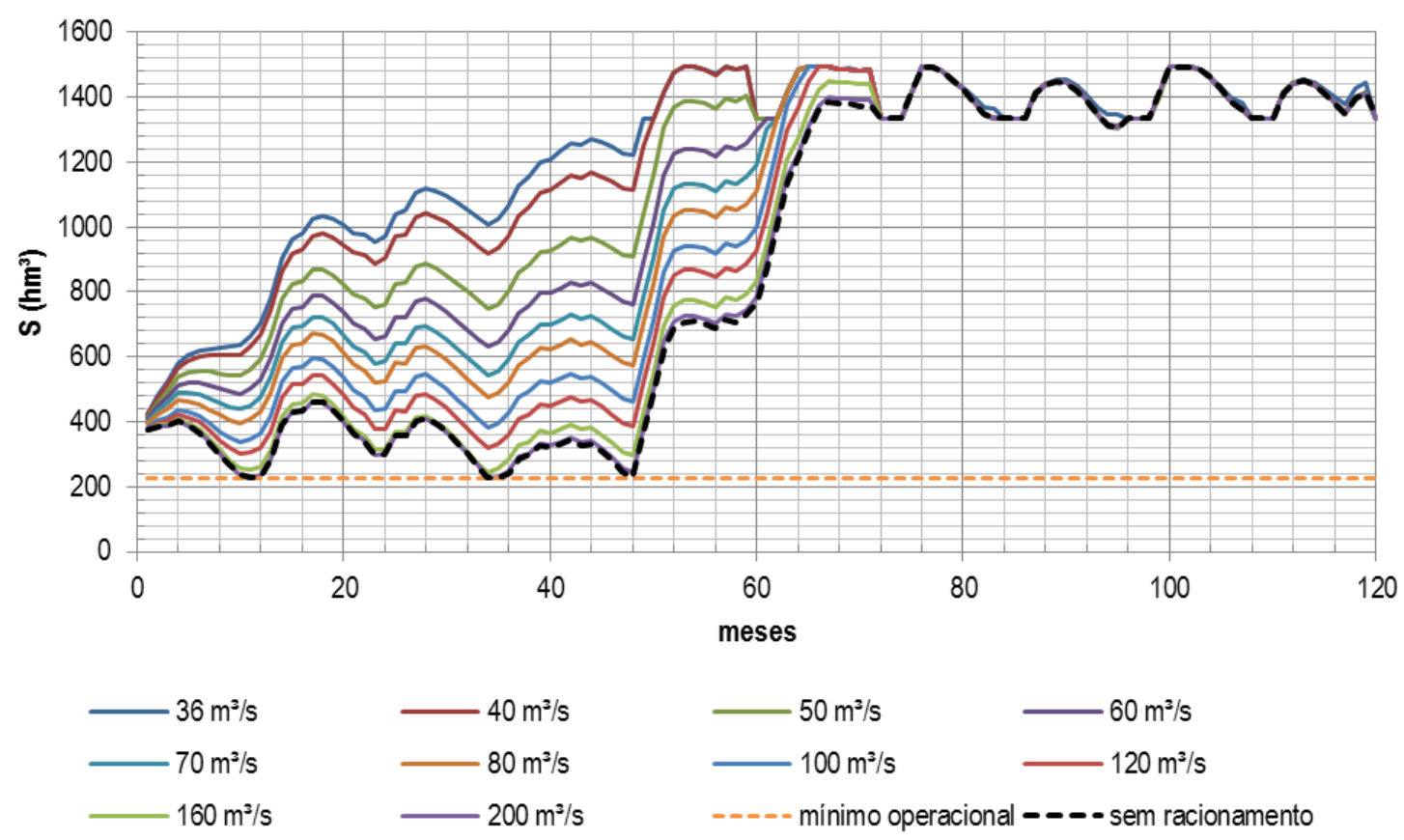

Figura 53 - Racionamento - Função Contínua - Cantareira - $Q_{0 \%}=0 \mathrm{~m}^{3} / \mathrm{s}-$ Volume reservado.

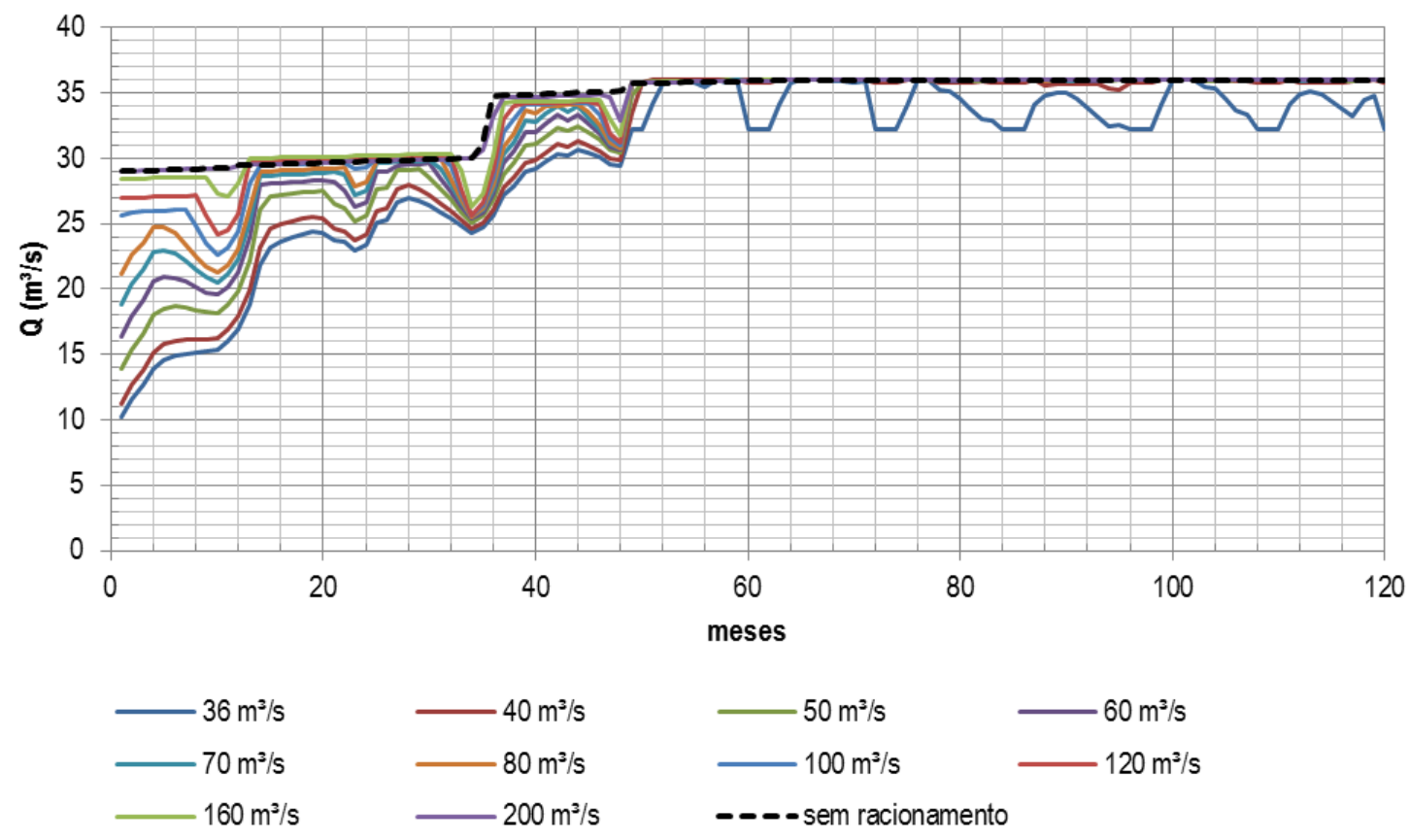

Figura 54 - Racionamento - Função Contínua - Cantareira $-Q_{0 \%}=0 \mathrm{~m}^{3} / \mathrm{s}-$ Vazão atendida.

Para um racionamento mais severo, com Q100\% de $36 \mathrm{~m}^{3} / \mathrm{s}$ e Q0\% de $0 \mathrm{~m}^{3} / \mathrm{s}$ a vazão mínima liberada é de 10,22 m³/s, enquanto sem racionamento e com uma previsão de afluências perfeita, a mínima vazão de atendimento é de $29,00 \mathrm{~m}^{3} / \mathrm{s}$.

Na Figura 55 e na Figura 56 estão apresentados os resultados para volume e vazão para uma vazão mínima Q\% de $5 \mathrm{~m}^{3} / \mathrm{s}$. 


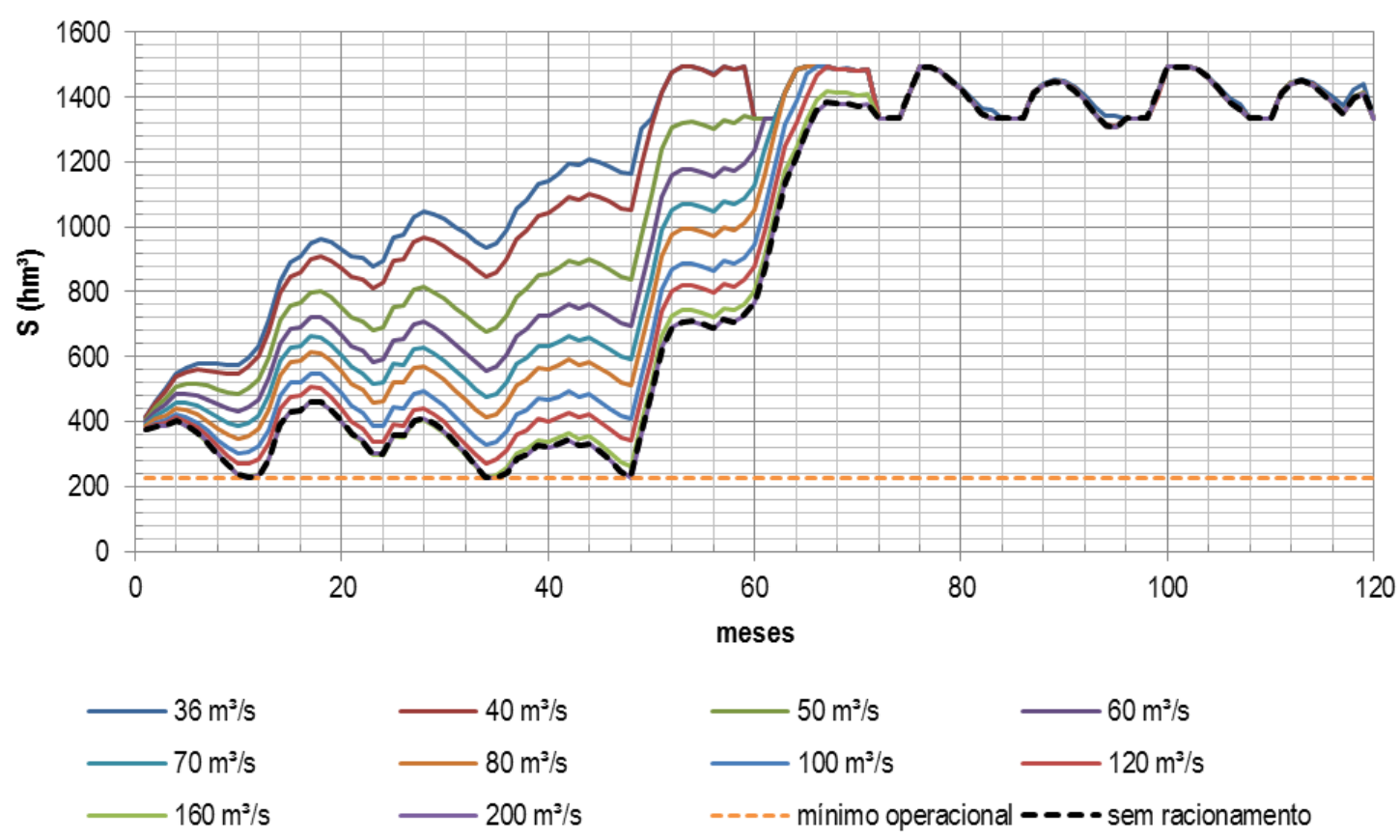

Figura 55 - Racionamento - Função Contínua - Cantareira $-Q_{0 \%}=5 \mathrm{~m}^{3} / \mathrm{s}-$ Volume reservado.

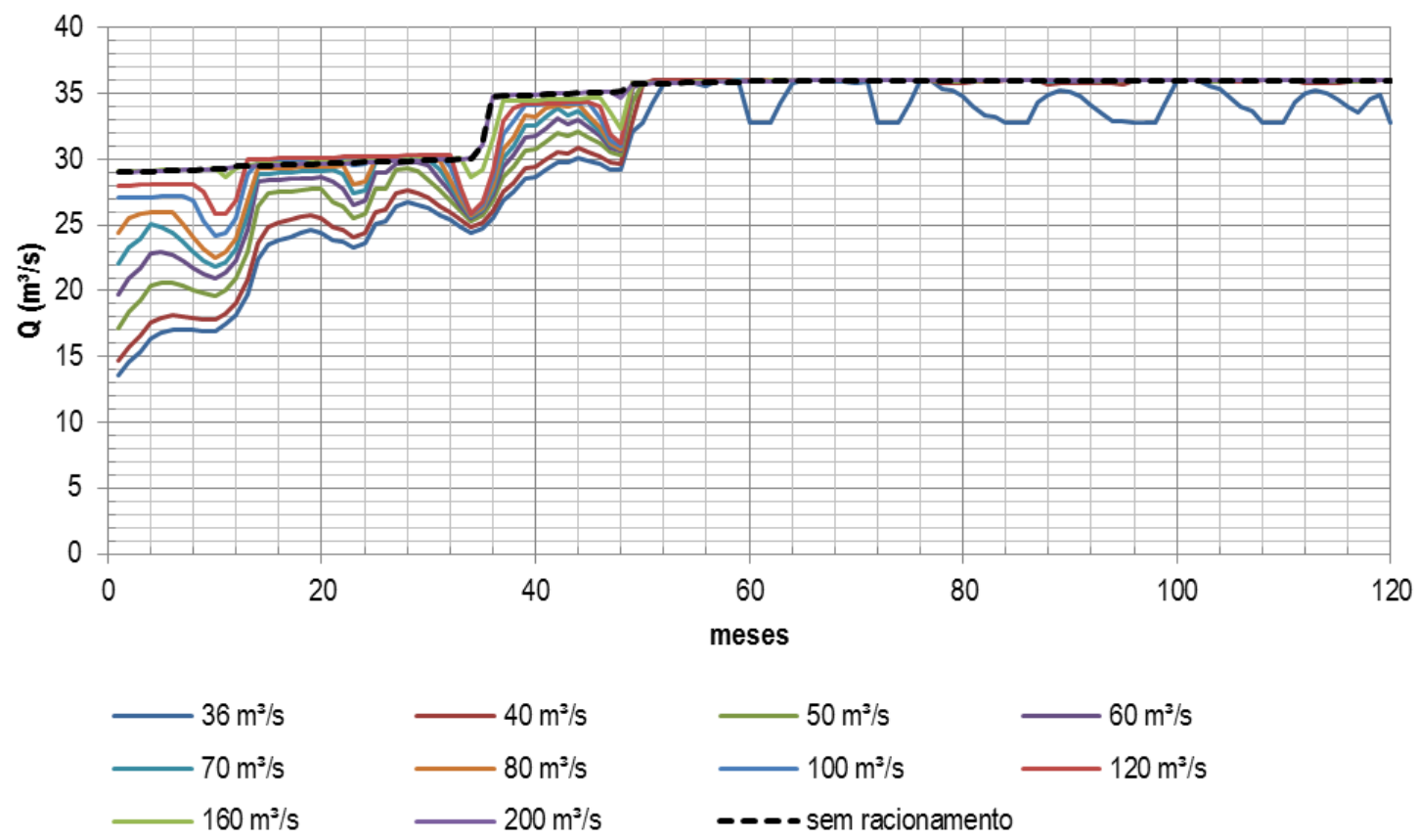

Figura 56 - Racionamento - Função Contínua - Cantareira - $Q_{0 \%}=5 \mathrm{~m}^{3} / \mathrm{s}-$ Vazão atendida.

Com a $Q_{0 \%}=5 \mathrm{~m}^{3} / \mathrm{s}$ e a $Q_{100 \%}=36 \mathrm{~m}^{3} / \mathrm{s}$, a vazão mínima de retirada foi de $13,61 \mathrm{~m}^{3} / \mathrm{s}$. Na Figura 57 e na Figura 58 estão contidos os resultados de volume e vazão para Q0\% de $10 \mathrm{~m}^{3} / \mathrm{s}$. 


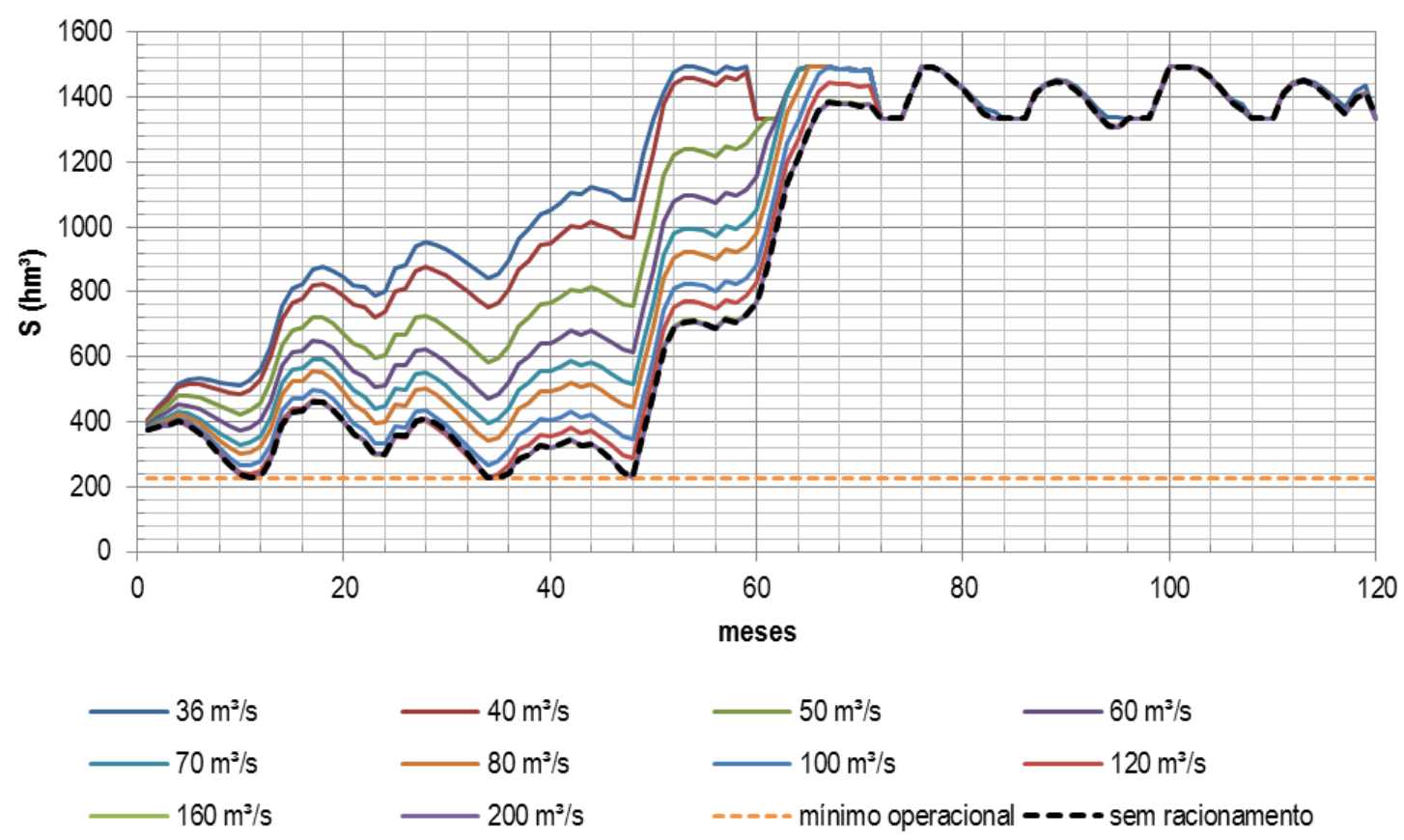

Figura 57-Racionamento - Função Contínua - Cantareira - Q $Q_{0}=10 \mathrm{~m}^{3} / \mathrm{s}-$ Volume reservado.

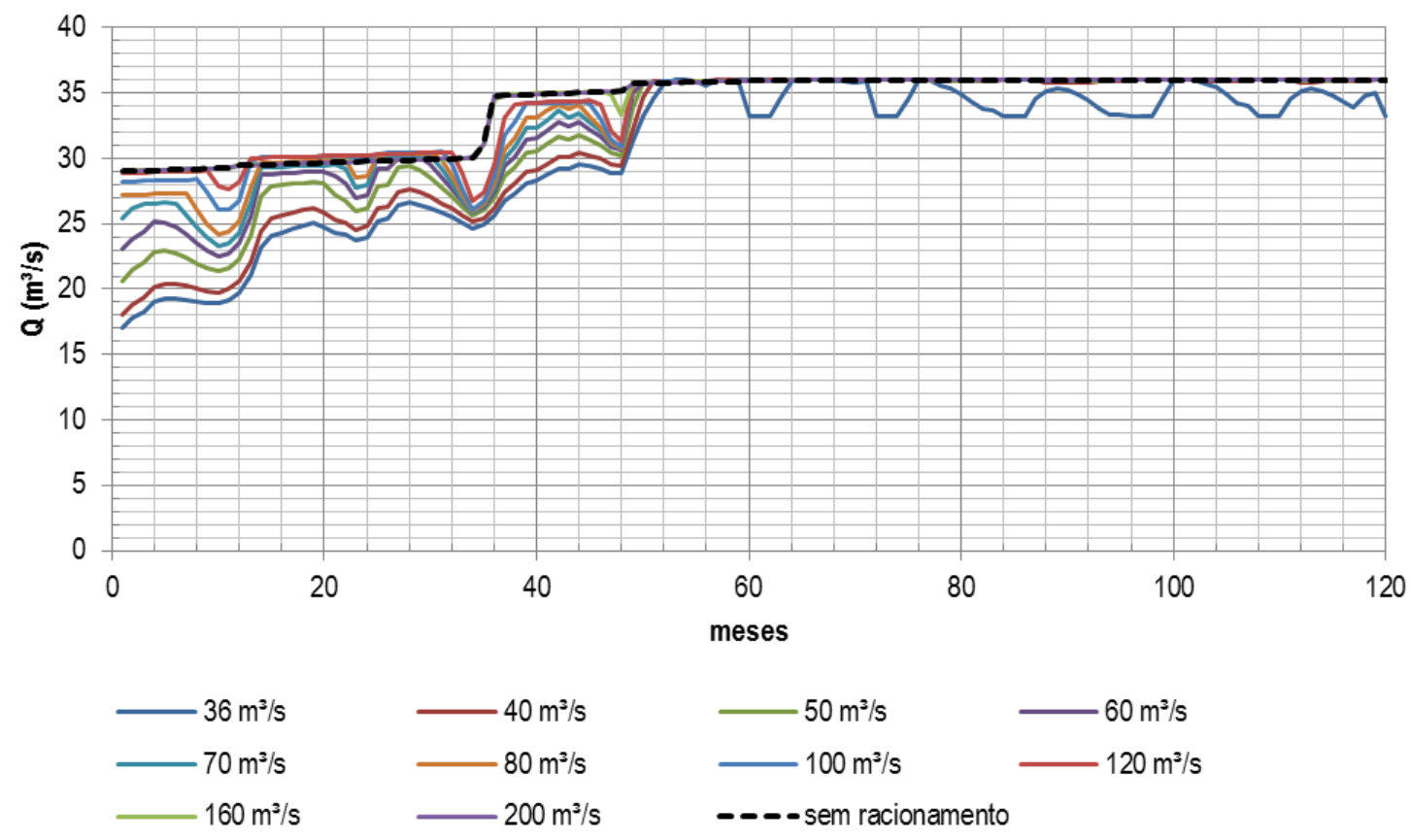

Figura 58 - Racionamento - Função Contínua - Cantareira - $Q_{0 \%}=10 \mathrm{~m}^{3} / \mathrm{s}-$ Vazão atendida.

Para a $Q_{0 \%}$ de $10 \mathrm{~m}^{3} / \mathrm{s}$ e uma $Q_{100 \%}$ de $36 \mathrm{~m}^{3} / \mathrm{s}$ a vazão mínima de retirada e atendimento foi de $17,06 \mathrm{~m}^{3} / \mathrm{s}$.

Na Figura 59 estão apresentados os resultados de volume armazenado e na Figura 60 o gráfico contendo as vazões de atendimento à demanda para a vazão mínima $Q_{0 \%}$ de $15 \mathrm{~m}^{3} / \mathrm{s}$. 


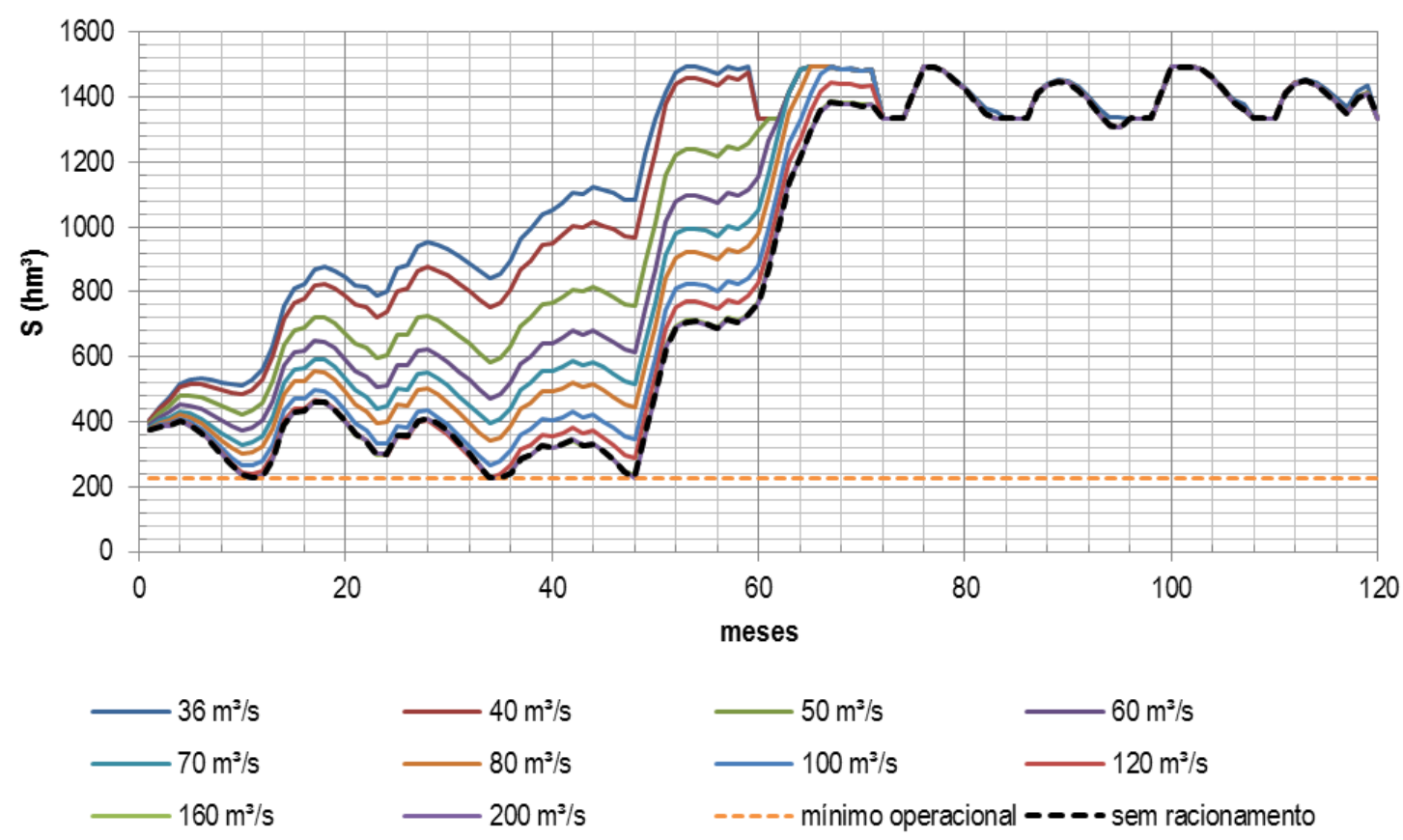

Figura 59 - Racionamento - Função Contínua - Cantareira - Q0 = $15 \mathrm{~m}^{3} / \mathrm{s}$ - Volume reservado.

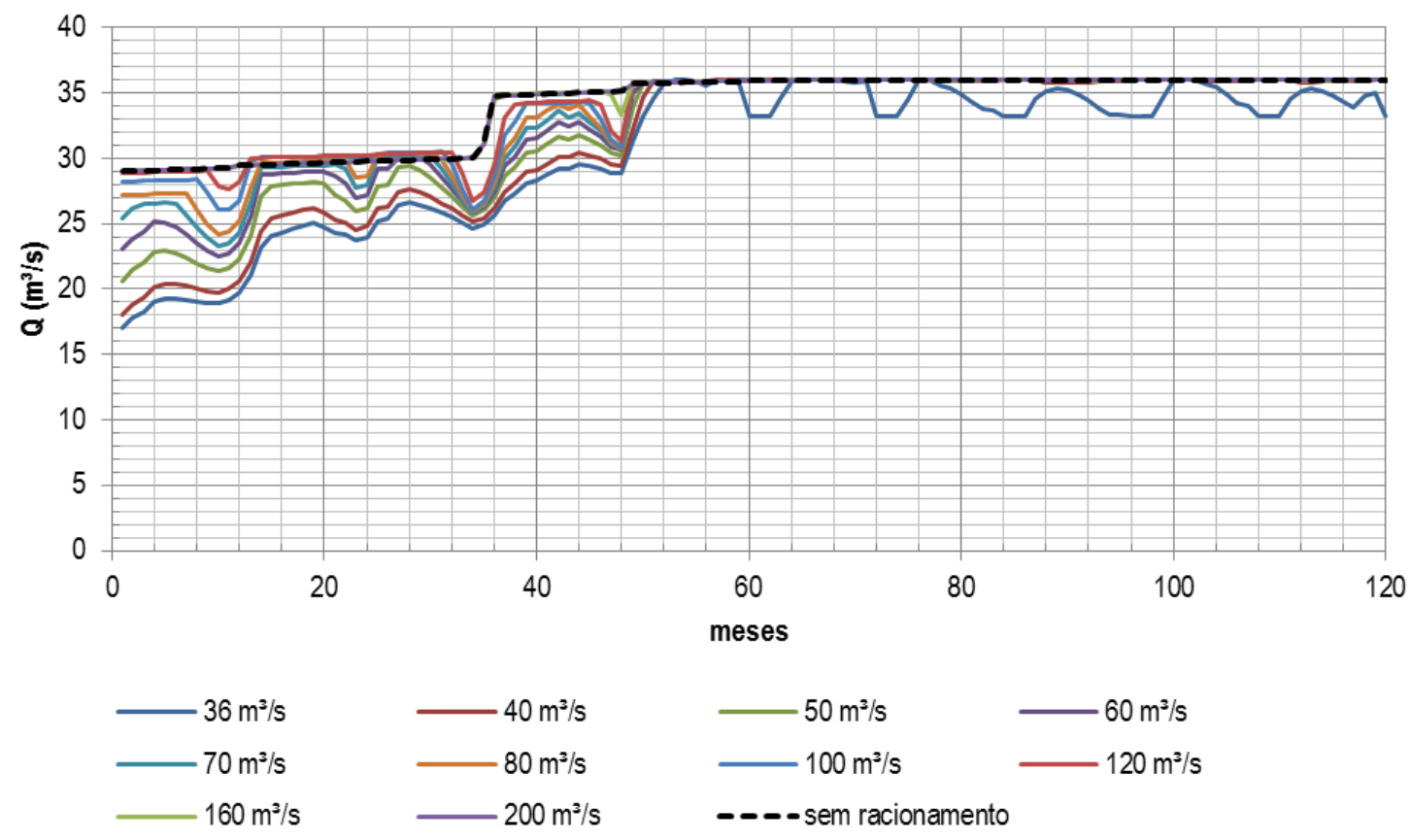

Figura 60 - Racionamento - Função Contínua - Cantareira - Q0 = $15 \mathrm{~m}^{3} / \mathrm{s}$ - Vazão atendida.

A vazão mínima de atendimento à demanda foi de $20,57 \mathrm{~m}^{3} / \mathrm{s}$ para um racionamento com $\mathrm{Q}_{100 \%}$ de $36 \mathrm{~m}^{3} / \mathrm{s}$. 


\subsubsection{Sistema Produtor Alto Tietê - Racionamento Linear}

A mesma análise de sensibilidade do sistema foi realizada para o Alto Tietê. A demanda de consumo adotada neste caso foi a capacidade nominal produtiva de $15 \mathrm{~m}^{3} / \mathrm{s}$, o volume inicial foi de $147,59 \mathrm{hm}^{3}$ e o volume mínimo útil de 68,98 hm³.

Inicialmente a vazão mínima de retirada para o reservatório com $0 \%$ de volume armazenado, foi de $0 \mathrm{~m}^{3} / \mathrm{s}$. A vazão máxima foi variada de $15 \mathrm{~m}^{3} / \mathrm{s}$ a $100 \mathrm{~m}^{3} / \mathrm{s}$. Os resultados de volume (Figura 61) armazenado e vazão (Figura 62) para Q0\% $=0 \mathrm{~m} 3 / \mathrm{s}$ estão apresentados na sequência.

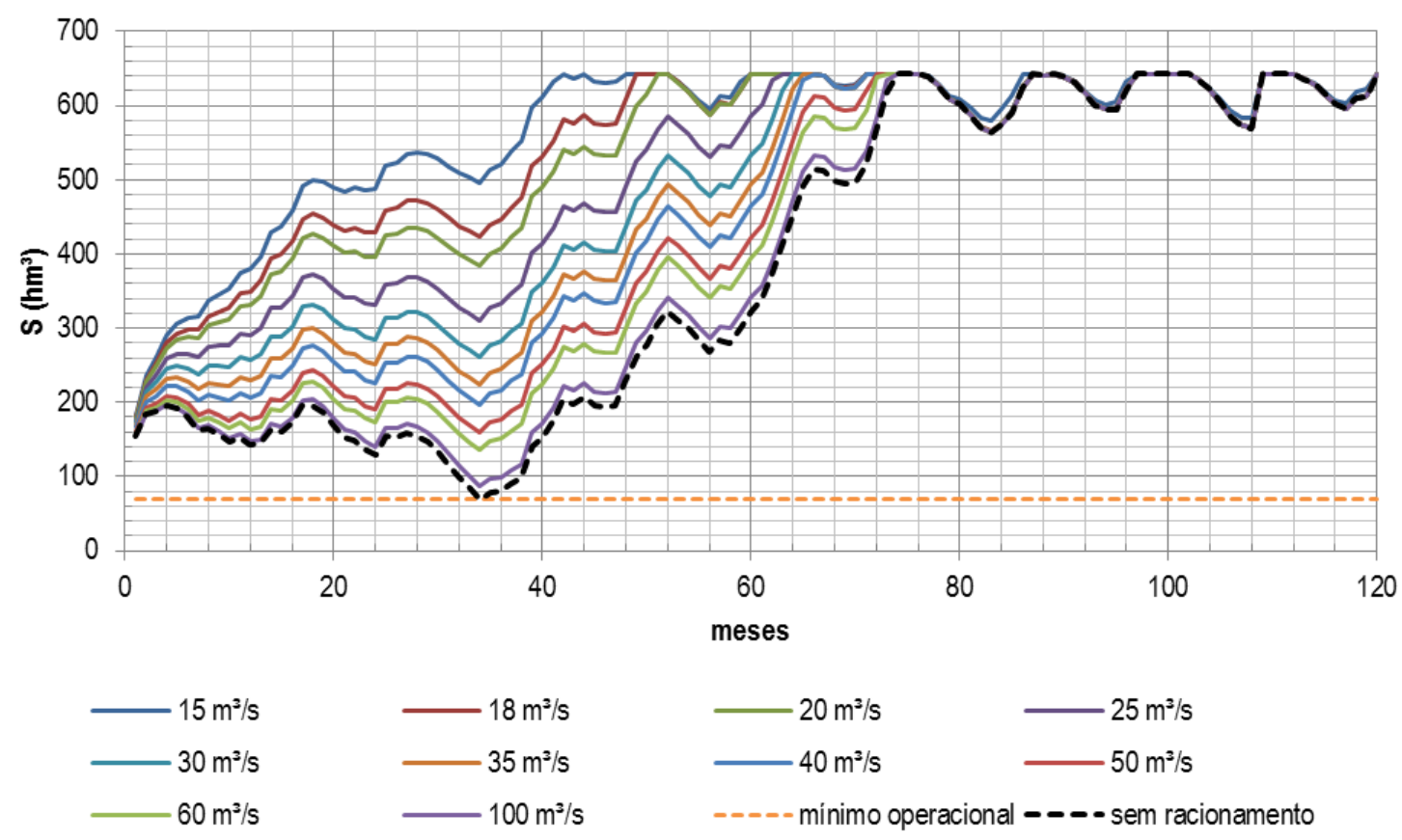

Figura 61 - Racionamento - Função Contínua - Alto Tietê - $Q_{0 \%}=0 \mathrm{~m}^{3} / \mathrm{s}-$ Volume reservado. 


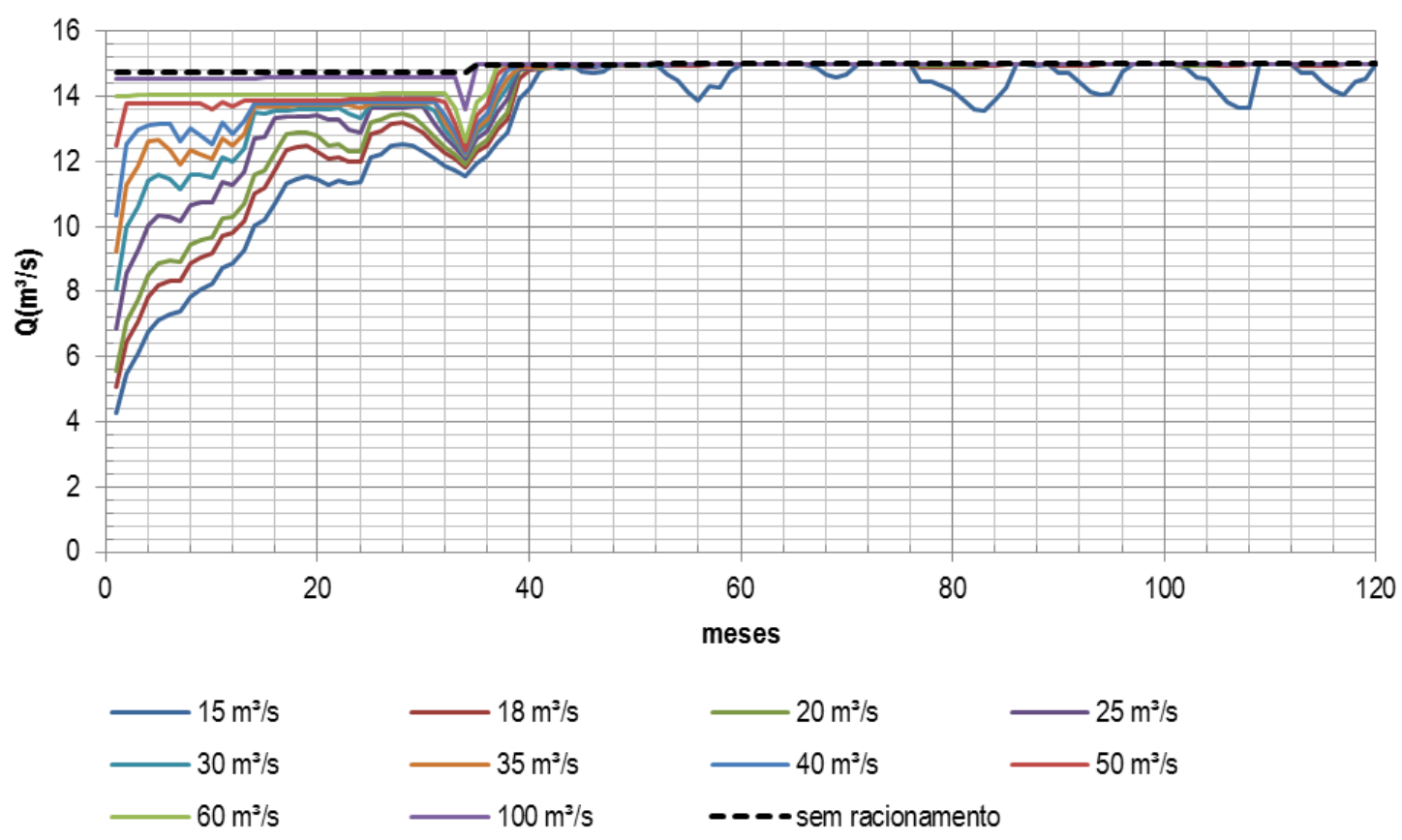

Figura 62 - Racionamento - Função Contínua - Alto Tietê - $Q_{0 \%}=0 \mathrm{~m}^{3} / \mathrm{s}-$ Vazão atendida.

Para um racionamento mais severo, a vazão mínima para uma variação de $Q_{0} \%=0 \mathrm{~m}^{3} / \mathrm{s}$ e $\mathrm{Q} 100 \%=15 \mathrm{~m}^{3} / \mathrm{s}$ foi de $4,26 \mathrm{~m}^{3} / \mathrm{s}$. Os resultados para um $\mathrm{Q}_{0 \%}$ de 2,5 m³/s estão apresentados na Figura 63 com a variação do volume em função do tempo e Figura 64 contendo a vazão de atendimento à demanda.

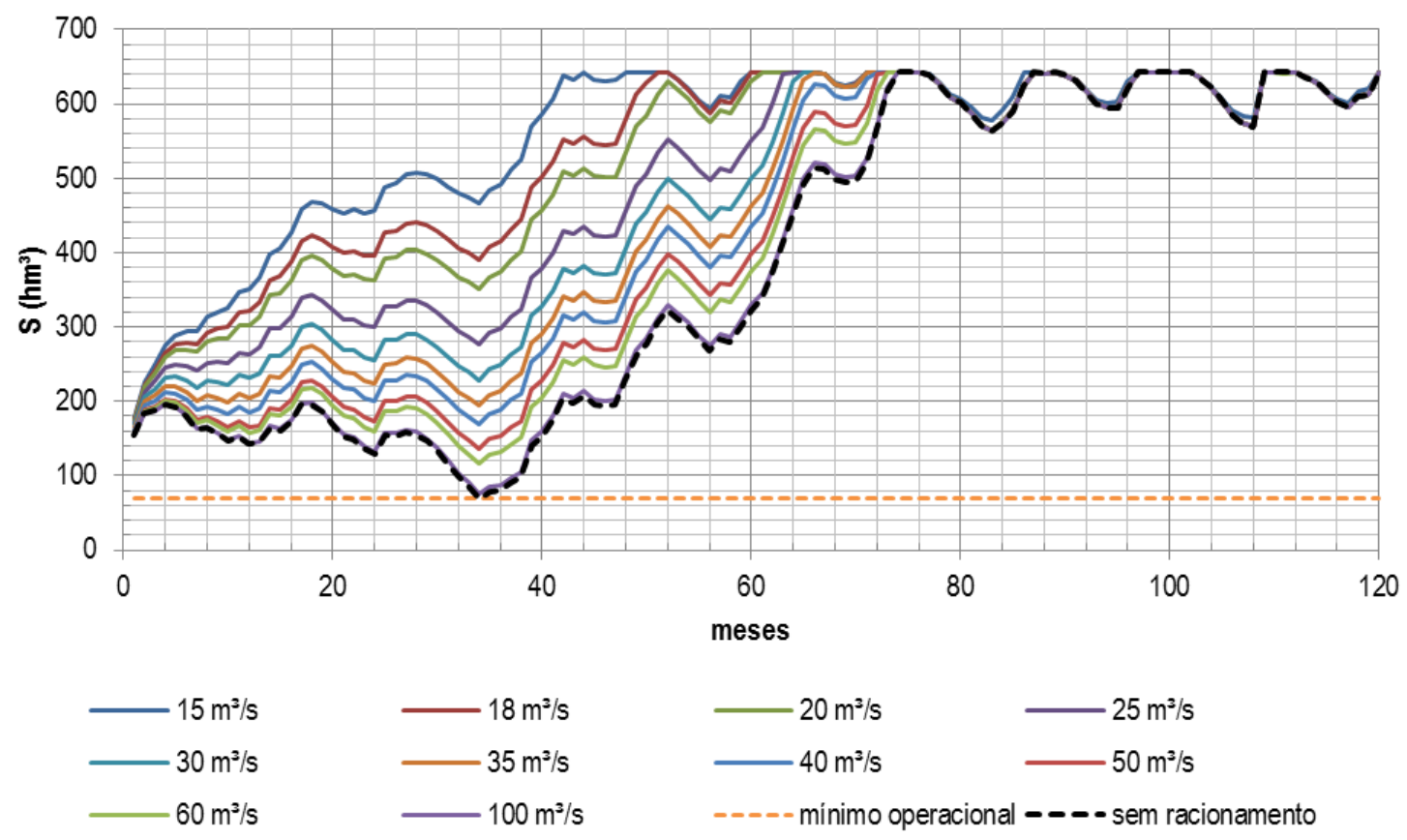

Figura 63-Racionamento - Função Contínua - Alto Tietê - $Q_{0 \%}=2,5 \mathrm{~m}^{3} / \mathrm{s}$ - Volume reservado. 


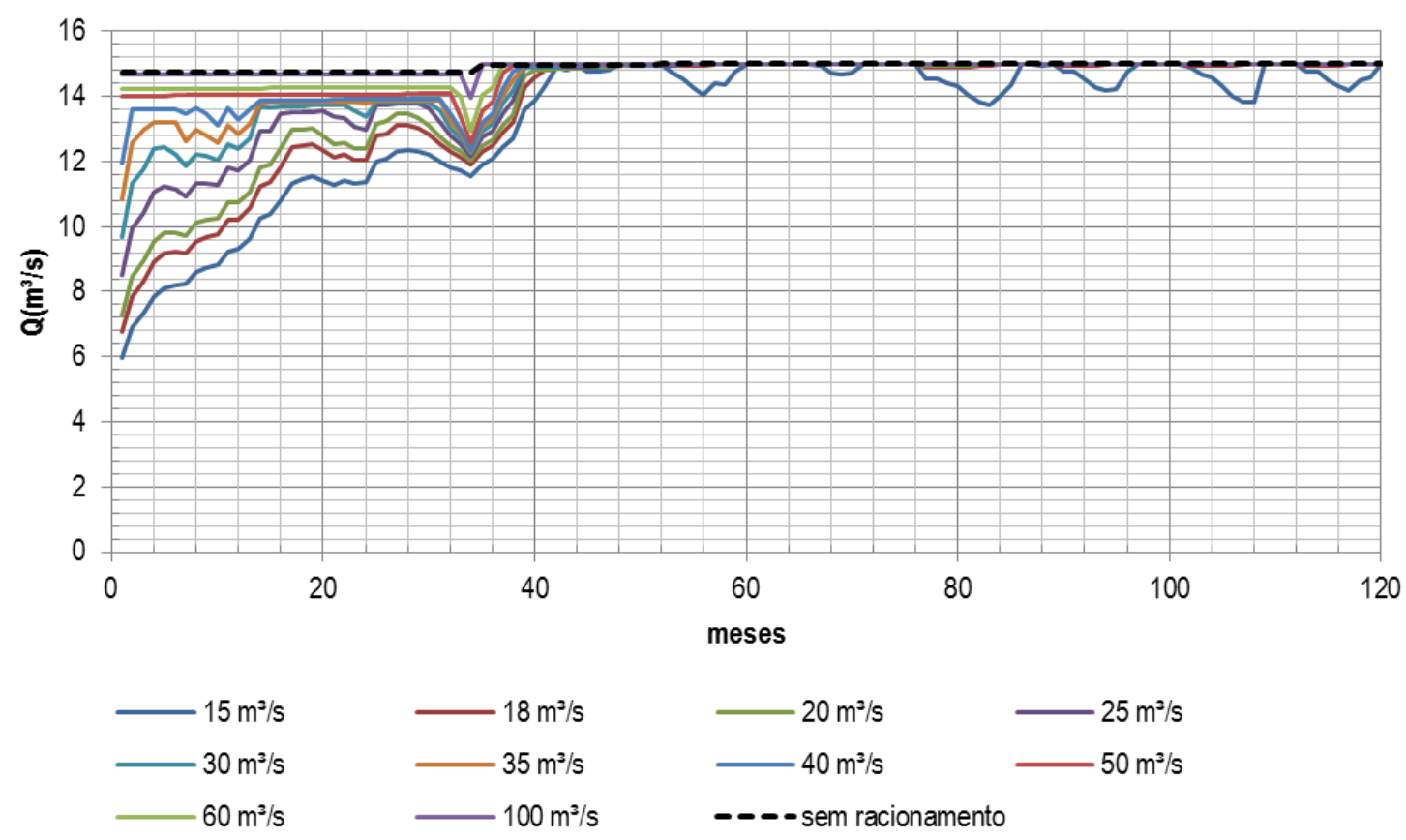

Figura 64 - Racionamento - Função Contínua - Alto Tietê - $Q_{0 \%}=2,5 \mathrm{~m}^{3} / \mathrm{s}$ - Vazão atendida.

A vazão mínima de atendimento à demanda foi de $5,96 \mathrm{~m}^{3} / \mathrm{s}$ para a $\mathrm{Q}_{100 \%}$ de $15 \mathrm{~m}^{3} / \mathrm{s}$. $\mathrm{Na}$ Figura 65 e na Figura 66 estão os resultados referentes à $Q_{0 \%}=5 \mathrm{~m}^{3} / \mathrm{s}$ para volume armazenado e vazão de retirada e atendimento à demanda.

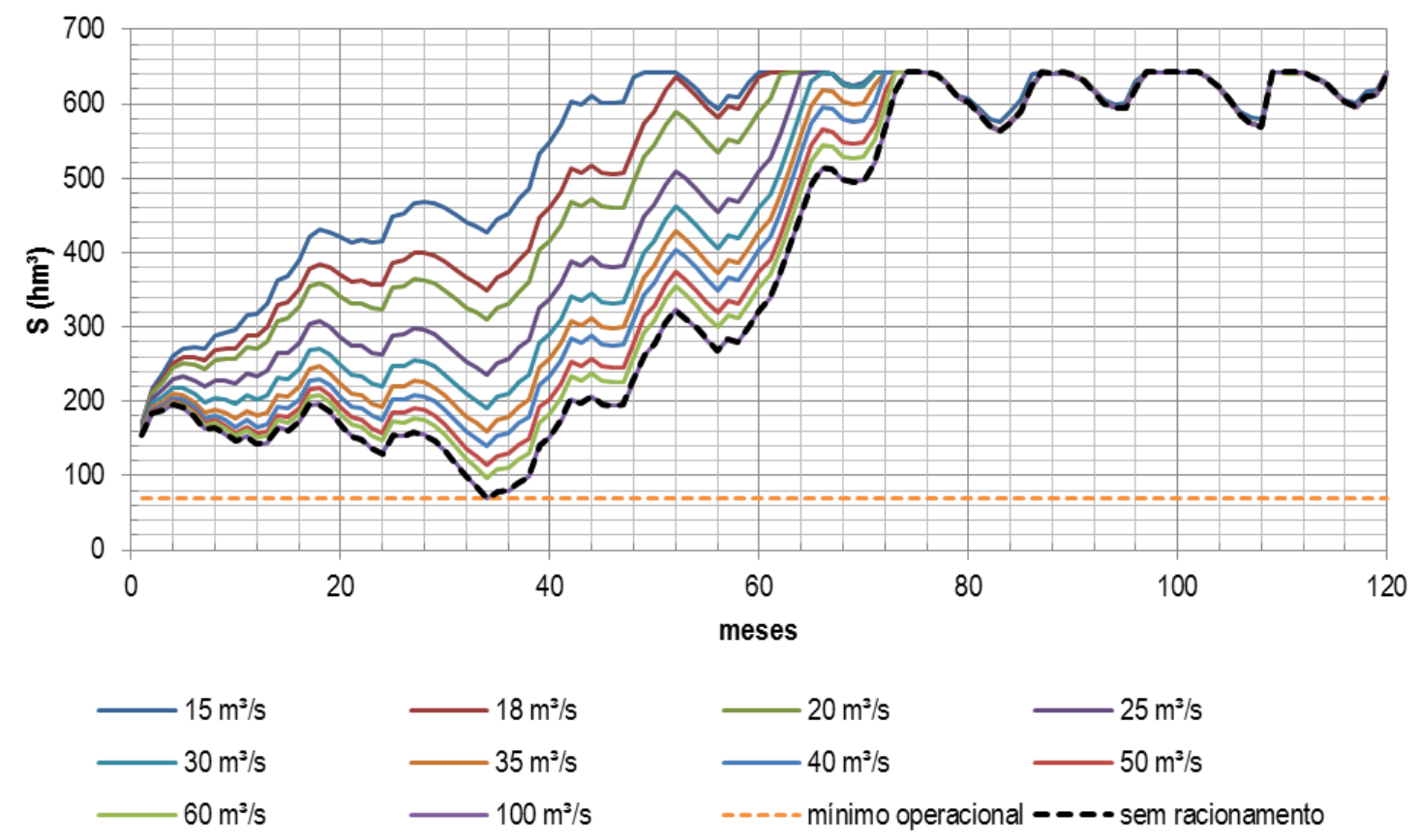

Figura 65 - Racionamento - Função Contínua - Alto Tietê - $Q_{0 \%}=5 \mathrm{~m}^{3} / \mathrm{s}-$ Volume reservado. 


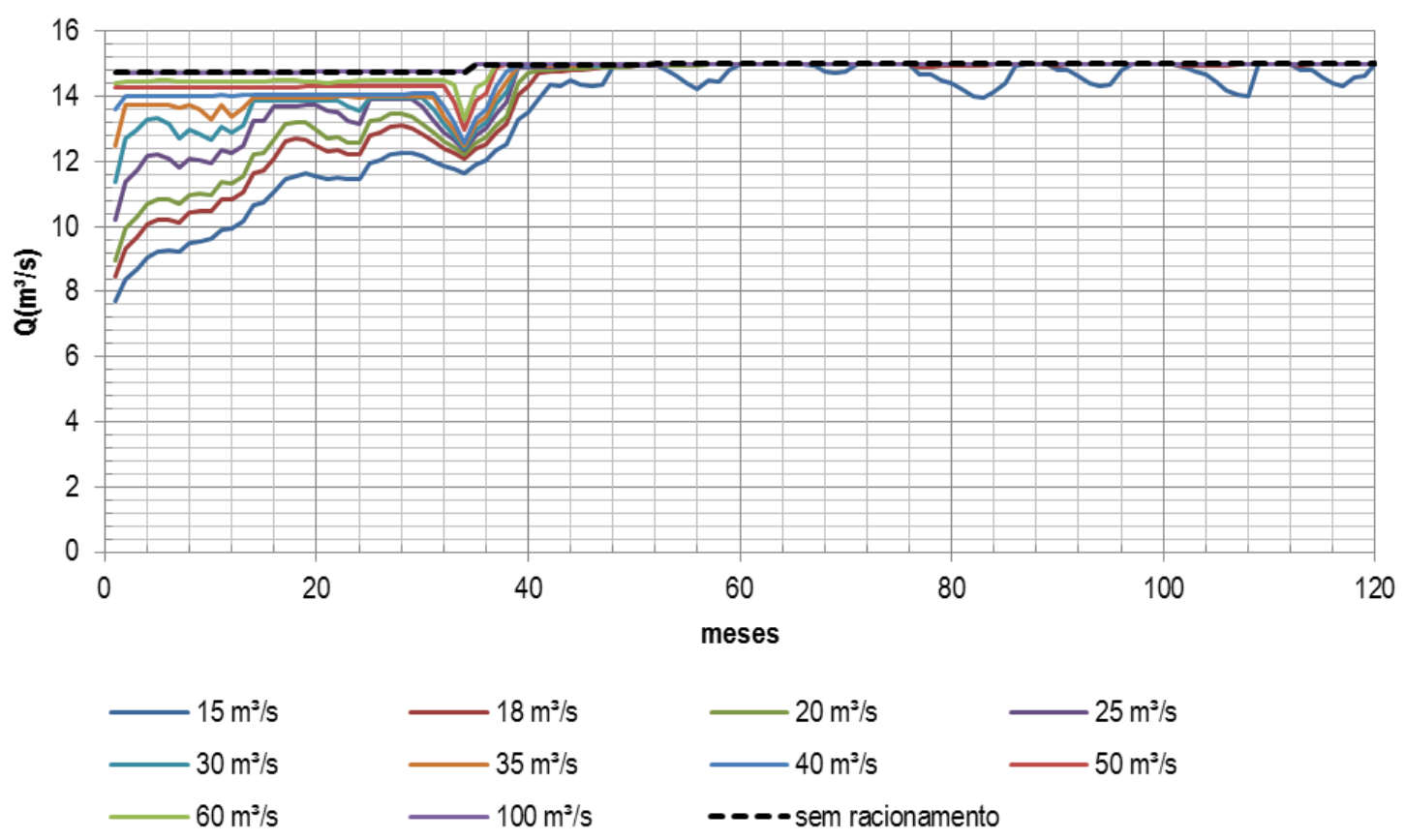

Figura 66 - Racionamento - Função Contínua - Alto Tietê - $Q_{0 \%}=5 \mathrm{~m}^{3} / \mathrm{s}-$ Vazão atendida.

A partir dos resultados apresentados, nota-se que a menor vazão de atendimento à demanda foi de $7,70 \mathrm{~m}^{3} / \mathrm{s}$, correspondente ao racionamento, para o $\mathrm{Q}_{100 \%}$ de $15 \mathrm{~m}^{3} / \mathrm{s}$. Na Figura 67 estão contidos os resultados de volume e na Figura 68 os de vazão de atendimento à demanda, para o valor de Q0\% de 7,5 m³/s.

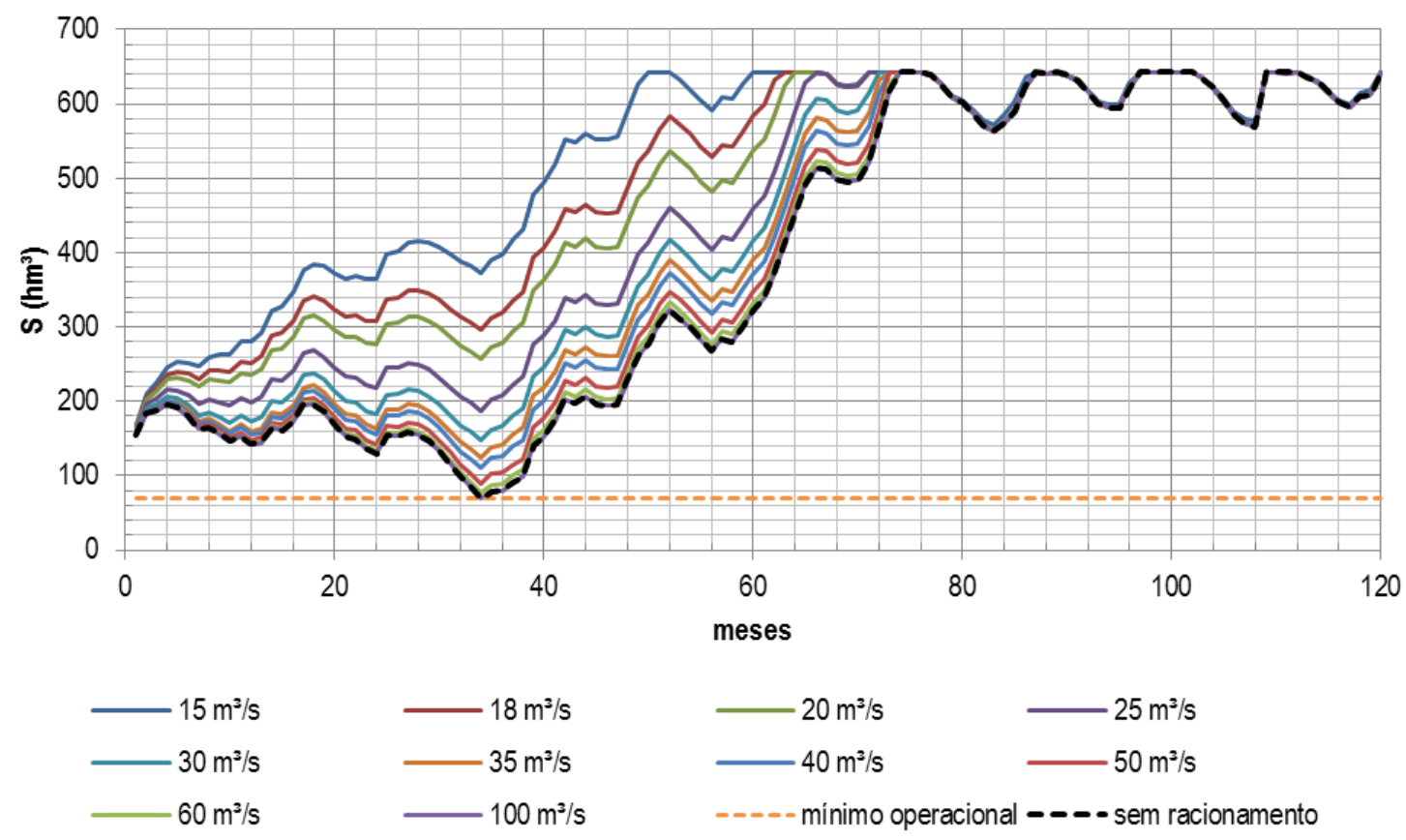

Figura 67-Racionamento - Função Contínua - Alto Tietê $-Q_{0 \%}=7,5 \mathrm{~m}^{3} / \mathrm{s}-$ Volume reservado. 


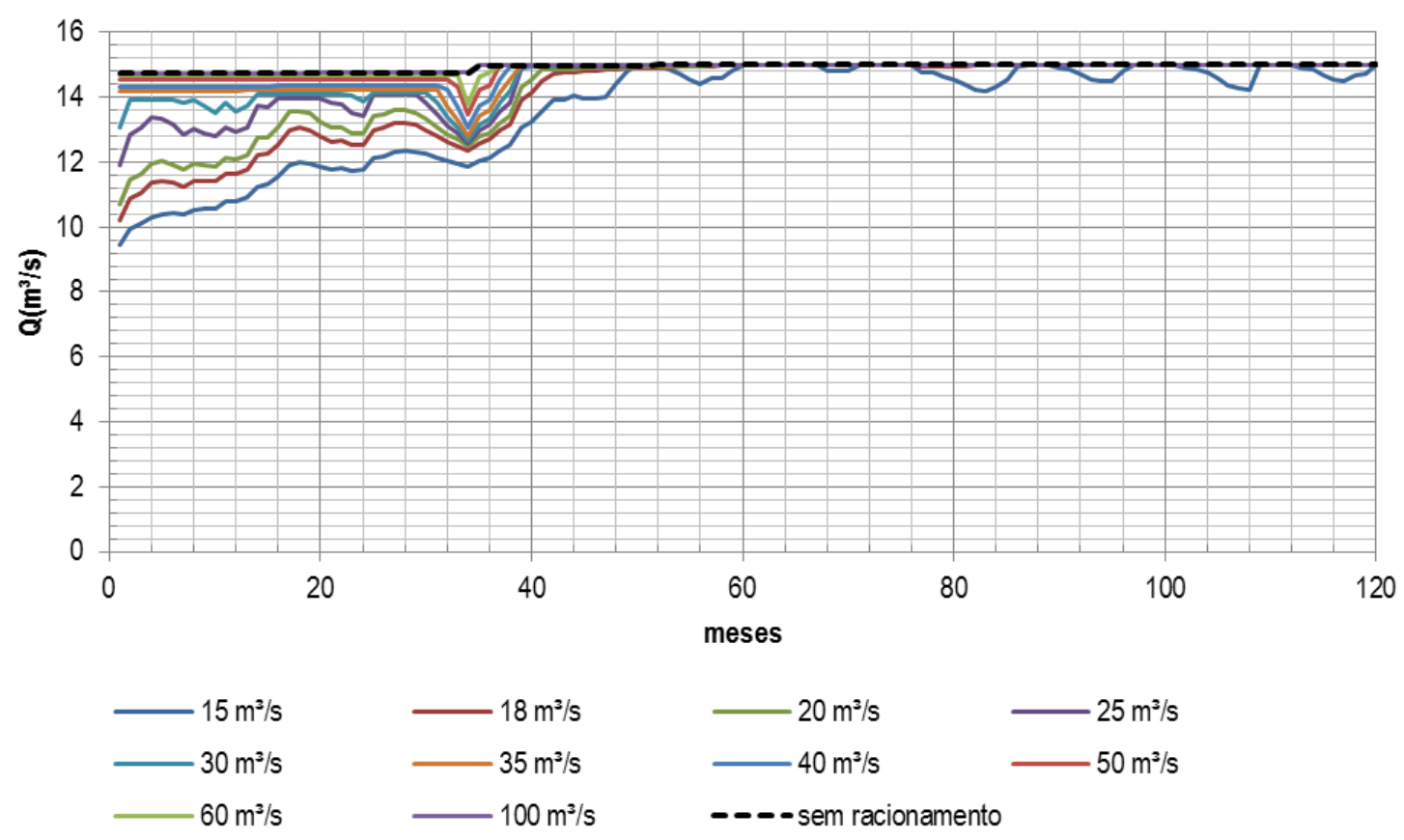

Figura 68 - Racionamento - Função Contínua - Alto Tietê - $Q_{0 \%}=7,5 \mathrm{~m}^{3} / \mathrm{s}-$ Vazão atendida.

A vazão mínima de atendimento à demanda foi de $9,47 \mathrm{~m} 3 / \mathrm{s}$.

\subsubsection{Guarapiranga - Racionamento Linear}

O racionamento linear foi aplicado também no reservatório de Guarapiranga com a demanda fixada na capacidade nominal produtiva de $16 \mathrm{~m} 3 / \mathrm{s}$. O volume inicial foi de $115,90 \mathrm{hm}^{3}$ e considerou-se que todo o volume disponível no reservatório é útil. Inicialmente, fixou-se a vazão mínima $Q_{0 \%}$ em $0,0 \mathrm{~m}^{3} / \mathrm{s}$ e os resultados estão apresentados nos gráficos de volume (Figura 69) e vazão (Figura 70) na sequência. 


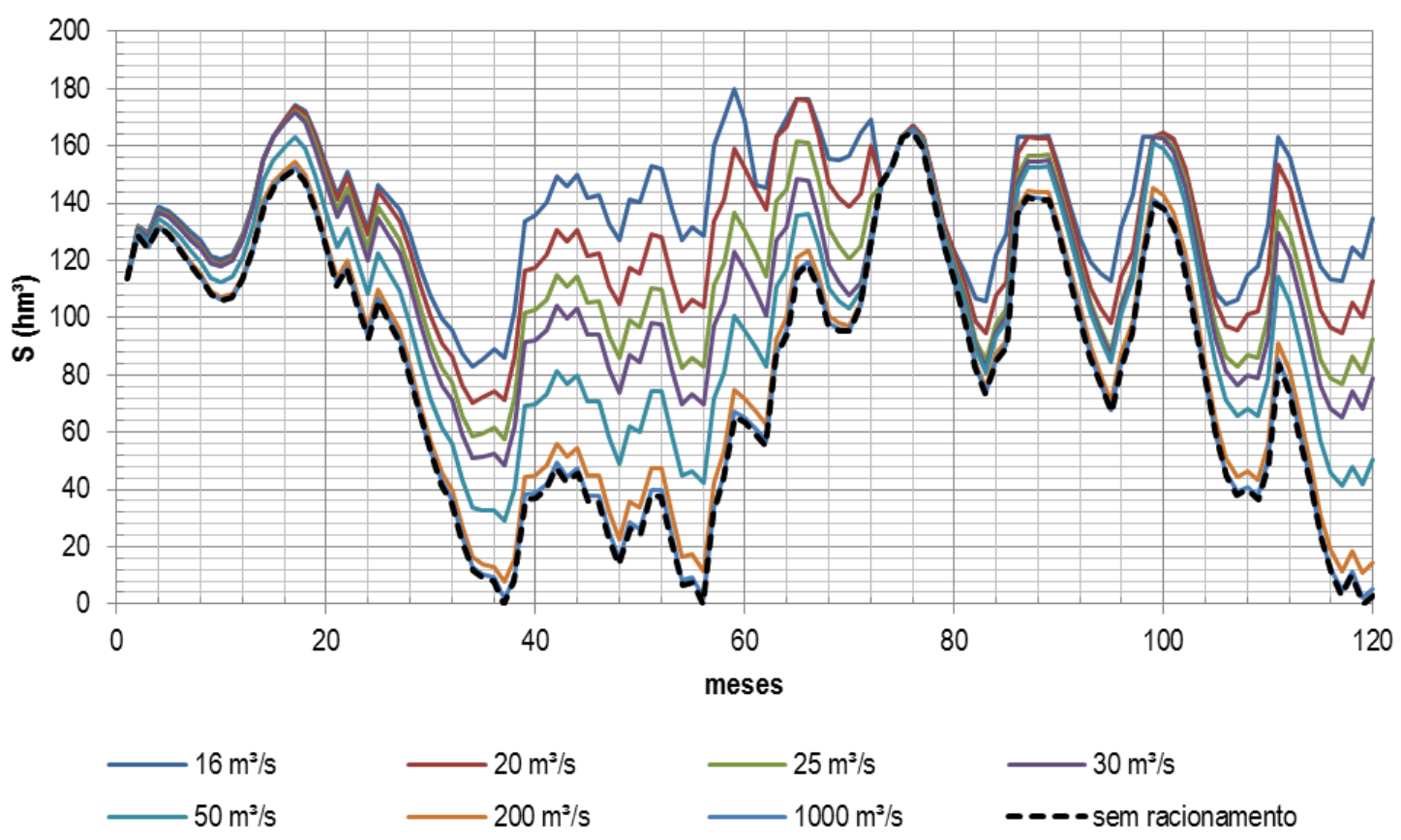

Figura 69 - Racionamento - Função Contínua - Guarapiranga - Q $Q_{0}=0 \mathrm{~m}^{3} / \mathrm{s}-$ Volume reservado.

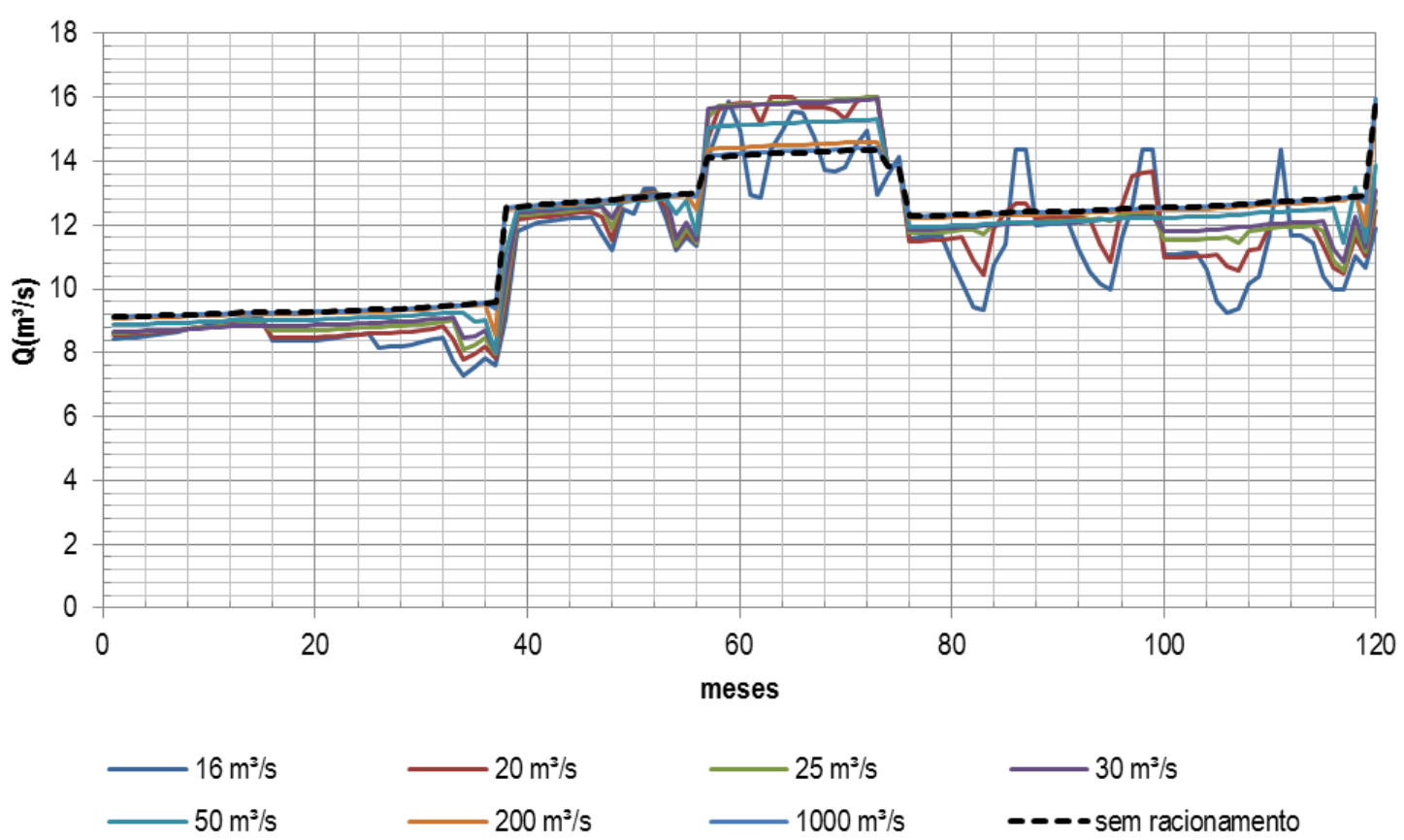

Figura 70 - Racionamento - Função Contínua - Guarapiranga $-Q_{0 \%}=0 \mathrm{~m}^{3} / \mathrm{s}-$ Vazão atendida.

A vazão mínima de demanda atendida foi de $7,30 \mathrm{~m}^{3} / \mathrm{s}$ enquanto para uma situação sem racionamento, foi de $9,13 \mathrm{~m}^{3} / \mathrm{s}$.

Para uma Q $0 \%$ de 2,5 m³/s os resultados de volume (Figura 71) e vazão (Figura 72) estão apresentados na sequência. A vazão mínima de demanda atendida foi de 
$7,61 \mathrm{~m}^{3} / \mathrm{s}$, para o valor de $\mathrm{Q}_{100 \%}$ de $16 \mathrm{~m}^{3} / \mathrm{s}$, ou seja, para o maior racionamento proposto.

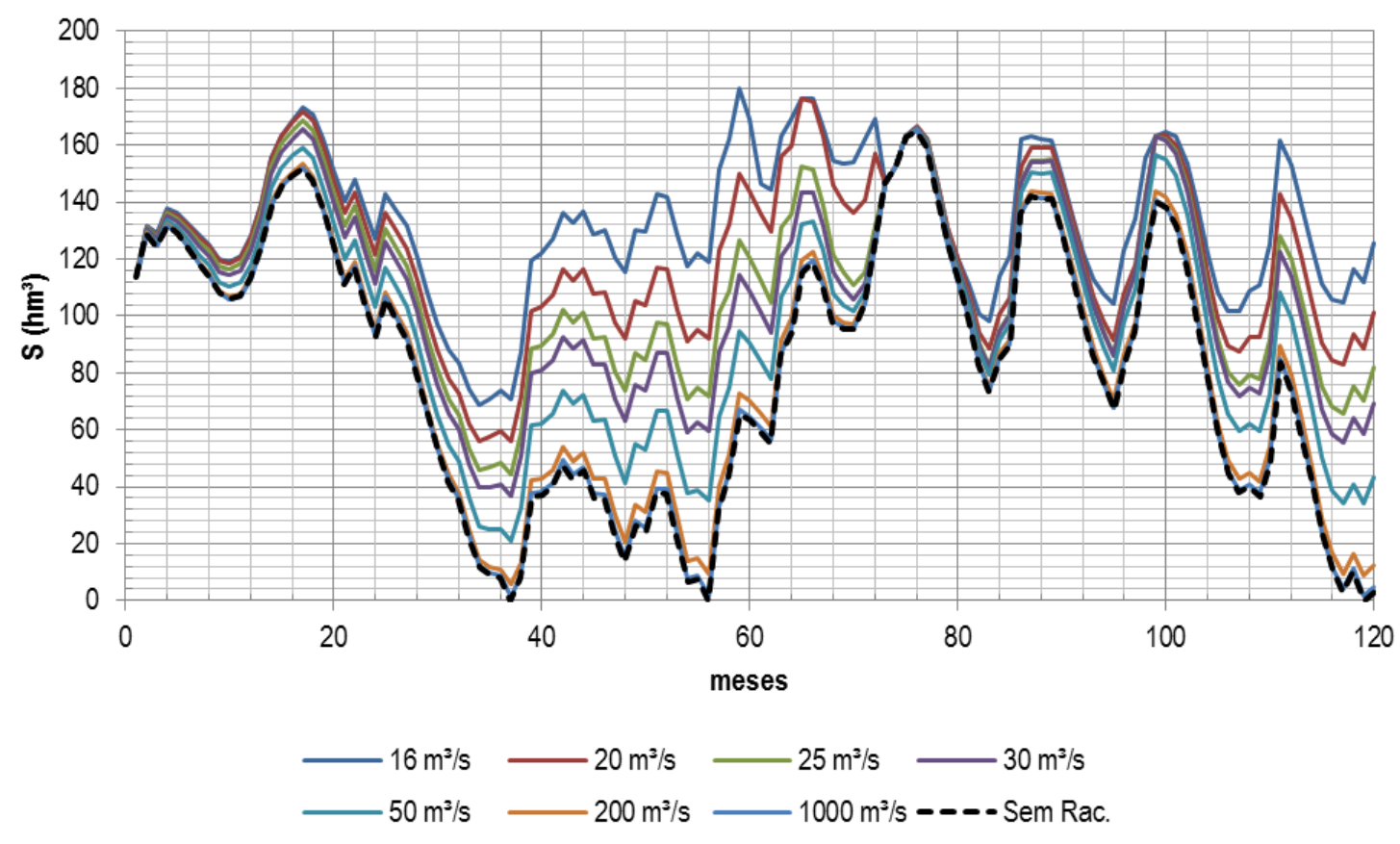

Figura 71 - Racionamento - Função Contínua - Guarapiranga - $Q_{0 \%}=2,5 \mathrm{~m}^{3} \mathrm{~s}-$ Volume reservado.

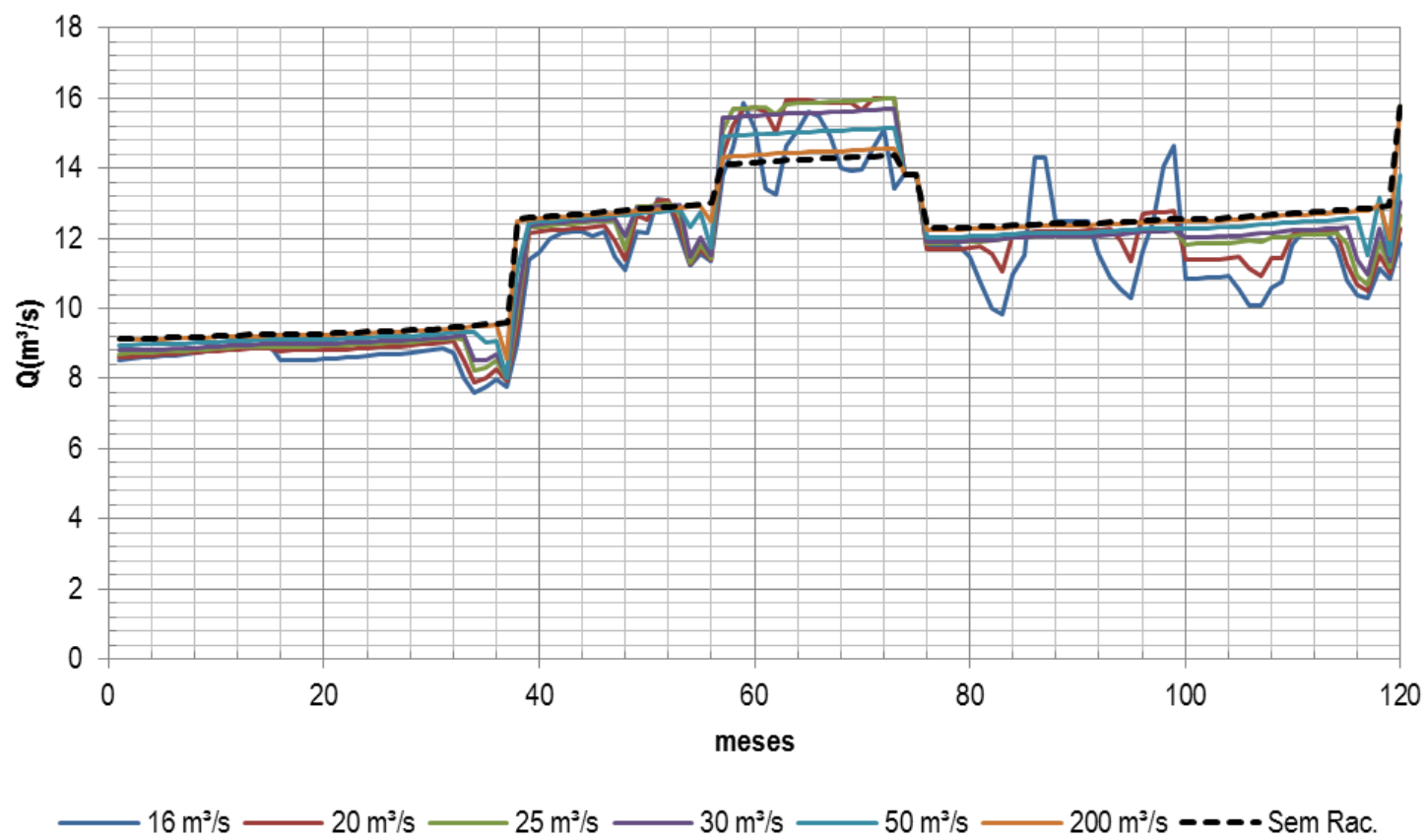

Figura 72 - Racionamento - Função Contínua - Guarapiranga - $Q_{0 \%}=2,5 \mathrm{~m}^{3} / \mathrm{s}$ - Vazão atendida. 
Os resultados para volume (Figura 73) e vazão (Figura 74) para uma Q0\% de 5,0 m³/s estão apresentados na sequência.

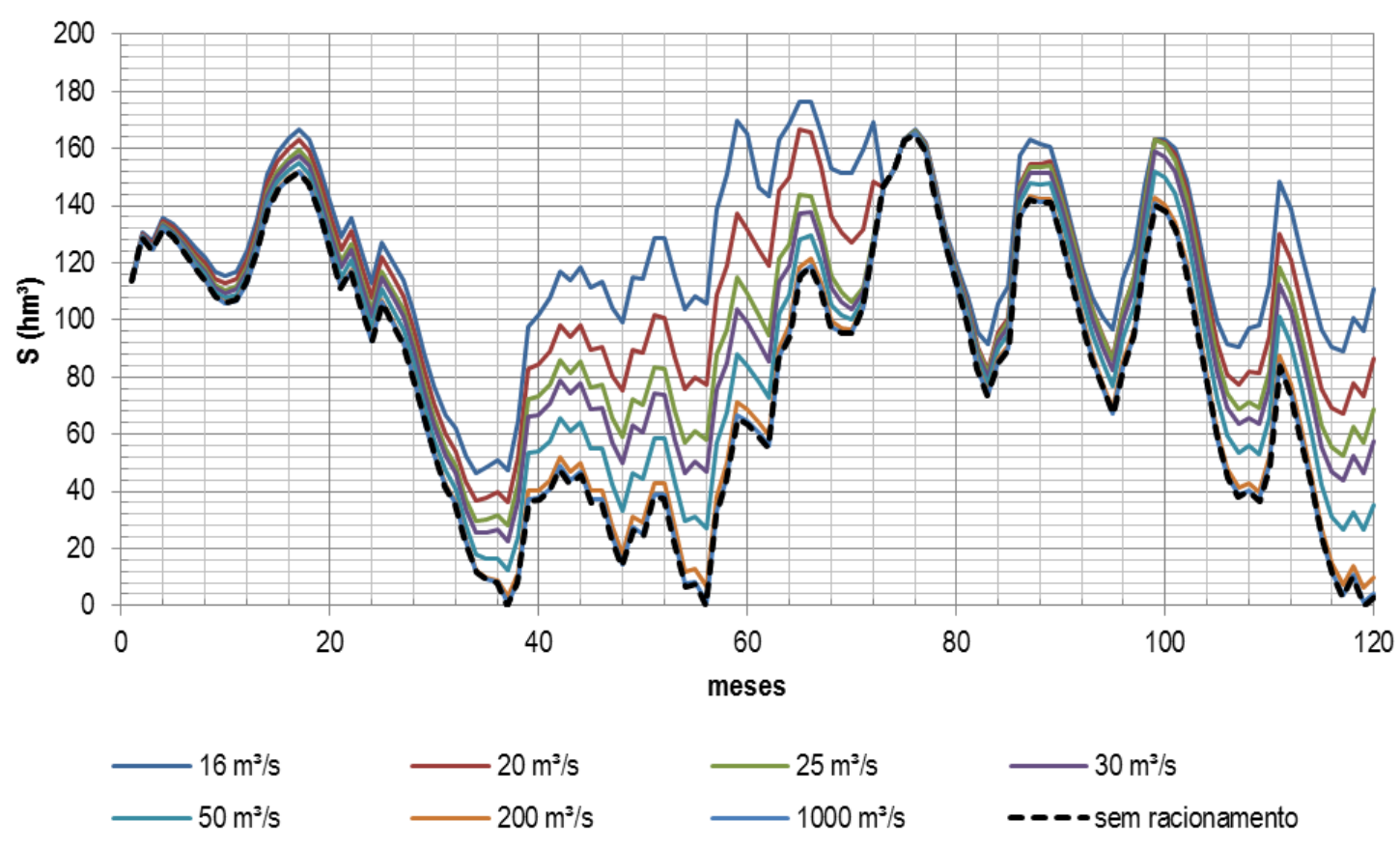

Figura 73 - Racionamento - Função Contínua - Guarapiranga $-Q_{0 \%}=5 \mathrm{~m}^{3} / \mathrm{s}-$ Volume reservado.

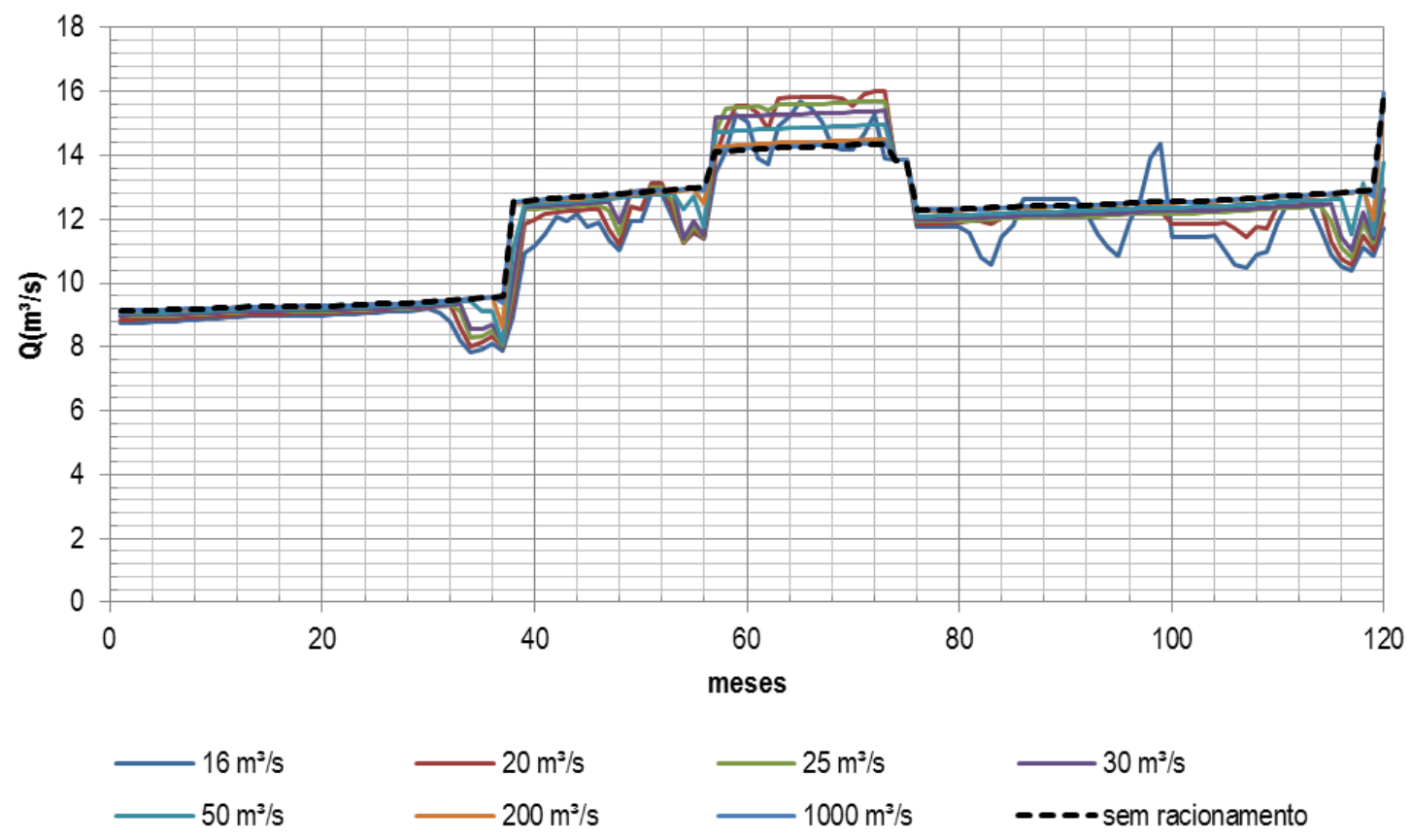

Figura 74 - Racionamento - Função Contínua - Guarapiranga $-Q_{0 \%}=5 \mathrm{~m}^{3} / \mathrm{s}-$ Vazão atendida. 
A vazão mínima de atendimento à demanda registrada, com racionamento, foi de $7,82 \mathrm{~m}^{3} / \mathrm{s}$. Para um Q0\% de $7,5 \mathrm{~m}^{3} / \mathrm{s}$ os resultados de volume e vazão estão contidos na Figura 75 e Figura 76 . O valor mínimo de atendimento à demanda foi de $8,09 \mathrm{~m}^{3} / \mathrm{s}$.

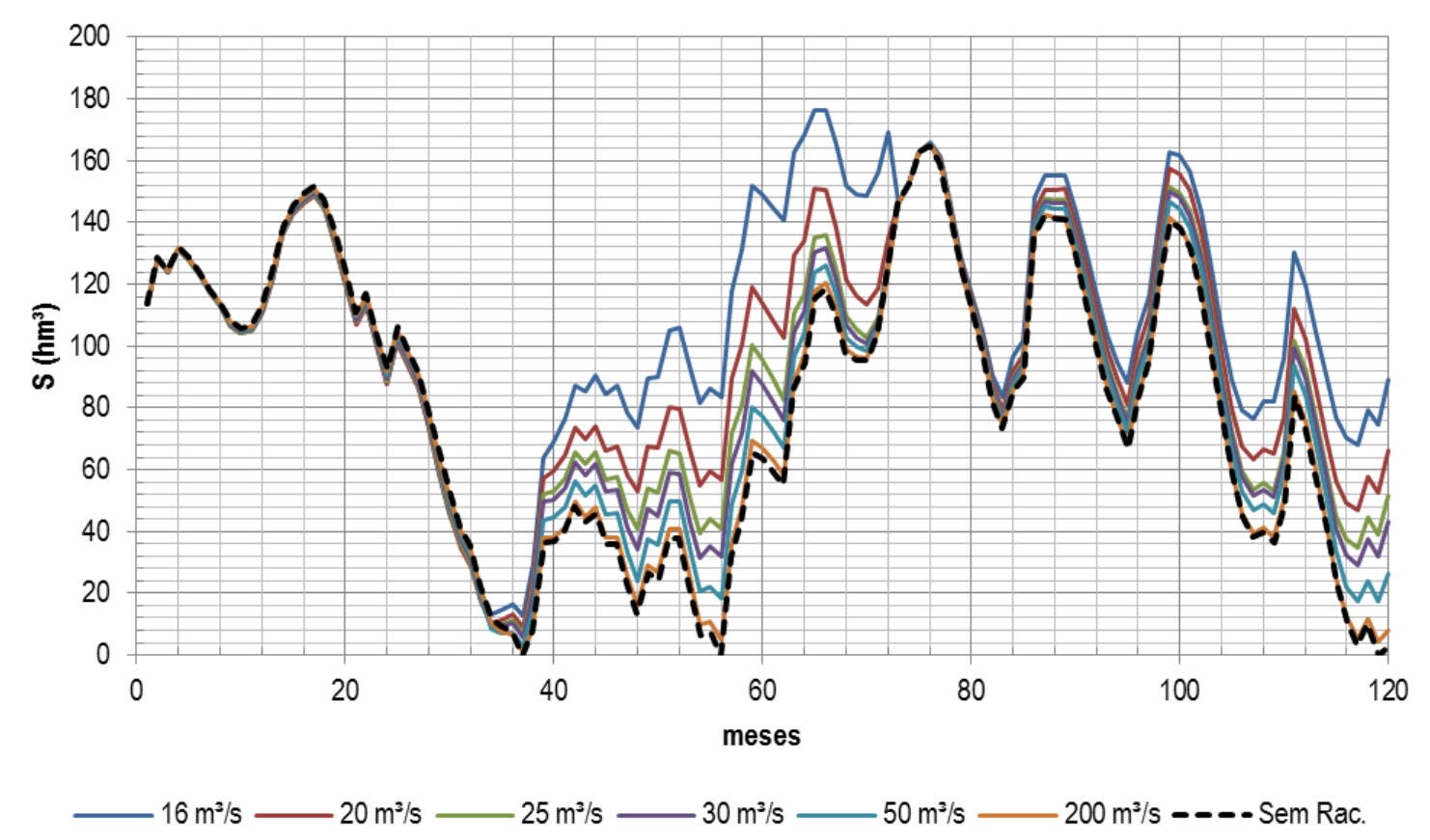

Figura 75 - Racionamento - Função Contínua - Guarapiranga - $Q_{0 \%}=7,5 \mathrm{~m}^{3} / \mathrm{s}-$ Volume reservado.

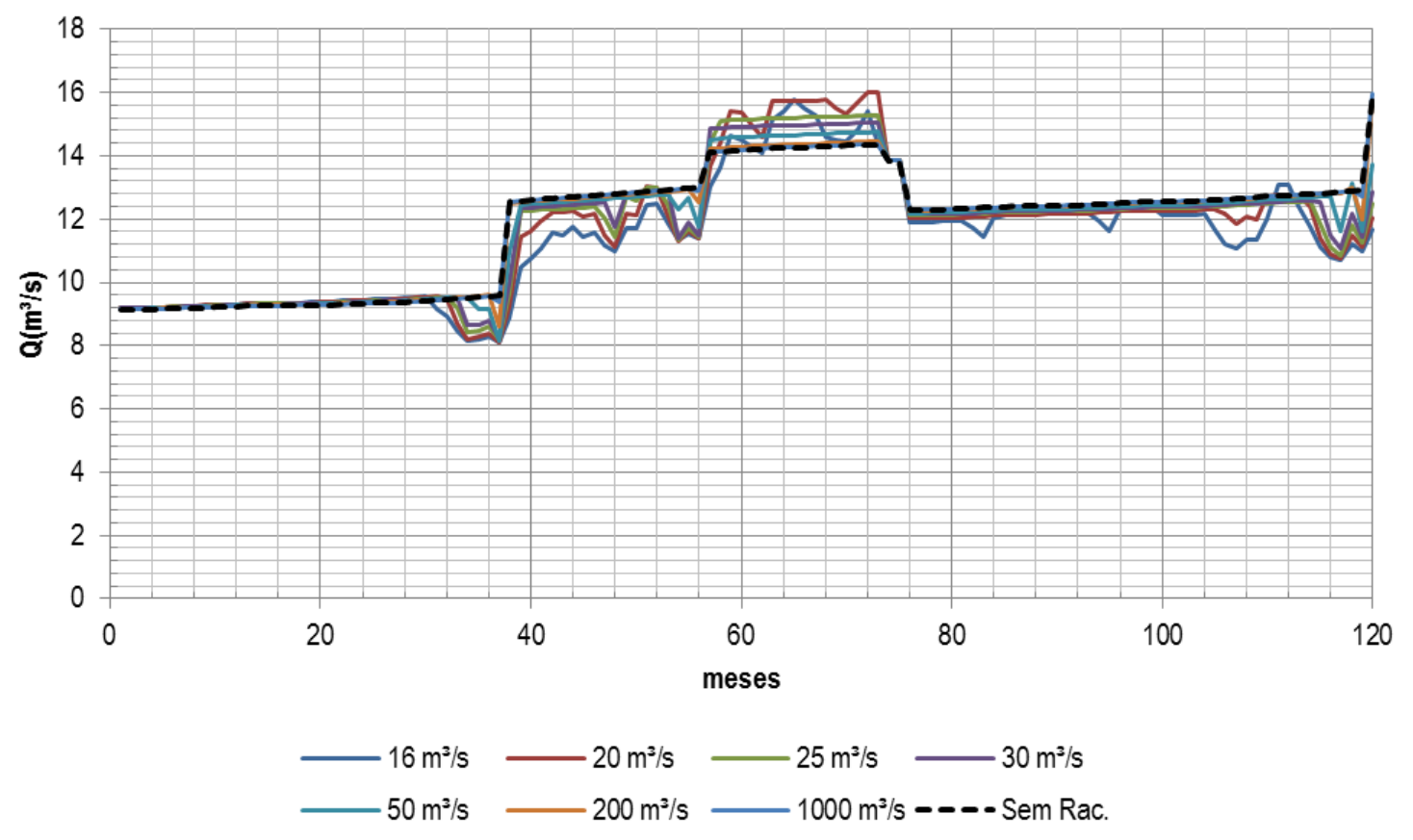

Figura 76 - Racionamento - Função Contínua - Guarapiranga - $Q_{0 \%}=7,5 \mathrm{~m}^{3} / \mathrm{s}-$ Vazão atendida. 


\subsection{Efeito da evaporação}

A evaporação foi considerada nos maiores reservatórios, formadores dos sistemas Cantareira, Alto Tietê e Guarapiranga, e os resultados com e sem evaporação foram comparados com a finalidade de se concluir quão significativa é a evaporação nos reservatórios utilizados para o abastecimento da RMSP e se deve ser considerada no modelo integrado, ou se pode ser desprezada.

No modelo SISAGUA, foram inseridos os dados de evaporação líquida mensal e a relação de área e volume, para que o balanço de volumes seja devidamente computado de acordo com o volume disponível e a área ocupada.

Nos reservatórios dos Sistemas Cantareira, Alto Tietê e Guarapiranga foram calculados os volumes armazenados e as demandas atendidas para duas situações extremas:

1) Racionamento linear máximo: Com $0 \%$ de volume armazenado, a vazão atendida é de $0 \mathrm{~m}^{3} / \mathrm{s}$ e com $100 \%$ de volume armazenado, a vazão é a da capacidade nominal de produção. A transição da vazão se dá de forma linear.

2) Sem racionamento: $O$ atendimento à demanda é maximizado de forma a se considerar a previsão perfeita de vazão afluente.

Os resultados gráficos de volume armazenado (Figura 77) e vazão atendida (Figura 78) para o Sistema Cantareira estão apresentados na sequência. A vazão de demanda considerada foi de $36 \mathrm{~m}^{3} / \mathrm{s}$, sendo $33 \mathrm{~m}^{3} / \mathrm{s}$ para atender a RMSP e $3 \mathrm{~m}^{3} / \mathrm{s}$ para as Bacias dos Rios PCJ. 


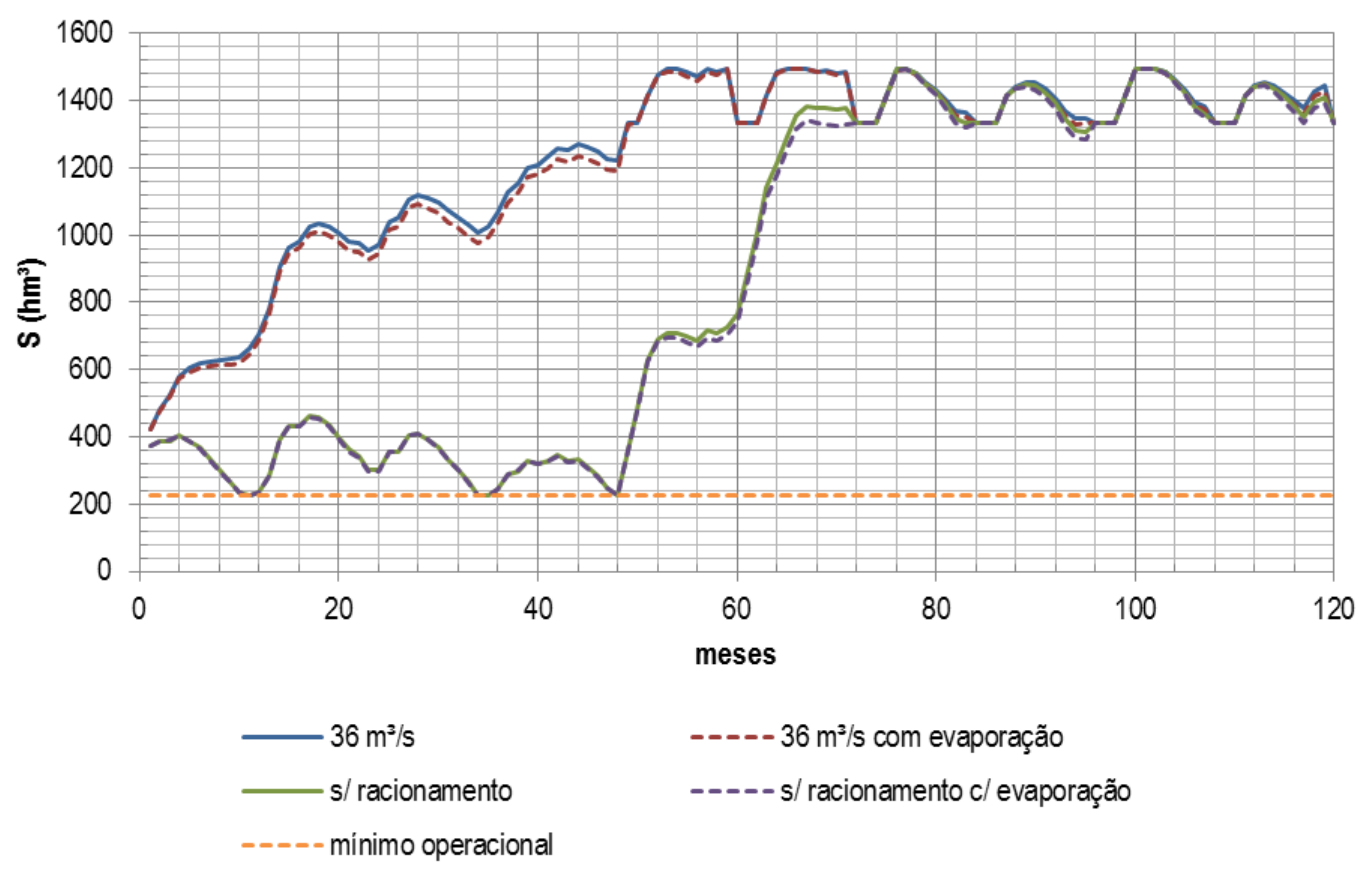

Figura 77 - Evaporação - Sistema Cantareira - Volume armazenado.

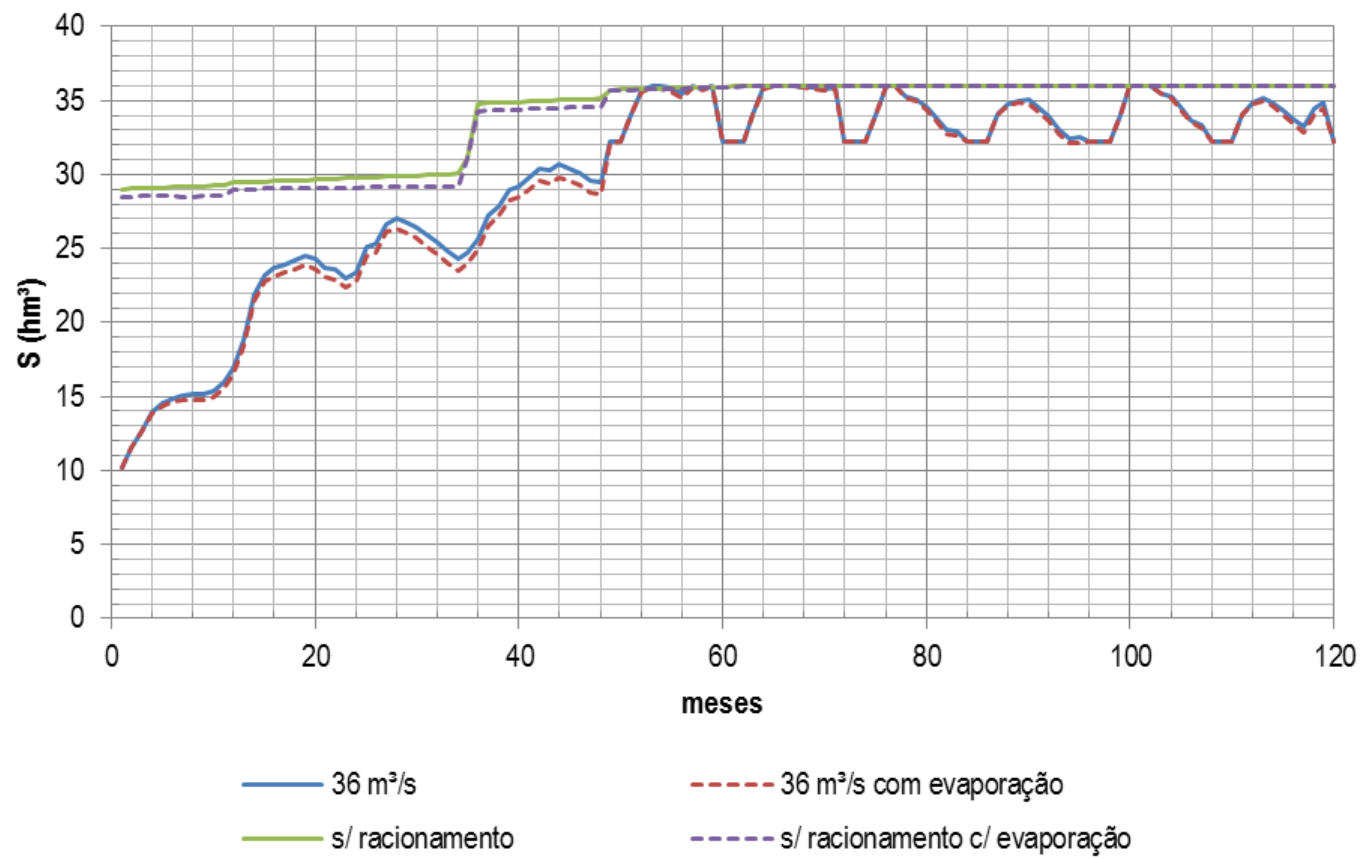

Figura 78 - Evaporação - Sistema Cantareira - Vazão atendida.

A partir dos resultados, notou-se que ao considerar a evaporação a diferença para o atendimento a demanda, na média foi de $0,300 \mathrm{~m}^{3} / \mathrm{s}$ para a operação e de $0,242 \mathrm{~m} / \mathrm{s}$ para a operação sem racionamento. Em uma situação na qual a vazão retirada total é de $17,50 \mathrm{~m}^{3} / \mathrm{s}$ (de 1 de setembro de 2015), uma diferença média de $0,271 \mathrm{~m}^{3} / \mathrm{s}$ representa $1,55 \%$ da vazão total disponibilizada. 
As mesmas otimizações foram realizadas para o conjunto de reservatórios do Sistema Produtor Alto Tietê, com a vazão de demanda fixada em $15 \mathrm{~m}^{3} / \mathrm{s}$. Os resultados gráficos para volume armazenado e vazão atendida estão apresentados na Figura 79 e na Figura 80.

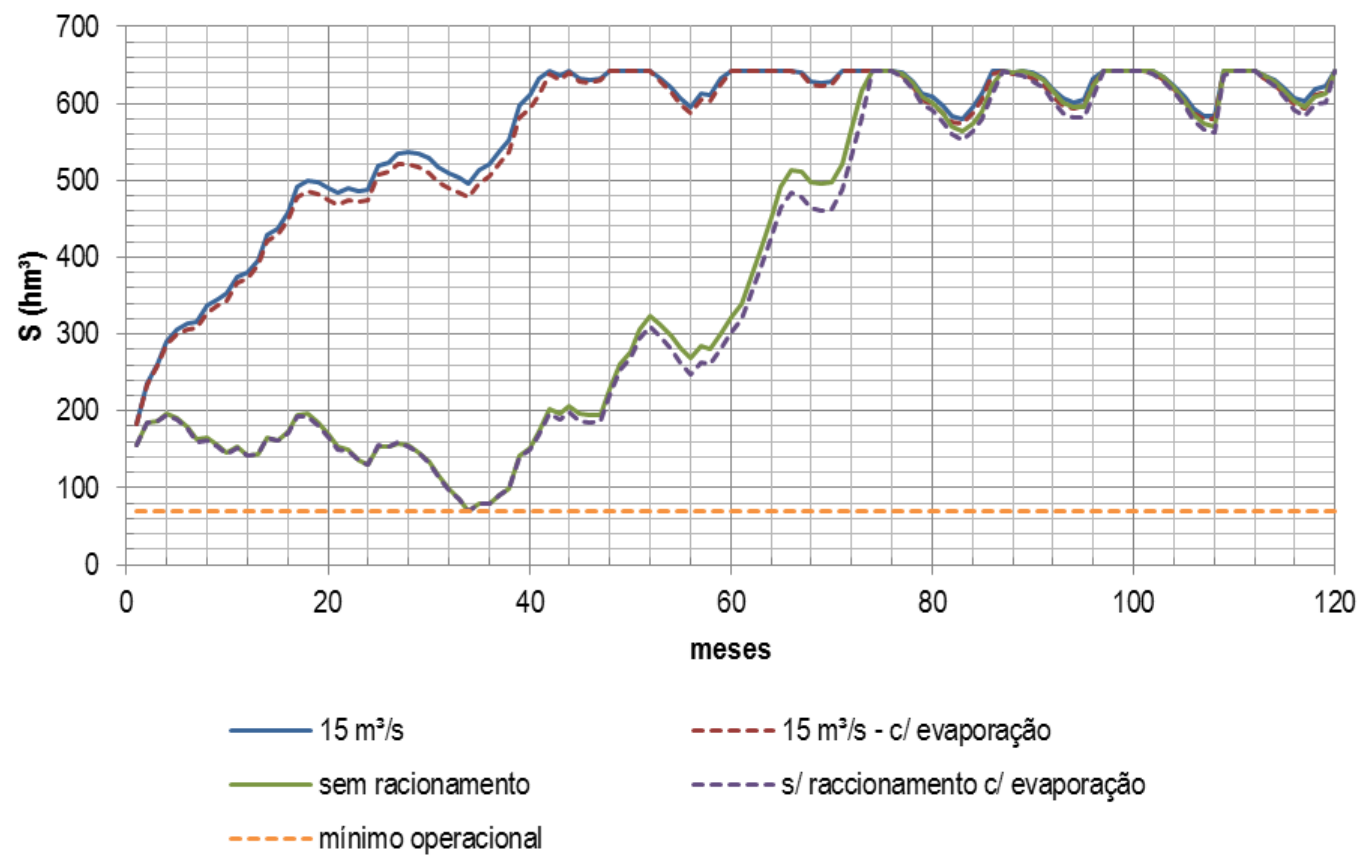

Figura 79 - Evaporação - Sistema Alto Tietê - Volume armazenado.

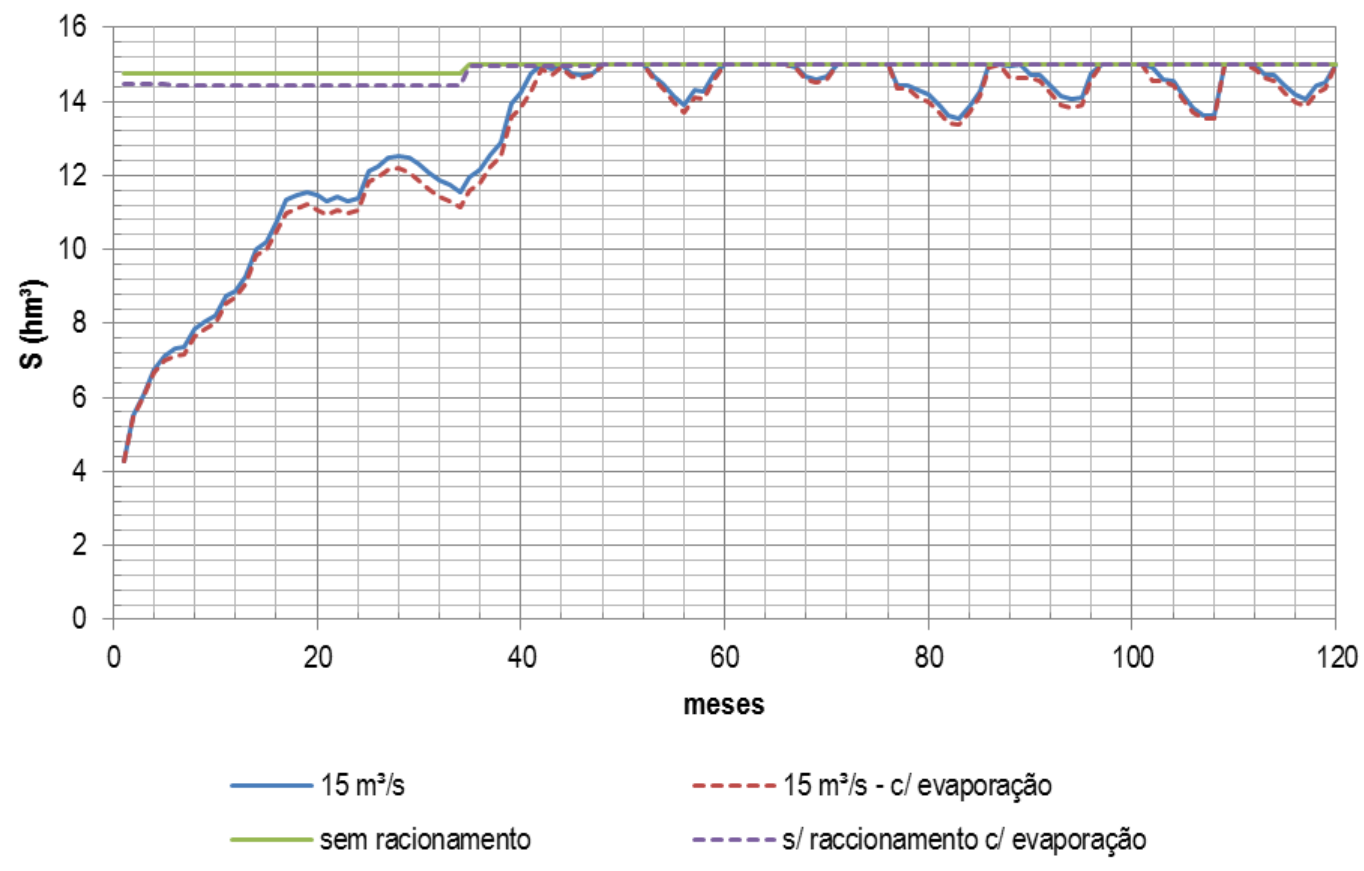

Figura 80 - Evaporação - Sistema Alto Tietê- Vazão atendida. 
A partir das otimizações, pode-se constatar que a evaporação causou uma diferença de $0,163 \mathrm{~m}^{3} / \mathrm{s}$ no cenário de operação com regra de racionamento e $0,086 \mathrm{~m}^{3} / \mathrm{s}$ no cenário sem regra de racionamento. Diante de uma vazão retirada de $14,96 \mathrm{~m} 3 / \mathrm{s} \mathrm{em}$ 01 de setembro de 2015 , a diferença média de $0,125 \mathrm{~m}^{3} / \mathrm{s}$ representa $0,84 \%$ da vazão total retirada do Sistema Alto Tietê.

A avaliação sem regra de racionamento, seja ele em patamares ou com função continua, resultaria na melhor solução possível se não houvesse incerteza sobre as afluências, ou seja, no caso de previsão perfeita de vazões para todo o horizonte de planejamento. Na prática essa opção não pode ser adotada pois implicaria esvaziamento completo dos reservatórios, incompatível com a segurança no abastecimento dada a elevada incerteza e aleatoriedade das vazões.

Para o Reservatório de Guarapiranga, os resultados gráficos para o volume armazenado e a vazão atendida estão apresentados na Figura 81 e na Figura 82. A vazão de demanda foi fixada em $16 \mathrm{~m}^{3} / \mathrm{s}$.

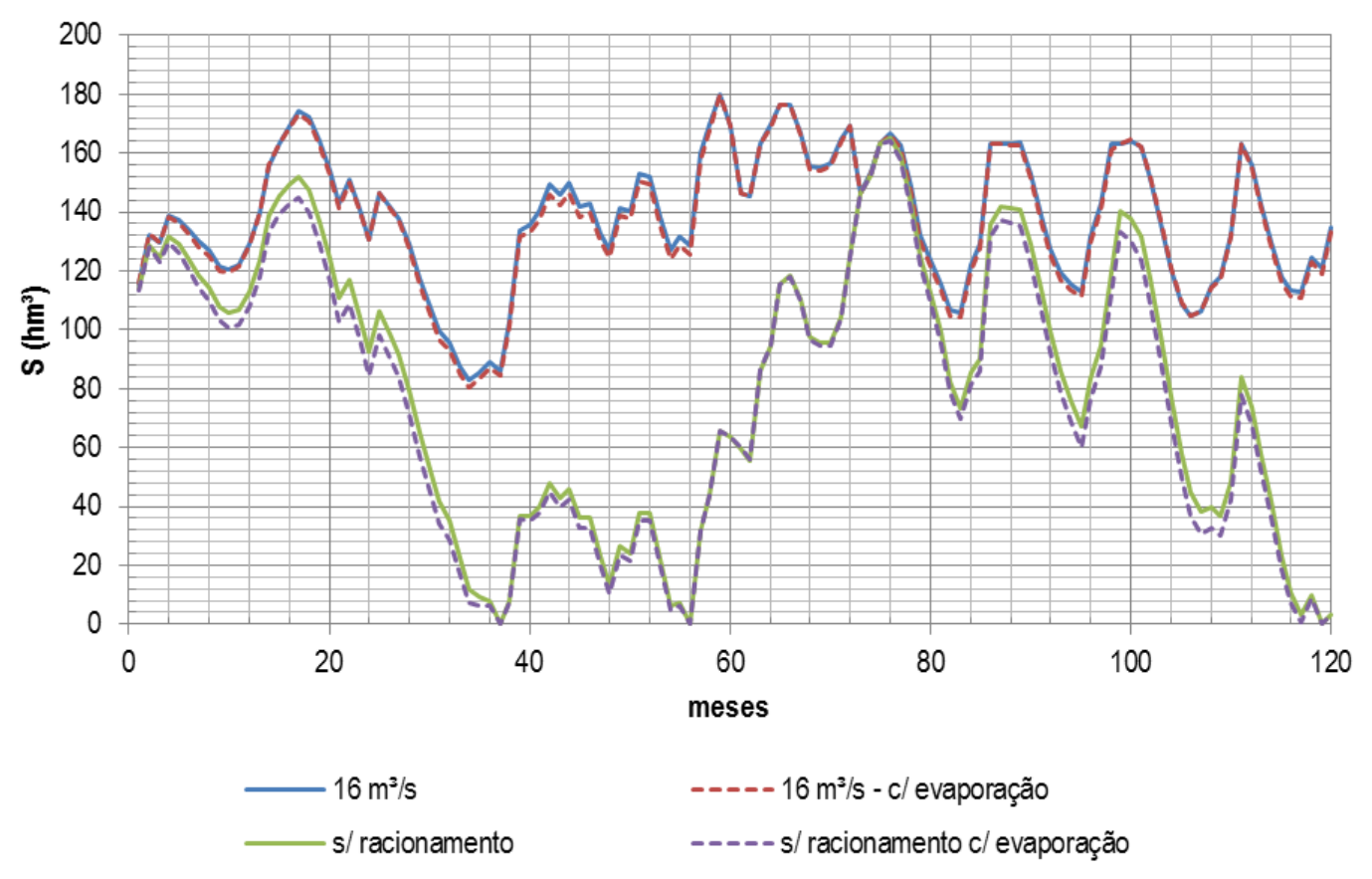

Figura 81 - Evaporação - Guarapiranga - Volume armazenado. 


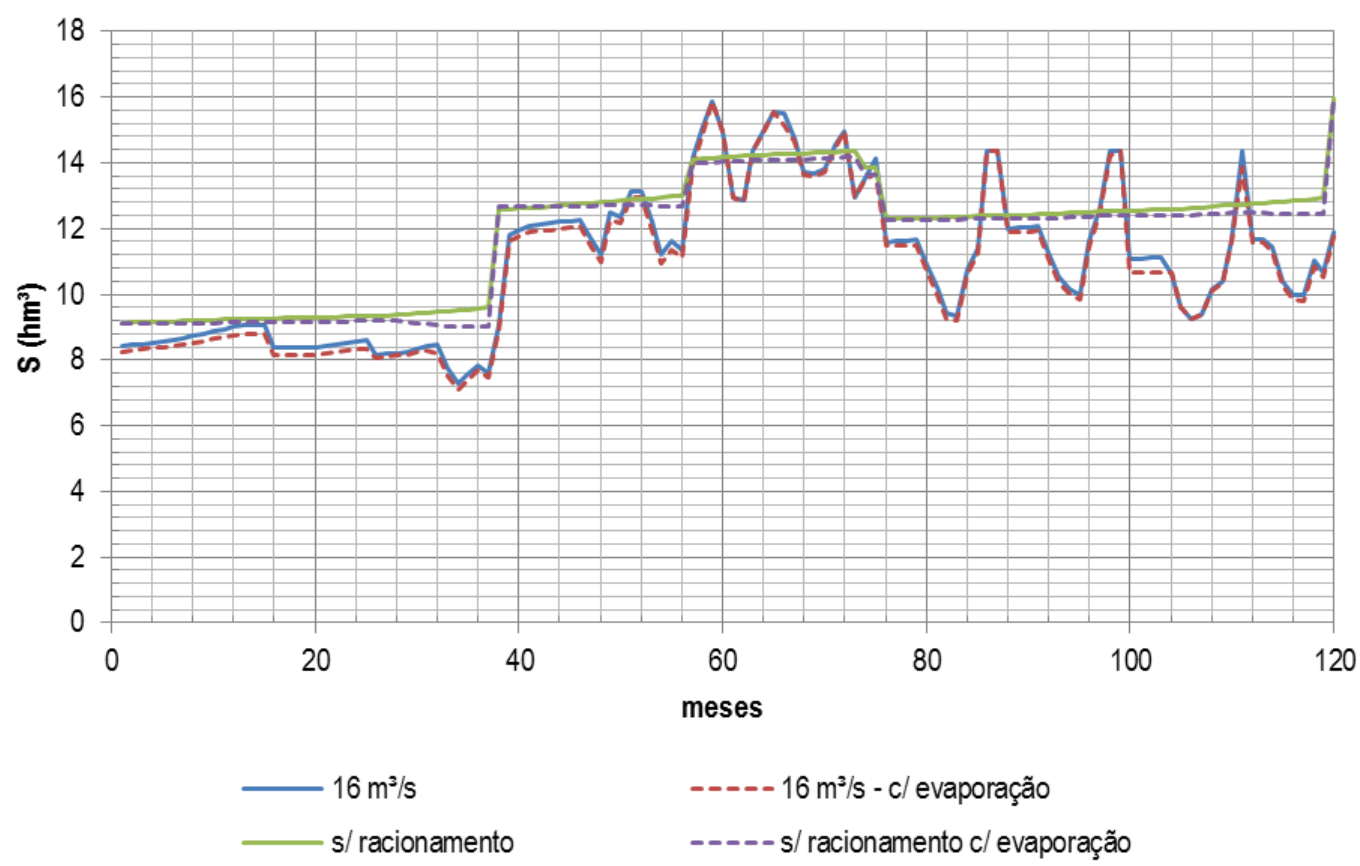

Figura 82 - Evaporação - Guarapiranga- Vazão atendida.

Guarapiranga apresentou uma diferença de 0,165 m³/s no atendimento a demanda com racionamento, e $0,162 \mathrm{~m}^{3} / \mathrm{s}$ sem racionamento. Uma diferença média entre as duas situações extremas, de $0,163 \mathrm{~m}^{3} / \mathrm{s}$ representa $1,19 \%$ da vazão total retirada na situação de 01 de setembro de 2015, que corresponde a 13,75 m³.s.

Ao considerar conjuntamente as evaporações dos Sistemas Cantareira, Alto Tietê e Guarapiranga, elas correspondem na média entre os resultados $0,559 \mathrm{~m}^{3} / \mathrm{s}$ de diferença. Este valor corresponde a $0,97 \%$ do valor total de vazão retirada de todo o sistema, que totalizou 57,620 m³/s em 01 de setembro de 2015. Na Tabela 11 estão apresentados os valores resultantes desta análise, de forma resumida.

Tabela 11 - Resultados das otimizações considerando a evaporação nos sistemas isolados de Cantareira, Alto Tietê e Guarapiranga.

\begin{tabular}{|c|c|c|c|c|}
\hline & $\begin{array}{c}\text { Diferença de } \\
\text { atendimento à } \\
\text { demanda - } \\
\text { com racionamento } \\
\left(\mathrm{m}^{3} / \mathrm{s}\right)\end{array}$ & $\begin{array}{c}\text { Diferença de } \\
\text { atendimento à } \\
\text { demanda - sem } \\
\text { racionamento }\left(\mathrm{m}^{3} / \mathrm{s}\right)\end{array}$ & $\begin{array}{l}\text { Retirada Total } \\
\text { (01 de setembro } \\
\text { de 2015) }\end{array}$ & $\begin{array}{c}\text { Porcentagem: } \\
\text { Diferença de } \\
\text { atendimento à } \\
\text { demanda com } \\
\text { evaporação / vazão } \\
\text { retirada }\end{array}$ \\
\hline Cantareira & 0,300 & 0,242 & 17,500 & $1,55 \%$ \\
\hline Alto Tietê & 0,163 & 0,086 & 14,960 & $0,84 \%$ \\
\hline Guarapiranga & 0,165 & 0,162 & 13,750 & $1,19 \%$ \\
\hline Total & 0,629 & 0,490 & 57,620 & $0,97 \%$ \\
\hline
\end{tabular}


Diante dos resultados apresentados, observa-se que a evaporação é pequena mas não desprezível nos reservatórios da RMSP, principalmente em uma situação de estiagem. Seus valores são superiores aos de dois dos menores sistema produtores que atendem a região. No modelo integrado entre os sistemas existentes apresentado no próximo item a evaporação será considerada como um dado de entrada.

Por outro lado, é importante salientar que a ordem de grandeza da evaporação, pode ser comparada e equivalente às inceretezas das vazões naturais medidas ou esimadas.

\subsection{Modelo integrado}

Após aplicar o racionamento linear e a evaporação nos sistemas de reservatórios mais representativos (Cantareira, Ato Tietê e Guarapiranga), foram realizadas as otimizações para o sistema integrado. A demanda foi fixada em $71 \mathrm{~m}^{3} / \mathrm{s}$, conforme a vazão retirada em janeiro de 2014 (SABESP, 2015a).

O modelo foi montado de forma simplificada, de acordo com as informações adquiridas. Na Figura 83 está apresentada a representação gráfica do modelo, com nós e arcos.

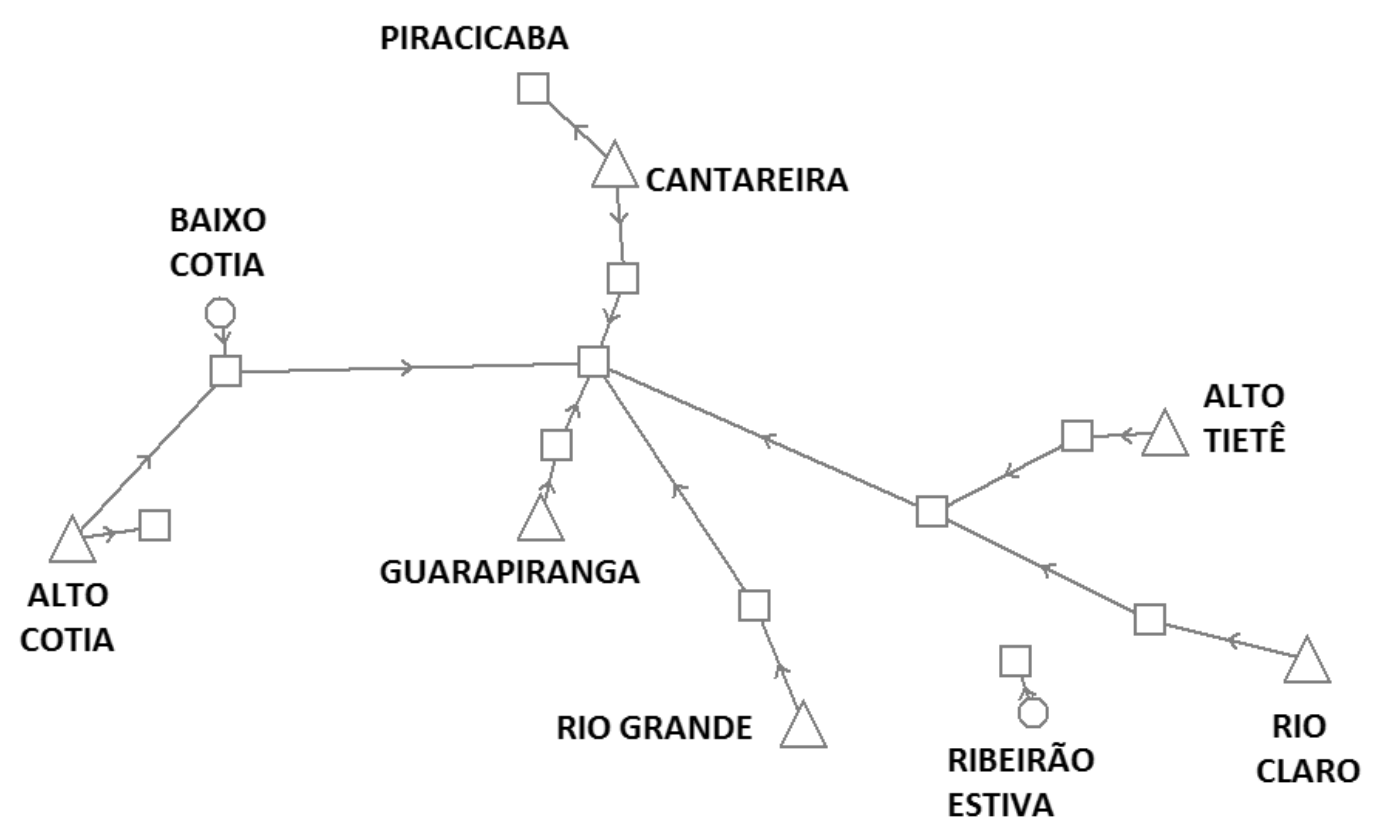


Figura 83 - Visualização gráfica do modelo.

Os resultados do sistema Cantareira estão apresentados graficamente na Figura 84 com informações de volume armazenado e na Figura 85 com vazão de atendimento à demanda.

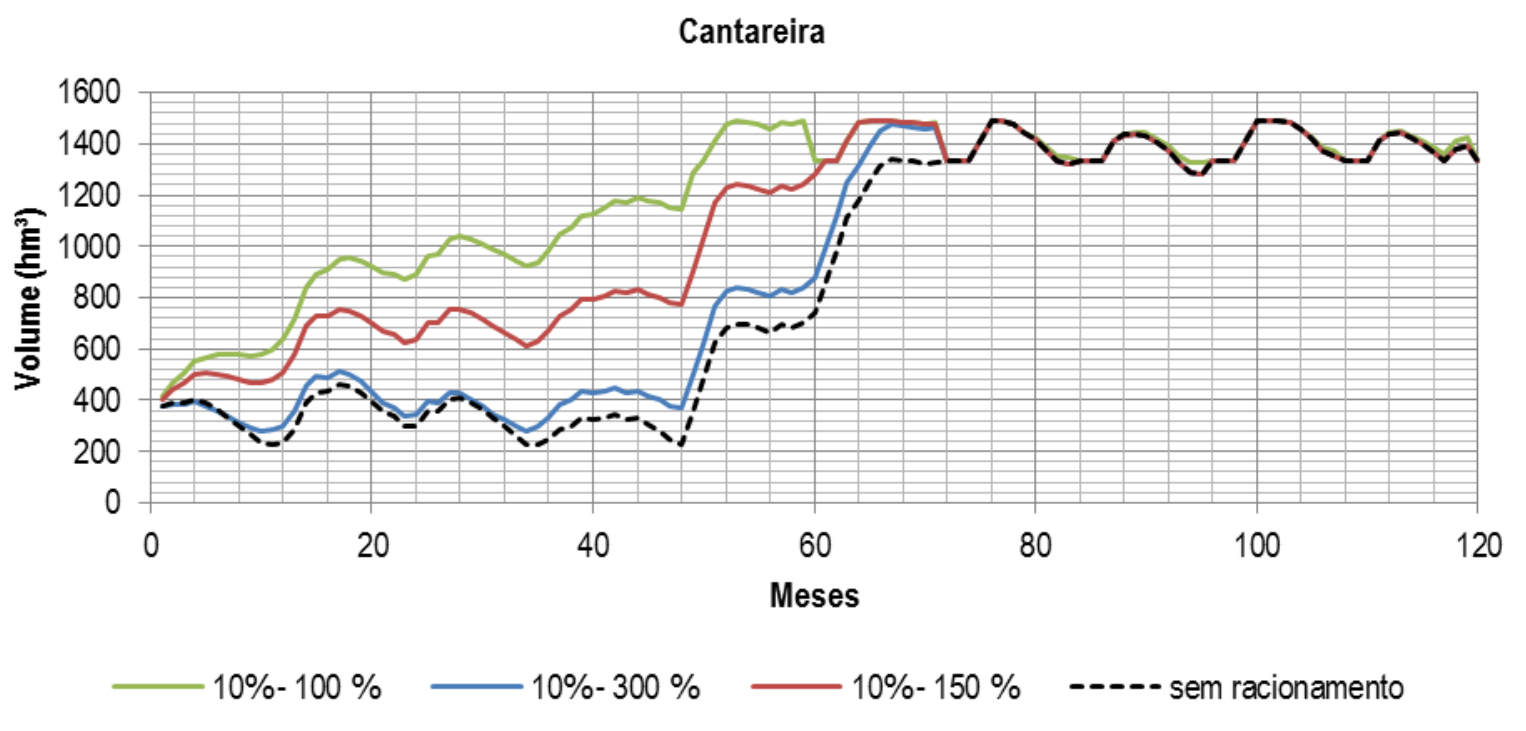

Figura 84 - Modelo integrado - Resultados: Cantareira - Volume Armazenado.

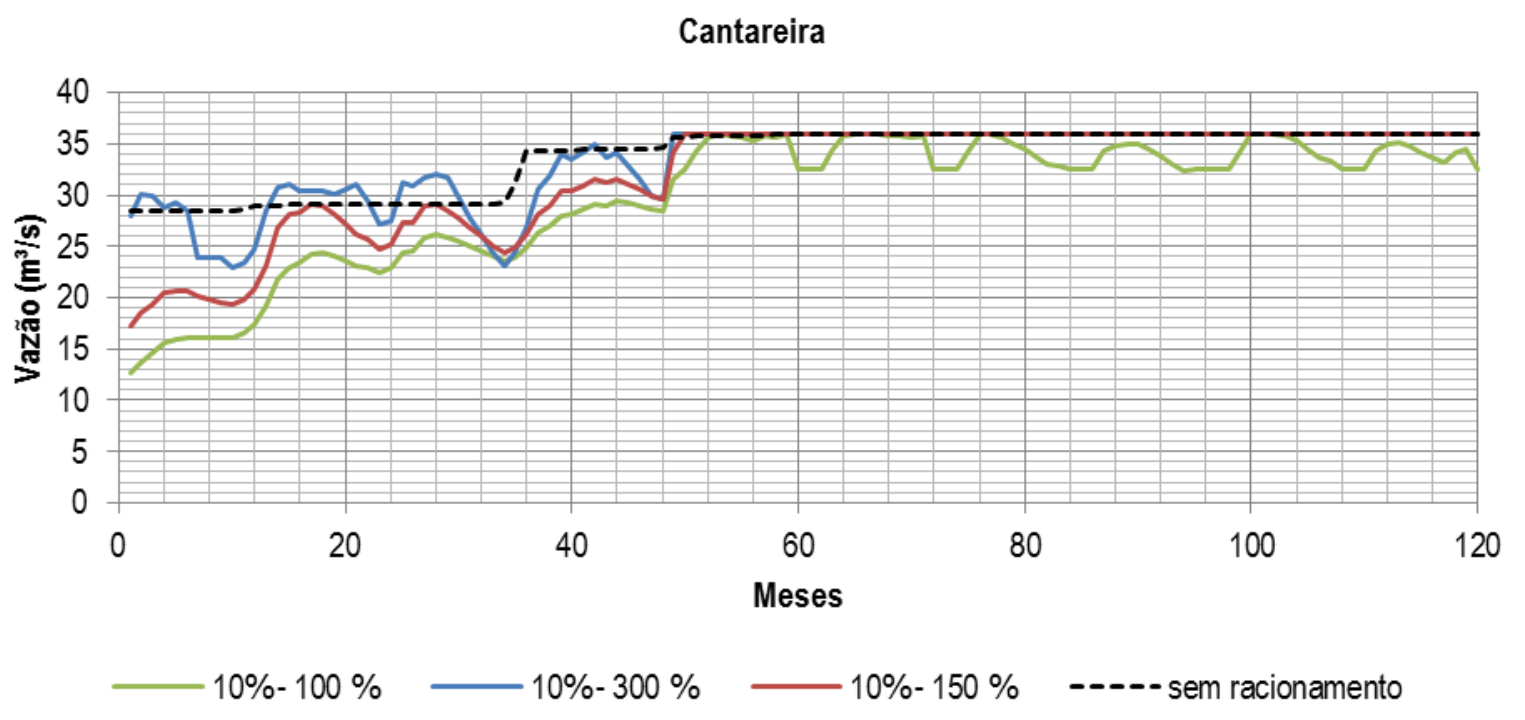

Figura 85 - Modelo integrado - Resultados: Cantareira - Vazão atendida.

Os resultados do sistema Alto Tietê estão apresentados na Figura 86 contendo os volumes armazenados e a Figura 87 com as vazões de atendimento à demanda. 


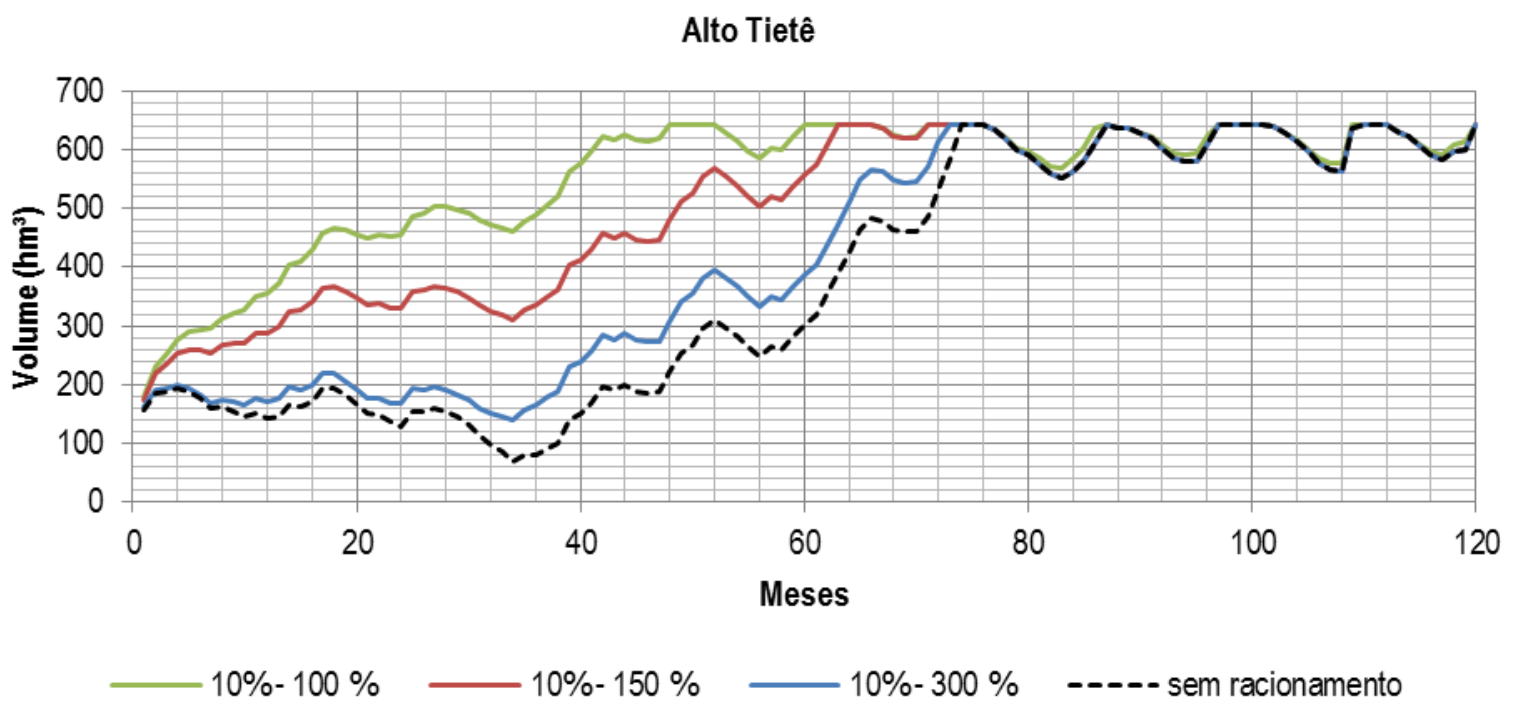

Figura 86 - Modelo integrado - Resultados: Alto Tietê - Volume Armazenado.

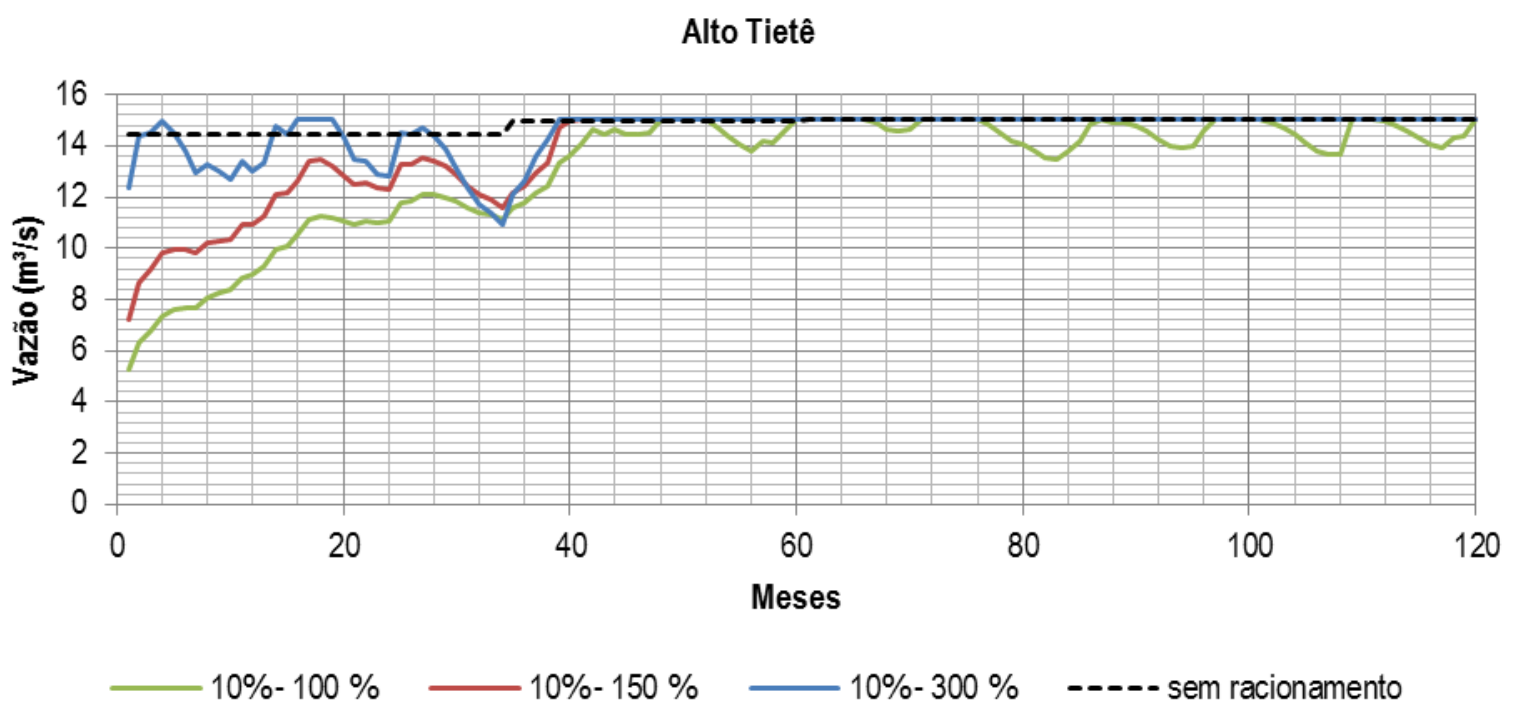

Figura 87-Modelo integrado - Resultados: Alto Tietê - Vazão atendida.

$\mathrm{Na}$ Figura 88 estão apresentados os resultados referentes aos volumes armazenados no reservatório de Guarapiranga. Na Figura 89 os resultados de vazão de atendimento à demanda. 


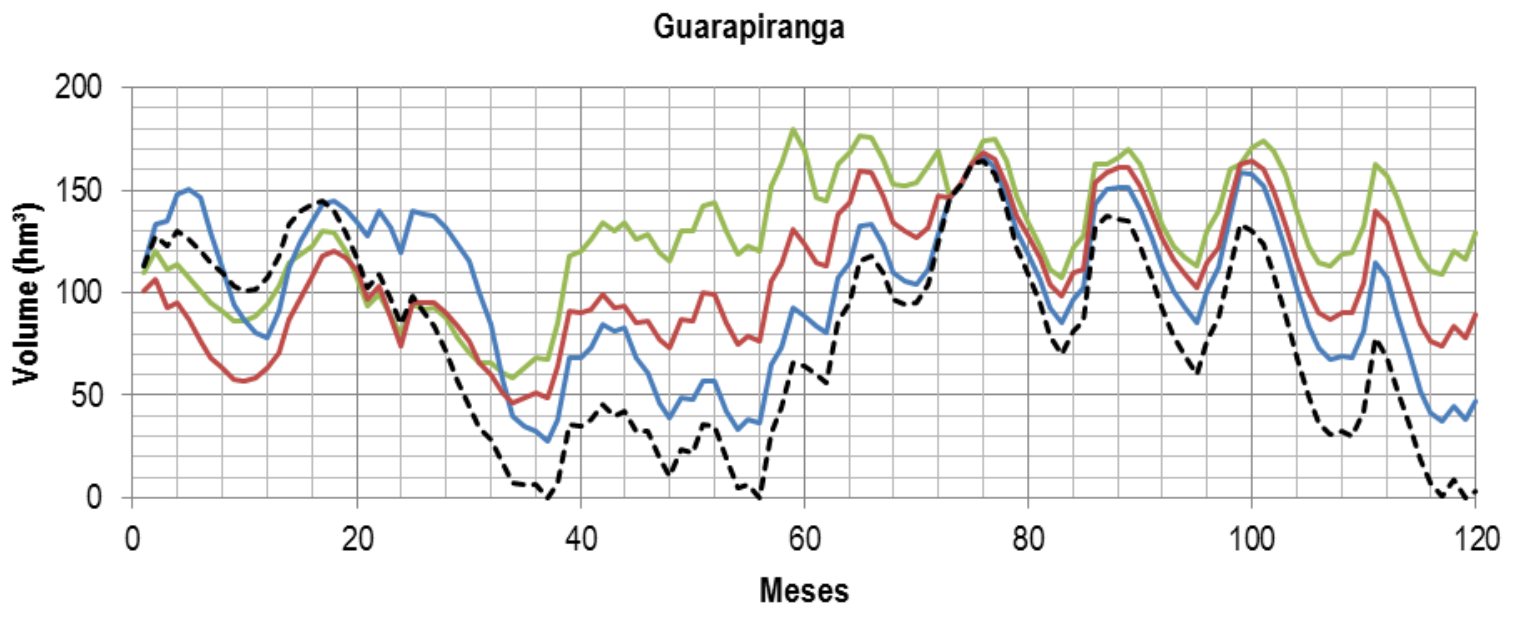

$-10 \%-100 \%$

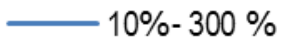
$10 \%-150 \%$ sem racionamento

Figura 88-Modelo integrado - Resultados: Guarapiranga - Volume Armazenado.

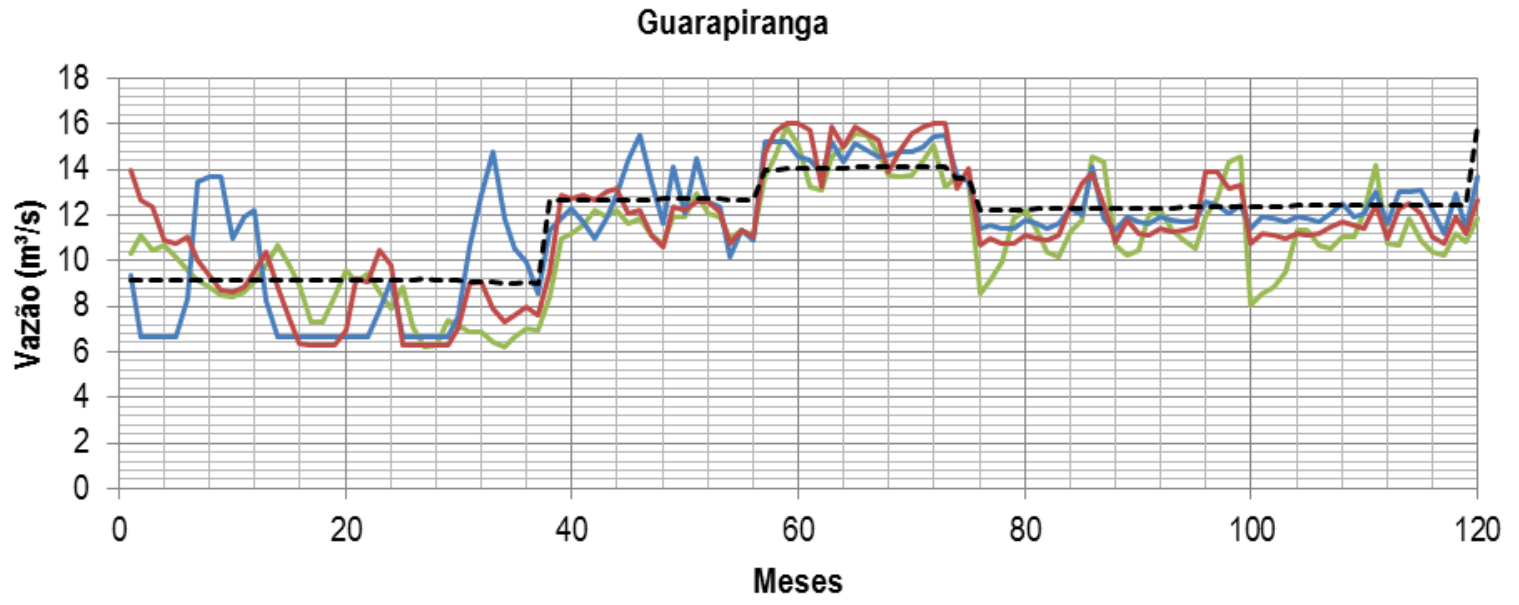

$-10 \%-100 \%$ $-10 \%-300 \%$ 10\%-150\% ------ sem racionamento

Figura 89 - Modelo integrado - Resultados: Guarapiranga - Vazão atendida. 


\section{DISCUSSÃO}

A partir dos resultados dos cenários obtidos no SISAGUA, foi possível analisar a resposta do modelo para uma situação de baixas afluências para uma demanda sem regra de racionamento. Para os cenários avaliados, foi considerada uma situação de estiagem, ao reproduzir a seca de 1953 e 1954 em um horizonte de tempo de 10 anos. Neste período de tempo foi possível notar a recuperação dos sistemas de forma individual e integrada. A capacidade produtiva do sistema, porém, é similar à implantada atualmente na RMSP e a operação é realizada levando em consideração uma previsão perfeita das afluências.

A regra de racionamento linear com diferentes patamares de racionamento variando em função do nível de cada reservatório foi testado. No modelo SISAGUA pode-se variar a vazão de produção em função do nível mínimo ( $\left.Q_{0 \%}\right)$, correspondente ao volume armazenado de $0 \%$ e qual a vazão correspondente ao nível máximo (Q100\%), correspondente a $100 \%$ do volume reservado, de capacidade do sistema. É importante notar que o valor de produção para atendimento à demanda se restringe à capacidade nominal de produção de cada sistema e que o valor $Q_{100 \%}$ é utilizado neste caso para estabelecer a inclinação da curva de racionamento. Quanto maior a vazão máxima ( $\left.Q_{100 \%}\right)$, maior a inclinação da curva, ou seja, o sistema inicia o racionamento apenas com níveis mais baixos, e menor é o racionamento em níveis intermediários, o que atrasa medidas de restrição e faz que em um momento de crise o reservatório demore mais para se recuperar.

O teste de racionamento foi realizado de forma isolada para os reservatórios dos sistemas Cantareira, Alto Tietê e Guarapiranga, que juntos correspondem à capacidade produtiva de cerca de $85 \%$ do sistema integrado da RMSP.

Para os casos estudados, pode-se perceber que ao variar os valores de $Q_{0 \%}$ e $Q_{100 \%}$ é possível de determinar qual é a sensibilidade do sistema com relação ao volume armazenado em função da demanda atendida. O trade-off entre atendimento de demanda e recuperação dos níveis dos reservatórios fica evidenciado neste contexto. Uma operação de reservatórios que melhor atenda as expectativas dos usuários e gestores é aquela intermediária que busca o equilíbrio com o objetivo de maximizar o atendimento da demanda e ao mesmo tempo buscar recuperar os níveis dos 
reservatórios. Além disso, na operação real, não se tem previsão perfeita das afluências, o que faz com quem gestores tenham que atuar com uma margem de volume armazenado ao lidar com uma situação crítica de escassez. Nota-se que o racionamento variado tem pouca influência no tempo de recupração dos sistemas.

Para o Sistema Cantareira, fixou-se o valor mínimo de atendimento à demanda nos valores de: $0,5,10$ e $15 \mathrm{~m}^{3} / \mathrm{s}$. O racionamento linear adotado visa o atendimento à demanda de $33 \mathrm{~m} / \mathrm{s}$ para a Região Metropolitana de São Paulo e de $3 \mathrm{~m}^{3} / \mathrm{s}$ para as Bacias dos Rios PCJ. As vazões máximas (Q100\%) variaram entre 36 e 200 m³/s sendo que com o $Q_{100 \%}$ de $200 \mathrm{~m}^{3} / \mathrm{s}$ o comportamento é similar a de uma operação sem racionamento.

A partir da Tabela 12, pode-se visualizar o resumo das informações obtidas das modelagens com diferentes taxas de racionamento.

Tabela 12 - Resumo dos resultados com diferentes regras de racionamento para o Sistema Cantareira.

\begin{tabular}{|c|c|c|c|c|c|c|c|c|}
\hline \multirow{3}{*}{$\begin{array}{l}Q_{100 \%} \\
\left(m^{3} / \mathbf{s}\right)\end{array}$} & \multicolumn{8}{|c|}{$Q_{0 \%}$} \\
\hline & \multicolumn{2}{|c|}{$0 \mathrm{~m}^{3} / \mathrm{s}$} & \multicolumn{2}{|c|}{$5 \mathrm{~m}^{3} / \mathrm{s}$} & \multicolumn{2}{|c|}{$10 \mathrm{~m}^{3} / \mathrm{s}$} & \multicolumn{2}{|c|}{$15 \mathrm{~m}^{3 / \mathrm{s}}$} \\
\hline & $\begin{array}{l}Q \min \\
\left(m^{3} / s\right)\end{array}$ & $\begin{array}{c}\text { Vol. } \\
\text { armazenado } \\
(\%)\end{array}$ & $\begin{array}{l}Q \min \\
\left(\mathrm{m}^{3} / \mathrm{s}\right)\end{array}$ & $\begin{array}{l}\text { Vol. } \\
\text { armazenado } \\
(\%)\end{array}$ & $\begin{array}{l}Q \min \\
\left(m^{3} / s\right)\end{array}$ & $\begin{array}{c}\text { Vol. } \\
\text { armazenado } \\
(\%)\end{array}$ & $\begin{array}{l}Q \min \\
\left(m^{3} / s\right)\end{array}$ & $\begin{array}{c}\text { Vol. } \\
\text { armazenado } \\
(\%)\end{array}$ \\
\hline 36 & 10,22 & $79,7 \%$ & 13,61 & $77,6 \%$ & 17,06 & $75,1 \%$ & 20,57 & $71,8 \%$ \\
\hline 40 & 11,27 & $77,4 \%$ & 14,65 & $75,3 \%$ & 18,09 & $72,6 \%$ & 21,58 & $68,8 \%$ \\
\hline 50 & 13,86 & $72,5 \%$ & 17,20 & $70,0 \%$ & 20,60 & $67,0 \%$ & 24,06 & $63,4 \%$ \\
\hline 60 & 16,36 & $68,4 \%$ & 19,67 & $66,0 \%$ & 23,04 & $63,1 \%$ & 26,46 & $59,7 \%$ \\
\hline 70 & 18,79 & $65,3 \%$ & 22,06 & $62,9 \%$ & 25,39 & $60,2 \%$ & 27,99 & $57,1 \%$ \\
\hline 80 & 21,13 & $62,8 \%$ & 25,48 & $60,6 \%$ & 27,18 & $58,0 \%$ & 28,56 & $55,2 \%$ \\
\hline 100 & 25,61 & $59,3 \%$ & 27,05 & $57,3 \%$ & 28,24 & $55,0 \%$ & 29,06 & $53,0 \%$ \\
\hline 120 & 26,98 & $56,8 \%$ & 28,00 & $55,0 \%$ & 28,87 & $53,2 \%$ & 29,03 & $52,2 \%$ \\
\hline 160 & 28,45 & $53,7 \%$ & 29,07 & $52,6 \%$ & 29,03 & $52,0 \%$ & 29,00 & $51,9 \%$ \\
\hline 200 & 29,02 & $52,2 \%$ & 29,00 & $51,9 \%$ & 29,00 & $51,9 \%$ & 29,00 & $51,9 \%$ \\
\hline
\end{tabular}

Nos gráficos apresentados na sequência (Figura 90 a Figura 92) estão apresentadas as relações das informações apresentadas na tabela. Cada linha representa uma abordagem diferente de Q0\%. Na Figura 90 está apresentada a relação de vazão mínima de atendimento à demanda $\left(\mathrm{m}^{3} / \mathrm{s}\right)$ em função da variação dos valores de $Q_{100 \%}$. 


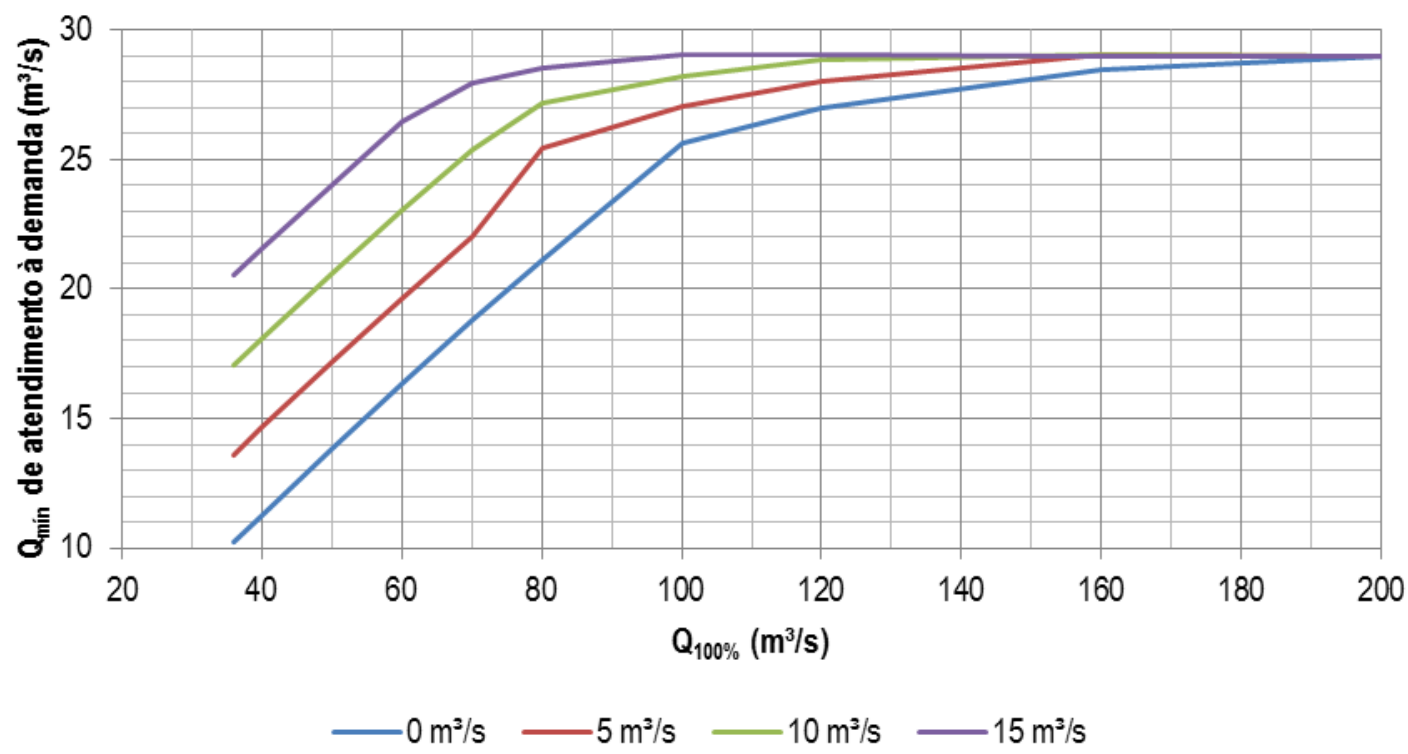

Figura 90 - Sistema Cantareira: Vazão mínima de atendimento à demanda $\left(m^{3} / \mathrm{s}\right)$ x $Q_{100 \%}\left(m^{3} / \mathrm{s}\right)$.

Na Figura 91 o gráfico apresentado é sobre o volume armazenado médio em função da variação da vazão máxima $\left(Q_{100 \%}\right)$ e a Figura 92 contém a variação do volume armazenado médio (\%) em função da vazão mínima de atendimento à demanda.

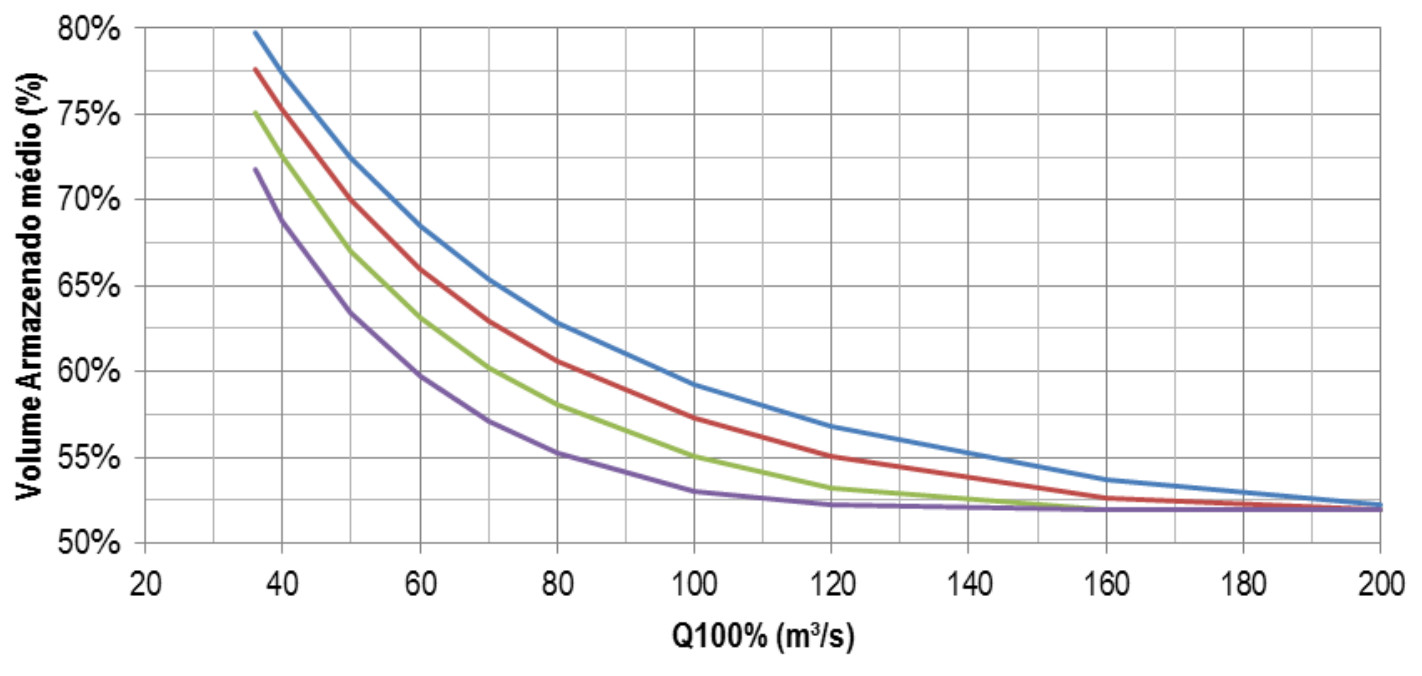

$-0 \mathrm{~m}^{2} / \mathrm{s}-5 \mathrm{~m}^{2} / \mathrm{s}-10 \mathrm{~m}^{2} / \mathrm{s}-15 \mathrm{~m}^{2} / \mathrm{s}$

Figura 91 - Sistema Cantareira: Volume Armazenado médio (\%) x $Q_{100 \%}\left(m^{3} / s\right)$. 


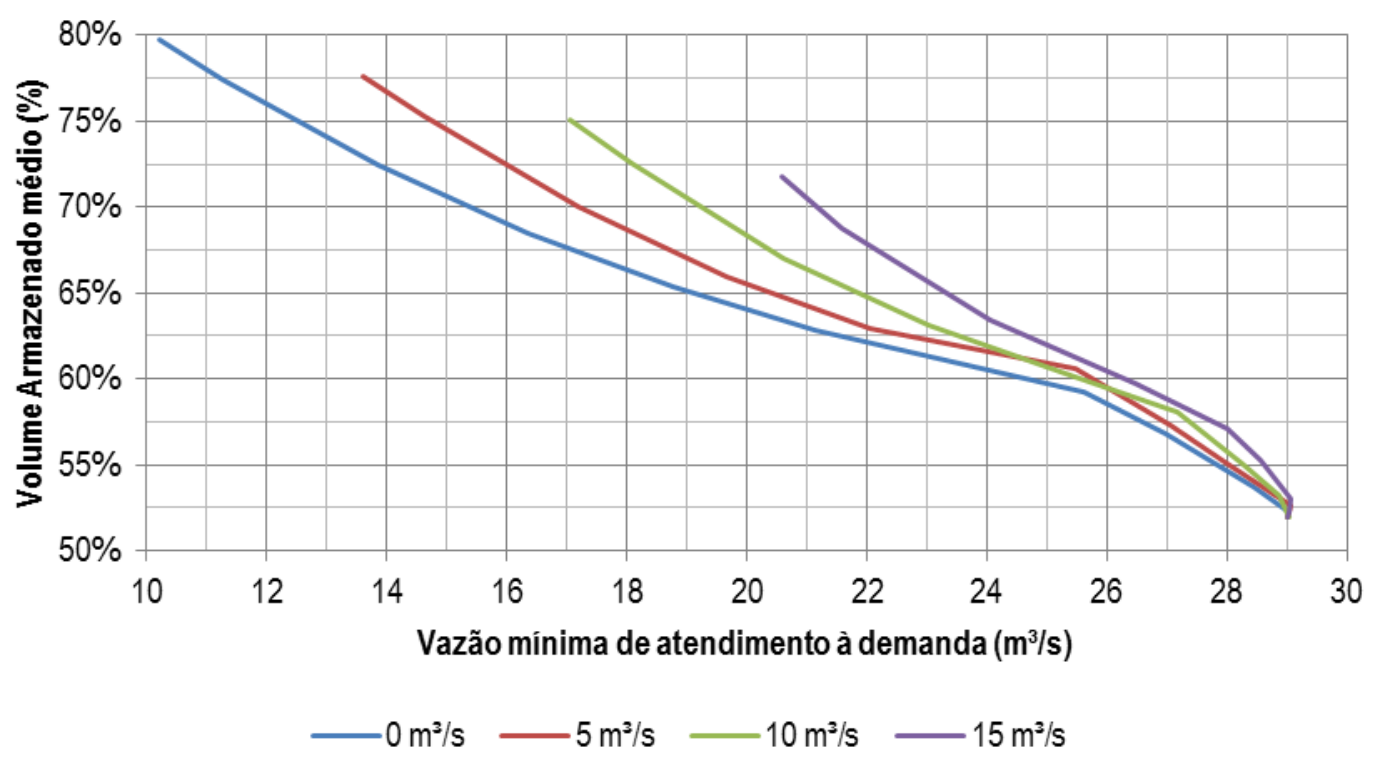

Figura 92 - Sistema Cantareira: Volume armazenado médio (\%) x Vazão mínima de atendimento à demanda $\left(\mathrm{m}^{3} / \mathrm{s}\right)$.

Nota-se que o comportamento das curvas com diferentes vazões mínimas é similar, e todas convergem para uma situação sem racionamento, ao elevar a vazão máxima. No Sistema Cantareira de janeiro a dezembro de 2015, de acordo com os boletins dos mananciais emitidos pela Sabesp, a vazão média retirada para abastecimento foi de $14,1 \mathrm{~m}^{3} / \mathrm{s}$ e a mínima média mensal de $13,3 \mathrm{~m}^{3} / \mathrm{s}$ (junho de 2015). Nota-se que essa vazão mínima ocorre para uma vazão mínima de $Q_{0 \%}$ de $0 \mathrm{~m}^{3} / \mathrm{s}$ e $Q_{100 \%}$ de aproximadamente $50 \mathrm{~m}^{3} / \mathrm{s}$.

Para o Sistema Alto Tietê, cuja capacidade nominal produtiva é de $15 \mathrm{~m}^{3} / \mathrm{s}$, a vazão mínima foi fixada em 0,0; 2,5; 5,0 e 7,5 m³/s e as vazões máximas $Q_{100 \%}$ variaram de $15 \mathrm{~m}^{3} / \mathrm{s}$ a $100 \mathrm{~m}^{3} / \mathrm{s}$ para cada vazão mínima. De forma análoga ao Sistema Cantareira, na Tabela 13 estão contidas as informações adquiridas a partir da modelagem de forma resumida. 
Tabela 13 - Resumo dos resultados com diferentes regras de racionamento para o Sistema Alto Tietê.

\begin{tabular}{|c|c|c|c|c|c|c|c|c|}
\hline \multirow{3}{*}{$\begin{array}{r}Q_{100 \%} \\
\left(m^{3} / \mathbf{s}\right)\end{array}$} & \multicolumn{8}{|c|}{$Q_{0 \%}$} \\
\hline & \multicolumn{2}{|c|}{$0 \mathrm{~m}^{3} / \mathrm{s}$} & \multicolumn{2}{|c|}{$2,5 \mathrm{~m}^{3} / \mathrm{s}$} & \multicolumn{2}{|c|}{$5 \mathrm{~m}^{3} / \mathrm{s}$} & \multicolumn{2}{|c|}{$7,5 \mathrm{~m}^{3} / \mathrm{s}$} \\
\hline & $\begin{array}{l}Q \min \\
\left(m^{3} / s\right)\end{array}$ & $\begin{array}{c}\text { Vol. } \\
\text { armazenad } \\
\text { o (\%) }\end{array}$ & $\begin{array}{l}Q \min \\
\left(m^{3} / s\right)\end{array}$ & $\begin{array}{c}\text { Vol. } \\
\text { armazenad } \\
\text { o (\%) }\end{array}$ & $\begin{array}{l}Q \min \\
\left(\mathbf{m}^{3} / \mathbf{s}\right)\end{array}$ & $\begin{array}{c}\text { Vol. } \\
\text { armazenad } \\
\text { o (\%) }\end{array}$ & $\begin{array}{l}Q \min \\
\left(m^{3} / s\right)\end{array}$ & $\begin{array}{c}\text { Vol. } \\
\text { armazenad } \\
\text { o (\%) }\end{array}$ \\
\hline 15 & 4,26 & $86,9 \%$ & 5,96 & $85,3 \%$ & 7,70 & $82,9 \%$ & 9,47 & $79,8 \%$ \\
\hline 18 & 5,06 & $83,1 \%$ & 6,75 & $81,1 \%$ & 8,47 & $78,5 \%$ & 10,22 & $74,5 \%$ \\
\hline 20 & 5,58 & $81,0 \%$ & 7,26 & $78,7 \%$ & 8,97 & $75,5 \%$ & 10,72 & $71,4 \%$ \\
\hline 25 & 6,84 & $75,9 \%$ & 8,50 & $73,2 \%$ & 10,19 & $69,9 \%$ & 11,92 & $66,0 \%$ \\
\hline 30 & 8,05 & $72,0 \%$ & 9,69 & $69,3 \%$ & 11,37 & $66,2 \%$ & 12,67 & $62,4 \%$ \\
\hline 35 & 9,23 & $68,9 \%$ & 10,85 & $66,4 \%$ & 12,48 & $63,5 \%$ & 12,81 & $60,3 \%$ \\
\hline 40 & 10,36 & $66,6 \%$ & 11,96 & $64,2 \%$ & 12,60 & $61,5 \%$ & 13,07 & $59,0 \%$ \\
\hline 45 & 12,34 & $63,0 \%$ & 12,57 & $61,1 \%$ & 12,98 & $59,2 \%$ & 13,45 & $57,2 \%$ \\
\hline 60 & 12,61 & $60,9 \%$ & 12,94 & $59,4 \%$ & 13,29 & $57,7 \%$ & 13,78 & $56,0 \%$ \\
\hline 100 & 13,60 & $56,8 \%$ & 13,98 & $55,8 \%$ & 14,74 & $55,3 \%$ & 14,74 & $55,3 \%$ \\
\hline
\end{tabular}

Da Figura 93 a Figura 95 estão apresentados os gráficos que mostram de forma visual os resultados apresentados na tabela de resumo das otimizações.

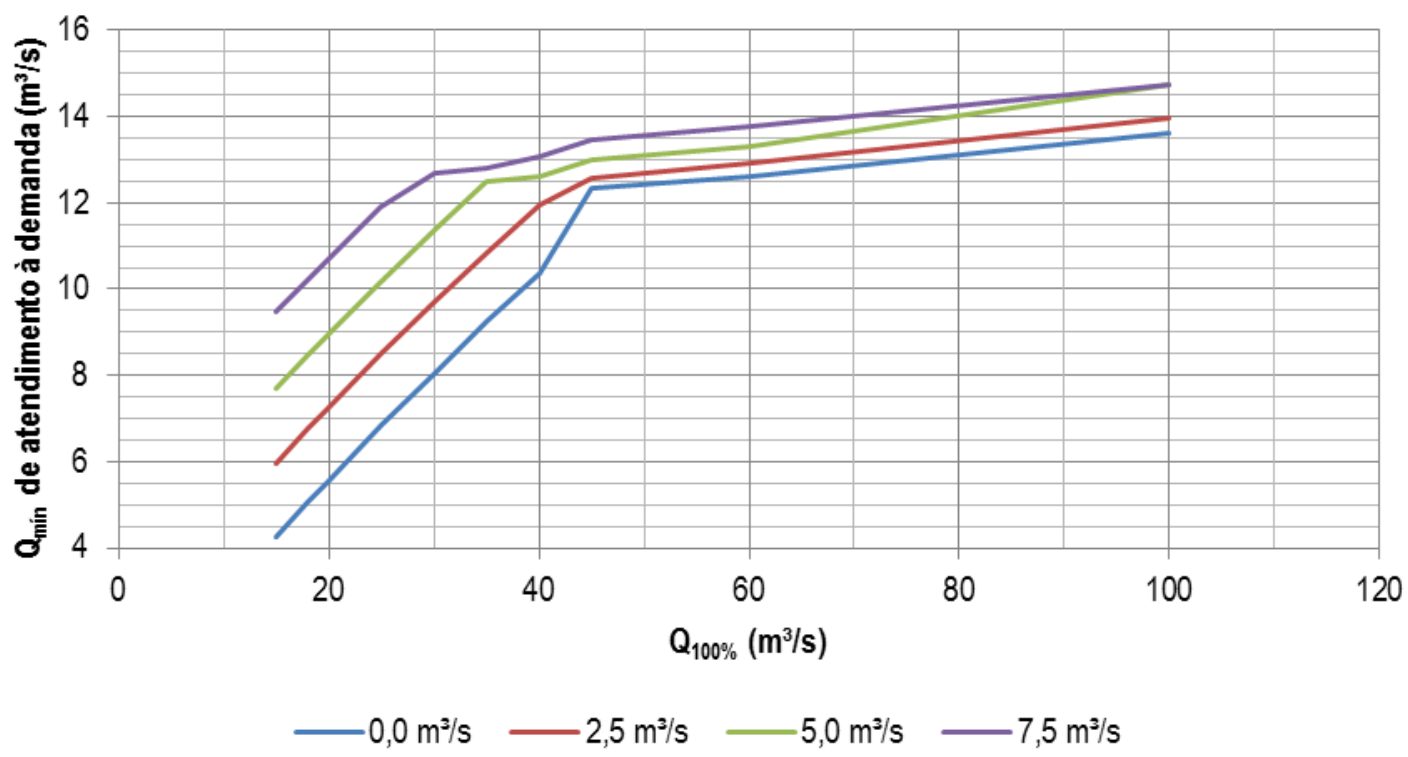

Figura 93 - Sistema Alto Tietê: Vazão mínima de atendimento à demanda $\left(\mathrm{m}^{3} / \mathrm{s}\right)$ × $\mathbf{Q}_{100 \%}\left(\mathrm{~m}^{3 / s}\right)$. 


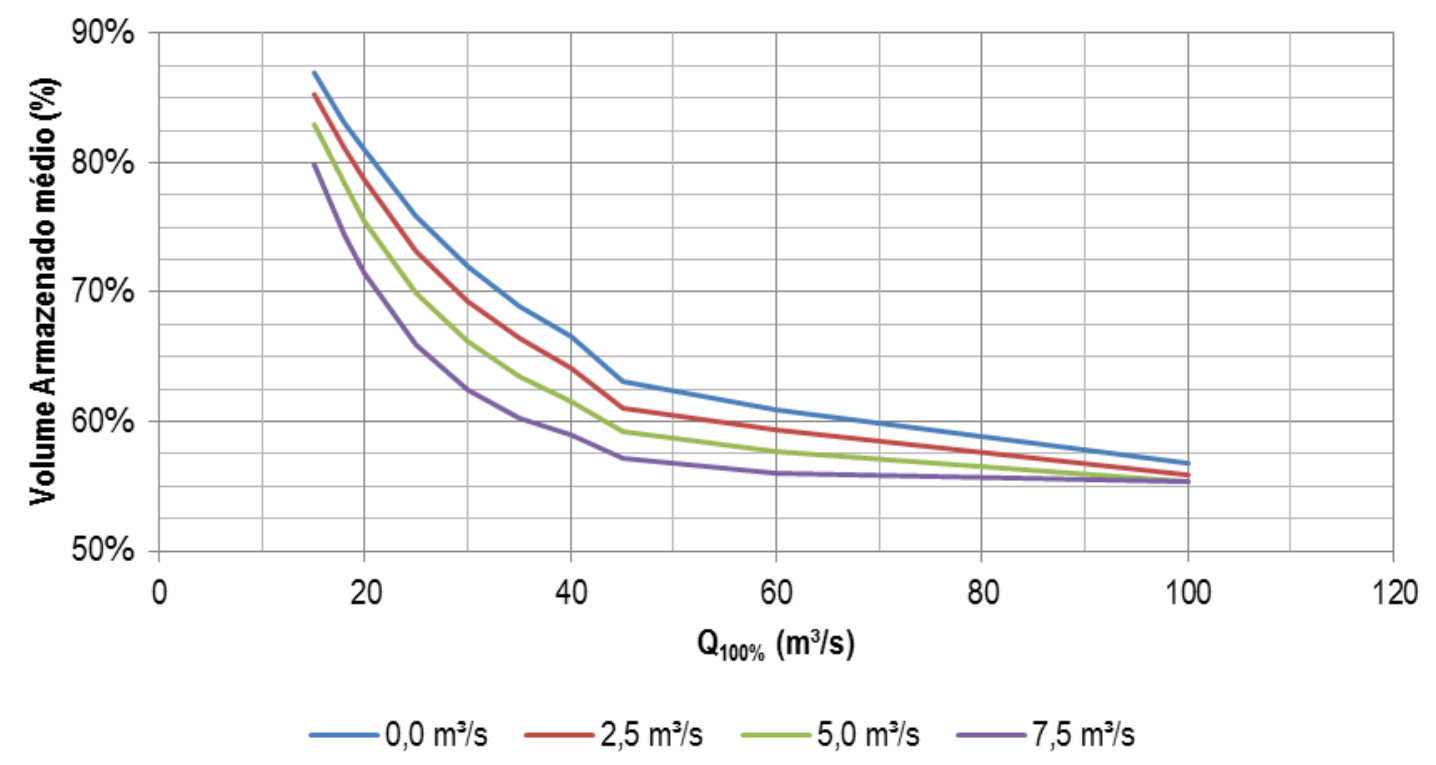

Figura 94 - Sistema Alto Tietê: Volume Armazenado médio (\%) x $Q_{100 \%}\left(\mathrm{~m}^{3} / \mathrm{s}\right)$.

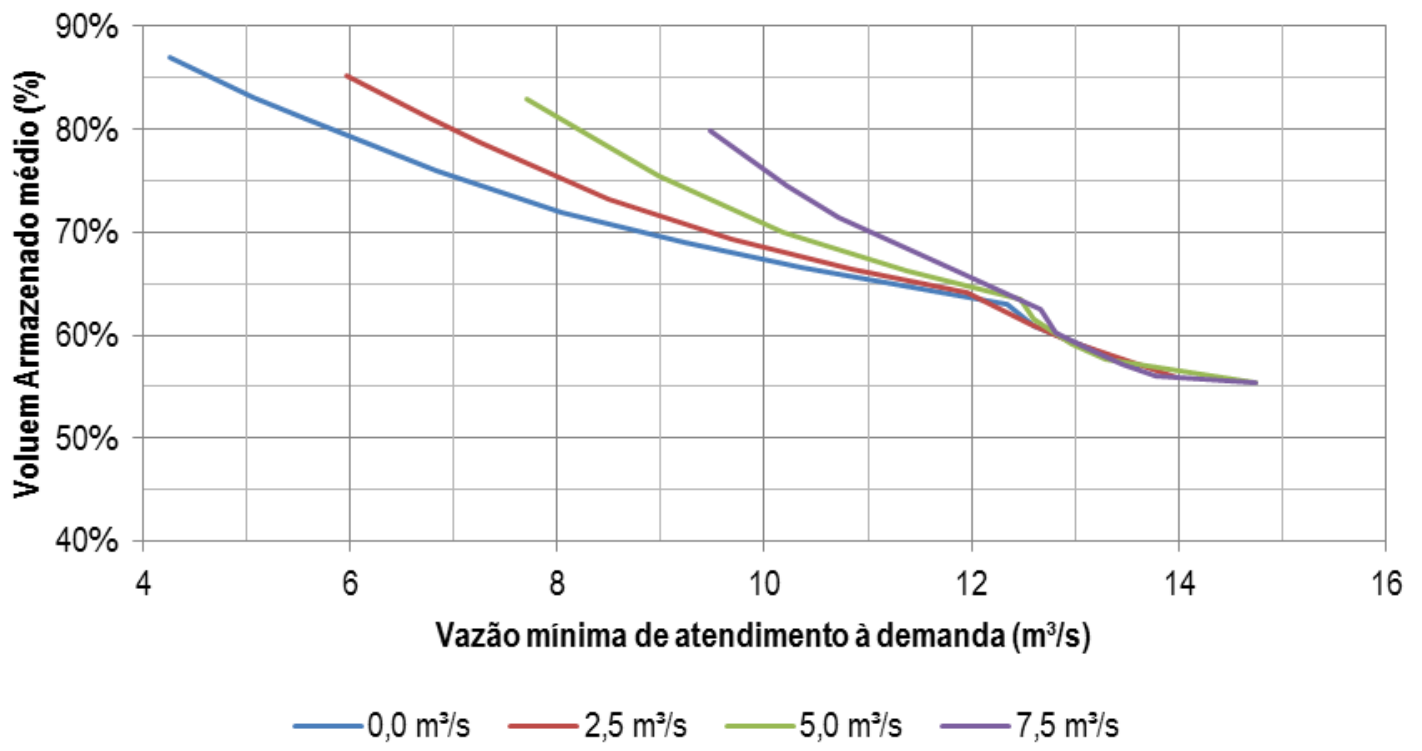

Figura 95 - Sistema Alto Tietê: Volume armazenado médio (\%) x Vazão mínima de atendimento à demanda $\left(\mathrm{m}^{3} / \mathrm{s}\right)$.

Para o Sistema Alto Tietê, a vazão media de retirada de janeiro a dezembro de 2015 foi de $12,4 \mathrm{~m}^{3} / \mathrm{s}$. A vazão mínima de atendimento foi de $10,71 \mathrm{~m} 3 / \mathrm{s}$ correspondente ao mês de janeiro de 2015. Para esta vazão mínima pode-se adotar diferentes políticas de racionamento, a depender do volume armazenado que se espera manter ao longo do tempo.

Para o Sistema Guarapiranga, com a capacidade produtiva de $16 \mathrm{~m}^{3} / \mathrm{s}$, as vazões mínimas foram fixadas em 0,$0 ; 2,5 ; 5,0$ e $7,5 \mathrm{~m}^{3} / \mathrm{s}$ e as vazões máximas para cada 
Q $\%$ foram variadas de 16 a 1.000 m³/s. Na Tabela 14 estão apresentados os resultados de vazão mínima de atendimento e volume médio armazenado para cada valor de racionamento utilizado para o Sistema Guarapiranga.

Tabela 14 - Resumo dos resultados com diferentes regras de racionamento para o Sistema Guarapiranga.

\begin{tabular}{|c|c|c|c|c|c|c|c|c|}
\hline \multirow{3}{*}{$\begin{array}{l}Q_{100 \%} \\
\left(m^{3} / s\right)\end{array}$} & \multicolumn{8}{|c|}{$Q_{0 \%}$} \\
\hline & \multicolumn{2}{|c|}{$0,0 \mathrm{~m}^{3} / \mathrm{s}$} & \multicolumn{2}{|c|}{$2,5 \mathrm{~m}^{3} / \mathrm{s}$} & \multicolumn{2}{|c|}{$5,0 \mathrm{~m}^{3} / \mathrm{s}$} & \multicolumn{2}{|c|}{$7,5 \mathrm{~m}^{3} / \mathrm{s}$} \\
\hline & $\begin{array}{l}Q \min \\
\left(\mathrm{m}^{3} / \mathrm{s}\right)\end{array}$ & $\begin{array}{c}\text { Vol. } \\
\text { armazenad } \\
\text { o (\%) }\end{array}$ & $\begin{array}{l}Q \min \\
\left(m^{3} / s\right)\end{array}$ & $\begin{array}{c}\text { Vol. } \\
\text { armazenad } \\
\text { o (\%) }\end{array}$ & $\begin{array}{l}Q \min \\
\left(\mathrm{m}^{3} / \mathrm{s}\right)\end{array}$ & $\begin{array}{c}\text { Vol. } \\
\text { armazenad } \\
\text { o (\%) }\end{array}$ & $\begin{array}{l}Q \min \\
\left(\mathrm{m}^{3} / \mathrm{s}\right)\end{array}$ & $\begin{array}{c}\text { Vol. } \\
\text { armazenad } \\
\text { o (\%) }\end{array}$ \\
\hline 16 & 7,30 & $76,2 \%$ & 7,61 & $73,4 \%$ & 7,82 & $68,3 \%$ & 8,09 & $60,3 \%$ \\
\hline 20 & 7,77 & $71,1 \%$ & 7,90 & $67,4 \%$ & 8,00 & $61,9 \%$ & 8,12 & $54,2 \%$ \\
\hline 25 & 7,97 & $65,6 \%$ & 8,03 & $61,9 \%$ & 8,08 & $57,3 \%$ & 8,19 & $50,9 \%$ \\
\hline 30 & 8,05 & $62,3 \%$ & 8,09 & $59,1 \%$ & 8,13 & $54,9 \%$ & 8,23 & $49,7 \%$ \\
\hline 50 & 7,99 & $55,9 \%$ & 8,04 & $53,4 \%$ & 8,10 & $50,7 \%$ & 8,16 & $47,7 \%$ \\
\hline 200 & 8,56 & $47,6 \%$ & 8,57 & $46,9 \%$ & 8,59 & $46,2 \%$ & 8,61 & $45,4 \%$ \\
\hline 1000 & 9,12 & $45,5 \%$ & 9,13 & $45,3 \%$ & 9,13 & $45,2 \%$ & 9,14 & $45,0 \%$ \\
\hline
\end{tabular}

Nas Figura 96 a Figura 98 estão apresentados os gráficos referentes às informações contidas na tabela resumo.

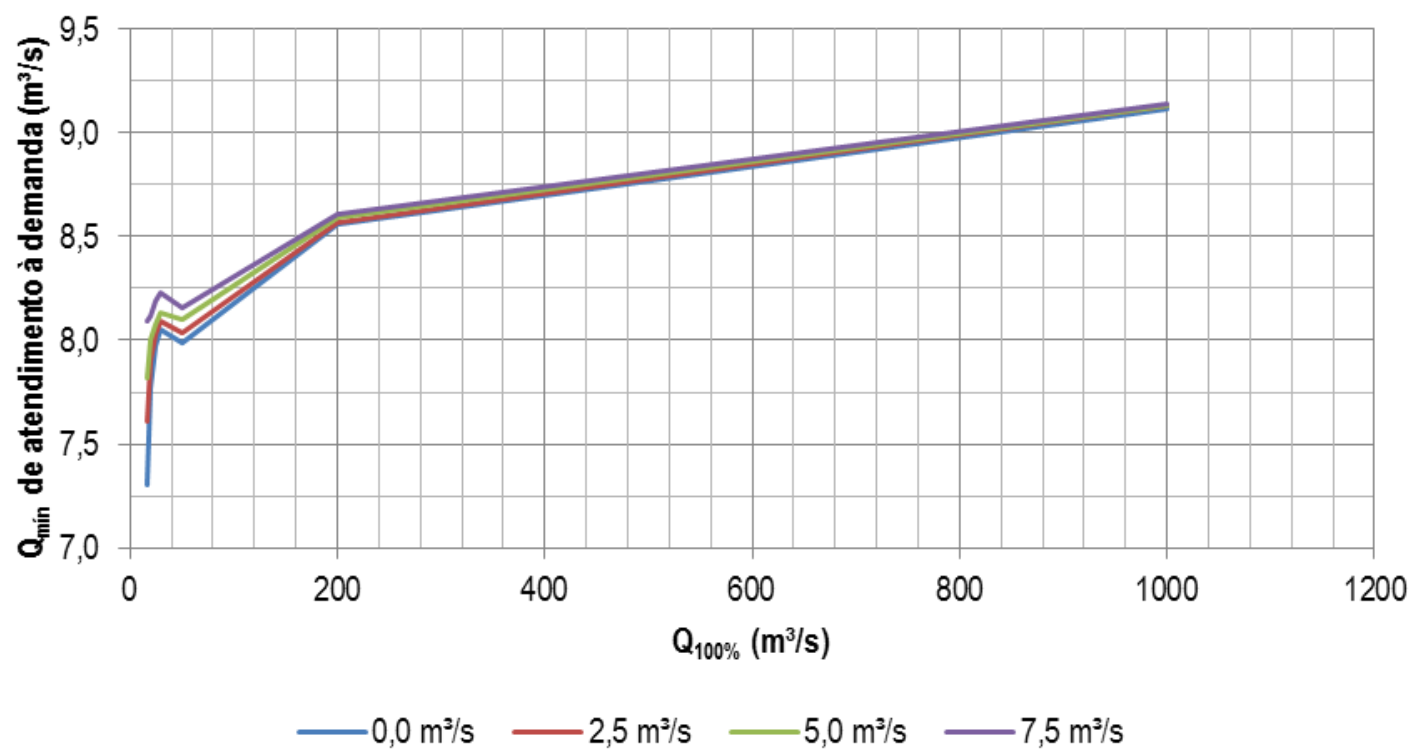

Figura 96 - Sistema Guarapiranga: Vazão mínima de atendimento à demanda $\left(m^{3} / s\right)$ x $Q_{100 \%}$ $\left(m^{3} / s\right)$. 


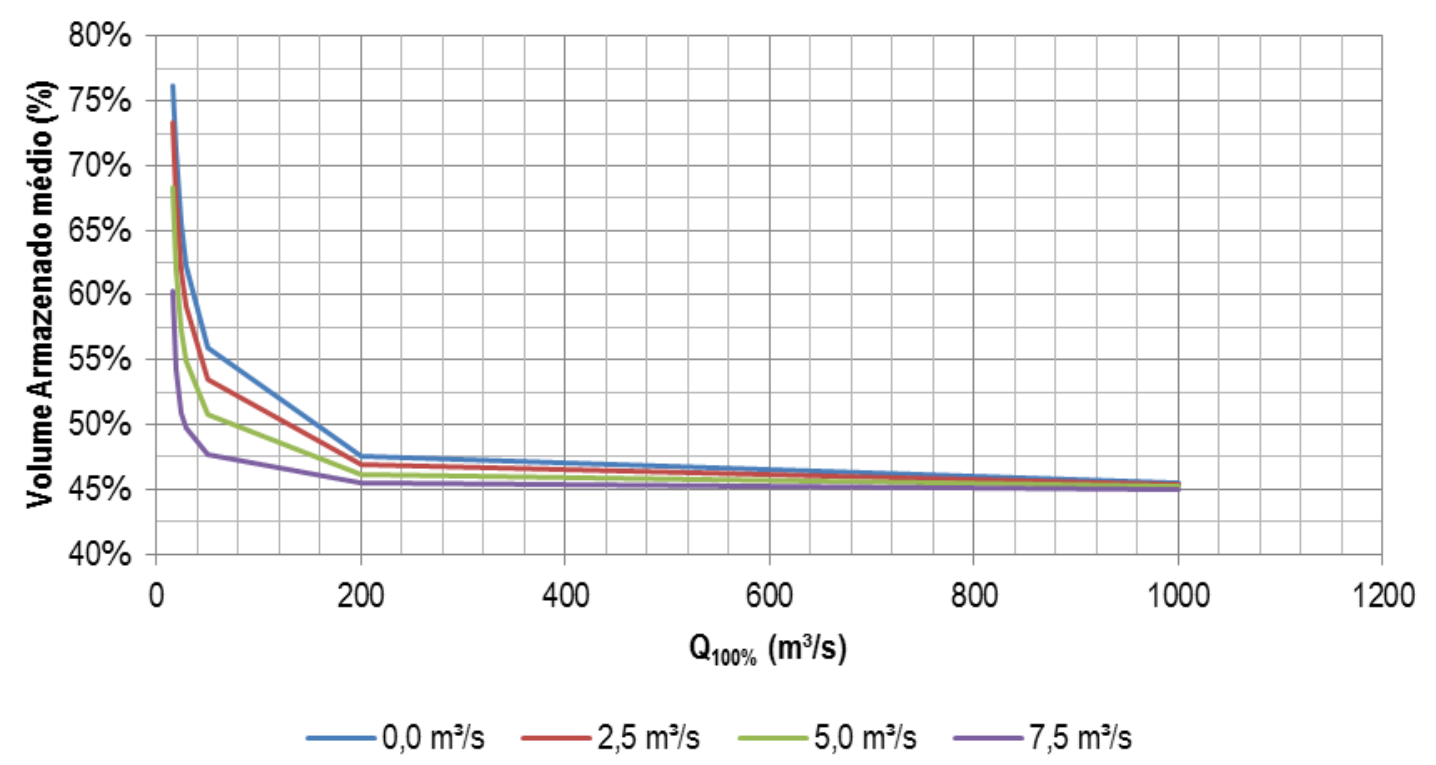

Figura 97 - Sistema Guarapiranga: Volume Armazenado médio (\%) x $Q_{100 \%}\left(m^{3} / s\right)$.

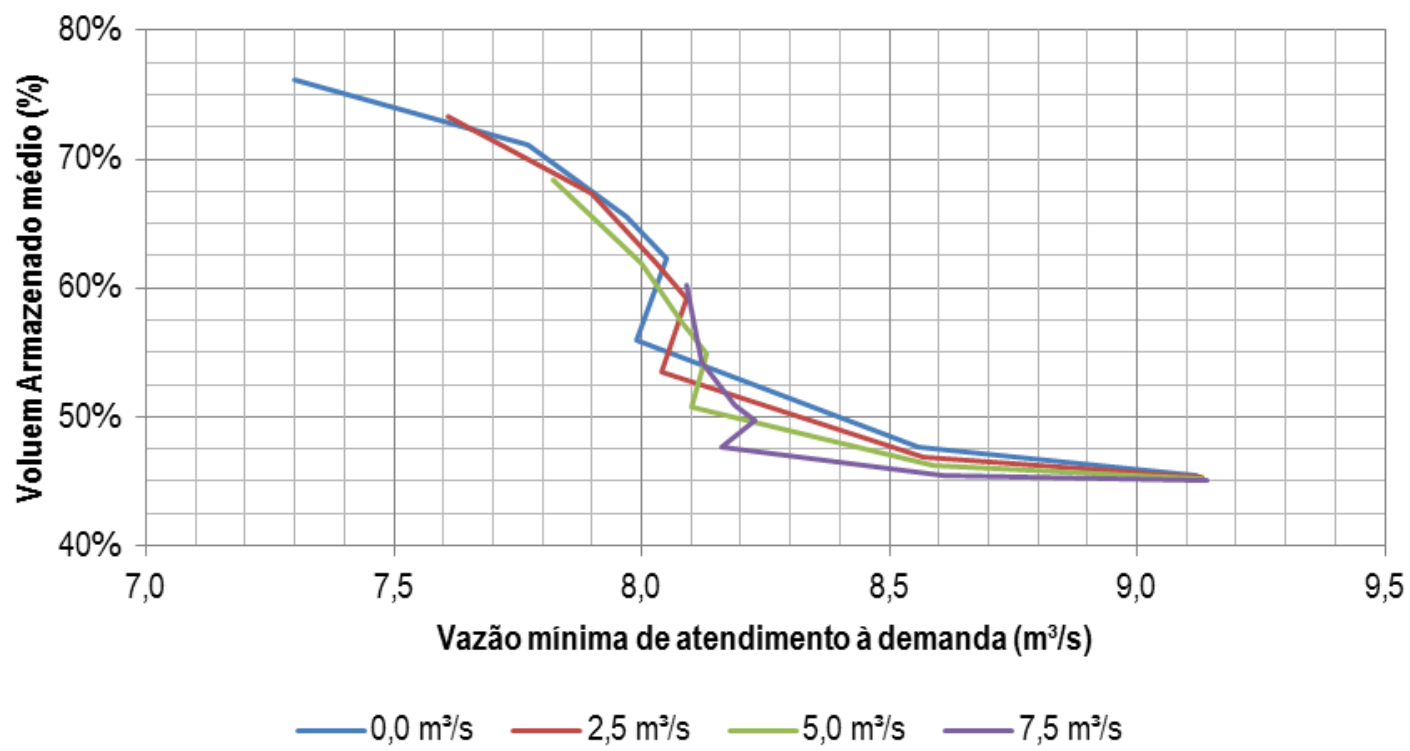

Figura 98 - Sistema Guarapiranga: Volume armazenado médio (\%) x Vazão mínima de atendimento à demanda $\left(\mathrm{m}^{3} / \mathrm{s}\right)$.

Ressalta-se que para o sistema Guarapiranga, os valores de vazão de atendimento mínimo à demanda e a porcentagem de volume armazenado médio não variam significativamente em função da vazão mínima Qo\%. Embora o Sistema Guarapiranga tenha uma capacidade produtiva superior ao do Sistema Alto Tietê, possui uma capacidade de armazenamento inferior correspondente a 31,6\%, além de apresentar uma série de afluências com valores de vazão também mais baixos. Dessa forma, a 
capacidade de regularização é mais baixa e trata-se, portanto, de um sistema mais suscetível à falhas de atendimento.

Durante o ano de 2015 (janeiro a dezembro) a média retirada foi de 15,0 $\mathrm{m}^{3} / \mathrm{s}$ e a vazão mínima mensal foi de $14,4 \mathrm{~m}^{3} / \mathrm{s}$, referente ao mês de janeiro de 2015 . Nota-se que as vazões média e mínima foram muito próxima à capacidade produtiva do sistema que atualmente corresponde a $16,0 \mathrm{~m}^{3} / \mathrm{s}$. A escolha de produzir mais água por este sistema estava atrelado ao fato de que a situação do manancial era mais favorável do que nos Sistemas Alto Tietê e Cantareira.

Para se ter um sensibilidade do sistema integrado, a partir das variações de racionamento e atendimento à demanda da RMSP, um novo conjunto de otimizações foi realizado.

Para o modelo integrado, de forma simplificada, foram utilizadas as afluências das séries históricas dos sistemas Cantareira, Alto Tietê, Guarapiranga e Alto Cotia. Para os Sistemas Rio Grande e Rio Claro foram utilizados os ciclos de afluências anuais enquanto os Sistemas de Baixo Cotia e Ribeirão Estiva foram consideradas como fontes constantes de vazão. A vazão de demanda foi fixada em $71 \mathrm{~m}^{3} / \mathrm{s}$ distribuídas de forma simplificada, que corresponde à vazão de demanda atendida antes das medidas de redução do consumo e de racionamento. Na Tabela 15 pode ser visualizado o resumo das otimizações para o modelo de sistema integrado, para os principais sistemas de reservatórios: Cantareira, Alto Tietê e Guarapiranga.

Tabela 15 - Resumo dos resultados com diferentes regras de racionamento para o Sistema Integrado: resultados dos sistemas Cantareira, Alto Tietê e Guarapiranga.

\begin{tabular}{|c|c|c|c|c|c|c|}
\hline \multirow[b]{2}{*}{$\mathbf{Q}_{0 \%}-\mathbf{Q}_{100 \%}$} & \multicolumn{2}{|c|}{ Cantareira } & \multicolumn{2}{|c|}{ Alto Tietê } & \multicolumn{2}{|c|}{ Guarapiranga } \\
\hline & $\begin{array}{c}Q \text { min } \\
\text { retirada } \\
\left(\mathrm{m}^{3} / \mathrm{s}\right)\end{array}$ & $\begin{array}{l}\text { V médio } \\
\text { útil (\%) }\end{array}$ & $\begin{array}{c}Q \text { min } \\
\text { retirada } \\
\left(\mathrm{m}^{3} / \mathrm{s}\right)\end{array}$ & $\begin{array}{c}\text { V médio útil } \\
(\%)\end{array}$ & $\begin{array}{c}Q \min \\
\text { retirada } \\
\left(\mathrm{m}^{3} / \mathrm{s}\right)\end{array}$ & $\begin{array}{l}\text { V médio } \\
\text { útil (\%) }\end{array}$ \\
\hline $10 \%-100 \%$ & 12,6 & $77 \%$ & 5,3 & $85 \%$ & 6,2 & $70 \%$ \\
\hline $10 \%-150 \%$ & 17,3 & $68 \%$ & 7,2 & $75 \%$ & 6,3 & $58 \%$ \\
\hline $10 \%-300 \%$ & 23,0 & $55 \%$ & 10,9 & $60 \%$ & 6,7 & $55 \%$ \\
\hline s/ racionamento & 28,5 & $51 \%$ & 14,4 & $54 \%$ & 9,0 & $43 \%$ \\
\hline
\end{tabular}

A partir dos resultados, pode-se observar que uma situação intermediária entre vazão e volume armazenado para todos os reservatórios é um racionamento com a vazão mínima de $Q_{0} \%$ de $10 \%$ da capacidade produtiva de cada sistema e Q100\% 
correspondente a $150 \%$ da vazão de capacidade produtiva. Embora tenha sido adotada a abordagem de se aplicar o mesmo grau de racionamento para todos os sistemas, em função da capacidade produtiva, as regras de racionamento podem ser estabelecidas de maneiras distintas.

O modelo SISAGUA é um modelo que utiliza a otimização com programação não linear inteira mista (PNLIM) e se mostrou flexível, ao permitir ser manipulada pelo usuário.

O presente estudo tem o propósito de indicar a resposta dos sistemas de reservatórios em função dos níveis de racionamento linear. As respostas do modelo com diferentes testes permitem saber qual a vazão de atendimento à demanda e os volumes de reservação para cada caso, o que facilitaria a tomada de decisão quanto à adoção do valor mais indicado.

As limitações da aplicabilidade estão relacionadas ao fato de que no modelo integrado, uma série de simplificações foram adotadas. Um teste com um maior detalhamento da rede de distribuição e preços variando em função do sistema de abastecimento podem ser implementados com a finalidade de se checar a significância que estes fatores implicariam nos resultados.

Outro fator limitante é atrelado ao fato de que as séries utilizadas são afluências da seca de 1953 e o modelo considera uma previsão perfeita de afluências para maximizar o atendimento e otimizar a operação, o que na realidade não se aplica. 


\section{CONCLUSÕES}

O estudo de operação de sistemas de reservatórios abrange um extenso campo de conhecimentos de diferentes áreas e tem ganhado espaço, uma vez que engloba diferentes variáveis e restrições em um contexto em que se vê a necessidade de gerir recursos de uso comum.

A partir da extensa bibliografia existente sobre o assunto, nota-se que não existe um único modelo geral indicado para resolver um problema. A metodologia abordada indicada para cada caso pode variar em função das características do sistema, das informações disponíveis, dos objetivos a serem definidos e dos resultados esperados. A escolha do modelo a ser adotado, deve ser realizada de forma ponderada, ao considerar o número de variáveis, o tempo de processamento e a eficiência esperada da modelagem.

Nota-se que embora haja uma grande aplicabilidade dos modelos em estudos de casos existe uma grande distancia da teoria e a aplicação prática. Neste trabalho ressaltam-se os benefícios que um estudo pode trazer ao tomador de decisões ao demonstrar a sensibilidade do sistema com relação a parâmetros de racionamento em uma operação.

O presente trabalho buscou contribuir, com a operação dos sistemas de múltiplos reservatórios de abastecimento para a Região Metropolitana de São Paulo. As baixas precipitações que ocorreram de 2013 a 2015 na região sudeste do país remeteram a reflexões relacionadas ao planejamento de gestão de recursos hídricos, ao passo que a criticidade da escassez impede a estimativas, o que traz certa insegurança à população.

Neste estudo a abordagem adotada foi a operação dos principais sistemas de forma individual e integrada através do racionamento linear, variando o racionamento a partir do volume armazenado.

O modelo SISAGUA é um modelo de otimização generalizado aplicável a sistemas de reservatórios complexos em diferentes fases do empreendimento. Sua estrutura permite a otimização para o planejamento da operação de um sistema de distribuição de água acoplado aos seus sistemas produtores, capaz de considerar diferentes regras de operação dos reservatórios e políticas de racionamento de água. 
O sistema, para todos os cenários, foi otimizado com o intervalo de tempo mensal, em um horizonte de planejamento de 10 anos e uma série de afluências de um período de escassez a partir de 1953. A configuração do sistema buscou se assimilar à atual. Ao avaliar isoladamente Cantareira, Guarapiranga e Alto Tietê, foi possível determinar a sensibilidade de cada sistema frente a uma demanda fixa correspondente à capacidade produtiva, em resposta a variações do nível de racionamento. O estudo realizado para sistemas isolados de reservatórios é mais simples e importante para a familiarização com o sistema, porém gera certa desvantagem quando surge a necessidade de se analisar este único sistema inserido em um sistema complexo. Ao se testar a sensibilidade dos sistemas de forma isolada, pôde-se notar que o racionamento, em diferentes escalas, tem pouca influência no tempo de recuperação dos sistemas.

Ao considerar o modelo integrado a rede de distribuição foi simplificada, a demanda foi fixada em $71 \mathrm{~m}^{3} / \mathrm{s}$, e os custos ou pesos para a priorização dos armazenamentos nos reservatórios foram considerados iguais. As vazões de racionamento foram estabelecidas em função da capacidade produtiva de cada sistema e a mesma porcentagem de volume armazenado para todos os sistemas considerados.

Neste trabalho, ressalta-se a importância da utilização de ferramentas de modelagem para suporte técnico à operação. O modelo também pode ser implementado em outras fases ou estar atrelado a decisões relacionadas ao dimensionamento do reservatório ou alternativas de expansão.

É relevante salientar que ao aplicar o modelo em um caso real, adota-se uma série de hipóteses simplificadoras, o que distancia o estudo e seus resultados obtidos da realidade em algumas situações. Dessa forma, é extremamente importante utilizar a modelagem como uma ferramenta que auxilia a tomada de decisão, porém sempre com muita cautela e senso crítico.

Outro fator que deve ser destacado é que o abastecimento é primordial não só para a sobrevivência de cerca de 20,4 milhões de habitantes na RMSP, mas também a influência que a falta d'água teria sobre a economia local. Em 2009 (SEADE, 2011) o PIB da região correspondeu a mais de 613 bilhões de reais, o que equivale a $56,5 \%$ da riqueza gerada no Estado de São Paulo, ou a 18,4\% do PIB nacional. A RMSP se destaca pela sua capacidade de polarização através de sua diversificada estrutura 
produtiva em diferentes áreas de investimentos. Destaca-se também, nos cenários nacional e latino-americano, como o principal e o mais moderno polo industrial e pela presença das sedes de grandes empresas nacionais e multinacionais.

O setor terciário representa 75,3 \% da atividade econômica regional ou 60,7\% do Valor Adicionado (VA) dos serviços do Estado de São Paulo. Em 2009, a indústria metropolitana, que correspondia a $24,6 \%$ do VA total da RMSP, foi responsável por $47,3 \%$ do produto industrial do Estado. Já a atividade primária, que tem participação menos expressiva na dinâmica econômica da região $(0,07 \%$ do VA total da RMSP). Dessa forma, toda e qualquer alteração no dinamismo da das atividades locais devido à falta de abastecimento de água, afetam não só a economia da região, como também a economia estadual, nacional e latino-americana.

A falta de água pode, portanto, não só levar a um processo inevitável que leva a destruição do recurso comum, uma vez que cada usuário ignora a necessidade dos demais, como também acarretar em impactos econômicos e sociais ao impedir as atividades locais e causar: o desemprego, aumento da violência e incentivo à irregularidade na captação de água e o aumento de doenças, como por exemplo, através da proliferação de vetores, ao incentivar uma situação que cause o armazenamento incorreto de água.

Outro assunto que deve ser destacado é que a possibilidade de uma mudança climática tem sido evidenciada, frente à severidade da escassez que a região de estudo vem sofrendo. Tal criticidade impede a previsão sobre a recorrência desses eventos e também o dificulta mensurar os impactos causados ao meio ambiente, à economia e à sociedade. Há modelos matemáticos globais climáticos e ferramentas geoespaciais capazes de efetuar projeções de eventos climáticos, e consequentemente indicar a alteração nos regimes e distribuição de chuva. Até que este cenário se confirme e diante da inconclusividade, é importante e necessário que os projetos e obras flexíveis que contemplem e permitam correções e complementações devidas às alterações climáticas.

Uma vez que o sistema de abastecimento foi calculado em função dos parâmetros de atendimento à demanda, é possível que a situação de seca ocorrida estava prevista. A estiagem e acontecimentos atuais remetem a reflexões sobre o dimensionamento das estruturas, os critérios de atendimento à demanda adotados, sobre o 
planejamento relacionado à infraestrutura e saneamento e aos investimentos realizados na região.

Como sugestões para desenvolvimento futuro pode-se considerar:

$\checkmark$ Comparar modelos de otimização com a finalidade de se analisar as metodologias abordadas e as soluções encontradas para cada situação;

$\checkmark$ Considerar a sazonalidade nas regras de racionamento.

$\checkmark$ Aplicar o modelo para uma série de afluências atuais, considerar a distribuição das demandas e a abrangência de cada sistema de forma atualizada, e considerar diferentes taxas de preços para os diferentes sistemas ao levar em consideração a adução e o tratamento da água.

$\checkmark$ Pesquisar mais a diferenciação das regras de racionamento e pesos entre os reservatórios. 


\section{REFERÊNCIAS BIBLIOGRÁFICAS}

ANA - Agência Nacional de Águas. ATLAS - Abastecimento Urbano de Água. Região Metropolitana de São Paulo. 2010. Disponível em <http://atlas.ana.gov.br/ Atlas/forms/analise/RegiaoMetropolitana.aspx?rme=24> Acesso em 01 out. 2014.

ANA - Agência Nacional de Águas. Renovação da outorga do Sistema Cantareira. 2015. Disponível em <http://www2.ana.gov.br/Paginas/servicos/outorga efiscalizacao/renovacaocantareira.aspx> Acesso em 22 de dezembro de 2015.

ANA; DAEE, Agência Nacional de Águas e Departamento de Águas e Energia Elétrica. Nota Técnica Conjunta ANA/DAEE: Subsídios para a Análise do pedido de Outorga do Sistema Cantareira e para a definição das Condições de Operação dos seus Reservatórios. Relatório Final. V1.1. São Paulo, jul. 2004.

ANA; DAEE. Agência Nacional de Águas e Departamento de Águas e Energia Elétrica. Dados de Referência Acerca da Outorga do Sistema Cantareira. V 1.0. Ago. 2013.

ANA; DAEE. Agência Nacional de Águas e Departamento de Águas e Energia Elétrica. Resolução Conjunta ANA/DAEE no 1672, de 17 de novembro de 2014.

ANA; DAEE. Agência Nacional de Águas e Departamento de Águas e Energia Elétrica. Boletim Diário ANA/DAEE de monitoramento do Sistema Cantareira. Situação do Sistema Equivalente - 31de dezembro de 2015. Sistema Cantareira. Disponível em $<$ http://arquivos.ana.gov.br/saladesituacao/BoletinsDiarios/

DivulgacaoSiteSabesp_31-12-2015.pdf> Acesso em 31 de janeiro de 2015.

ALBANO, G. D. Integração de um modelo matemático de quantidade de água em rede de fluxo (ACQUANET) com um modelo matemático de qualidade de água em represas (CE-QUAL-R1) - estudo de caso: Represa Jaguari - Jacareí - Sistema Cantareira / G.D. Albano. - ed. Ver. São Paulo, 2004. 230p. Dissertação de Mestrado - Escola Politécnica, Universidade de São Paulo, São Paulo.

ALCKMIN, Geraldo. Eleições 2014: Entrevistas com Geraldo Alckmin. Entrevistas Estadão. Entrevistador: luri Pitta. São Paulo: 04 ago. 2014. Disponível em $<$ https://www.youtube.com/watch?v=n4ihuT86u1Q>.

AZEVEDO, L.G.T.; GATES, T. K.; Fontane, D. G., LABADIE, J. W.; PORTO, R. L. Integration of Water Quantity and Quality in Strategic River Basin Planning. Journal of Water Resources Planning and Management. v. 126, n. 2, p. 85-97, 2000.

BARROS, M. T. L., ZAMBON, R. C., DELGADO, D. M., BARBOSA, P. S. F., and YEH, W. W.-G. 2005. Planning and operation of large-scale water distribution system with hedging rules. Proc., 2005 World Water and Environmental Resources Congress, Anchorage, Alaska.

BARROS, M.T.L.; ZAMBON, R.C.; BARBOSA, P.S.F.; YEH, W. W.-G. Planning and operation of large-scale water distribution systems with preemptive priorities. Journal of Water Resources Planning and Management, v. 134, n. 3, p. 247-256, 2008. 
CAI X.; MCKINNEY D. C.; LASDON, L. S. Solving nonlinear water management models using a combined genetic algorithm and linear programming approach. Advances in Water Resources, v. 24, n. 6, p. 667-676, 2001.

CAMARGO CORREA. Sistema Produtor São Lourenço: Construtora Camargo Corrêa participa da maior obra de saneamento do país. 22 de ago. 1014. Disponível em < http://www.camargocorrea.com.br/grupo-camargo-correa/comunicacao/noticias /construtora-camargo-correa-assina-seu-primeiro-contrato-de-parceria-publicoprivada.html> Acesso em 04 de out. 2014.

CHANDRAMOULI, V.; RAMAN, H. Multireservoir Modeling with Dynamic Programming and Neural Networks. Journal of Water Resources Planning and Management, v. 127, n. 2, p. 89-98, 2001.

CHAPOLA, R.; LEITE, F. Agência aprova multa de até 100\% para quem gastar mais água em SP. O Estado de São Paulo, 07 de janeiro de 2015. Disponível em < http://sao-paulo.estadao.com.br/noticias/geral,agencia-aprova-multa-de-ate-100para-quem-gastar-mais-agua-em-sp,1616763> Acesso em 08 de janeiro de 2015.

COLLET, L. ANA concorda com pedido da Sabesp para uso de $2^{a}$ cota. 0 Estado de São Paulo, 17 de outubro de 2014. Disponível em $<$ http://www.estadao.com.br/noticias/geral,ana-concorda-com-pedido-da-sabesppara-uso-de-2-cota,1578584> Acesso em 17 de outubro de 2014.

CONSTANCIO, T. Transposição pode ser julgada no Supremo. O Estado de São Paulo, 15 ago., 2014. Disponível em <http://sao-paulo.estadao.com.br/noticias /geral,transposicao-pode-ser-julgada-no-supremo,1544300> Acesso em 15 ago., 2014.

CHUNG, I.; HELWEG, M. Modeling the California State Water Project. Journal of Water Resources Planning and Management, v. 111, n. 1, p. 82-97, 1985.

CRAWLEY, P. D.; DANDY, G. C. Optimal Operation of Multiple-Reservoir System. Journal of Water Resources Planning and Management, v. 119, n. 1, p. 1-17, 1993.

DAEE, Departamento de Águas e Energia Elétrica . Portaria DAEE n 1213. 06 ago. 2004. Disponível em <http://www.comitepcj.sp.gov.br/download/Port-1213Cantareira-06-08-04.PDF> Acesso em 14 jul. 2014.

DAEE, Departamento de Águas e Energia Elétrica. Elaboração do Plano Diretor de Aproveitamento e Recursos Hídricos para a Macrometrópole Paulista. 'Rl-1'Revisão 1. Relatório Intermediário - Tomo I. Julho de 2009. Disponível em < http://www.daee.sp.gov.br/macrometropole/Intermediario.htm>. Acesso em 14 de julho de 2014.

DAEE, Departamento de Águas e Energia Elétrica. Elaboração do Plano Diretor de Aproveitamento e Recursos Hídricos para a Macrometrópole Paulista. 'RI-02'Revisão 1. Relatório Intermediário. 25 de outubro de 2010. Disponível em $<$ http://www.daee.sp.gov.br/macrometropole/Intermediario.htm $>$. Acesso em $14 \mathrm{de}$ julho de 2014. 
DAEE - Departamento de Águas e Energia Elétrica. Serviços de Consultoria Especializada para a Elaboração do Terceiro Plano Diretor de Macrodrenagem da Bacia do Alto Tietê - PDMAT 3. 5147-IEH - Levantamento de Dados e Informações Secundárias e Primárias. Volume II - Inventário das Estruturas Hidráulicas. Consórcio Cobrape, ENGECORPS, Maubertec. Relatório n 4 , volume 2. Março de 2012.

DAEE, Departamento de Águas e Energia Elétrica. Resolução Conjunta ANA/DAEE n.120, 10 fevereiro de 2014a. Diário Oficial do Estado de São Paulo, Poder Executivo, São Paulo, SP, 13 fev. 2014a, Seção 1, p. 46.

DAEE, Departamento de Águas e Energia Elétrica. Portaria DAEE n.1396, 11 julho de 2014b. Diário Oficial do Estado de São Paulo, Poder Executivo, São Paulo, SP, 12 jul. 2014, Seção 1, p. 40.

DAHE, P. D.; SRIVASTAVA, D. K. Multireservoir Multiyield Model with Allowable Deficit in Annual Yield. Journal of Water Resources Planning and Management, $v$. 128, n. 6, p. 406-414, 2002.

Estado de São Paulo. Diário Oficial, Comunicados. Volume 125 Número 238 São Paulo, quarta-feira, 23 de dezembro de 2015. Disponível em <http://www.jusbrasil.com.br/diarios/106773462/dosp-empresarial-23-12-2015-pg24> Acesso em 29 de dezembro de 2015.

FABER, B.; HAROU, J. Multi-objective Optimization of Reservoir Systems Using HECResPRM. World Environmental and Water Resources Congress 2007, p. 1-14, 2007.

FERRAZ, A.; ITALIANI, R. Água tratada de esgoto tem dobro o custo e será jogada em represa poluída. O Estado de São Paulo, 09 de novembro de 2014. Disponível em < http://sao-paulo.estadao.com.br/noticias/geral,agua-tratada-de-esgoto-temdobro-do-custo-e-sera-jogada-em-represa-poluida-imp-,1590215> Acesso em 09 de novembro de 2014.

FERRAZ, A.; ITALIANI, R. Sabesp oferece volume morto de Paraibuna em troca de transposição. O Estado de São Paulo, 23 de novembro de 2014. Disponível em < http://sao-paulo.estadao.com.br/noticias/geral,sabesp-oferece-volume-morto-deparaibuna-em-troca-de-transposicao-imp-,1596686> Acesso em 26 de novembro de 2014.

GAGNON, C. R.; HICKS, R. H.; JACOBY, S. L. S.; KOWALIK, J. S. A Nonlinear Programming Approach to a very large Hydroeletric System Optimization. Mathematical Programming, v. 6 , n.1, p. 28-41, 1974.

GAMBALE, S.R. Aplicação de Algoritmo Genético na Calibração de Redes de Água. 2000. Dissertação (Mestrado em Engenharia Hidráulica e Sanitária) Universidade de São Paulo.

GAMS, General Algebraic Modeling System, (2013). <http://www.gams.com> 
GEORGAKAKOS, A. P.; YAO, H.; Yu, Y. Control Model for Hydroeletric Energy-Value Optimization. Journal of Water Resources Planning and Management, v. 123, n. 1, p. 30-38, 1997.

GOLDBERG, D. E.; Kuo, C. H. Genetic Algorithms in Pipeline Optimization. Journal of Computing in Civil Engineering, v. 1, n. 2, p. 128-141, 1987.

Grupo Técnico de Assessoramento para a Gestão do Sistema Cantareira GTAGCANTAREIRA, Comunicado $\mathbf{n}^{\circ}$ 1, 2014a. <http://www.comitespcj.org.br /images/Download/GTAG-Cantareira Comunicado-01 18-02-14.pdf>

Grupo Técnico de Assessoramento para a Gestão do Sistema Cantareira GTAG Cantareira. Comunicado n $^{\circ}$ 5, 2014b. Disponível em <http://arquivos.ana.gov.br/institucional/sof/GTAGCantareira/20140415Comunicado_ GTAG_nr_5_V_final.pdf>

Grupo Técnico de Assessoramento para a Gestão do Sistema Cantareira GTAG CANTAREIRA, Comunicado $\mathbf{n}^{\circ}$ 9, 2014c. Disponível em < http://arquivos.ana.gov.br/institucional/sof/GTAGCantareira/20140613_Comunicado GTAG_n_9.pdf>

Grupo Técnico de Assessoramento para a Gestão do Sistema Cantareira GTAGCANTAREIRA, Comunicado $\mathbf{n}^{\circ}$ 10, 2014d. <http://www.comitespcj.org.br /images/Download/GTAG-Cantareira Comunicado-10 30-06-14.pdf>

GOY, L. Sabesp quer usar mais $100 \mathrm{mi}$ de metros cúbicos do volume morto do Cantareira, diz ANA. O Estado de São Paulo, 21 de julho de 2014a. Disponível em < http://economia.estadao.com.br/noticias/negocios,sabesp-quer-usar-mais-100-mi-demetros-cubicos-do-volume-morto-do-cantareira-diz-ana,1532038> Acesso em 17 de janeiro de 2014.

GOY, Leonardo. ANA decide sair de grupo de gestão do Sistema Cantareira. O Estado de São Paulo, 19 de set. 2014b .Disponível em $<$ http://economia.estadao.com.br/noticias/negocios, ana-decide-sair-de-grupo-degestao-do-sistema-cantareira,1563040> Acesso em 19 set. 2014.

HARDIN, G. The Tragedy of the Commons. Science, New Series, Vol. 162, No. 3859. Dec. 13, 1968. 1243-1248.

ITALLIANI, F. Alckmin culpa chuva por atraso em obra contra seca. O Estado de São Paulo, 05 de novembro de 2015. Disponível em <http://saopaulo.estadao.com.br/noticias/geral,alckmin-culpa-chuva-por-atraso-em-obra-contraseca,1791595> Acesso em 23 de dezembro de 2015.

ITO, K.; XU, Z. X.; JINNO, K.; KOJIRI, T.; KAWAKURA, A. Decision Support System for Surface Water Planning in River Basins. Journal of Water Resources Planning and Management, v. 127, n. 4, p. 272-276, 2001.

KARUNANITHI, N.; GRENNEY, W.; WHITLEY, D.; BOVEE, K. Neural Networks for River Flow Prediction. Journal of Computing in Civil Engineering, v. 8, n. 2, p. 201 220, 1994. 
KELMAN, J. Medida do governo de SP põe em risco abastecimento no Rio, diz especialista. Entrevista Jornal Globonews. 12 ago. 2014. Disponível em $<$ http://globotv.globo.com/globo-news/jornal-globo-news/v/medida-do-governo-de-sppoe-em-risco-abastecimento-no-rio-diz-especialista/3558245/> Acesso em 13 ago. 2014.

LABADIE, J. W. Optimal Operation of Multireservoir Systems: State-of-the-Art-Review. Journal of Water Resources Planning and Management, v. 130, n. 2, p. 93-111, 2004.

LABADIE, J. W.; SULLIVAN C. H.. Computerized Decision Support Systems For Water Managers. Journal of Water Resources Planning and Management, v. 112, v. 3, p. 299-307, 1986.

LEITE, F. Alckmin vai multar quem consumir mais água: púnico pode chegar a $30 \%$. O Estado de São Paulo, 17 de abril de 2014a. Disponivel em <http://saopaulo.estadao.com.br/noticias/geral,alckmin-vai-multar-quem-consumir-mais-aguapunicao-pode-chegar-a-30,1155232> Acesso em 15 de agosto de 2014.

LEITE, F. Sabesp inicia captação do volume morto em segunda represa. O Estado de São Paulo, 15 ago., 2014b. Disponível em: <http://saopaulo.estadao.com.br/noticias/geral,sabesp-inicia-captacao-do-volume-morto-emsegunda-represa, 1544064> Acesso em 16 ago., 2014.

LEITE, F. Com bônus, Sabesp deixa de arrecadar $\mathrm{R} \$ 98,9$ milhões. O Estado de São Paulo, 16 ago., 2014c. Disponível em: < http://sao-paulo.estadao.com.br /noticias/geral,com-bonus-sabesp-deixa-de-arrecadar-r-98-9-milhoes, 1544673> Acesso em 16 ago., 2014.

LEITE, F. Custo da transposição do Paraíba do Sul sobe $66 \%$ com novo projeto. 0 Estado de São Paulo, 22 de dezembro de 2014d. Disponível em <http://saopaulo.estadao.com.br/noticias/geral,custo-da-transposicao-do-paraiba-do-sul-sobe66-com-novo-projeto-imp-,1610700> Acesso em 23 de dezembro de 2014.

LEITE, F. Transposição do Paraíba do Sul depende da chuva. O Estado de São Paulo, 17 de janeiro de 2015a. Disponível em <http://sao-paulo.estadao.com.br /noticias/geral,transposicao-do-paraiba-do-sul-depende-da-chuva,1621052> Acesso em 17 de janeiro de 2015.

LEITE, F. Sabesp pede licença após concluir obra. O Estado de São Paulo, 22 de setembro de 2015b. Disponível em <http://sao-paulo.estadao.com.br/noticias Igeral,sabesp-pede-licenca-apos-concluir-obra, 1766528 > Acesso em 22 de dezembro de 2015.

LEITE, F.; CHAPOLA, R.; Alckmin desiste de multa; volume útil do Cantareira zera. O Estado de São Paulo, 09 de julho de 2014. Disponível em < http://saopaulo.estadao.com.br/noticias/geral,alckmin-desiste-de-multa-volume-util-docantareira-zera,1525985> Acesso em 15 de agosto de 2014. 
MIZYED, N. R.; LOFTIS, J. C.; FONTANE D. G. Operation of Large Multireservoir Systems using Optimal-Control Theory. Journal of Water Resources Planning and Management, v. 118, n. 4, p. 371-387, 1992.

MORETTIN P. A.; TOLOI, C. M. C. Análise de Séries Temporais. São Paulo: Edgard Blücher, 2004.

MORIDI, A. and KARAMOUZ, M. Dealing with Conflict on How to Operate MultiPurpose Reservoirs: A Case Study. World Environmental and Water Resources Congress 2007, 2007.

MOUSAVI, S. J.; KARAMOUZ, M.; MENHADJ, M. B. Fuzzy-State Stochastic Dynamic Programming for Reservoir Operation. Journal of Water Resources Planning and Management, v. 130, n. 6, p. 460-470, 2004.

NEELAKANTAN, T. R.; PUNDARIKANTHAN, N. V. Neural Network-Based SimulationOptimization Model for Reservoir Operation. Journal of Water Resources Planning and Management, v. 126, n. 2, p. 57-64, 2000.

OLIVEIRA, R.; LOUCKS, D. P. Operation rules for multireservoir systems. Water Resources Research, v. 33, n. 4, p. 839-852, 1997.

ONS - Operador Nacional do Sistema Elétrico. Evaporações Líquidas nas Usinas Hidrelétricas. Rio de Janeiro, 2004.

ONS - Operador Nacional do Sistema Elétrico. Atualização de séries histórica de vazões - período 1931 a 2013. Rio de Janeiro, nov. 2013. Disponível em < http://www.ons.org.br/download/operacao/hidrologia/Atualiza\%C3\%A7\%C3\%A30\%2 0de\%20S\%C3\%A9ries\%20Hist\%C3\%B3ricas\%20de\%20Vaz\%C3\%B5es\%20\%201931\%20a\%202012.pdf> Acesso em 30 set. 2014.

OSTROM, E.; BURGER, J.; FIELD, C. B.; NORGAARD R. B.; POLICANSKY D. Revisiting the Commons: Local Lessons, Global Challenges. Science, v. 284, n. 5412, p. 278-282, 1999.

PIMAN, T.; COCHRANE, T.; ARIAS, M.; GREEN, A.; DAT, N. Assessment of Flow Changes from Hydropower Development and Operations in Sekong, Sesan and Srepok Rivers of the Mekong Basin. Journal of Water Resources Planning and Management, v. 139, n. 6, p. 723-732, 2013.

PORTO, R. L. L.; LANNA, A. E. L.; BRAGA Jr., B. P. F.; CIRILLO, J. A.; ZAHED FILLHO, K.; GOBETTI, L.; AZEVEDO, L. G. T.; BARROS, M. L. T.; BARBOSA, P. S. F. Técnicas Quantitativas para o Gerenciamento de Recursos Hídricos. Coleção da ABRH, UFRGS, 1997.

PORTO, R. L. L.; Mello, A. V.; ROBERTO, A. N.; PALOS, J. C. ACQUANET: Arquitetura, Estratégias e Ferramentas. XVI Simpósio Brasileiro de Recursos Hídricos, João Pessoa, 2005.

RANI, D.; MOREIRA, M. M. Simulation-Optimization Modeling: A Survey and Potential Application in Reservoir Systems Operation. Water Resources Management, v. 24, n. 6, p. 1107-1138, 2010. 
REITSMA R.; ZIGURS I.; LEWIS C.; WILSON, V. SLOANE A. Experiment With Simulation Models In Water-Resources Negotiations. Journal of Water Resources Planning and Management, v. 122, n. 1, p. 64-70, 1996.

REOLOM, M. PPP vai construir maior Sistema de abastecimento e água dos últimos 20 anos. O Estado de São Paulo, 21 ago. 2013. Disponível em < http://saopaulo.estadao.com.br/noticias/geral,ppp-vai-construir-maior-sistema-deabastecimento-de-agua-dos-ultimos-20-anos,1066415> Acesso em 04 out. 2014.

RESK, F. É pouco provável que $2^{\text {a }}$ cota do Alto Tietê seja usada, diz Alckmin. 0 Estado de São Paulo, 15 de dezembro de 2014. Disponível em < http://saopaulo.estadao.com.br/noticias/geral,e-pouco-provavel-que-2-cota-do-alto-tiete-sejausada-diz-alckmin,1607383> Acesso em 15 de dezembro de 2014.

RIBEIRO, G.P. Operação otimizada do sistema adutor metropolitano utilizando algoritmos genéticos. Estudo de caso: SAM Leste da Região Metropolitana de São Paulo (R.M.S.P.). 2005. 239 p. Tese (Doutorado) - Escola Politécnica, Universidade de São Paulo, São Paulo, 2005.

RODRIGUES, A; BRENHA, H. Plano prevê a interrupção diária de retirada de água no sistema Cantareira. Folha de São Paulo, 30 set. 2014. Disponível em $<$ http://www1.folha.uol.com.br/cotidiano/2014/09/1524612-plano-preve-interrupcaodiaria-de-retirada-de-agua-no-sistema-cantareira.shtml> Acesso em 04 out. 2014.

RODRIGUES, E. Agência multa Cesp por vazão menor de rio. O Estado de São Paulo, 03 out. 2014a. Disponível em < http://sao-paulo.estadao.com.br /noticias/geral,agencia-multa-cesp-por-vazao-menor-de-rio,1570546> Acesso em 03 out. 2014.

RODRIGUES E., MOURA, R. M., MONTEIRO, T. Dilma assina financiamento de obras do São Lourenço. O Estado de São Paulo, 04 de dezembro de 2014. Disponível em < http://sao-paulo.estadao.com.br/noticias/geral,dilma-assinafinanciamento-de-obras-do-sao-lourenco,1602163> Acesso em 06 de dezembro de 2014.

RODRIGUES, J. Alckmin nega racionamento de água em SP. O Estado de São Paulo, 01 de novembro de 2014b. Disponível em <http://saopaulo.estadao.com.br/noticias/geral,alckmin-nega-racionamento-de-agua-emsp,1586646> Acesso em 01 de novembro de 2014.

ROTHMAN, D. W.; MAYS, L.W. Water Resources Sustainability: Development of a Multiobjective Optimization Model. Journal of Water Resources Planning and Management, v. 140, n. 12, 2014.

RUSSEL, S. O.; CAMPBELL, P. F. Reservoir Operating Rules with Fuzzy Programming. Journal of Water Resources Planning and Management, v. 122, n. 3, p. 165-170, 1996.

SABESP, Companhia de Saneamento Básico do Estado de São Paulo. Estudo de Concepção e Projeto Básico do Sistema Produtor São Lourenço - Relatório de 
Impacto ao Meio Ambiente - RIMA. Encibra S.A. Estudos e Projetos de Engenharia / Prime Engenharia. Março de 2011.

SABESP, Companhia de Saneamento Básico do Estado de São Paulo. Plano de Contingência II - Ações Contingenciais e Resultados. Jun., 2014.

SABESP, Companhia de Saneamento Básico do Estado de São Paulo. CHESS Crise Hídrica, Estratégia e Soluções da Sabesp para a Região Metropolitana de São Paulo. São Paulo, 30 de abril de 2015a. Disponível em <http://site.sabesp.com.br/site/uploads/file/crisehidrica/chess crise hidrica.pdf> Acesso em 15 de novembro de 2015.

SABESP, Companhia de Saneamento Básico do Estado de São Paulo. Ações para Enfretamento da Crise Hídrica. CBH-AT. São Paulo, 16 de julho de 2015b.

SABESP, Companhia de Saneamento Básico do Estado de São Paulo. Ofício MA 055/2015. São Paulo, 23 de julho de 2015c.

SALOMÃO, L. Se a União decidir transferir água do Paraíba do Sul, vou acatar, diz Pezão. G1, Globo, 05 de novembro de 2014. Disponível em < http://g1 .globo.com/riode-janeiro/noticia/2014/11/se-uniao-decidir-transferir-agua-do-paraiba-do-sul-vouacatar-diz-pezao.html> Acesso em 05 de novembro de 2014.

SAMPAIO, L. Cantareira libera mais águas para o interior para evitar racionamento. Folha de São Paulo. São Paulo, 19 set. 2014. Disponível em < http://www1.folha.uol.com.br/cotidiano/2014/09/1518603-cantareira-libera-maisagua-para-o-interior-para-evitar-racionamento.shtml> Acesso em 04 out. 2014.

SANTANA, J.; CARPANI, J.; LOURENÇO, F. Alckmin amplia transferência de Rio Guaratuba para o Sistema Alto Tietê. G1 Mogi das Cruzes e Suzano, 27 de janeiro de 2015. Disponível em <http://g1.globo.com/sp/mogi-das-cruzessuzano/noticia/2015/01/alckmin-amplia-transferencia-de-rio-guaratuba-para-osistema-alto-tiete.html Acesso em 14 de dezembro 2015.

SEADE - Fundação Sistema Estadual de Análise de Dados. Região Metropolitana de São Paulo. Foco - Publicação integrante do Diagnostico para Ações Regionais da Secretaria do Emprego e Relações do Trabalho do Estado de São Paulo. Governo de Estado de São Paulo, Secretaria de Planejamento e Desenvolvimento Regional. São Paulo, 2011.

SEADE - Fundação Sistema Estadual de Análise de Dados. Estimativa da população da RMSP em 2015. Disponível em <http://produtos.seade.gov.br/produtos/distritos /index.php?page=tabela $>$ Acesso em 29 de novembro de 2015.

Secretaria de Saneamento e Recursos Hídricos. Reunião Inauguração do Comitê de Crise Hídrica - Segurança Hídrica para São Paulo. São Paulo, 12 de fevereiro de 2015.

SCHARDONG, A.; MELLO Jr., A. V.; MARCELLINI, S. S.; PORTO, R. L. Aplicação de técnicas de programação linear e extensões para otimização da alocação da água em sistemas de recursos hídricos considerando amortecimento de canais. I Simpósio de Recursos Hídricos do Sul-Sudeste, 2006, Curitiba, 2006. 
SHARIF, M.; WARDLAW R. Multireservoir Systems Optimization Using Genetic Algorithms: Case Study. Journal of Computing in Civil Engineering, v. 14, n. 4, p. 255-263, 2000.

SHUMWAY, R.H.; STOFFER, D.S. Time Series Analysis and Its Applications. Springer, Second Edition, 2006.

SIMONOVIC, S. P.; SAVIC, D. A. Intelligent Decision Support and Reservoir Management and Operations. Journal of Computing in Civil Engineering, v. 3, n. 4, p. 367-385, 1989.

SIMONOVIC, S. P. Reservoir Systems Analysis: Closing Gap between Theory and Practice. Journal of Water Resources Planning and Management, v. 118, n. 3, p. 262-280, 1992.

SOUZA, N. Governos de SP, Rio e Minas firmam acordo sobre a transposição da bacia do Paraíba do Sul. O Estado de São Paulo, 27 de novembro de 2014. Disponível em < http://sao-paulo.estadao.com.br/noticias/geral,governos-de-sp-rio-eminas-firmam-acordo-sobre-transposicao-da-bacia-do-paraiba-do-sul, 1598873> Acesso em 29 de novembro de 2014.

SLYKE, R. M.; WETS, R. L-Shaped Linear Programs with Applications to Optimal Control and Stochastic Programming. SIAM Journal on Applied Mathematics, v. 17, n. 4, p. 638-663, 1969.

STEFANOVIC, D. and KREYMBORG, L. Red River CWMS Watershed Modeling. Critical Transitions in Water and Environmental Resources Management, 2004 World Water and Environmental Resources Congress, 2004.

STEDINGER, J. R.; FABER, B. A.; LAMONTAGNE, J. R. Developments in Stochastic Dynamic Programming for Reservoir Operation Optimization. World Environmental and Water Resources Congress 2013, p. 1266-1278, 2013.

TALUKDAR, B.; DEB, D.; SRIVASTAVA, D. Development of Multiobjective Stochastic Dynamic Programming (MOSDP) Reservoir Operation Model. World Environmental and Water Resources Congress 2012, p. 985-997, 2012.

TEIXEIRA A. S.; MARIÑO, M. A. Coupled Reservoir Operation-Irrigation Scheduling by Dynamic Programming. Journal of Irrigation and Drainage Engineering, v. 128, n. 2, p. 63-73, 2002.

TAGHAVI, S. A.; HOWITT, R. E.; MARIÑO, M. A. Optimal Control of Ground-Water Quality Management: Nonlinear Programming Approach. Journal of Water Resources Planning and Management, v. 120, n. 6, p. 962-982, 1994.

TOMAZELA, J. M. Macrometrópole paulista terá 58 novas barragens até 2035 . O Estado de São Paulo, 20 set. 2014. Disponível em < http://blogs.estadao.com.br/pelo-interior/macrometropole-paulista-tera-58-novasbarragens-ate-2035/> Acesso em 04 out. 2014. 
USACE, HEC-ResSim Reservoir System Simulation - User's Manual. Version 3.1, May, 2013. U.S. Army Corps of Engineers Hydrologic Engineering Center. $<$ http://www.hec.usace.army.mil/software/hec-ressim/>

VIEIRA, G. Com $2^{\text {a }}$ cota do volume morto, Cantareira cai para 13,4\%. O Estado de São Paulo, 25 de outubro de 2014. Disponível em < http://www.estadao.com.br/noticias/geral,com-2-cota-do-volume-morto-cantareiracai-para-13-4,1582577> Acesso em 25 de outubro de 2014.

WARDLAW, R.; SHARIF, M. Evaluation of Genetic Algorithms for Optimal Reservoir System Operation. Journal of Water Resources Planning and Management, v. 125, n. 1 , p. 25-33,1999.

WURBS, R. A. Reservoir System Simulation and Optimization Models. Journal of Water Resources Planning and Management, v. 119, n. 4, p. 455-472, 1993.

YEH, W. W-G. Reservoir Management and Operations Models: A State-of-the-Art Review. Water Resources Research, v. 21, n. 12, p. 1797-1818, 1985.

ZAMBON, R.C.; BARROS, M. L. T.; BARBOSA; YEH, W. The São Francisco River Water Transfer System: An Optimization Model for Planning Operation. World Environmental and Water Resources Congress 2008: Ahupua'A, 2008.

ZAHED FILHO, K. Algumas Metodologias para o Dimensionamento e Operação de Reservatórios. 1984. 258 p. Dissertação (Mestrado) - Departamento de Engenharia Hidráulica e Sanitária - Escola Politécnica da Universidade de São Paulo. São Paulo. 